\title{
ISOTOPIC CONSTRAINTS ON THE SOURCES AND ASSOCIATIONS OF ORGANIC COMPOUNDS IN MARINE SEDIMENTS
}

\author{
By \\ HELEN K. WHITE \\ B.Sc. Chemistry, University of Sussex, U.K., 2000 \\ Submitted in partial fulfillment of the requirements for the degree of \\ Doctor of Philosophy \\ at the \\ MASSACHUSETTS InSTITUTE OF TECHNOLOGY \\ and the \\ WOODS HOLE OCEANOGRAPHIC INSTITUTION \\ February 2006
}

(c) 2006 Helen K. White. All rights reserved.

The author hereby grants to MIT and WHOI the permission to reproduce paper and electronic copies of this thesis in whole or in part and to distribute them publicly.

Author:

Joint Program in Oceanography

Massachusetts Institute of Technology and

Woods Hole Oceanographic Institution

Certified by:

Timothy I. Eglinton, Thesis Co-supervisor

Certified by:

Christopher M. Reddy, Thesis Co-supervisor

Accepted by:

Timothy I. Eglinton

Chair, Joint Committee for Chemical Oceanography

Woods Hole Oceanographic Institution 


\section{ISOTOPIC CONSTRAINTS ON THE SOURCES AND ASSOCIATIONS OF ORGANIC COMPOUNDS IN MARINE SEDIMENTS}

By

Helen K. White

Submitted to the MIT/WHOI Joint Program in Oceanography on January 9, 2006, in partial fulfillment of the requirements for the degree of Doctor of Philosophy in the field of Chemical Oceanography

\section{THESIS ABSTRACT}

To provide a new perspective on the fate of both natural organic matter and hydrophobic organic contaminants (HOCs) in marine sediments, we have investigated the relationship between radiocarbon $\left({ }^{14} \mathrm{C}\right)$ age and the different modes of association in aquatic sediments and soils. Radiocarbon is a sensitive tracer of OM provenance, with variations in its natural abundance reflecting the age and origin of material. The main objective has been to determine the significance of these associations, and to assess how they affect the transport, bioavailability, preservation and residence times of organic compounds in the environment.

Our results indicate that the majority of HOCs that persist in marine sediments are solvent-extractable and incorporation into insoluble sediment residues is not quantitatively significant. For pristine sediments, systematic variations in ${ }^{14} \mathrm{C}$ content are observed between different chemically defined sedimentary organic fractions. These variations are dependent on organic matter inputs and/or the affects of diagenesis. Our observations also provide evidence for the protection of labile marine carbon by chemical binding. Finally, the persistence of $n$-alkanes from biogenic sources compared to those derived from petroleum indicates that protective matrix association can play a crucial role in determining the long-term fate of a compound. Overall, it is clear that both natural organic compounds and HOCs can undergo very different fates depending on their mode of introduction to, and physical disposition in environmental matrices. 


\section{ACKNOWLEDGMENTS}

Funding for this research was provided by the National Science Foundation, CHE0089172 to T.I. Eglinton and C.M. Reddy, and OCE-82567700 to T.I. Eglinton. I received support from a Charles Davis Hollister Fellowship from Woods Hole Oceanographic Institution.

The past five years or so have been a tremendous amount of fun. I am extremely grateful to Tim Eglinton and Chris Reddy for providing me with the opportunity to explore the field of oceanography and for guiding me through this with much patience and support. As members of my committee, John Hayes and Phil Gschwend also contributed significantly to this work and I am grateful for their interest in my research and stimulating conversation.

While the work in this thesis would have been possible without the help of Daniel Montluçon and Sean Sylva, it may have taken ten times as long and would have been many times less fun. I am forever appreciative of their willingness to assist, fix, tighten, teach, joke and listen. I am also thankful to Li Xu, Bob Nelson, Emma Teuten, Leah Houghton, Carl Johnson, John Andrews and the staff at NOSAMS for their help with various aspects of data collection and analysis. I also would like to thank those who kindly donated sediments or helped collect them. In particular the crew of the R/V Clifford Barnes, R/V New Horizon and Emily Peacock and John King.

The Academic Programs Office at WHOI seemed to make any problem I had disappear and this was mainly due to the wonderful work of Marsha Gomes and Julia Westwater. I am particularly grateful to John Farrington and Judy McDowell for their tremendous investment in, and commitment to the MIT/WHOI Joint Program.

The support from fellow Joint Program students (past and present) has been amazing and seemingly endless. Thanks to Rachel Wisniewski, Nathalie Goodkin, Kristy Dahl, Linda Kalnejais, Matt Makou, Nick Drenzek, Gareth Lawson, Rachel Stanley, Cara Santelli, Bridget Bergquist, Ana Lima and Ann Pearson.

Special thanks for numerous distractions from and reminders of the world outside of Science are owed to Justin Huxol, Sonia Brenner, Kristin Myers, Layla Gibbon, Kay Withers, Katie Green, Nick Relph, Justin Dellecave, Caroline Grace, Amy Henneveld and Ethan Swan. The love and support of my family made all of this possible. 
TABLE OF CONTENTS

AbSTRACT 3

TABLE OF CONTENTS

TABLE OF FigurES $\quad 10$

TABLE OF TABLES 16

$\begin{array}{lr}\text { CHAPTER 1 - INTRODUCTION } & 19\end{array}$

CHAPTER 2 - ABUNDANCE, COMPOSITION, AND VERTICAL 27

TRANSPORT OF PAHS IN MARSH SEDIMENTS

2.1 INTRODUCTION 28

2.2 MATERIALS AND METHOdS 30

2.2.1 Sediment Collection $\quad 30$

2.2.2 Radiochronology 31

2.2.3 Sediment Characteristics $\quad 31$

2.2.4 Petroleum Residue Analysis 32

2.2.5 Quality Control $\quad 34$

2.3 RESULTS AND DISCUSSION 34

2.3.1 General Trends of PAHs in Sediments 34

2.3.2 Downcore PAH Profiles 38

2.3.3 Mathematical Modeling of Postdepositional Transport 41 of PAHs

Supporting Information $\quad 46$

2.4 REFERENCES $\quad 48$

CHAPTER 3 - ISOTOPIC CONSTRAINTS ON THE FATE OF 51

PETROLEUM RESIDUES SEQUESTERED IN SALT MARSH SEDIMENTS

3.1 INTRODUCTION

3.2 MATERIALS AND METHODS $\quad 54$

$\begin{array}{ll}\text { 3.2.1 Samples } & 54\end{array}$

3.2.2 Sediment Chronology $\quad 54$

3.2.3 Solvent Extraction $\quad 54$

3.2.4 Saponification 56

3.2.5 Acid Hydrolysis 56

3.2.6 Gas Chromatography-Mass Spectrometry (GC/MS) 57

Analysis

3.2.7 Bulk Sediment and Extract Analyses 57

3.3 RESULTS AND DisCUSSION 58

3.3.1 Vertical Distribution of Petroleum Hydrocarbon 58

Contaminants in Salt Marsh Sediments

3.3.2 Radiocarbon as an Inverse Tracer 60 
3.3.3 Stable Carbon Isotopic Composition of Sediments, Residues and Extracts

3.3.4 Isotope Mass Balance 65

3.3.5 Sensitivity of Isotopic Approach 68

$\begin{array}{ll}\text { 3.4 REFERENCES } & 70\end{array}$

3.5 APPENDIX 73

CHAPTER 4 - RELATIONSHIPS BETWEEN RADIOCARBON 77 CONTENT AND MODES OF ASSOCIATION OF NATURAL ORGANIC MATTER IN COASTAL AND CONTINENTAL MARGIN SEDIMENTS

4.1 INTRODUCTION $\quad 78$

4.2 MATERIALS AND METHODS $\quad 81$

4.2.1 Study Area and Samples $\quad 81$

4.2.2 Sequential Lipid Extraction $\quad 85$

4.2.3 Bulk Sediment Analyses 86

4.2.4 Gas Chromatography-Mass Spectrometry (GC/MS) 87 Analysis

4.3 RESULTS AND DisCUSSION $\quad 87$

4.3.1 General Trends in Surface Sediments 87

4.3.2 Organic-Rich Marine Sediments 106

4.3.3 Open Shelf and River Dominated Sediments 109

4.3.4 Near-Coast Sediments 112

4.3.5 Arctic Sediments 112

4.3.6 Antarctic Sediments 114

4.3.7 Diagenetic Considerations 116

4.4 CONCLUSIONS 120

4.5 REFERENCES $\quad 122$

$\begin{array}{ll}\text { 4.6 APPENDIX } & 127\end{array}$

CHAPTER 5 -RADIOCARBON AS AN INVERSE TRACER OF 133

FOSSIL FUEL-DERIVED CONTAMINANTS IN SEDIMENTS

5.1 INTRODUCTION 134

5.2 MATERIALS AND METHODS 138

5.2.1 Study Area and Samples 138

5.2.2 Sequential Chemical Treatment 142

5.2.3 Demineralization of Pawtuxet River Sediments 143

5.2.4 Bulk Sediment Analyses 143

5.2.5 Gas Chromatography-Mass Spectrometry (GC/MS) 144

Analysis

5.3 RESULTS AND DISCUSSION 145

5.3.1 Solvent-Extractable Contaminants $\quad 145$

5.3.2 Nonextractable Contaminants $\quad 150$ 
5.3.3 Nature of Nonextractable Contaminants $\quad 155$

5.3.4 Radiocarbon as an Inverse Tracer of Contaminants 156

5.3.5 Isotopic Evidence of Nonextractable Contaminants 163

5.4 CONCLUSIONS 166

5.5 REFERENCES 167

5.6 APPENDIX 172

CHAPTER 6 - ISOTOPIC CONSTRAINTS ON THE PROVENANCE 177 OF INDIVIDUAL BIOMARKERS IN SALT MARSH SEDIMENTS

6.1 INTRODUCTION 178

6.2 MATERIALS AND METHODS $\quad 180$

6.2.1 Study Area and Samples $\quad 180$

6.2.2 Lipid Extraction and Purification 180

6.2.3 Preparative Capillary Gas Chromatography (PCGC) 182

6.2.4 Radiocarbon Analysis 183

6.3 RESUlTS AND DiSCUSSION 183

6.3.1 Fatty Acid and Alkane Distributions 183

6.3.2 Compound Specific Isotope Analysis of Fatty Acids 186

6.3.3 Compound Specific Isotope Analysis of Alkanes 190

6.4 CONCLUSIONS 194

6.5 REFERENCES 194

6.6 APPENDIX 198

CHAPTER 7 - CONCLUSIONS AND FUTURE WORK 201 


\section{TABLE OF FIGURES}

\section{CHAPTER 1}

Figure 1.1 The global organic carbon cycle (ca. 1950).

Units $=10^{15}$ gC. Modified after Hedges, 1992.

\section{CHAPTER 2}

Figure 2.1 Downcore profile of (a) TPH (Reddy et al., 2002), (b) इPAHs 35 (Table 1) and (c) ratio of $\mathrm{C}_{1}$-phenanthrenes.

Figure 2.2. $\quad$ PAH signatures of sediment extracts from (a) 0-2 cm, (b) 14-16 $\mathrm{cm}$, (c) 28-30 cm compared to (d) the relative abundance of PAHs present in an average composition of four No. 2 fuel oils (Reddy, 1997). Abbreviations for PAHs are detailed in Table 2.1.

Figure 2.3 Downcore profiles of TPH (Reddy et al., 2002) (a and e), alkylated naphthalenes, $\mathrm{N}_{1}, \mathrm{~N}_{2}, \mathrm{~N}_{3}$, (b, c, d respectively), and alkylated phenanthrenes $\mathrm{P}_{1}, \mathrm{P}_{2}, \mathrm{P}_{3}$, (f, g, h respectively). Abbreviations for PAHs are explained in Table 1.

Figure 2.4 Downcore profiles of alkylated naphthalenes; $\mathrm{N}_{1}, \mathrm{~N}_{2}, \mathrm{~N}_{3}$ (a, b, c respectively, solid line) and alkylated phenanthrenes; $\mathrm{P}_{1}, \mathrm{P}_{2}, \mathrm{P}_{3}$ (d, e, f respectively, solid line) compared to model data (dashed line). All concentrations are normalized to their maximum concentration. Abbreviations for PAHs are explained in Table 2.1.

Figure 2. SI Downcore profiles of (a) excess ${ }^{210} \mathrm{~Pb}$ in disintegrations per minute (dpm) per gram of dry, homogenized sediment (error bars are $+/$ - error counts for ${ }^{210} \mathrm{~Pb}$ ), (b) ${ }^{137}$ Cs counts in dpm per gram of dry, homogenized sediment (error bars are +/- error ) counts for ${ }^{137} \mathrm{Cs}$ ) and (c) total organic carbon weight \% (error bars are $+/$ - one standard deviation from triplicate analyses).

\section{CHAPTER 3}

Figure 3.1 Flow diagram to illustrate the sequential treatment of sediments and residues.

Figure 3.2 Downcore profile of (a) total petroleum hydrocarbons (TPH) concentrations (from Reddy et al., 2002), (b) $\Delta^{14} \mathrm{C}$ of the total organic carbon of the untreated sediment (TOC, filled black circles) and solvent-extracted sediment residue (EX-RES, unfilled circles), (c) $\Delta^{14} \mathrm{C}$ of the total lipid extract (TLE), (d) $\Delta^{14} \mathrm{C}$ of solvent-extracted sediment residue (EX-RES, unfilled circles) and saponified sediment residue (SA-RES, filled diamonds), (e) $\Delta^{14} \mathrm{C}$ saponification extract (SA-EX) and (f) 
$\Delta^{14} \mathrm{C}$ of saponified sediment residue (SA-RES, filled diamonds) and acid hydrolyzed sediment residue (AH-RES, unfilled diamonds). Dashed horizontal lines highlight the zone of maximum TPH contamination.

Figure 3.3 Downcore profile of (a) total petroleum hydrocarbons (TPH) concentrations (from Reddy et al., 2002), (b) $\delta^{13} \mathrm{C}$ of the total organic carbon of the untreated sediment (TOC, filled black circles) and solvent-extracted sediment residue (EX-RES, unfilled circles), (c) $\delta^{13} \mathrm{C}$ of the total lipid extract (TLE), (d) $\delta^{13} \mathrm{C}$ of solvent-extracted sediment residue (EX-RES, unfilled circles) and saponified sediment residue (SA-RES, filled diamonds), (e) $\delta^{13} \mathrm{C}$ saponification extract (SA-EX) and (f) $\delta^{13} \mathrm{C}$ of saponified sediment residue(SA-RES, filled diamonds) and acid hydrolyzed sediment residue (AH-RES, unfilled diamonds). Dashed horizontal lines highlight the zone of maximum TPH contamination.

Figure 3.4 The sensitivity of $\Delta^{14} \mathrm{C}$ of total organic carbon $\left(\Delta^{14} \mathrm{C}_{\mathrm{TOC}}\right)$ to additions of petroleum $\left(\Delta^{14} \mathrm{C}=-1000 \%\right)$ to sediments with varying $\Delta^{14} \mathrm{C}_{\mathrm{TOC}}$ values. Modern sediments are represented by a $\Delta{ }^{14} C_{\text {TOC }}$ of $+100 \%$. Two other potential end members were chosen to represent the particulate organic carbon (POC) of the salt marsh. These were Eel grass and Spartina and are represented by $\Delta{ }^{14} \mathrm{C}_{\mathrm{TOC}}$ values of $+62 \%$ and $+198 \%$ o respectively, as in McNichol et al., 1994.

CHAPTER 4

Figure 4.1 Locations of sediments examined in this study.

Figure 4.2 $\quad \Delta^{14} \mathrm{C}$ and $\delta^{13} \mathrm{C}$ of unextracted sediment residues (TOC) for (a) organic-rich marine sediments; (b) open shelf and river dominated sites; (c) near-coast sediments; (d) Arctic sediments; (e) Antarctic sediments and (f) all core-top samples compared. Error bars for $\Delta^{14} \mathrm{C}$ and $\delta^{13} \mathrm{C}$ are $10 \%$ and $0.1 \%$ respectively and are smaller than the symbols shown in the figure and thus are not visible.

Figure 4.3 Relative contribution of $n$-alkanoic acids, $n$-alcohols and alkanes for a) organic-rich marine sediments; b) open shelf and river dominated sediments; c) near-coast sediments; d) Arctic sediments and e) Antarctic sediments to $i$ ) the total lipid extract (TLE) and (ii) the saponification extract (SAE). See text for description of 'other'.

Figure 4.4 Percent contribution to compound class for individual $n$-alkanoic 94 acids, $n$-alkanols and $n$-alkanes in the total lipid extract (TLE) 
in organic-rich marine sediments. '*' represents the unsaturated counterpart of the previous $n$-alkanoic acid. Values superimposed on histogram bars represent those that are off scale and odd over even predominance (OEP) for $n$-alkanes is indicated. Diagonal lines are present where compounds are below detection limits.

Figure 4.5 Percent contribution to compound class for individual

$n$-alkanoic acids, $n$-alkanols and $n$-alkanes in the total lipid

extract (TLE) to open shelf and river dominated sediments.

'*' represents the unsaturated counterpart of the previous

$n$-alkanoic acid. Values superimposed on histogram bars

represent those that are off scale and odd over even predominance (OEP) for $n$-alkanes is indicated.

Figure 4.6 Percent contribution to compound class for individual

$n$-alkanoic acids, $n$-alkanols and $n$-alkanes in the total lipid extract (TLE) to Near-coast sediments. '*' represents the unsaturated counterpart of the previous $n$-alkanoic acid. Values superimposed on histogram bars represent those that are off scale and odd over even predominance (OEP) for $n$-alkanes is indicated.

Figure 4.7 Percent contribution to compound class for individual $n$-alkanoic acids, $n$-alkanols and $n$-alkanes in the total lipid extract (TLE) to Arctic sediments. '*' represents the unsaturated counterpart of the previous $n$-alkanoic acid. Values superimposed on histogram bars represent those that are off scale and odd over even predominance (OEP) for $n$-alkanes is indicated.

Figure 4.8 Percent contribution to compound class for individual $n$-alkanoic acids and $n$-alkanols in the total lipid extract (TLE) to Antarctic sediments. '*' represents the unsaturated counterpart of the previous $n$-alkanoic acid. Values superimposed on histogram bars represent those that are off scale. Diagonal lines are present where compounds are below detection limits.

Figure 4.9 Percent contribution to compound class for individual $n$-alkanoic acids and $n$-alkanols in the saponification extract (SAE) for organic-rich marine sediments. '*' represents the unsaturated counterpart of the previous $n$-alkanoic acid. Values superimposed on histogram bars represent those that are off scale.

Figure 4.10 Percent contribution to compound class for individual $n$-alkanoic acids and $n$-alkanols in the saponification extract (SAE) for open shelf and river dominated sediments. '*' represents the unsaturated counterpart of the previous $n$-alkanoic acid. Values superimposed on histogram bars 
represent those that are off scale.

Figure 4.11 Percent contribution to compound class for individual

$n$-alkanoic acids and $n$-alkanols in the saponification

extract (SAE) for near-coast sediments. '*' represents

the unsaturated counterpart of the previous $n$-alkanoic acid.

Figure 4.12 Percent contribution to compound class for individual

$n$-alkanoic acids and $n$-alkanols in the saponification extract

(SAE) for Arctic sediments. '*' represents the unsaturated counterpart of the previous $n$-alkanoic acid. Values superimposed on histogram bars represent those that are off scale. Diagonal lines are present where compounds are below detection limits.

Figure 4.13 Differences in $\delta^{13} \mathrm{C}$ of the extracted residue (EX-RES;

filled grey symbols) and saponified residue (SA-RES; open symbols) from $\delta^{13} \mathrm{C}$ of bulk sediment (TOC; filled

black symbol) expressed as $\Delta \delta^{13} \mathrm{C} \%$ vs. the differences in $\Delta^{14} \mathrm{C}$ of the EX-RES and SA-RES from the TOC expressed as $\Delta \Delta^{14} \mathrm{C} \%$ for organic-rich marine sediments (core-top samples only). Error bars represent $0.1 \%$ error for $\delta^{13} \mathrm{C}$ values and $10 \%$ error for $\Delta^{14} \mathrm{C}$.

Figure 4.14 Differences in $\delta^{13} \mathrm{C}$ of the extracted residue (EX-RES; filled grey 110 symbols) and saponified residue (SA-RES; open symbols) from $\delta^{13} \mathrm{C}$ of bulk sediment (TOC; filled black symbol) expressed as $\Delta \delta^{13} \mathrm{C} \%$ vs. the differences in $\Delta^{14} \mathrm{C}$ of the EX-RES and SA-RES from the TOC expressed as $\Delta \Delta^{14} \mathrm{C}$ \%o for open shelf and river dominated sediments (core-top samples only). Error bars represent $0.1 \%$ error for $\delta^{13} \mathrm{C}$ values and $10 \%$ error for $\Delta^{14} \mathrm{C}$.

Figure 4.15 Differences in $\delta^{13} \mathrm{C}$ of the extracted residue (EX-RES; filled grey symbols) and saponified residue (SA-RES; open symbols) from $\delta^{13} \mathrm{C}$ of bulk sediment (TOC; filled black symbol) expressed as $\Delta \delta^{13} \mathrm{C}$ \%o vs. the differences in $\Delta^{14} \mathrm{C}$ of the EX-RES and SA-RES from the TOC expressed as $\Delta \Delta^{14} \mathrm{C} \%$ o for near-coast sediments. Error bars represent $0.1 \%$ error for $\delta^{13} \mathrm{C}$ values and $10 \%$ error for $\Delta^{14} \mathrm{C}$.

Figure 4.16 Differences in $\delta^{13} \mathrm{C}$ of the extracted residue (EX-RES; filled grey symbols) and saponified residue (SA-RES; open symbols) from $\delta^{13} \mathrm{C}$ of bulk sediment (TOC; filled black symbol) expressed as $\Delta \delta^{13} \mathrm{C} \%$ vs. the differences in $\Delta^{14} \mathrm{C}$ of the EX-RES and SA-RES from the TOC expressed as $\Delta \Delta^{14} \mathrm{C} \%$ or for Arctic sediments. Error bars represent $0.1 \%$ o error for $\delta^{13} \mathrm{C}$ values and $10 \%$ orror for $\Delta^{14} \mathrm{C}$.

Figure 4.17 Differences in $\delta^{13} \mathrm{C}$ of the extracted residue (EX-RES; filled grey 114 symbols) and saponified residue (SA-RES; open symbols) from 
$\delta^{13} \mathrm{C}$ of bulk sediment (TOC; filled black symbol) expressed as $\Delta \delta^{13} \mathrm{C} \%$ vs. the differences in $\Delta^{14} \mathrm{C}$ of the EX-RES and SA-RES from the TOC expressed as $\Delta \Delta^{14} \mathrm{C} \%$ for Antarctic sediments (core-top samples only). Error bars represent $0.1 \%$ error for $\delta^{13} \mathrm{C}$ values and $10 \%$ error for $\Delta^{14} \mathrm{C}$.

Figure 4.18 Differences in $\delta^{13} \mathrm{C}$ of the extracted residue (EX-RES; filled grey symbols) and saponified residue (SA-RES; open symbols) from $\delta^{13} \mathrm{C}$ of bulk sediment (TOC; filled black symbol) expressed as $\Delta \delta^{13} \mathrm{C} \%$ vs. the differences in $\Delta{ }^{14} \mathrm{C}$ of the EX-RES and SA-RES from the TOC expressed as $\Delta \Delta^{14} \mathrm{C} \%$ for sediment horizons below the surface mixed layer. Error bars represent $0.1 \%$ error for $\delta^{13} \mathrm{C}$ values and $10 \%$ error for $\Delta^{14} \mathrm{C}$.

\section{CHAPTER 5}

Figure 5.1 Structures of hydrophobic organic contaminants examined in this study.

Figure 5.2 Location of sediments examined in this study.

Figure 5.3 Gas chromatograms of total lipid extracts from a) New Bedford Harbor, b) Hudson River, c) Chattanooga Creek and d) Eagle Harbor. The dashed line is the GC baseline. In a) and d) PCBs and PAHs dominate. In b) and c) contaminants are designated with “*” and biogenic hydrocarbons $n$-alkanoic acids, $n$-alkanols, alkanes and sterols are labeled with "F", "O", "A" and "S" respectively. The internal standard hexatriacontane is designated with "is" and an external contaminant is labeled with "e."

Figure 5.4 Percent contribution of biogenic hydrocarbons and contaminants (specified in the text) to the total lipid extract.

Figure 5.5 Structures of hydrophobic organic contaminants released by alkaline hydrolysis from various samples examined in this study.

Figure 5.6 Gas chromatograms of saponification acidic extracts from a) New 152 Bedford Harbor, b) Hudson River, c) Chattanooga Creek and d) Eagle Harbor. The dashed line is the GC baseline. In all samples, the $n$-alkanoic acids are numbered. The $n$-alkanoic acids in d) have different retention times as they were methylated in the saponification process. The internal standard hexatriacontane is designated with "is".

Figure 5.7 Gas chromatograms of saponification neutral extracts from

a) New Bedford Harbor, b) Hudson River, c) Chattanooga Creek and d) Eagle Harbor. The dashed line is the GC baseline. In all samples, the $n$-alkanols acids are numbered. Contaminants are designated in c) and d) with “*”. The internal standard hexatriacontane is designated with "is". 
Figure 5.8 Percent contribution of biogenic hydrocarbons and contaminants 154 (specified in the text) to the saponification extract.

Figure 5.9 Difference between $\Delta^{14} \mathrm{C}$ of unextracted sediment (TOC) and solvent-extracted sediment residue (EX-RES) as a function of percent TOC that is comprised of solvent-extractable fossil-fuelderived contaminants measured by gas chromatography.

Figure 5.10 Difference between the percent of total lipid extract (TLE) that is non-GC amenable and the deviation from the relationship between the percent total organic carbon (\%TOC) that is fossil -fuel derived calculated by GC-FID and isotope mass balance.

Figure 5.11 Difference between $\Delta^{14} \mathrm{C}$ of solvent-extracted (EX-RES) and saponified (SA-RES) sediment residues plotted against the difference between $\delta^{13} \mathrm{C}$ of solvent-extracted (EX-RES) and saponified (SA-RES) sediment residues.

\section{CHAPTER 6}

Figure 6.1 Abundance of individual free fatty acids from sediment horizons 0-2, 12-14 and 32-34 cm.

Figure 6.2 Abundance of individual bound fatty acids from sediment horizons 0-2, 12-14 and 32-34 cm.

Figure 6.3 Abundance of individual $n$-alkanes from sediment horizons 0-2, 12-14 and 32-34 cm.

Figure 6.4 $\quad \Delta^{14} \mathrm{C}$ and $\delta^{13} \mathrm{C}$ compositions of individual free (filled symbols) and bound (open symbols) short (triangles and diamonds) and long chain (squares) fatty acids from $0-2,12-14$ and $32-34 \mathrm{~cm}$ compared to the $\Delta^{14} \mathrm{C}$ and $\delta^{13} \mathrm{C}$ composition of the solvent extracted sediment residue (EX-RES) from White et al., $2005 a$. Errors for $\Delta^{14} \mathrm{C}$ and $\delta^{13} \mathrm{C}$ are smaller than the symbols representing the data and thus are not observed.

Figure 6.5 $\quad \Delta^{14} \mathrm{C}$ and $\delta^{13} \mathrm{C}$ compositions of individual $n$-alkanes from 0 -2, 12-14 and 32-34 cm compared to the $\Delta^{14} \mathrm{C}$ and $\delta^{13} \mathrm{C}$ composition of the solvent extracted sediment residue (EX-RES) from White et al., 2005a. Errors for $\Delta^{14} \mathrm{C}$ and $\delta^{13} \mathrm{C}$ are smaller than the symbols representing the data and thus are not observed. 


\section{TABLE OF TABLES}

CHAPTER 2

Table 2.1 Target PAHs analyzed and their concentrations $\left(\mu \mathrm{g} \mathrm{g}^{-1}\right)$ in 0-2, 14-16 and 28-30 cm sediment horizons.

Table 2.2 Properties of PAHs calculated to determine the effective diffusivity ( $\left.\mathrm{D}_{\text {ieff }}\right)$ of each PAH.

CHAPTER 3

Table 3.1 Stable carbon and radiocarbon abundances for sediment

61 residues and extracts.

Table 3.2 Elemental and petroleum concentrations in West Falmouth 67 sediments, 2000.

Table 3.3 Radiocarbon $\left(\Delta^{14} \mathrm{C}\right)$ measurements conducted by the National $\quad 74$ Ocean Sciences AMS facility (NOSAMS).

CHAPTER 4

Table 4.1 Locations, dates, depths and sedimentary environments of samples analyzed in this study.

Table 4.2 Percent organic carbon, stable carbon and radiocarbon

Table 4.3 Percent organic carbon for all samples that is extractable, saponifiable and non-hydrolyzable and the percent of the extracts that is amenable by gas chromatography.

Table 4.4 Radiocarbon $\left(\Delta^{14} \mathrm{C}\right)$ measurements conducted by the National 128 Ocean Sciences AMS facility (NOSAMS).

\section{CHAPTER 5}

Table 5.1 Locations, dates, depths and sedimentary environments of samples analyzed in this study.

Table 5.2 Quantities of solvent-extractable fossil-fuel-derived contaminants measured by gas chromatography and mass balance.

Table 5.3 Percent organic carbon, stable carbon and radiocarbon abundances for bulk samples and their respective residues.

Table 5.4 Percent organic carbon for all samples that is extractable, saponifiable and non-hydrolyzable and the percent of the extracts that is amenable by gas chromatography.

Table 5.5 Radiocarbon $\left(\Delta^{14} \mathrm{C}\right)$ measurements conducted by the National Ocean Sciences AMS facility (NOSAMS). 


\section{CHAPTER 6}

Table 6.1 Fraction of fossil-derived $n$-alkanes in West Falmouth sediments 193

Table 6.2 Radiocarbon $\left(\Delta^{14} \mathrm{C}\right)$ measurements conducted by the National 199 Ocean Sciences AMS facility (NOSAMS). 


\section{CHAPTER 1}

\section{GENERAL INTRODUCTION}

The burial of organic matter in recent marine sediments plays a critical role in the global organic carbon cycle (Figure 1.1). Quantitatively, there is more organic carbon (OC) derived from non-living organic molecules occurring in recent marine sediments, soil humus and dissolved in seawater than in all living land plants and marine organisms combined (Hedges et al., 2000). Once deposited in marine sediments, organic compounds are subjected to various processes that may influence their long-term fate, including sorption to mineral surfaces, entrapment or partitioning into macromolecular organic matter (MOM), reaction with MOM, and degradation by microorganisms. The susceptibility of an organic compound to these processes is largely determined by its intrinsic reactivity as well as its mode of delivery and physical disposition in the sediment.

The main aim of this thesis was to improve upon our understanding of the nature and distribution of organic compounds derived from both biogenic and anthropogenic sources in marine sediments. By examining the associations of organic compounds to MOM we aimed to make predictions regarding their long-term fate. In the case of hydrophobic organic contaminants (HOCs) this is of interest as previous studies have shown that certain HOCs or their metabolites can bind to MOM in sediments (Beller et al., 1998; Richnow et al., 1994; Reddy et al., 2000; Schwarzbauer et al., 2003), but this process is difficult to follow and quantitatively constrain. Binding to sedimentary MOM has the potential to influence the bioavalability, toxicity and transport of HOCs, and thus understanding these processes is of great interest from an environmental and human health perspective. Associations between natural organic compounds and MOM have

also been described (Farrington and Quinn, 1971; Lee, 1977; Zegouagh et al., 1996) and are of interest as they may exert strong controls on the preservation of labile organic 


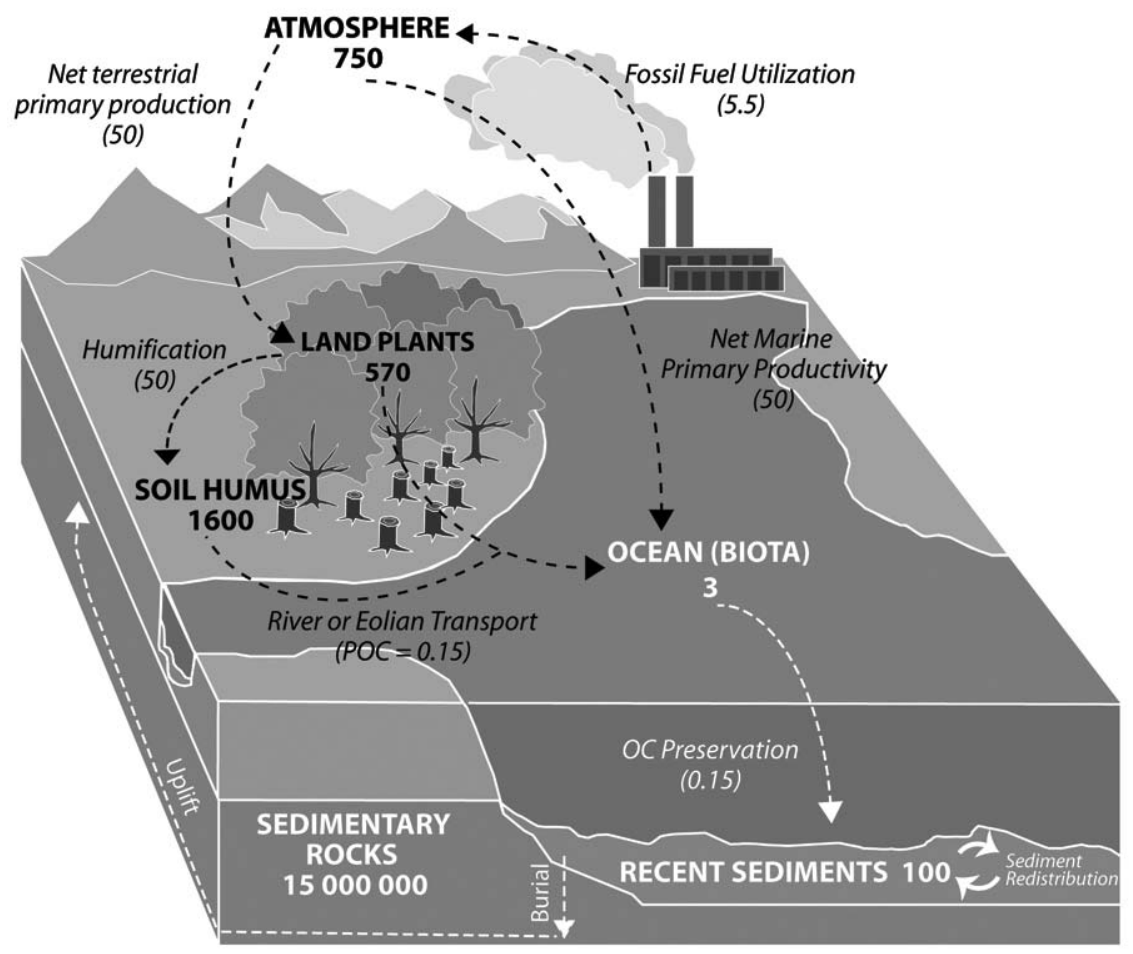

Figure 1.1 The global organic carbon cycle (ca. 1950). Units $=10^{15} \mathrm{gC}$. Modified after Hedges, (1992).

compounds (Wakeham et al., 1999) as well as affect their residence times in different carbon reservoirs. Binding to MOM, for example, may slow the delivery of a terrestrial derived organic compound to the ocean through association with relatively immobile particulate phases (e.g. soils).

To assess the associations between MOM and organic compounds, sequential chemical treatments are typically performed. Samples are first solvent extracted to isolate compounds with non-covalent associations and these are defined as "free" or "unbound"; those that remain associated to MOM and only released by harsher chemical treatments are defined as "nonextractable" or "bound". It is important to note that not all nonextractable residues are covalently associated with MOM and some may be 
physically entrapped in MOM networks or mineral matrices (Gevao et al., and references therein; Knicker and Hatcher, 1997).

In order to determine the significance of the associations of both natural organic compounds and HOCs with MOM, I have examined variations in the natural abundance of radiocarbon $\left({ }^{14} \mathrm{C}\right)$ in different sediment fractions. Radiocarbon is a sensitive tracer of organic matter and variations in its natural abundance reflect the age and origin of material. All recently photosynthesized carbon contains significant amounts of ${ }^{14} \mathrm{C}$, which is produced in the Earth's atmosphere by cosmic ray interactions, and makes its way into the biosphere mainly via photosynthetic fixation of $\mathrm{CO}_{2}$. Additionally, any natural product derived from carbon reservoirs in communication with the atmosphere since 1952 contains an excess quantity of ${ }^{14} \mathrm{C}$ due to incorporation of ${ }^{14} \mathrm{C}$ produced by the above-ground testing of thermonuclear weapons. Due to the slow equilibrium between the atmosphere and surface ocean waters, compounds of oceanic origin are depleted in ${ }^{14} \mathrm{C}$ relative to those of continental origin.

The $5730 \mathrm{yr}$ half-life of ${ }^{14} \mathrm{C}$ makes this isotope ideal for the detection of fossil fuel-derived HOCs $\left({ }^{14} \mathrm{C}\right.$-free) within different fractions of natural organic matter in contemporary environmental matrices (modern ${ }^{14} \mathrm{C}$ content). Using ${ }^{14} \mathrm{C}$, it is also possible to make quantitative assessments through the principle of isotope mass balance. For example, if we consider bulk total organic carbon (TOC) in sediments to be a mixture $(t)$ comprised of exogenous $(x)$ and endogenous $(n)$ components, this can be represented by

$$
(T O C) t=(T O C) x+(T O C) n
$$

and the isotopic composition of the mixture given by

$$
F t=f F x+(1-f) F n
$$

where the Fs represent isotopic abundances (e.g., ${ }^{14} \mathrm{C} /$ total carbon) and $f$ is the fraction of the mixture that is exogenous. In terms of radiocarbon abundances $(\Delta)$, we can write

$$
f=(\Delta t-\Delta n) /(\Delta x-\Delta n)
$$

where the $\Delta \mathrm{s}$ represent, in terms of $\Delta{ }^{14} \mathrm{C}$, the abundances of ${ }^{14} \mathrm{C}$ in the mixture and in its endogenous and exogenous components. This expression implies that $f$ can be determined precisely if there is a big isotopic contrast between the endogenous and exogenous 
components (i.e., for large values of $\Delta x-\Delta n$ ). This is optimized in this approach whenever the exogenous material is of fossil origin (and thus ${ }^{14} \mathrm{C}$-free, $\Delta x=-1000 \%$ ) and the endogenous material is modern biological debris $(\Delta n \approx+200 \%)$. Stable carbon isotope $\left(\delta^{13} \mathrm{C}\right)$ compositions of organic matter also provide insights into the cycling of natural organic compounds in the environment. Understanding the factors that control the $\delta^{13} \mathrm{C}$ of natural organic matter can place quantitative constraints on both source and carbon flow.

The long-term fate of HOCs in marine sediments is explored in Chapter 2 which examines the abundance, composition, and mobility of polycyclic aromatic hydrocarbons (PAHs) in salt marsh sediments of Wild Harbor, West Falmouth. This site was impacted by a spill of No. 2 fuel oil in 1969 (Sanders et al., 1980) and has since been the subject of numerous historical studies (Peacock et al., 2005 and references therein). Recent analysis of total petroleum hydrocarbons in the sediments reveals that the concentrations of these HOCs have not markedly changed over the past 30 years (Reddy et al., 2002 and references therein). In this study, downcore profiles of PAHs are compared to a numerical model to assess whether sediment-water partitioning and molecular diffusion in the interstitial medium are the dominant processes controlling the vertical distribution of PAHs that we observe today.

Chapter 3 builds upon this previous study examining the fate of PAHs at the West Falmouth site and utilizes variations in the natural abundance of radiocarbon $\left(\Delta^{14} \mathrm{C}\right)$ to detect and quantify No. 2 fuel oil residues in different fractions of sedimentary organic matter. This study examines the utility of radiocarbon as an inverse tracer of HOCs in marine sediments where the input of HOCs is well constrained in time and space. The sensitivity of this approach is assessed and isotope mass balance calculations of the total organic carbon (TOC) in the sediments derived from solvent-extractable petroleum are compared to values calculated from a fractional abundance of total petroleum hydrocarbon concentrations (measured by gas chromatography) as a function of TOC content (determined by elemental analysis). 
Examination of $\Delta^{14} \mathrm{C}$ values and molecular compositions of different sediment fractions and extracts from West Falmouth (Chapter 3) not only provides information about petroleum residues, but also emphasizes the persistence of natural organic compounds (alkanes, fatty acids, alkanols and sterols) in sediments. In some instances, these natural organic compounds strongly influence the $\Delta^{14} \mathrm{C}$ values of the bulk residues and extracts obtained, and provide information about the sources and fate of these compounds. Chapter 4 therefore, is aimed at investigating the relationships between ${ }^{14} \mathrm{C}$ content and the different modes of association of natural organic matter present in a variety of surficial sediments from near-shore and continental margin sites. Sediments deposited under both oxic and anoxic bottom waters, containing variable contributions from autochthonous and allochthonous (terrestrial, ancient and petroleum carbon) sources, subjected to different degrees of diagenesis were examined in terms of the nature and distribution of organic matter.

With this improved understanding of $\Delta^{14} \mathrm{C}$ distribution in different sediment fractions from uncontaminated sites, we return to examine sediments impacted by various fossil fuel-derived HOCs including petroleum, creosote, coal tar, polychlorinated biphenyls (PCBs), benzotriazoles (BZTs), 2,2-bis(chlorophenyl)-1,1,1-trichlorethane (DDT) and other chlorinated pesticides. Radiocarbon and stable carbon isotopic analyses, are again utilized, as in the study of the West Falmouth sediments (Chapter 3), to determine if binding of these more reactive HOCs is significant in marine sediments. Structures of HOCs and their metabolites released from different fractions of sediment are also examined and potential binding mechanisms discussed.

The investigations in the aforementioned chapters rely on bulk $\Delta \Delta^{14} \mathrm{C}$ measurements of sediments, residues and extracts. In order to provide a molecular-level basis for our findings, we return to the West Falmouth site and perform compoundspecific ${ }^{14} \mathrm{C}$ analysis of individual short $\left(n-\mathrm{C}_{14-18}\right)$ and long chain $\left(n-\mathrm{C}_{24-28}\right)$ fatty acids and long chain $\left(n-\mathrm{C}_{26}-\mathrm{C}_{32}\right)$ alkanes from contaminated and uncontaminated sediment horizons as well as those deposited before and after the bomb-spike. Natural abundance ${ }^{14} \mathrm{C}$ measurements of specific biomarkers provide a powerful tool to determine the sources of 
organic compounds in contemporary environmental matrices (Eglinton et al., 1997; Pearson and Eglinton, 2000). Through this work, we aim to not only provide information about the sources of organic matter to saltmarsh sediments, but to also conclusively determine whether any petroleum-derived $n$-alkanes persist at the site.

In Chapter 7, results presented in this thesis are summarized and suggestions are made for future research directions.

\section{REFERENCES}

Beller, H.R., Simoneit, B.R.T. 1988. Hexachlorophene distributions in estuarine sediments. Bulletin of Environmental Contamination and Toxicology 41, 645-650.

Eglinton, T. I., Benitez-Nelson, B.C., Pearson, A., McNichol, A.P., Bauer, J.E., Druffel, E.R.M. 1997. Variability in radiocarbon ages of individual organic compounds from marine sediments. Science 277, 796-799.

Farrington, J.W., Quinn, J.G., 1971. Comparison of sampling and extraction techniques for fatty acids in recent sediments. Geochimica et Cosmochimica Acta 35, 735-741.

Gevao, B., Semple, K.T., Jones, K.C. 2000. Bound pesticide residues in soils: a review. Environmental Pollution 108, 3-14.

Hedges, J. I. 1992. Global biogeochemical cycles - progress and problems. Marine Chemistry 39, 67-93.

Hedges, J. I., Eglinton, G., Hatcher, P.G., Kirchman, D.L., Arnosti, C., Derenne, S., Evershed, R.P., Kögel-Knaber, I., de Leeuw, J.W., Littke, R., Michaelis, W., Rullkötter, J. 2000. The molecularly-uncharacterized component of nonliving organic matter in natural environments. Organic Geochemistry 31, 945-958.

Knicker, H., Hatcher, P.G. 1997. Survival of protein in an organic-rich sediment: Possible protection by encapsulation in organic matter. Naturwissenschaften 84,231 234.

Lee, C., Gagosian, R.B., Farrington, J.W. 1977, Sterol diagenesis in recent sediments from Buzzards Bay, Massachusetts. Geochimica et Cosmochimica Acta 41, 985-992.

Peacock, E. E., Nelson, R. K., Solow, A. R., Warren, J. D., Baker, J. L., Reddy, C. M. 2005. The West Falmouth oil spill: $100 \mathrm{~kg}$ of oil found to persist decades later. Environmental Forensics 2005, 6, 273-281.

Pearson, A., Eglinton, T.I. 2000. The origin of $n$-alkanes in Santa Monica Basin surface sediment: A model based on compound-specific $\Delta^{14} \mathrm{C}$ and $\delta{ }^{13} \mathrm{C}$ data. Organic Geochemistry 31, 1103-1116.

Reddy, C.M., Quinn J.G., King J. 2000. Free and bound benzotriazoles in marine and freshwater sediments. Environmental Science and Technology 34, 973-979.

Reddy, C.M., Eglinton, T.I., Hounshell, A.H., White, H.K., Xu, L., Gaines, R.B., Frysinger, G.S., 2002. The West Falmouth oil spill after thirty years: The persistence 
of petroleum hydrocarbons in marsh sediments. Environmental Science and Technology 36, 4754-4760.

Richnow, H.H., Seifert, R., Hefter, J., Kästner, M., Mahro, B., Michaelis, W. 1994. Metabolites of xenobiotica and mineral oil constituents linked to macromolecular organic matter in polluted environments. Organic Geochemistry 22, 671-681.

Sanders, H.L., Grassle, J.F., Hampson, G.R., Morse, L.S., Garner-Price, S., Jones, C. 1980. Anatomy of an oil spill: long term effects from the grounding of the barge Florida off West Falmouth, Massachusetts. Journal of Marine Research, 265-380.

Schwarzbauer, J., Ricking, M., Littke, R. 2003. DDT-Related compounds bound to the nonextractable particulate matter in sediments of the Teltow Canal, Germany. Environmental Science and Technology 37, 488-495.

Wakeham, S.G., 1999. Monocarboxylic, dicarboxylic and hydroxy acids released by sequential treatments of suspended particles and sediments of the Black Sea. Organic Geochemistry 30, 1059-1074.

Zegouagh, Y., Derenne, S., Largeau, C., Saliot, A., 1996. Organic matter sources and early diagenetic alterations in Arctic surface sediments (Lena River delta and Laptev Sea, Eastern Siberia) - I. Analysis of the carboxylic acids released via sequential treatments. Organic Geochemistry 24, 841-857. 


\title{
CHAPTER 2
}

This manuscript appeared in:

Environmental Science and Technology (2005), 39, 8273-8280

It is reprinted here with permission of the publisher

\section{ABUNDANCE, COMPOSITION, AND VERTICAL TRANSPORT OF PAHS IN MARSH SEDIMENTS}

Helen K. White, Li Xu, Ana Lúcia C. Lima, Timothy I. Eglinton and Christopher M. Reddy

Department of Marine Chemistry and Geochemistry, Woods Hole Oceanographic Institution, Woods Hole, MA 02543

\begin{abstract}
Petroleum-derived hydrocarbons continue to persist in Wild Harbor, West Falmouth, MA, following a spill of No. 2 fuel oil in 1969 from the barge Florida. Recent analysis of marsh sediments revealed that residues of degraded oil are present with concentrations of total petroleum hydrocarbons as high as $\sim 9 \mathrm{mg} \mathrm{g}^{-1}$. Polycyclic aromatic hydrocarbons (PAHs) constitute only a minor fraction of these residues with maximum concentrations of $134 \mu \mathrm{g} \mathrm{g}^{-1}$, but their fate is of interest because of their potential toxicity to organisms. Compared to typical unweathered No. 2 fuel oil, the current distribution of PAHs in the sediments reflects substantial weathering by abiotic and biotic processes; specifically a preferential loss of naphthalenes relative to phenanthrenes, as well as isomer-specific biodegradation of alkylated PAHs. Based on comparison to results from an earlier study, it appears that little or no change has occurred to the distribution of PAHs since 1989, indicating that weathering at this site has stalled or is now proceeding
\end{abstract}


at a significantly slower rate. To assess whether sediment-water partitioning and molecular diffusion in the interstitial medium are now the dominant processes controlling the vertical distribution of PAHs, downcore profiles were compared to a numerical model. Whilst in some cases the model accurately reproduced the measured data, there were instances where the distribution of PAHs was slightly under or overestimated. Reasons for these discrepancies are discussed and are likely due to either bioturbation, colloid-facilitated transport or both. Assessment of the influence of these processes on the spilled oil expands our understanding of the overall fate of these compounds and their potential long-term effects on the environment.

\subsection{INTRODUCTION}

A major effort to understand the fate and long-term persistence of oil in the coastal marine environment has been directed at the sediments from the Wild Harbor salt marsh, West Falmouth, MA. This site was contaminated when the barge Florida ran aground and released 700,000 L of No. 2 fuel oil into Buzzards Bay on September 16, 1969 (Sanders et al., 1980). Previous work at the M-1 site in Wild Harbor, which was heavily impacted by the spill and the subject of numerous historical studies, revealed that the concentration of total petroleum hydrocarbons (TPH) in these sediments has not changed substantially in the past 30 years (Reddy et al., 2002). In addition, the use of comprehensive two-dimensional gas chromatography $(\mathrm{GC} \times \mathrm{GC})$ provided a detailed assessment of the composition of petroleum residues that continue to persist (Frysinger et al., 2003). These studies have revealed that distinct groups of branched alkanes, cycloalkanes, and polycyclic aromatic hydrocarbons (PAHs) remain whereas compounds typically abundant in No. 2 fuel oil, such as the $n$-alkanes, are not detectable (Reddy et al., 2002; Frysinger et al., 2003). A more recent survey of TPH in Wild Harbor has found that only $\sim 100 \mathrm{~kg}$ continues to persist in $\sim 0.001 \mathrm{~km}^{2}$ of salt marsh (Peacock et al., 2005). Examination of the natural abundance of radiocarbon within different pools of sedimentary organic matter has also shown that the majority of this oil has not been 
incorporated in the insoluble organic matter of the sediment and hence likely remains available to microorganisms and/or subject to physical processes such as diffusion (White et al., 2005). Natural radiocarbon abundances within phospholipids isolated from contaminated sediment intervals at site M-1, however, indicate that the oil is not currently being degraded by the resident microbial population (Slater et al., 2005). The latter is consistent with the findings of Reddy et al. (2002) who suggested that microbial degradation of the branched alkanes and other constituents of the spilled oil may have ceased over 25 years ago. Physical processes, therefore, likely play the most important role in determining the fate of the residual oil at this time.

Marshes are considered to be the shorelines most capable of long-term oil preservation (Peacock et al., 2005 and references therein) and thus it is critical that we fully understand the processes that control the fate of petroleum in these environments. In addition, such information is essential to damage assessors who must determine whether to restore, rehabilitate, or replace oil-impacted areas as per the United States Oil Pollution Act of 1990 (33 U.S.C. 2701-2761). Although minor constituents of petroleum, PAHs are of particular interest due to their carcinogenic, mutagenic, and toxic properties (Office of Health and Environmental Assessment, 1985).

Analysis of PAHs in surface sediments from Wild Harbor following the spill revealed a decrease in concentration of the lower molecular weight PAHs as the dominance of the $\mathrm{C}_{1}$-naphthalenes gave way to $\mathrm{C}_{2}$-naphthalenes by January $1971, \mathrm{C}_{3}$ naphthalenes by November 1972, and C4-naphthalenes by September 1975 (Teal et al., 1978). Twenty years after the spill, PAHs continued to be observed in the sediment at significant concentrations. For example, 2,3,6-trimethylnaphthalene and 3,6dimethylphenanthrene were detected at concentrations greater than 3 and $5 \mu \mathrm{g} \mathrm{g}^{-1}$, respectively (Teal et al., 1992). Molecular-specific differential weathering of PAHs has been observed at other sites (Wang and Fingas, 1995 and 2000), and general trends show that degradation rates are proportional to the number of aromatic rings and alkyl substitutions. The concentration of the lower molecular weight and less alkylated compounds typically decreases over time. This is in part due to higher solubilities and 
vapor pressures that increase the likelihood of removal by processes such as evaporation, water solubilization, diffusion, and microbial degradation. The degradation potential of PAHs also differs within isomeric groups, for example, isomers of $\mathrm{C}_{2}$-naphthalene have different susceptibilities to microbial degradation depending on the substitution patterns (Wang and Fingas, 1995; Farrington et al., 1982). Examination of individual PAHs persisting in marine sediments at the West Falmouth site provides an opportunity to study a single pulse addition of oil-derived PAHs to an otherwise pristine system. While other sites from the salt marsh contain PAHs with vertical distributions similar to those detailed here (Peacock et al., 2005), this study focuses on the M-1 site because of the extensive historical data available (Teal et al., 1978 and 1992) as well as the more recent geochemical studies (Reddy et al., 2002; Frysinger et al., 2003; Peacock et al., 2005; White et al., 2005; Slater et al., 2005). In addition, it was the most contaminated site when Teal et al. (1992) surveyed five sites in and around Wild Harbor in 1989. Unfortunately, the original Florida oil is no longer available and hence absolute differences between the original oil and current residues are not possible. Teal and colleagues also analyzed sediment horizons at a much coarser resolution $(5 \mathrm{~cm})$ and did not quantify the alkylated PAHs. For samples collected after the spill, through the 1970s (Teal et al., 1978) and in 1989 (Teal et al., 1992), extracted ion chromatograms for alkylated naphthalenes and phenanthrenes are only available for qualitative comparisons. Here, we present the results from the analysis of PAHs from one sediment core collected in 2000 and discuss the abundance, distribution, and vertical transport of these contaminants.

\subsection{MATERIALS AND METHODS}

\subsubsection{Sediment Collection}

In August 2000, a 15-cm diameter core was collected from the intertidal sediment at the M-1 station in Wild Harbor, West Falmouth, MA. The core was returned to the 
laboratory, sectioned at 2-cm intervals and frozen until further analysis as previously described (Reddy et al., 2002).

\subsubsection{Radiochronology}

One to two grams of air-dried, homogenized sediment was counted for gamma decay of ${ }^{210} \mathrm{~Pb},{ }^{214} \mathrm{~Pb}$ and ${ }^{137} \mathrm{Cs}$ using a high purity germanium detector (Canberra model GCW 4023S) with a closed-end coaxial well. Counting errors for total ${ }^{210} \mathrm{~Pb}$ and ${ }^{214} \mathrm{~Pb}$ were propagated to unsupported ${ }^{210} \mathrm{~Pb}$ and ranged from 5 to $26 \%$ of the activity $( \pm 1 \sigma$ ), with a mean error of $12 \%$ or 0.58 disintegrations per minute (dpm) per gram of dry weight sediment. Counting errors for ${ }^{137} \mathrm{Cs}$ ranged from 12 to $30 \%$ of the total activity ( \pm $1 \sigma$ ), with a mean error of $7 \%$ or $0.03 \mathrm{dpm}$ per gram of dry weight sediment. An approximate sedimentation rate of $0.35 \mathrm{~cm} \mathrm{yr}^{-1}$ was estimated from the activity of unsupported ${ }^{210} \mathrm{~Pb}$ (Figure 2.SIa) using the constant initial concentration (CIC) model (Eakins, 1983). This rate is consistent with a maximum in ${ }^{137} \mathrm{Cs}$ activity at a depth corresponding to 1963 (Figure 2.SIb), as well as a coincident maximum in radiocarbon (White et al., 2005), both observed as a result of the peak in nuclear weapons testing. The oil spill itself, as well as environmental effects such as erosion, storm events, and bioturbation, have had a significant effect on the site, hindering the establishment of a precise chronology for the core. Potentially, the most significant effect on sediment accumulation occurred after the oil spill when the Spartina alterniflora was killed and did not grow back until 1975 (Reddy et al., 2002).

\subsubsection{Sediment Characteristics}

Roots of the marsh grass Spartina alterniflora that grows at the M-1 site were observed throughout the length of the core. Moisture contents were determined as the difference between sample weights before and after drying. The average solid-to-water ratio of the sediment bed was calculated to be $0.28 \mathrm{~g} \mathrm{ml}^{-1}$ (ranging from 0.22 to $0.35 \mathrm{~g}$ $\mathrm{ml}^{-1}$ ). Total organic carbon (TOC) was calculated from dried and homogenized samples 
as described in $\mathrm{Xu}$ et al. (2001) and ranged from 8-13\% with an average of 11\% (Figure 2.SIc).

\subsubsection{Petroleum Residue Analysis}

One to five grams of air-dried sediment was spiked with the perdeuterated parent PAHs, fluorene- $d_{10}$, phenanthrene- $d_{10}$, pyrene- $d_{10}$, chrysene- $d_{12}$ and benzo[b]fluoranthene- $d_{12}(0.1-0.6 \mu \mathrm{g}$ of each), and extracted with dichloromethane and methanol (9:1) by pressurized fluid extraction $\left(100^{\circ} \mathrm{C} ; 1000 \mathrm{psi}\right)$. Extracts were reduced in volume, percolated through a copper column to remove elemental sulfur, solvent exchanged into hexane, and charged onto a glass column $(20 \mathrm{~cm}$ x $0.6 \mathrm{~cm})$ packed with fully activated silica gel (100-200 mesh). The column was eluted with ten milliliters of an equal mixture of hexane and dichloromethane. Half of the extract was removed and spiked with 9,10dihydrophenanthrene (0.1-0.6 $\mu \mathrm{g})$. The samples were analyzed on an Agilent 6890 series gas chromatograph with an Agilent 5973 mass selective detector (MSD). The MSD was operated in the selected-ion monitoring (SIM) mode for quantitation of target PAHs shown in Table 2.1. Compounds were separated on a J\&W DB-XLB capillary column (60 m, $0.25 \mathrm{~mm}$ ID, $0.25 \mu \mathrm{m}$ film) with helium carrier gas at a constant flow of $1 \mathrm{ml}$ $\min ^{-1}$. The GC oven had an initial temperature of $50{ }^{\circ} \mathrm{C}(1$ minute hold $)$ and was ramped at $10{ }^{\circ} \mathrm{C} \min ^{-1}$ until $320{ }^{\circ} \mathrm{C}$ (37 minute hold). Parent PAHs were quantified using the mass and area of the corresponding internal standard and a linear term of a six-point calibration curve generated with standard solutions prepared from the National Institute of Standards and Technology (NIST) Standard Reference Material 2260 "Aromatic Hydrocarbons in Toluene". For quantification of the alkylated PAH series, the response factors of the parent PAHs were used. We recognize that extracted ion chromatograms for alkylated phenanthrenes include alkylated anthracenes, and that extracted ion chromatograms for $\mathrm{C}_{1}$-pyrenes include $\mathrm{C}_{1}$-fluoranthenes and benzofluorenes, but the concentrations of these compounds is relatively small and thus for simplicity we only refer to the former in this manuscript. 
Table 2.1 Target PAHs analyzed and their concentrations $\left(\mu \mathrm{g} \mathrm{g}^{-1}\right)$ in $0-2,14-16$ and 28$30 \mathrm{~cm}$ sediment horizons.

\begin{tabular}{|c|c|c|c|c|}
\hline PAH & Symbol & 0-2 cm & $14-16 \mathrm{~cm}$ & $28-30 \mathrm{~cm}$ \\
\hline Naphthalene $*^{a}$ & $\mathrm{~N}_{0}$ & nd & nd & nd \\
\hline 2-Methylnaphthalene & $2 \mathrm{MN}$ & nd & 0.013 & nd \\
\hline 1-Methylnaphthalene & $1 \mathrm{MN}$ & nd & nd & nd \\
\hline $\mathrm{C}_{1}$-naphthalenes $*$ & $\mathrm{~N}_{1}$ & nd & 0.023 & nd \\
\hline $\mathrm{C}_{2}$-naphthalenes $* \S b$ & $\mathrm{~N}_{2}$ & nd & 0.318 & 0.011 \\
\hline $\mathrm{C}_{3}$-naphthalenes $* \S$ & $\mathrm{N}_{3}$ & 0.050 & 18.9 & 0.081 \\
\hline $\mathrm{C}_{4}$-naphthalenes $* \S$ & $\mathrm{N}_{4}$ & 0.102 & 51.3 & 0.058 \\
\hline Biphenyl * & $\mathrm{BIP}$ & nd & nd & nd \\
\hline 2,6-Dimethylnaphthalene & $\mathrm{DMN}$ & nd & 0.027 & nd \\
\hline Acenaphthylene * & ANY & nd & nd & nd \\
\hline Acenaphthene * & ANE & nd & 0.221 & nd \\
\hline 2,3,5-Trimethylnaphthalene & $\mathrm{TMN}$ & nd & nd & nd \\
\hline Fluorene * & $\mathrm{F}_{0}$ & nd & nd & nd \\
\hline Dibenzothiophene * & $\mathrm{D}_{0}$ & nd & 0.438 & nd \\
\hline Phenanthrene * & $\mathrm{P}_{0}$ & 0.066 & 0.492 & 0.027 \\
\hline $\mathrm{C}_{1}$-phenanthrenes $* \S$ & $\mathrm{P}_{1}$ & 0.056 & 8.76 & 0.022 \\
\hline $\mathrm{C}_{2}$-phenanthrenes $* \S$ & $\mathrm{P}_{2}$ & 0.076 & 27.9 & 0.035 \\
\hline $\mathrm{C}_{3}$-phenanthrenes $* \S$ & $\mathrm{P}_{3}$ & 0.035 & 17.5 & 0.025 \\
\hline $\mathrm{C}_{4}$-phenanthrenes $*$ & $\mathrm{P}_{4}$ & nd & 4.68 & 0.018 \\
\hline 1-Methylphenanthrene & $1 \mathrm{MP}$ & nd & 2.17 & nd \\
\hline 1,7-Dimethylphenanthrene & DMP & nd & nd & nd \\
\hline Anthracene * & ANT & nd & nd & nd \\
\hline Fluoranthene * & FLT & 0.178 & 0.376 & 0.068 \\
\hline Pyrene * & $\mathrm{PYR}_{0}$ & 0.124 & 0.856 & 0.047 \\
\hline $\mathrm{C}_{1}$-pyrene $*$ & $\mathrm{PYR}_{1}$ & 0.050 & 1.69 & 0.030 \\
\hline Benzo $[a]$ anthracene $*$ & BAA & 0.025 & 0.035 & 0.015 \\
\hline Chrysene * & CHR & 0.066 & 0.089 & 0.018 \\
\hline Benzo $[b]$ fluoranthene * & $\mathrm{BBF}$ & 0.098 & 0.064 & 0.030 \\
\hline Benzo $[k]$ fluoranthene * & $\mathrm{BKF}$ & 0.028 & 0.019 & nd \\
\hline Benzo $[e]$ pyrene * & BEP & 0.058 & 0.036 & 0.015 \\
\hline Benzo $[a]$ pyrene * & BAP & 0.023 & 0.020 & nd \\
\hline Perylene * & PER & nd & nd & nd \\
\hline $\operatorname{Dibenzo}[a, h]$ anthracene * & DANT & nd & nd & nd \\
\hline Indeno[1,23-cd]pyrene * & INP & nd & nd & nd \\
\hline Benzo[ghi]perylene * & BPER & nd & nd & nd \\
\hline Coronene * & $\mathrm{COR}$ & nd & nd & nd \\
\hline$\sum \mathrm{PAHs}$ & & 1.05 & 134 & 0.539 \\
\hline
\end{tabular}

${ }^{a} \Sigma$ PAHs is the sum of the PAHs marked with a "*”.

${ }^{b}$ Concentrations above which adverse effects frequently occur, Effects Range-Median (ERM) (Long et al., 1995) for low molecular weight PAHs is $3.16 \mu \mathrm{g} \mathrm{g}^{-1}$. Here, the sum of $\mathrm{C}_{2^{-}}, \mathrm{C}_{3^{-}}, \mathrm{C}_{4^{-}}$ naphthalenes and $\mathrm{C}_{1^{-}}, \mathrm{C}_{2^{-}}, \mathrm{C}_{3}$-phenanthrenes (marked with $\mathrm{a}^{\S}$ ) is $125 \mu \mathrm{g} \mathrm{g}^{-1}$ in the most contaminated horizon (14 to $16 \mathrm{~cm})$. 


\subsubsection{Quality Control}

Recoveries of the deuterated internal standards ranged from $50-70 \%$ with an average of $60 \%$. The accuracy of the method was assessed by analysis of the NIST Standard Reference Material 1944 “New York/New Jersey Waterway Sediment” and values within $70-130 \%$ of the certified values were obtained. The method detection limit (MDL) for PAHs was $10 \mathrm{ng} \mathrm{g}^{-1}$ and procedural blanks were always at or below the MDL. The precision for multiple analyses, as expressed by the relative standard deviation, was less than $10 \%$.

\subsection{RESULTS AND DISCUSSION}

\subsubsection{General Trends of PAHs in Sediments}

PAHs from the Florida spill continue to persist in salt marsh sediments in Wild Harbor with concentrations of $\Sigma$ PAHs as high as $134 \mu \mathrm{g} \mathrm{g}^{-1}$ at 14 to $16 \mathrm{~cm}$ (Table 2.1), coincident with the maximum concentration of TPHs ( $\sim 9 \mathrm{mg} \mathrm{g}^{-1}$, Figure 2.1a). PAHs were detected in each horizon of the sediment core but levels were most elevated between 8 and $20 \mathrm{~cm}$ (Figure 2.1b). The small sub-surface maximum observed at 24 to $28 \mathrm{~cm}$ most likely represents spilled oil that penetrated through channels in the sediment. Sediments at the M-1 site are very heterogeneous due to the presence of these channels and the extensive Spartina alterniflora root systems. Analysis of sediments a few years after the spill noted significant penetration of oil to depths of $70 \mathrm{~cm}$ and, in some cases, to depths greater than 1 meter (Burns and Teal, 1979). Concentrations of individual or groups of alkylated PAHs that are detectable in the sediments are relatively low $(0.01-$ $\left.0.2 \mu \mathrm{g} \mathrm{g}^{-1}\right)$ in the uppermost $(0-2 \mathrm{~cm}$; Figure 2.2a) and deepest $(28-30 \mathrm{~cm}$; Figure $2.2 \mathrm{c})$ intervals compared to significantly higher concentrations $\left(10-50 \mu \mathrm{g} \mathrm{g}^{-1}\right)$ at $14-16 \mathrm{~cm}$ (Figure 2.2b). The distribution of PAHs in the 14-16 cm horizon is typical of weathered No. 2 fuel oil. Specifically, parent PAHs, naphthalene and phenanthrene are absent, with a predominance of $\mathrm{C}_{3}$ - and $\mathrm{C}_{4}$-naphthalenes and $\mathrm{C}_{2}$ - and $\mathrm{C}_{3}$-phenanthrenes compared to an average composition of four different No. 2 fuel oils (Figure 2.2d) (Reddy, 1997). This 


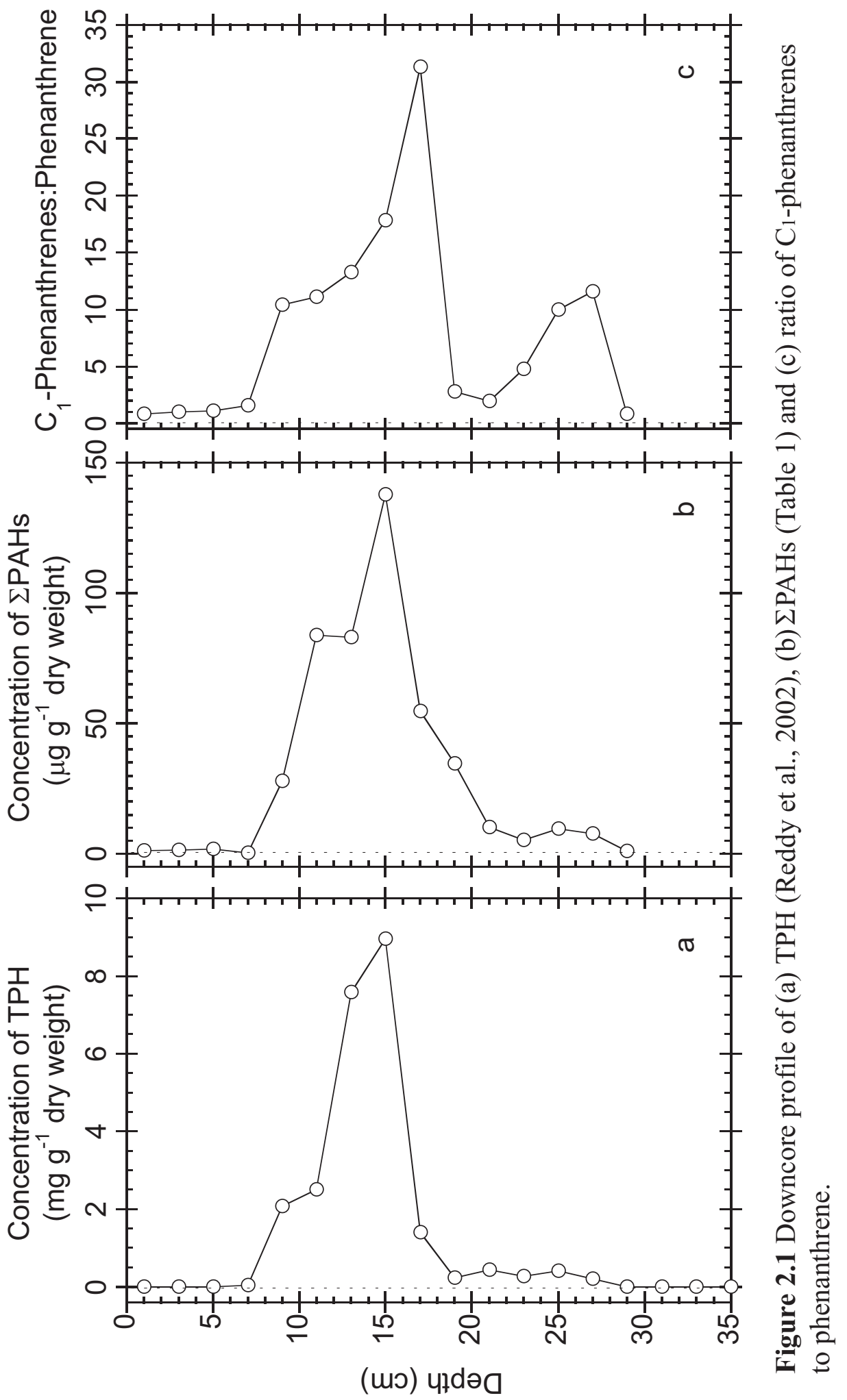



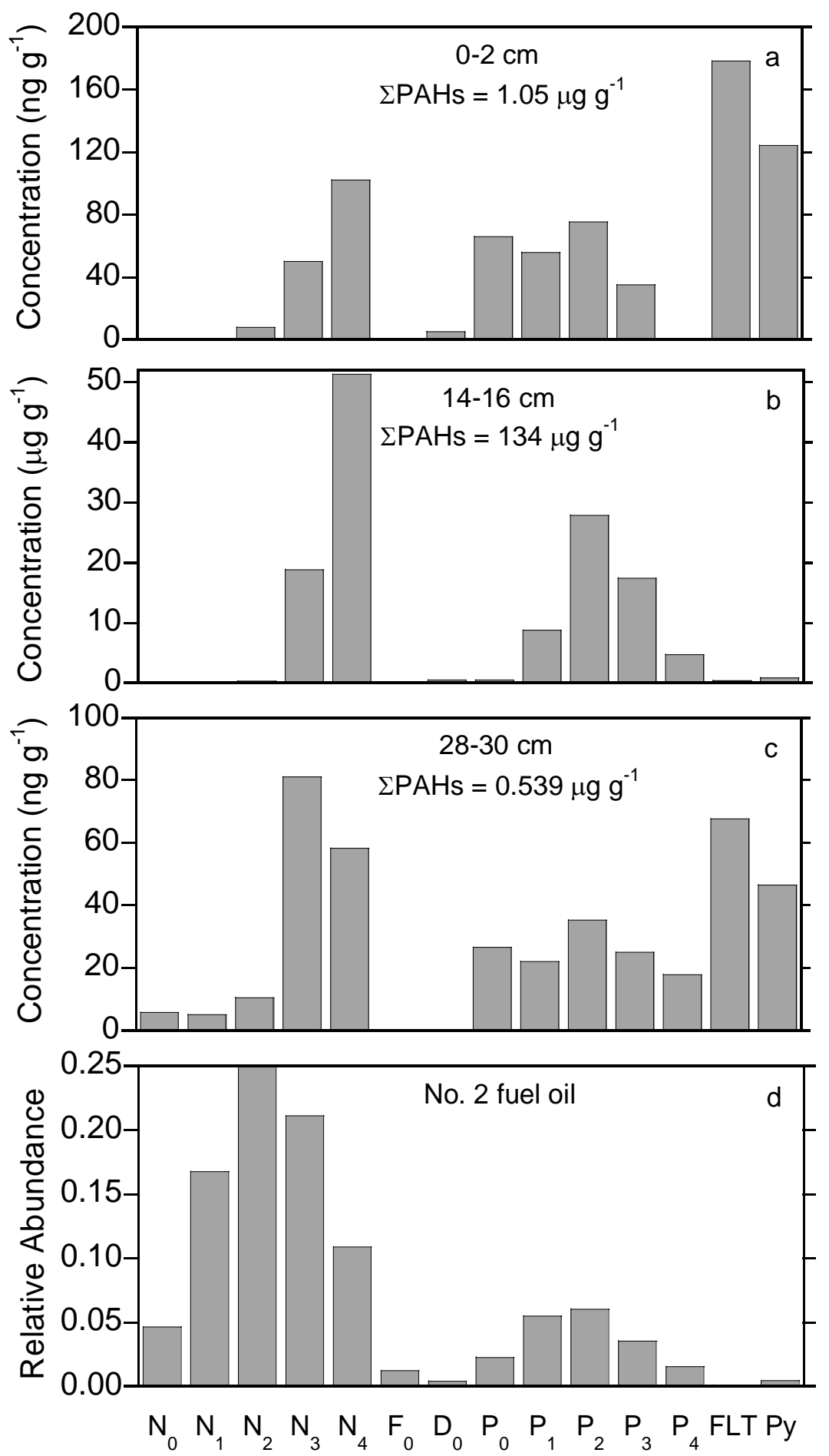

Figure 2.2. PAH signatures of sediment extracts from (a) 0-2 cm, (b) $14-16 \mathrm{~cm}$, (c) $28-30$ $\mathrm{cm}$ compared to (d) the relative abundance of PAHs present in an average composition of four No. 2 fuel oils (Reddy, 1997). Abbreviations for PAHs are detailed in Table 2.1. 
depletion of the less alkylated compounds and continuing dominance of the latter compounds is supported by qualitative observations made seven (Teal et al., 1978) and 20 years (Teal et al., 1992) after the spill and in other studies (Wang and Fingas, 1995; Wang et al., 2001; Ho et al., 1999). Sources of these PAHs can be confirmed by ratios of specific PAHs such as fluoranthene to pyrene and $\mathrm{C}_{1}$-phenanthrene to phenanthrene. Fluoranthene is thermodynamically more stable than pyrene and thus it is possible to differentiate between pyrogenic (fluoranthene : pyrene $>1$ ) and petrogenic (fluoranthene: pyrene $<1$ ) sources (Sicre et al., 1987). At the M-1 site, the top $8 \mathrm{~cm}$ and bottom 18 through $30 \mathrm{~cm}$ (excluding the sub-surface maximum at 24 to $28 \mathrm{~cm}$ ) have fluoranthene to pyrene ratios ranging from 1.1 to 1.5 , indicative of a pyrogenic source most likely from atmospheric deposition of combustion-derived material. The middle horizons (8 to 18 $\mathrm{cm}$ ) and the sub-surface maximum (24 to $28 \mathrm{~cm}$ ), however, exhibit a petrogenic signature with fluoranthene to pyrene ratios ranging from 0.4 to 0.9 . This is consistent with No. 2 fuel oil that has a fluoranthene to pyrene ratio of 0.6 to 0.9 (Gschwend and Hites, 1981). Because unsubstituted PAHs are the most abundant compounds in combustion-derived sources and petroleum has an increased abundance of alkylated compounds (Gustafsson and Gschwend, 1997), the $\mathrm{C}_{1}$-phenanthrene to phenanthrene ratio can also be examined. The downcore profile (Figure 2.1c) displays $\mathrm{C}_{1}$-phenanthrene to phenanthrene ratios ranging from 10-30 in the sediments heavily impacted by oil (10 to $18 \mathrm{~cm}$ and 24 to 28 $\mathrm{cm})$ and $\sim 1$ elsewhere.

The concentrations of PAHs persisting at the M-1 site were compared to guidelines for contaminant levels below or above which adverse effects rarely and frequently occur, the Effects Range-Low (ERL), and Effects Range-Median (ERM), respectively (Long et al., 1995). The sum of $\mathrm{C}_{2^{-}}, \mathrm{C}_{3^{-}}, \mathrm{C}_{4}$-naphthalenes and $\mathrm{C}_{1^{-}}, \mathrm{C}_{2^{-}}, \mathrm{C}_{3^{-}}$ phenanthrenes approaches $125 \mu \mathrm{g} \mathrm{g}^{-1}$ in the most contaminated horizon (14 to $16 \mathrm{~cm}$ ), which is 40 times greater the ERM value for low molecular weight PAHs $\left(3.16 \mu \mathrm{g} \mathrm{g}^{-1}\right)$. In fact, all sediment horizons with a clear petrogenic source $\left(\mathrm{C}_{1}\right.$-phenanthrene to phenanthrene ratios $>10$ ) in this core exceed the ERM, thus indicating the potential to 
adversely affect benthic infauna. Efforts are underway to more accurately gauge the biological effects of the petroleum residues that persist at this site.

Previous studies have revealed that both aerobic and anaerobic biodegradation of alkylated PAHs leaves distinct patterns in their relative abundances due to the preferential loss of certain isomers. For example, 2-methylphenanthrene is more easily biodegraded than other methylphenanthrenes (Wang and Fingas, 1995; Huang et al., 2004). Extracted ion chromatograms for the $\mathrm{C}_{1^{-}}, \mathrm{C}_{2^{-}}, \mathrm{C}_{3}$-naphthalenes and $\mathrm{C}_{1}$-phenanthrenes from oilcontaminated sediment horizons $(8$ to $18 \mathrm{~cm}$ ), which are not shown, exhibit isomer specific biodegradation similar to trends observed by Wang and Fingas (1995). Again, we do not have a sample of the original Florida oil and cannot make absolute comparisons. It is also not possible to determine exactly when biodegradation occurred, but the distribution of $\mathrm{C}_{1}$-phenanthrenes observed in this study (collected in 2000) appear to be similar to those shown for sediments collected in 1989 (Teal et al., 1992). This suggests that biodegradation of PAHs is no longer a dominant process, thus leading us to more closely investigate the role of vertical transport by examining downcore profiles of individual PAHs.

\subsubsection{Downcore PAH Profiles}

The downcore profile of $\Sigma$ PAHs at the M-1 site has a significantly broader peak than that of the TPH (Figure 2.1). The peak width, which is determined by measuring the width of the peak base, is $16 \mathrm{~cm}$ for $\mathrm{EPAHs}$ and $12 \mathrm{~cm}$ for the TPH. Further examination of downcore profiles of alkylated naphthalenes and phenanthrenes (the most abundant PAHs), indicate that variations in vertical distribution are also evident at the molecular level (Figure 2.3), for example, the peak maximum for $\mathrm{C}_{1}$-naphthalene $(19 \mathrm{~cm})$ is shifted downward compared to the TPH maximum $(15 \mathrm{~cm})$ and is considerably broader with a width of $16 \mathrm{~cm}$. The $\mathrm{C}_{2}$ - and $\mathrm{C}_{3}$-naphthalenes, however, have peak maxima concurrent with the $\mathrm{TPH}$, and the $\mathrm{C}_{3}$-naphthalenes exhibit a more symmetric profile. The phenanthrenes show broader peaks $(\sim 14 \mathrm{~cm})$ than the TPH, but narrower than the naphthalenes and have peak maxima that coincide with the TPH. Peak widths of the 

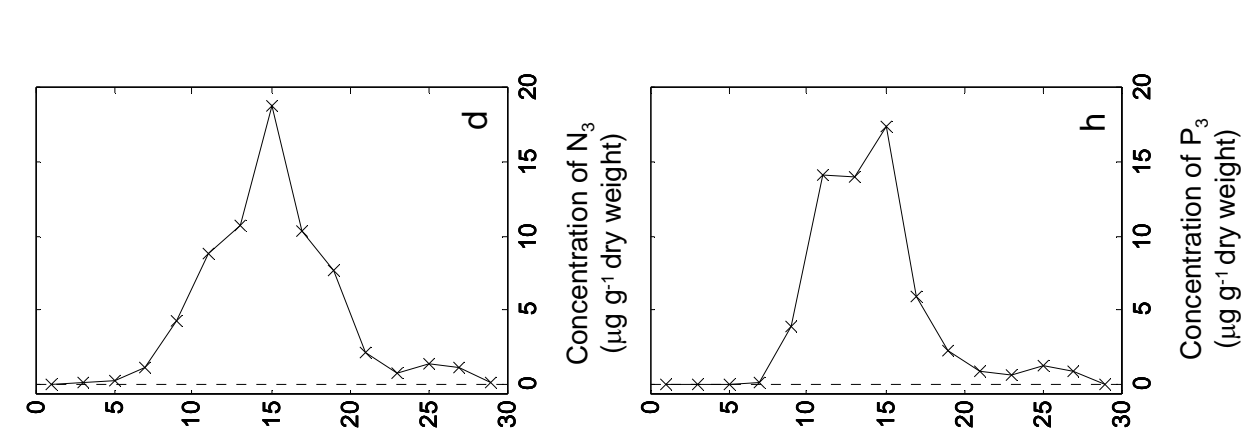

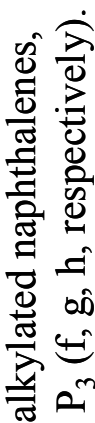
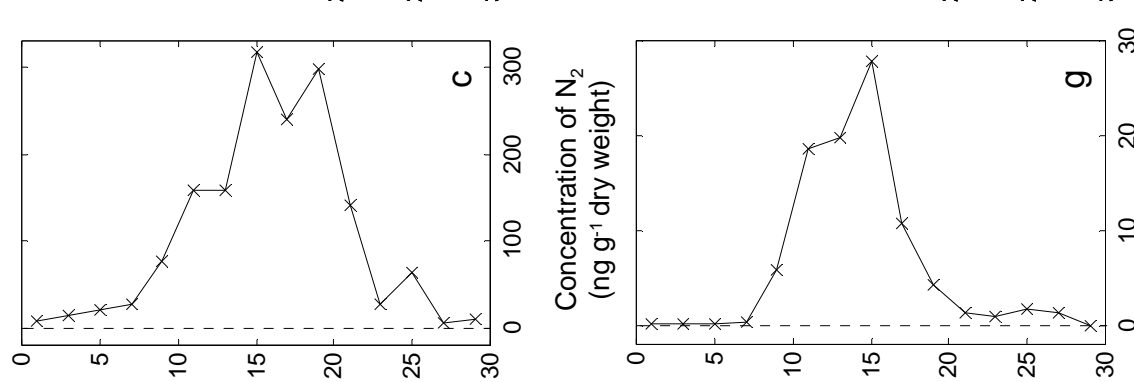

के

造㺃

ᄃ ब

플

สิ

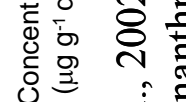

(ं)

त

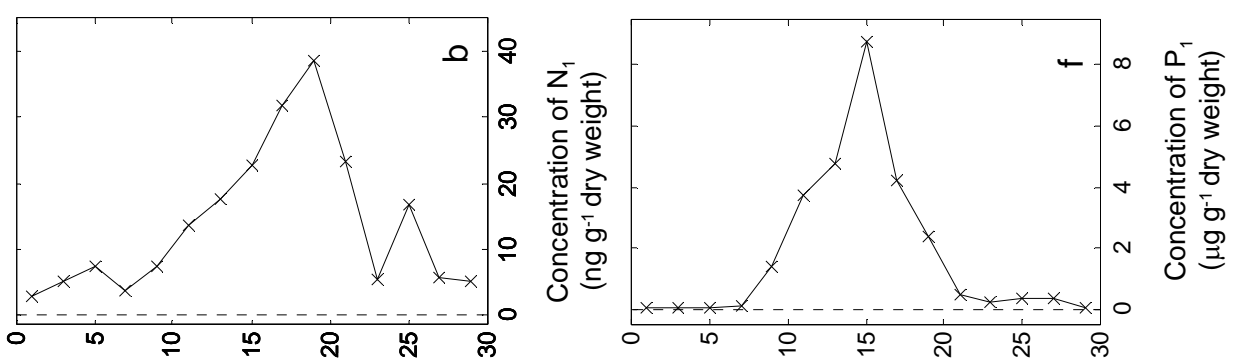

궁

응

㱐

I

트

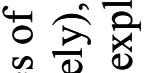

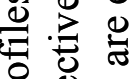

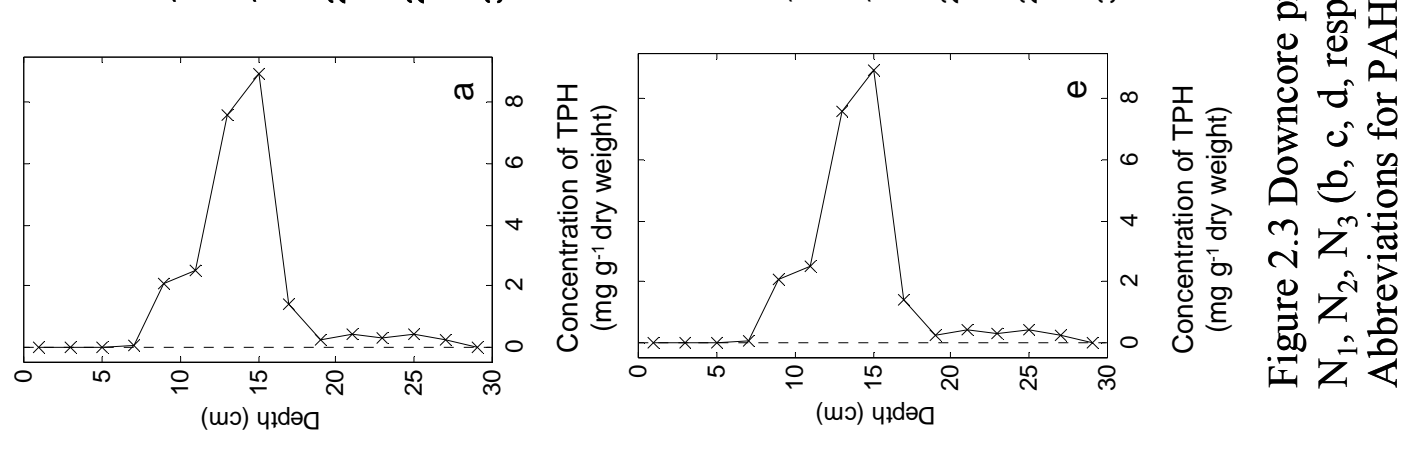


phenanthrenes broaden slightly, but consistently as alkyl substituents are added, which is the reverse of that observed for the naphthalenes.

The general observations of the peak widths for the TPH, alkylated naphthalenes, and phenanthrenes can be explained by the diffusivities of these compounds in the bulk sediment. The effective diffusivity coefficient $\left(D_{\text {ieff }}\right)$ is calculated for each compound assuming a two-phase system of sediment and interstitial water, including the effects of porosity, tortuosity, and the solid-water partition coefficient $\left(\mathrm{K}_{\mathrm{d}}\right)$ (Table 2.2). The naphthalenes have the greatest $\mathrm{D}_{\text {ieff }}$ and hence diffuse the farthest and exhibit the broadest peaks (Figure 2.3). The narrowing of the peak widths as alkyl substituents are added to the naphthalene structure is reflected in a similar decrease in the values of $\mathrm{D}_{\text {ieff }}$ (Table 2.2). The $D_{\text {ieff }}$ of the phenanthrenes, is an order of magnitude lower than the naphthalenes (Table 2.2) and this is evidenced by their narrower peak widths (Figure 2.3). The $\mathrm{D}_{\text {ieff }}$ for the phenanthrenes also decreases as alkyl substituents are added, but unlike the naphthalenes, this is not reflected in the measured data and a slight broadening of the peak width is observed as alkyl substituents are added. To increase the diffusion of these more hydrophobic compounds, a third phase is considered. The presence of porewater colloids has previously been observed to enhance "dissolved" concentrations of compounds beyond that predicted by their solubilities (Chiou et al., 1998; Brownawell, 1986) and concentrations of porewater dissolved organic carbon (DOC) in a Spartina alterniflora salt marsh have been observed to range from 0.4 to $1.9 \mathrm{mM}$ (Gribsholt et al., 2003). A significant portion ( $51 \pm 26 \%)$ of DOC in freshwater samples is known to be of high molecular weight (Repeta et al., 2002) and would thus serve as a good sorbent that could facilitate diffusion. The more alkylated and therefore hydrophobic the compound, the greater this contribution would be, potentially explaining the increase in observed peak width with increase in alkylation for the phenanthrenes.

The overall increased dispersion of the PAHs compared to the TPH highlights their increased partitioning into water and ability to diffuse over a wider area. The TPH at this site is represented by an unresolved complex mixture (UCM) that is composed mainly of saturated hydrocarbons (85\%) (Frysinger et al., 2003). The latter have 
considerably greater $\log \mathrm{K}_{\mathrm{ow}}$ values (e.g. dodecane: $\log \mathrm{K}_{\mathrm{ow}} \sim 7$ (MacKay et al., 1992) than the PAHs (Table 2.2) and as a result of their increased hydrophobicity, are unlikely to have undergone significant diffusion in the past 30 years. The relatively narrow peak width likely represents the initial oil-covered sediment distribution. At its highest concentration (11-17 cm, Figure 2.1a), the peak width of the TPH is $\sim 6 \mathrm{~cm}$ suggesting that when the oil was spilled, it penetrated to approximately this depth at this site. In general, the peak widths of the PAHs can be explained by their diffusivities, but to determine whether or not this component controls their distribution, the calculated $\mathrm{D}_{\text {ieff }}$ for each compound and a simple model was constructed.

\subsubsection{Mathematical Modeling of Postdepositional Transport of PAHs}

The processes controlling the vertical distribution of PAHs in the marsh sediment were examined by comparison of the measured data to a one-dimensional model. This approach was developed previously by Reiser et al. (1997) to study alkylbenzenesulfonates in lake sediments and is based on a simplified version of the diagenetic equation (Berner et al., 1989) having the form:

$$
(d C / d t)=D_{\text {ieff }} \cdot\left(d^{2} C / d x^{2}\right)+\omega \cdot(d C / d x)
$$

where $\mathrm{C}$ is the concentration of the solute in mass per unit volume of pore water solution, $\mathrm{D}_{\text {ieff }}$ is the effective diffusivity coefficient in the bulk sediment of the compound of interest (Table 2.2), $\omega$ is the sediment accumulation rate, i.e. the velocity of sediment flow relative to the sediment-water interface, $\mathrm{t}$ is time, and $\mathrm{x}$ is depth in the sedimentary column. The sediment-water interface was chosen as the origin of the depth coordinate. The initial input of oil was set at a depth of 0 through $6 \mathrm{~cm}$ allowing for settling of oil in the top layers of sediment as previously discussed. The velocity of burial of pore water was set equal to the velocity of particle burial thereby neglecting the advective flow of pore water relative to sediment particles. The velocity of burial was set constant at 0.35 $\mathrm{cm} \mathrm{y}^{-1}$ based on sediment deposited between $\sim 1910$ and 2000 and as there was no

significant evidence for mixing processes from the ${ }^{210} \mathrm{~Pb}$ profile (Figure 2.SIa), only molecular diffusion was assumed for $\mathrm{D}_{\text {ieff }}$, thus excluding bioturbation affects. Any loss 
Table 2.2 Properties of PAHs calculated to determine the effective diffusivity ( $\left.D_{\text {ieff }}\right)$ of each PAH.

\begin{tabular}{l|llllll}
\hline PAH & $\log _{\mathbf{~ K w}{ }^{a}}$ & $\log \mathbf{K}_{\mathbf{~ o c}}{ }^{b}$ & $\mathbf{K}_{\mathbf{d}}{ }^{c}$ & $\mathbf{f}_{\text {iw }}{ }^{d}$ & $\mathbf{D}_{\text {iw }}{ }^{e}$ & $\mathbf{D}_{\text {ieff }}{ }^{f}$ \\
\hline $\mathrm{C}_{1}$-Naphthalene & 3.94 & 3.54 & 350 & $1.0 \mathrm{E}-02$ & $5.7 \mathrm{E}-06$ & $8.1 \mathrm{E}-01$ \\
$\mathrm{C}_{2}$-Naphthalene & 4.15 & 3.75 & 560 & $6.4 \mathrm{E}-03$ & $5.3 \mathrm{E}-06$ & $4.7 \mathrm{E}-01$ \\
$\mathrm{C}_{3}$-Naphthalene & 4.36 & 3.95 & 900 & $4.0 \mathrm{E}-03$ & $5.0 \mathrm{E}-06$ & $2.8 \mathrm{E}-01$ \\
$\mathrm{C}_{1}$-Phenanthrene & 4.99 & 4.57 & 3720 & $9.6 \mathrm{E}-04$ & $4.9 \mathrm{E}-06$ & $6.5 \mathrm{E}-02$ \\
$\mathrm{C}_{2}$-Phenanthrene & 5.20 & 4.78 & 5970 & $6.0 \mathrm{E}-04$ & $4.6 \mathrm{E}-06$ & $3.8 \mathrm{E}-02$ \\
$\mathrm{C}_{3}$-Phenanthrene & 5.40 & 4.97 & 9380 & $3.8 \mathrm{E}-04$ & $4.4 \mathrm{E}-06$ & $2.3 \mathrm{E}-02$ \\
\hline
\end{tabular}

${ }^{a}$ Octanol-water partition coefficients $\left(\log \mathrm{K}_{\mathrm{ow}}\right)$ were calculated with an equation from Eastcott et al. (1988) based on the number of carbons in each compound. These values compare well with expected and measured values previously described (MacKay et al., 1992; Ruelle, 2000). Measured values are not available for all compounds examined in this study and thus the calculated values were used to maintain consistency between compounds.

${ }^{b}$ Log values of the organic matter-water partition coefficient $\left(\mathrm{K}_{\mathrm{oc}}\right)$ were calculated from $\mathrm{Log} \mathrm{K}_{\mathrm{ow}}$ using a linear free-energy relationship for aromatic hydrocarbons (Schwarzenbach et al., 2003 and references therein), where $\log \mathrm{K}_{\mathrm{oc}}=0.98 * \log \mathrm{K}_{\mathrm{ow}}-0.32$.

${ }^{c}$ Solid-water partition coefficient $\left(\mathrm{K}_{\mathrm{d}}\right)$ was calculated by multiplying $\mathrm{K}_{\mathrm{oc}}$ by the weight fraction of solid which is organic carbon $\left(f_{o c}\right)$ (Schwarzenbach et al., 2003), which at the M-1 site is an average of $0.1 \mathrm{~kg}$ organic carbon $\mathrm{kg}^{-1}$ solid (Figure 2.SIc).

${ }^{d}$ By combining $\mathrm{K}_{\mathrm{d}}$, and the solid-to-water ratio of the sediment $\left(\mathrm{r}_{\mathrm{sw}}\right)$ discussed in the text, the fraction of the PAH dissolved is determined, $f_{i w}=\left(1+r_{s w} K_{d}\right)^{-1}$.

${ }^{e}$ The diffusivity in water $\left(\mathrm{D}_{\mathrm{iw}}\right)$ is calculated by estimating the size $\left(\mathrm{V}_{\mathrm{i}}\right)$ of the PAHs using the approach of Fuller et al., (1966) as well as determining the solution viscosity at the temperature of interest $(\eta)$, which in this case is 1.139 . Combining this, we can solve the following equation from Hayduck and Laudie $(1974)$ where, $D_{\text {iw }}=\left(13.26 * 10^{-5}\right) /\left(\eta^{1.14} * V_{i}^{-0.58}\right)$.

${ }^{f}$ The effective diffusivity $\left(D_{\text {ieff }}\right)$ is calculated by multiplying $D_{\text {iw }}$ by $f_{i w}$ and dividing by the tortuosity (2.27)

due to biodegradation was assumed negligible when compared to the concentrations present in the sediments and considering that significant biodegradation is not occurring today (Slater et al., 2005). The validity of this assumption and the role that biodegradation may have played since the oil was spilled is revisited in the discussion. This model considers a two phase system of sediment and interstitial water, but it has been shown that the oil itself should be considered as a third phase as it may affect the 
partitioning of PAHs depending on its type, concentration, and age or weathering state (Jonker et al., 2003). Sorption enhancing effects, however, are only observed at high oil concentrations above $15 \%(\mathrm{w} / \mathrm{w})$ on a sedimentary organic carbon basis. At the M-1 site, the oil comprises less than $10 \%(\mathrm{w} / \mathrm{w})$ of the total organic carbon at all depth horizons (Figure 2.SIc) and thus this third phase is not incorporated into the model. The CrankNicholson implicit method was employed to determine concentrations of $\mathrm{C}_{1^{-}}, \mathrm{C}_{2^{-}}, \mathrm{C}_{3^{-}}$ naphthalene and $\mathrm{C}_{1^{-}}, \mathrm{C}_{2^{-}}, \mathrm{C}_{3}$-phenanthrene based on equation (I) as a function of depth. This method estimates spatial derivatives at both the present and a future time step and then uses these to obtain a spatial estimate that corresponds to the midpoint of the time step (Crank, 1975). No attempts were made to model the sub-surface maximum at 24-26 $\mathrm{cm}$. It is worth noting that the salt marsh sediment in this study is considerably more heterogeneous than the lake sediment examined by Reiser et al. (1997), and thus it is of interest to assess the utility of this method for a different sediment matrix.

The downcore profiles of the alkylated PAHs and the fit to the corresponding model data (Figure 2.4) can be summarized into three main groups. The first consists of the $\mathrm{C}_{1}$ - and $\mathrm{C}_{2}$-naphthalenes that show broad, asymmetric profiles that are overestimated by the model in the upper portion of the profile (Figure 2.4a and b). These are the only PAHs to exhibit concentrations in the upper $5 \mathrm{~cm}$ that are significantly greater than the detection limits (Figure $2.3 \mathrm{~b}$ and $\mathrm{c}$ ). The model predicts the presence of $\mathrm{C}_{1}$ - and $\mathrm{C}_{2}$ - naphthalenes in the upper $5 \mathrm{~cm}$ because their diffusivities ( 0.81 and $0.47 \mathrm{~cm}^{2} \mathrm{y}^{-1}$ respectively) exceed the rate of burial $\left(0.35 \mathrm{~cm} \mathrm{y}^{-1}\right)$, but the failure to correctly predict their relative contributions is most likely due to a loss term in the surface sediments that is not considered by the model. This loss term may include diffusion into the overlying water, evaporation or biodegradation that is more likely to occur in shallow sediments where the availabilities of electron acceptors (such as oxygen, nitrate or sulfate) is high and where microbial populations are greater (Slater et al., 2005). Since prior work indicates that biodegradation is no longer significant (Slater et al., 2005), the major loss may be due to evaporation or diffusion. Biodegradation may still be important, however, if it is a seasonal process that was not actively occurring when the work by Slater et al., (2005) 
was performed. The second group consists of the $\mathrm{C}_{3^{-}}$naphthalenes and $\mathrm{C}_{1}-$ phenanthrenes (Figure 2.4c and d) that display average width, symmetrical profiles well represented by the model that therefore appear to be controlled by diffusion only. Slight discrepancies between the model and measured data are observed, but most likely arise from an overestimation of the calculated diffusivity. The third group of compounds are the least diffusive and most hydrophobic, and consist of the $\mathrm{C}_{2}$ and $\mathrm{C}_{3}$-phenanthrenes (Figure $2.4 \mathrm{e}$ and $\mathrm{f}$ ). These compounds have relatively narrow peak widths that fit the model well, but have asymmetric profiles, displaying a sharp decrease in concentration below the peak maximum, but a much shallower decrease above. This apparent "smearing" of the concentration profile may be a result of bioturbation that only occurs above the peak maximum. Bioturbation would affect all compounds present in the oil, but the smearing is not observed for all. The magnitude of bioturbation may be too small to be noticeable for the more diffusive PAHs and thus is only observed for the least diffusive compounds, such as the $\mathrm{C}_{2^{-}}$and $\mathrm{C}_{3^{-}}$phenanthrenes. This hypothesis is supported by the TPH profile, which has a similar smearing and as discussed previously, is considered to be mainly composed of hydrophobic compounds with low diffusivities. Understanding past variations in bioturbation since the spill, and possible reasons for its occurrence above the peak maximum, but not below, are important considerations. In the years following the spill, bioturbation decreased significantly due to the eradication of the macrobenthos observed twelve hours after the spill, with the only slight recovery in infauna populations six years later (Krebs and Burns, 1977). Subsequently, as the marsh began to recover and recolonization took place, bioturbation could again become a factor. The macrobenthos, however, may not have penetrated into or through the sediment containing the highest concentration of the oil due to its inherent toxicity (as previously discussed), and thus the bottom half of the PAH profile would remain intact, as appears to be the case (Figure 2.4e-f). The effects of pollution on the mixing intensities of macrobenthos have previously been examined (Wheatcroft and Martin, 1996). While it is difficult to constrain this factor in the heterogeneous sediments examined here, it seems likely that such effects played a role in determining the profiles of the PAHs that we 

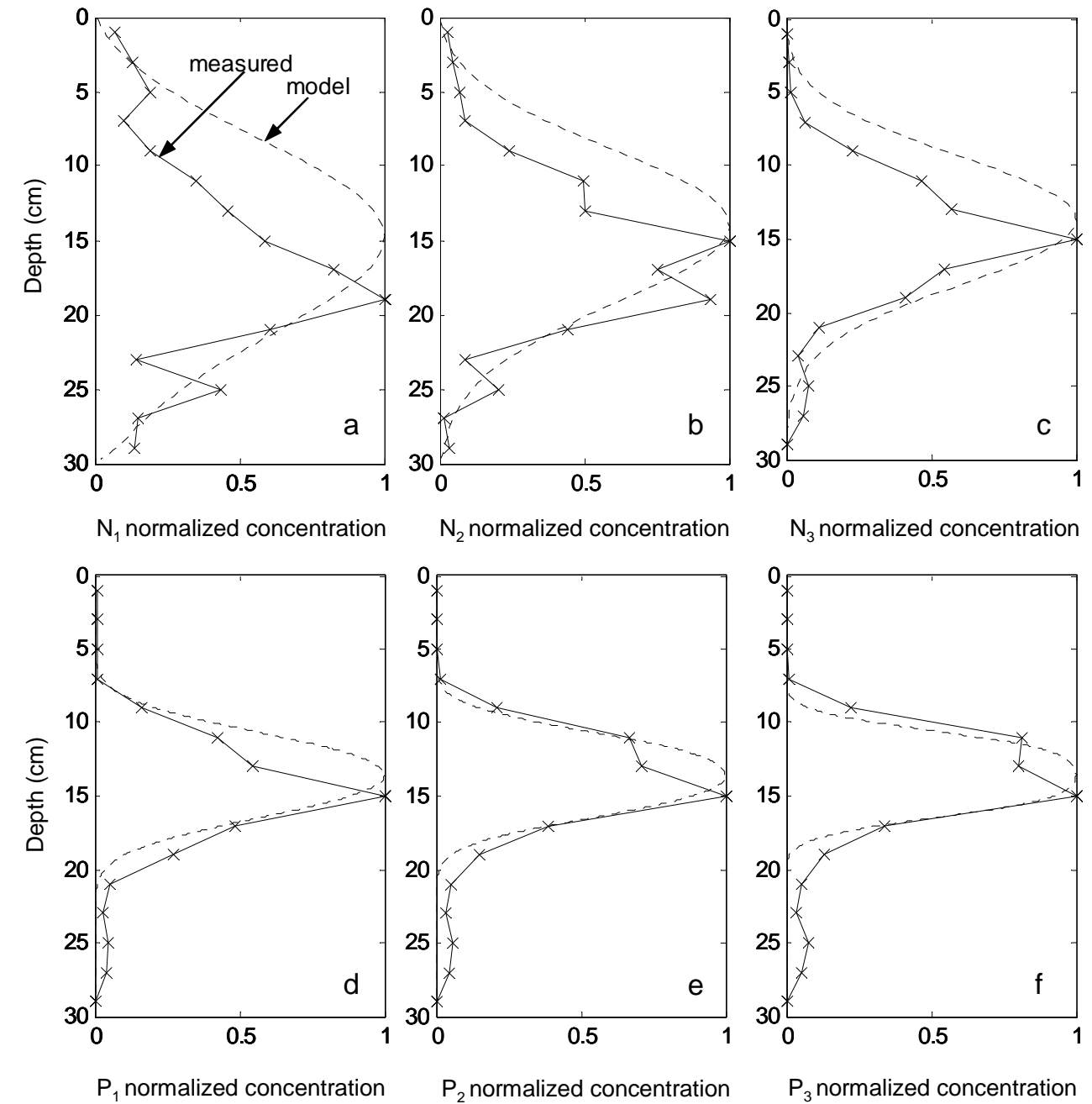

Figure 2.4 Downcore profiles of alkylated naphthalenes; $\mathrm{N}_{1}, \mathrm{~N}_{2}, \mathrm{~N}_{3}(\mathrm{a}, \mathrm{b}, \mathrm{c}$ respectively, solid line) and alkylated phenanthrenes; $\mathrm{P}_{1}, \mathrm{P}_{2}, \mathrm{P}_{3}$ (d, e, f respectively, solid line) compared to model data (dashed line). All concentrations are normalized to their maximum concentration. Abbreviations for PAHs are explained in Table 2.1.

observe today.

Considering these different profile types, it is clear that diffusivity is important, but that other factors should be considered. The discrepancies between the measured and model profiles highlight the complexities involved in understanding the post depositional 
fate of organic compounds. It appears that a combination of diffusion in the porewater, sorption onto colloidal matter, bioturbation and biodegradation contribute to the distribution of PAHs observed in the sediments today. Given the rates of diffusion for the PAHs (Table 2.2) and the sedimentation rate at the site $\left(0.35 \mathrm{~cm} \mathrm{y}^{-1}\right)$, only the $\mathrm{C}_{1}-$ and $\mathrm{C}_{2}$ -naphthalenes are likely to diffuse out of the sediment and into the overlying water. In summary, this study provides a quantitative evaluation of some of the most toxic and persistent compounds present in the environment today. The role that these postdepositional physical processes may exert on organic contaminants in marine sediments is not, however, limited to PAHs (Achman et al., 1996) and the findings of this study should be considered when predicting the long term fate of a variety of organic contaminants as well as when using sediments to reconstruct histories of environmental contamination.

\section{Acknowledgment}

We thank J. Andrews and L.A. Houghton for their help with this project and W.R. Martin, L.H. Kalnejais, J.S. Arey and P.M. Gschwend for helpful discussions. This work was supported by funds from the National Science Foundation (CHE-0089172), an Office

of Naval Research Young Investigator Award (CMR) N00014-04-01-0029, and the WHOI Coastal Ocean Institute.

\section{Supporting Information}

Figure displaying downcore profile of excess ${ }^{210} \mathrm{~Pb},{ }^{137} \mathrm{Cs}$ and total organic carbon (TOC). 


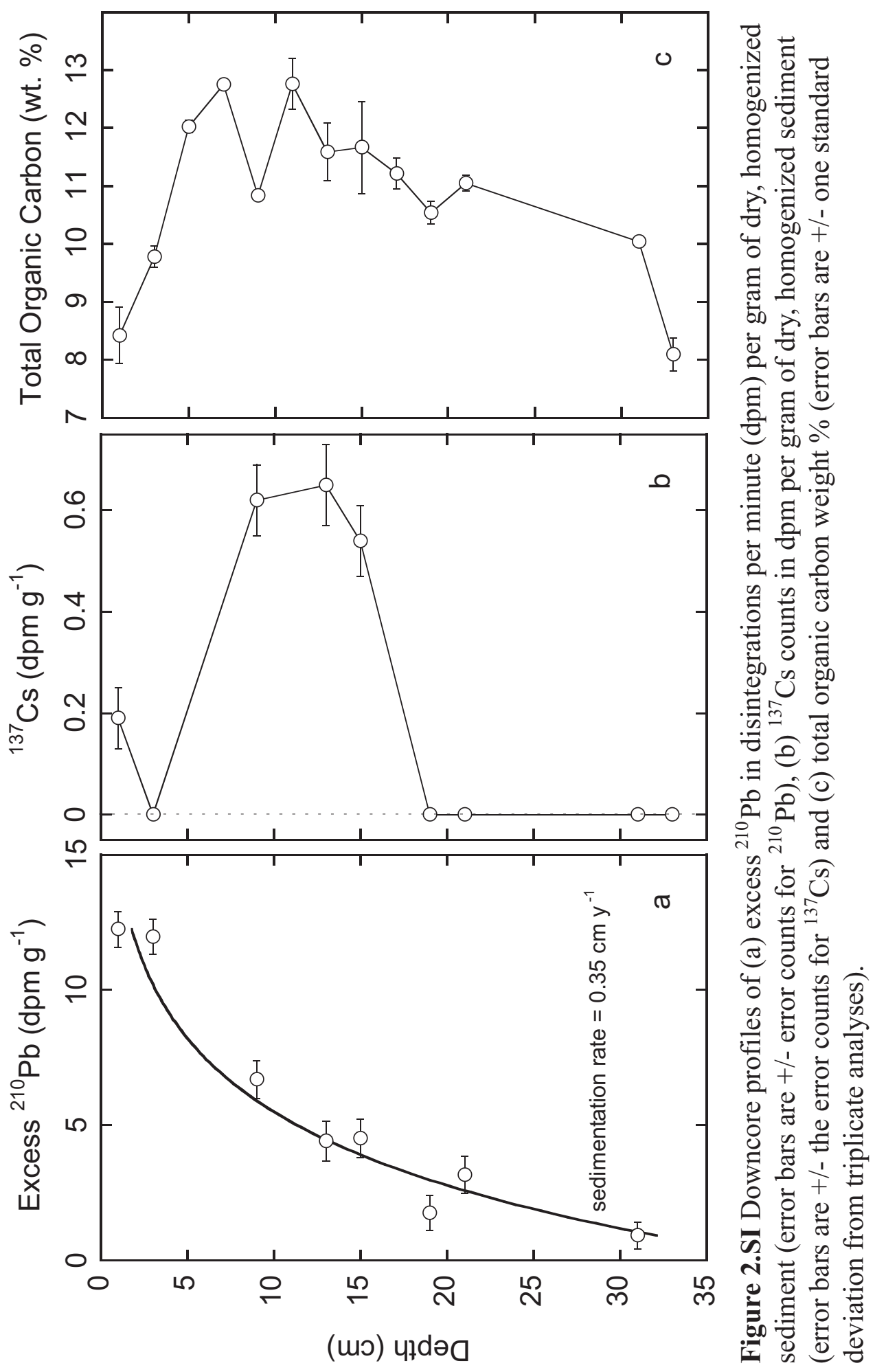




\subsection{REFERENCES}

Achman, D.R., Brownawell, B.J., Zhang, L. 1996. Exchange of polychlorinated biphenyls between sediment and water in the Hudson River Estuary. Estuaries 19, 950-965.

Berner, R.A. Early diagenesis: A theoretical approach, Princeton University Press, New Jersey USA, 1980.

Brownawell, B.J. Ph.D. Dissertation, Massachusetts Institute of Technology/Woods Hole Oceanographic Institution Joint Program in Oceanography, Woods Hole, MA, 1986.

Burns, K.A., Teal, J.M. 1979. The West Falmouth oil spill: Hydrocarbons in the salt marsh ecosystem. Estuarine and Coastal Marine Science 8, 349-360.

Chiou, C.T., McGroddy, S.E., Kile, D.E. 1998. Partition characteristics of polycyclic aromatic hydrocarbons on soils and sediments. Environmental Science and Technology 32, 264-269.

Crank, J. The Mathematics of Diffusion 2nd ed., Oxford University Press, U.K, 1975.

Eakins, J.D. $210 \mathrm{~Pb}$ technique for dating sediments, and some applications. In: Radioisotopes in sediment studies; IAEA-TEC ROC 298, Vienna, 1983; pp. 31-47.

Eastcott, L., Shiu, W.Y., Mackay, D. 1988. Environmentally relevant physical-chemical properties of hydrocarbons: a review of data and development of simple correlations. Oil and Chemical Pollution 4, 191-216.

Farrington, J.W., Tripp, B.W., Teal, J.M., Mille, G., Tjessem, K., Davis, A.C., Livramento, J.B., Hayward N.A., Frew N.M. 1982. Biogeochemistry of aromatic hydrocarbons in the benthos of microcosms. Toxicological and Environmental Chemistry 5, 331-346.

Frysinger, G.S., Gaines, R.B., Xu, L., Reddy C.M. 2003. Resolving the unresolved complex mixture in petroleum-contaminated sediments. Environmental Science and Technology 37, 1653-1662.

Fuller, E.N., Schettler, P.D., Giddings, J.C. 1966. A new method for prediction of binary gas-phase diffusion coefficient. Industrial \& Engineering Chemistry Research 58, 1927.

Gribsholt, B., Kostka, J.E., Kristensen, E. 2003. Impact of fiddler crabs and plant roots on sediment biogeochemistry in a Georgia saltmarsh. Marine Ecology Progress Series $259,237-251$.

Gschwend, P.M., Hites, R.A. 1981. Fluxes of polycyclic aromatic hydrocarbons to marine and lacustrine sediments in the northeastern United States. Geochimica et Cosmochimica Acta 45, 2359-2367.

Gustafsson, Ö., Gschwend, P.M. Soot as a strong partition medium for polycyclic aromatic hydrocarbons in aquatic systems. In Molecular markers in environmental geochemistry, ed. Eganhouse, R.P. American Chemical Society, Washington, D.C., USA, 1997; pp. 365-381.

Hayduck, W., Laudie, H. 1974. Prediction of diffusion coefficients for non-electrolytes in dilute aqueous solutions. Journal of the American Institute of Chemical Engineers 20, 611-615. 
Ho, K., Patton, L., Latimer, J.S., Pruell, R.J., Pelletier, M., McKinney, R., Jayaraman S. 1999. The chemistry and toxicity of sediment affected by oil from the North Cape spilled into Rhode Island Sound. Marine Pollution Bulletin 38, 314-323.

Huang, H., Bowler, B.F.J., Oldenburg, T.B.P., Larter, S.R. 2004. The effect of biodegradation on polycyclic aromatic hydrocarbons in reservoired oils from the Liaohe Basin, NE China. Organic Geochemistry 35, 1619-1634.

Jonker, M.T.O., Sinke, A.J.C., Brils J.M., Koelmans A.A. 2003. Sorption of polycyclic aromatic hydrocarbons to oil contaminated sediment: Unresolved complex? Environmental Science and Technology 37, 5197-5203.

Krebs, C.T., Burns, K.A. 1977. Long-term effects of an oil spill on populations of the salt-marsh crab Uca pugnax. Science 197, 484-487.

Long, E.R., MacDonald, D.D., Smith, S.L., Calder, F.D. Incidence of adverse biological effects within ranges of chemical concentrations in marine and estuarine sediments. Environmental Management 19, 81-97.

MacKay, D.; Ying Shin, W.; Ching Ma, K. Illustrated Handbook of Physical-Chemical Properties and Environmental Fate for Organic Chemicals Volume II., Lewis Publishers, Michigan USA, 1992.

Office of Health and Environmental Assessment, Office of Research and Development. Evaluation and Estimation of Potential Carcinogenic Risks of Polynuclear Aromatic Hydrocarbons; US Environmental Protection Agency, Washington, DC, 1985.

Peacock, E.E., Nelson, R.K., Solow, A.R., Warren, J.D., Baker, J.L., Reddy, C.M. 2005. The West Falmouth oil spill: $100 \mathrm{~kg}$ of oil found to persist decades later. Environmental Forensics 6, 273-281.

Reddy, C.M. 1997. Ph. D. Dissertation. University of Rhode Island, Kingston, RI, 1997.

Reddy, C.M., Eglinton, T.I., Hounshell, A.H., White, H.K., Xu, L., Gaines, R.B., Frysinger, G.S. The West Falmouth oil spill after thirty years: The persistence of petroleum hydrocarbons in marsh sediments. 2002. Environmental Science and Technology 36, 4754-4760.

Reiser, R., Toljander, H., Albrecht, A., Giger, W. Alkylbenzenesulfonates in recent lake sediments as molecular markers for the environmental behavior of detergent-derived chemicals, In: Molecular markers in environmental geochemistry, Eganhouse, R.P. Ed.; American Chemical Society: Washington, D.C., USA, 1997; pp 196-212.

Repeta, D.J.; Quan, T.M.; Aluhiware, L.I.; Accardi, A. 2002. Chemical characterization of high molecular weight dissolved organic matter in fresh and marine waters. Geochimica et Cosmochimica Acta 66, 955-962.

Ruelle, P. 2000. The n-octanol and n-hexane/water partition coefficient of environmentally relevant chemicals predicted from the mobile order and disorder (MOD) thermodynamics. Chemosphere 40, 457-512.

Sanders, H.L., Grassle, J.F., Hampson, G.R., Morse, L.S., Garner-Price, S., Jones, C. 1980. Anatomy of an oil spill: long term effects from the grounding of the barge Florida off West Falmouth, Massachusetts. Journal of Marine Research, 265-380.

Schwarzenbach, R.P., Gschwend, P.M., Imboden, D.M. Environmental Organic Chemistry, Second Edition, John Wiley \& Sons, Inc., USA, 2003. 
Sicre, M.A., Marty, J.C., Saliot, A., Aparicio, X., Grimalt, J., Albaiges, J. 1987. Aliphatic and aromatic hydrocarbons in different sized aerosols over the Mediterranean Sea; occurrence and origin. Atmospheric Environment 21, 2247-2259.

Slater, G., White, H.K., Eglinton, T.I., Reddy, C.M. 2005. Determination of microbial carbon sources in petroleum contaminated sediments using molecular ${ }^{14} \mathrm{C}$ analysis. Environmental Science and Technology 39, 2552-2558.

Teal, J.M., Burns, K.A., Farrington, J.W. 1978. Analyses of aromatic hydrocarbons in intertidal sediments resulting from two spills of No. 2 fuel oil in Buzzards Bay, Massachusetts. Journal of the Fisheries Research Board of Canada 35, 510-520.

Teal, J. M., Farrington, J.W., Burns, K.A., Stegeman, J.J., Tripp, B.W., Woodin, B., Phinney, C. 1992. The West Falmouth oil spill after 20 years: Fate of fuel oil compounds and effects in animals. Marine Pollution Bulletin 24, 607-614.

Wang, Z., Fingas, M. 1995. Differentiation of the source of spilled oil and monitoring of the oil weathering process using gas chromatography-mass spectrometry. Journal of Chromatography A 712, 321-343.

Wang, Z., Fingas, M., Owens, E.H., Sigouin, L., Brown C.E. 2001. Long-term fate and persistence of the spilled Metula oil in a marine salt marsh environment. Degradation of petroleum biomarkers. Journal of Chromatography A 926, 275-290.

Wheatcroft, R.A., Martin, W.R. 1996. Spatial variation in short-term $\left({ }^{234} \mathrm{Th}\right)$ sediment bioturbation intensity along an organic-carbon gradient. Journal of Marine Research 54, 763-792.

White, H.K., Reddy, C.M., Eglinton T.I. 2005 Isotopic constraints on the fate of petroleum residues sequestered in salt marsh sediments. Environmental Science and Technology 39, 2545-2551.

Xu, L., Reddy, C.M., Farrington, J.W.,Frysinger, G.S., Gaines, R.B., Johnson, C.G., Nelson, R.K., Eglinton, T.I. 2001. Identification of a novel alkenone in Black Sea sediments. Organic Geochemistry 32, 633-645. 


\title{
CHAPTER 3
}

This manuscript appeared in:

Environmental Science and Technology (2005), 39, 2545-2551

It is reprinted here with permission of the publisher

\section{ISOTOPIC CONSTRAINTS ON THE FATE OF PETROLEUM SEQUESTERED IN SALT MARSH SEDIMENTS}

\author{
Helen K. White, Christopher M. Reddy and Timothy I. Eglinton \\ Department of Marine Chemistry and Geochemistry, \\ Woods Hole Oceanographic Institution, Woods Hole, MA 02543
}

\begin{abstract}
To provide a new perspective on the fate of petroleum in the marine environment, we utilized variations in the natural abundance of radiocarbon $\left({ }^{14} \mathrm{C}\right)$ to detect and quantify petroleum residues that have persisted in Wild Harbor sediments, West Falmouth, MA, for more than thirty years. The $5730 \mathrm{yr}$ half-life of ${ }^{14} \mathrm{C}$ makes this isotope ideal for the detection of fossil fuel-derived contaminants $\left({ }^{14} \mathrm{C}\right.$ free) within different fractions of natural organic matter (modern ${ }^{14} \mathrm{C}$ content) in environmental matrices. Samples of both contaminated and uncontaminated sediments were sequentially treated, first by solvent extraction, followed by saponification, and then acid hydrolysis. Radiocarbon analysis of the sediment residues and select extracts was performed to probe for the presence of fossil fuel contaminants and/or their metabolites in different pools of sedimentary organic matter. Our results indicate that the majority of fossil carbon is solvent extractable and has not been incorporated in the insoluble organic matter in sediment. Unextracted
\end{abstract}


sediments contaminated with petroleum contain significantly less ${ }^{14} \mathrm{C}$ than extracted sediments, and isotope mass balance calculations suggest that up to $\sim 9 \%$ of the total organic carbon (TOC) in the petroleum contaminated sediment horizons is derived from solvent-extractable petroleum. These estimates are similar to values calculated when the total quantities of oil (measured by gas chromatography with flame ionization detector (GC-FID)) are compared to TOC content (determined by elemental analysis). These results pave the way for applications of this isotopic approach to more complex environmental systems where the fate of contaminants is less certain.

\subsection{INTRODUCTION}

The fate of hydrophobic organic contaminants (HOCs) in the aquatic environment is largely controlled by their low aqueous solubility and high affinity for particles, rendering sediments their primary sink. Once incorporated into sediments, HOCs are subject to varied and complex processes that confound our understanding of their ultimate fate. For example, laboratory (Richnow et al., 1997, 1998, 2000; Hatcher et al., 1993) and field studies (Beller et al., 1998; Richnow et al., 1994; Reddy et al., 2000; Schwarzbauer et al., 2003) have shown that certain HOCs (or their metabolites) can bind to natural organic matter, but this process is not easy to follow and is especially difficult to quantify using current analytical approaches. These associations are, however, of interest as they can potentially affect the bioavailability, toxicity, transport and long-term fate of HOCs (Alexander, 1995). The aforementioned studies define HOCs in sediment as either "free" or "unbound" and therefore solvent extractable, or "non-extractable" or "bound" and released only by harsher chemical treatments such as base or acid hydrolysis.

Defining and quantifying free and bound pools is critical when assessing the potential impact that contaminants may have on the environment and human health. In soils, it is proposed that irreversible formation of bound residues could be a major sink for certain organic contaminants (Dec and Bollag, 1997). Promotion of this process has 
thus been considered as a bioremediation strategy. It is not clear how robust this approach would be when applied to aquatic sediments as opposed to soils, as there are significant differences between the two environments. Such differences include water content, oxygen availability, pH and microbial population (Hedges et al., 1997) as well as the presence of reactive species such as hydroxyl radicals that may affect potential reactions between HOCs and organic matter. Processes affecting the overall fate of HOCs in sediments must therefore be examined independently.

The use of natural abundance ${ }^{14} \mathrm{C}$ measurements is a novel approach to trace HOCs into various pools of sedimentary organic matter (Reddy et al., 2002a). The absence of ${ }^{14} \mathrm{C}$ in fossil fuel-derived contaminants serves as a natural isotopic label (i.e. an inverse tracer) that is intrinsic to the contaminant. Thus its presence and provenance in environmental samples can be studied directly. This is desirable, as model studies involving additions of labeled compounds (i.e., laboratory incubations or even additions in situ) may not accurately reflect processes occurring in the field. Work by Steinberg et al. (1987), for example, examined the degradation of ${ }^{14} \mathrm{C}$-labelled ethylene dibromide (EDB) in EDB contaminated soils and noted that the added label was metabolized faster than the native contaminant. Using natural abundance ${ }^{14} \mathrm{C}$ measurements, it is also possible to quantitatively assess contributions of fossil carbon through the principle of isotope mass balance. Variations in ${ }^{14} \mathrm{C}$ have previously been used to constrain contributions of fossil hydrocarbons to marine sediments (Zafiriou, 1973; Farrington and Tripp, 1977; Giger et al., 1984; Wakeham et al., 2004). In these studies, significant depletions in ${ }^{14} \mathrm{C}$ confirm the presence of a fossil component to the sedimentary organic matter.

In the present study, sediments from Wild Harbor, West Falmouth, MA, a site contaminated with No. 2 fuel oil from the Florida oil spill of 1969, were examined to attempt to constrain contributions from fossil-fuel derived compounds to the sediment. Since the spill, this site has been the subject of extensive and long-term studies (Reddy et al., $2002 b$ and references therein) and provides a well characterized site at which to evaluate the utility of these molecular and isotopic approaches. 


\subsection{MATERIALS AND METHODS}

\subsubsection{Samples}

In August 2000, a 15-cm diameter sediment core was collected from the intertidal zone at the M-1 station in Wild Harbor, West Falmouth, MA as previously described (Reddy et al., 2002b). The core was extruded and sectioned at 2-cm intervals from 0 to 36 $\mathrm{cm}$. The sections were placed in precombusted glass jars and frozen until further analysis. Ten to twenty grams of each sediment horizon was defrosted and wet sieved through a $1.4 \mathrm{~mm}$ sieve to remove the intact roots of the marsh grass Spartina alterniflora that grows at the M-1 site. The sieved sediment was left to air dry before homogenizing with a mortar and pestle. The sequential chemical treatment of these sediments is summarized in Figure 3.1.

\subsubsection{Sediment Chronology}

One to two grams of air-dried, homogenized sediment was counted for gamma decay of ${ }^{210} \mathrm{~Pb},{ }^{214} \mathrm{~Pb}$ and ${ }^{137} \mathrm{Cs}$ using a high purity germanium detector (Canberra model GCW 4023S) with a closed-end coaxial well. An approximate sedimentation rate of 0.35 $\mathrm{cm} \mathrm{yr}^{-1}$ was estimated from the activity of unsupported ${ }^{210} \mathrm{~Pb}$ using the constant initial concentration (CIC) model (Eakins, 1983). This rate is consistent with a maximum in

${ }^{137}$ Cs activity at a depth corresponding to 1963 , which was the peak in nuclear weapons testing activities that occurred during the late fifties and early sixties. Obtaining a precise chronology of this core is difficult because of physical effects such as erosion, storm events and bioturbation. The oil spill also had a significant effect on the site, killing the Spartina alterniflora. The latter did not grow back until 1975 with an attendant influence on sediment accumulation (Reddy et al., 2002b).

\subsubsection{Solvent Extraction}

One to five grams of air-dried and homogenized sediment were extracted with dichloromethane (DCM) and methanol $(\mathrm{MeOH})(9: 1)$ by pressurized fluid extraction (100 
${ }^{\circ} \mathrm{C}, 1000 \mathrm{psi}$ ). The resulting total lipid extracts (TLEs) were reduced in volume by rotary evaporation and percolated through a copper column to remove sulfur prior to further analysis.

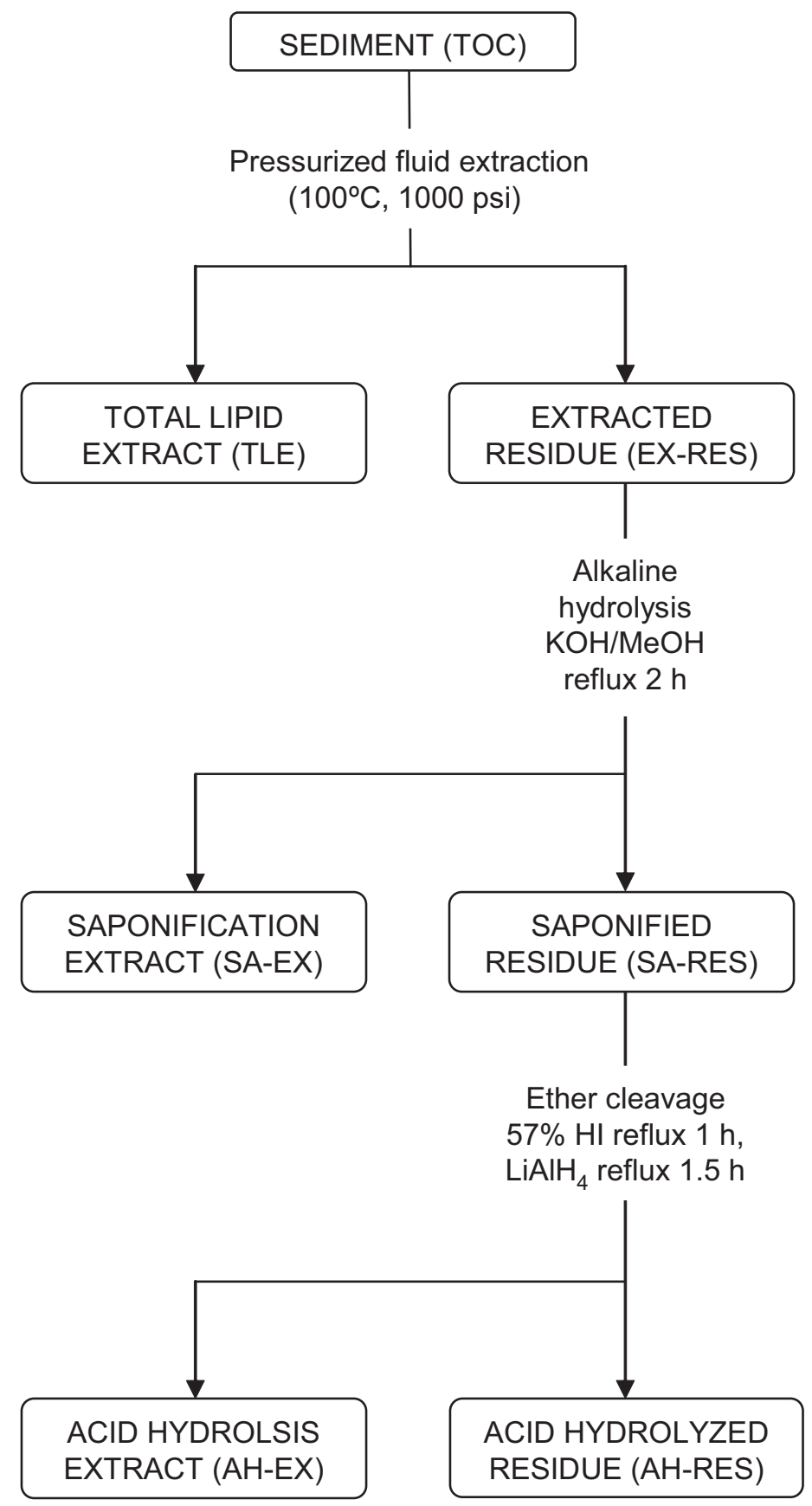

Figure 3.1 Flow diagram to illustrate the sequential treatment of sediments and residues. 


\subsubsection{Saponification}

Saponification was performed to cleave ester-linked moieties from the solventextracted sediments, as in (Richnow et al., 1994). A solution of $0.5 \mathrm{~N}$ potassium hydroxide $(\mathrm{KOH})$ (in $\mathrm{MeOH}, 100 \mathrm{~mL})$ and water $\left(\mathrm{H}_{2} \mathrm{O}\right)(20 \mathrm{~mL})$ were added to one to five grams of pre-extracted sediments from horizons 0-2, 8-10, 10-12, 12-14, 14-16, 3032 and 32-34 cm and refluxed for $2 \mathrm{~h}$. Extracted sediment samples from 30-32 and 32-34 $\mathrm{cm}$ were combined to obtain the desired quantity of sediment. Approximately $67 \%$ of the total pooled sample with a TOC content of $9.8 \%$ came from the $30-32 \mathrm{~cm}$ horizon and the remainder with a TOC content of $8.7 \%$ came from the $32-34 \mathrm{~cm}$ horizon. Extracted sediments from 12-14 (11.1\% TOC content) and 14-16 cm (10.9\% TOC content) were

processed separately as well as a mixture comprised of equal quantities of the two horizons to obtain enough material for further chemical treatment post saponification. After cooling, the reaction mixture was separated by centrifugation and the remaining sediment rinsed with $\mathrm{MeOH}$, followed by $\mathrm{DCM}$, and then hexane. The alkaline solution was acidified with $4 \mathrm{~N}$ hydrochloric acid $(\mathrm{HCl})$ to $\mathrm{pH} 2$ and extracted with DCM. The combined extracts were reduced in volume by rotary evaporation and dried over $\mathrm{Na}_{2} \mathrm{SO}_{4}$.

\subsubsection{Acid Hydrolysis}

Hydriodic acid (HI) has previously been used to cleave ether bound compounds in sedimentary samples (Hoefs et al., 1997; Höld et al., 1998; Schouten et al., 2000) and was used here to release any petroleum residues bound by ether linkages. One to two grams of previously saponified sediment residues from 0-2, 10-12, 12-16 and 30-34 cm horizons were each added to $57 \% \mathrm{HI}$ solution (in $\mathrm{H}_{2} \mathrm{O}, 50 \mathrm{~mL}$ ) and refluxed under a nitrogen atmosphere for $1 \mathrm{~h}$. After cooling, the sediment residue was removed by centrifugation and rinsed with $\mathrm{H}_{2} \mathrm{O}$, followed by hexane and allowed to air dry. The reaction solution was extracted with hexane and the combined extracts washed with $\mathrm{H}_{2} \mathrm{O}$ saturated with sodium chloride $(\mathrm{NaCl})$ to remove any excess acid, followed by $5 \%$ sodium thiosulfate $\left(\mathrm{Na}_{2} \mathrm{~S}_{2} \mathrm{O}_{3}\right)$ solution (to remove iodine). The extract was reduced in volume by rotary evaporation before being charged onto a glass column $(20 \mathrm{~cm} \times 0.6 \mathrm{~cm})$ 
packed with fully activated silica gel (100-200 mesh). The column was eluted with hexane and DCM (9:1) and the extract air-dried before being taken up in 1,4-dioxane. Lithium aluminum hydride $\left(\mathrm{LiAlH}_{4}\right)(600 \mathrm{mg})$ was added to the extract, which was then refluxed under nitrogen for $1.5 \mathrm{~h}$ to reduce any alkyliodides to hydrocarbons. After cooling to room temperature, ethyl acetate was slowly added to deactivate the remaining $\mathrm{LiAlH}_{4}$. The reaction mixture was then centrifuged and the recovered supernatant washed with $\mathrm{H}_{2} \mathrm{O}$ saturated with $\mathrm{NaCl}$ followed by $\mathrm{H}_{2} \mathrm{O}$ alone, before being reduced in volume and dried over $\mathrm{Na}_{2} \mathrm{SO}_{4}$.

\subsubsection{Gas Chromatography-Mass Spectrometry (GC/MS) Analysis}

TLEs, saponified extracts and extracts from acid hydrolysis were derivatized with bis-(trimethylsilyl)-trifluoroacetamide (BSTFA) and pyridine to improve chromatography by silylating active hydrogens present in the samples. For compound identification, electron ionization (EI) spectra were acquired on an Agilent 6890 series gas chromatograph with an Agilent 5973 mass selective detector (MSD). Compounds were separated on a J\&W DB-5MS capillary column $(60 \mathrm{~m} \times 0.32 \mathrm{~mm}$ ID, $0.25 \mu \mathrm{m}$ film thickness) with helium carrier gas at a constant flow of $1 \mathrm{ml} \mathrm{min}^{-1}$. The GC oven had an initial temperature of $40^{\circ} \mathrm{C}$ ( 1 minute hold) and was ramped at $20^{\circ} \mathrm{C} \mathrm{min}^{-1}$ until $130^{\circ} \mathrm{C}$ and then at $2^{\circ} \mathrm{C} \min ^{-1}$ until $320^{\circ} \mathrm{C}(30$ minute hold). Spectra were acquired between $\mathrm{m} / \mathrm{z}$

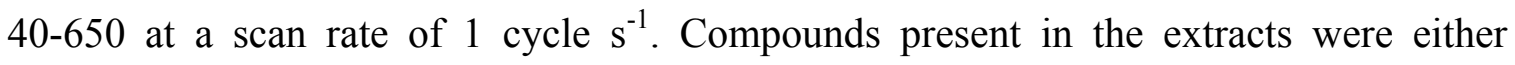
tentatively identified from mass spectra and gas chromatographic retention characteristics or identified by comparison to pure standards.

\subsubsection{Bulk Sediment and Extract Analyses}

Aliquots of the dried, homogenized untreated, extracted, saponified and acid hydrolyzed sediment residues were treated with $10 \% \mathrm{HCl}$ to remove any carbonates. The sediments were then analyzed for organic carbon content with a Carlo Erba 1108 elemental analyzer. The stable carbon isotope ratio $\left(\delta^{13} \mathrm{C}\right)$ and radiocarbon abundance $\left(\Delta^{14} \mathrm{C}\right)$ of the sediments as well as select TLEs and saponified extracts (representing both 
the contaminated region of the core and the uncontaminated areas above and below) was measured on purified carbon dioxide $\left(\mathrm{CO}_{2}\right)$ after their combustion in the presence of cupric oxide $(\mathrm{CuO})$. Stable carbon values were determined by isotope ratio mass spectrometry and ${ }^{14} \mathrm{C}$ content by accelerator mass spectrometry (AMS) at the National Ocean Sciences Accelerator Mass Spectrometry (NOSAMS) facility at Woods Hole Oceanographic Institution (WHOI), Woods Hole, MA, after conversion of the $\mathrm{CO}_{2}$ to graphite (McNichol et al., 1994). All ${ }^{14} \mathrm{C}$ measurements are normalized to $\delta^{13} \mathrm{C}$ values of $-25 \%$ and expressed as $\Delta^{14} \mathrm{C}$ values, which is the per mille (\%o) deviation from the international standard for ${ }^{14} \mathrm{C}$ dating, Standard Reference Material 4990B “Oxalic Acid". Routine precision for $\delta^{13} \mathrm{C}$ and $\Delta^{14} \mathrm{C}$ measurements are $\sim 0.1$ and $10 \%$, respectively. All radiocarbon abundances obtained in this study were corrected for in-situ ${ }^{14} \mathrm{C}$ decay using $\Delta^{14} \mathrm{C}=\left[f_{\mathrm{m}} e^{(1950-x) \lambda}-1\right] 1000$ (Stuiver and Polach, 1977), where $\lambda=1 / 8267$ (year $\left.{ }^{-1}\right), f_{\mathrm{m}}=$ fraction modern ${ }^{14} \mathrm{C}$, corrected for isotopic fractionation using $\delta^{13} \mathrm{C}$, and " $x$ " equals the year of deposition (determined from the ${ }^{210} \mathrm{~Pb}$ chronology, Table 2). This yields the $\Delta^{14} \mathrm{C}$ values at the time of sediment deposition.

\subsection{RESULTS AND DISCUSSION}

\subsubsection{Vertical distribution of petroleum hydrocarbon contaminants in salt marsh sediments}

A recent study examining sediments from the Wild Harbor site shows that in discrete locations within the salt marsh, oil residues persist more than 30 years after the original oil was spilled (Reddy et al., 2002b). This study provided a refined inventory of the petroleum hydrocarbons that have been removed from the sediments, such as the $n$ alkanes, as well as those that continue to persist. The latter include, branched alkanes, cycloalkanes and aromatic hydrocarbons. The persistence of these compounds is apparent when examining the downcore profile of total petroleum hydrocarbons (TPH) in marsh sediments (Figure 3.2a). A maximum of $\sim 8-9 \mathrm{mg} \mathrm{g}^{-1}$ is observed in the $12-16 \mathrm{~cm}$ depth interval, which, based on ${ }^{210} \mathrm{~Pb}$ and ${ }^{137} \mathrm{Cs}$ profiles corresponds well with the timing of the 

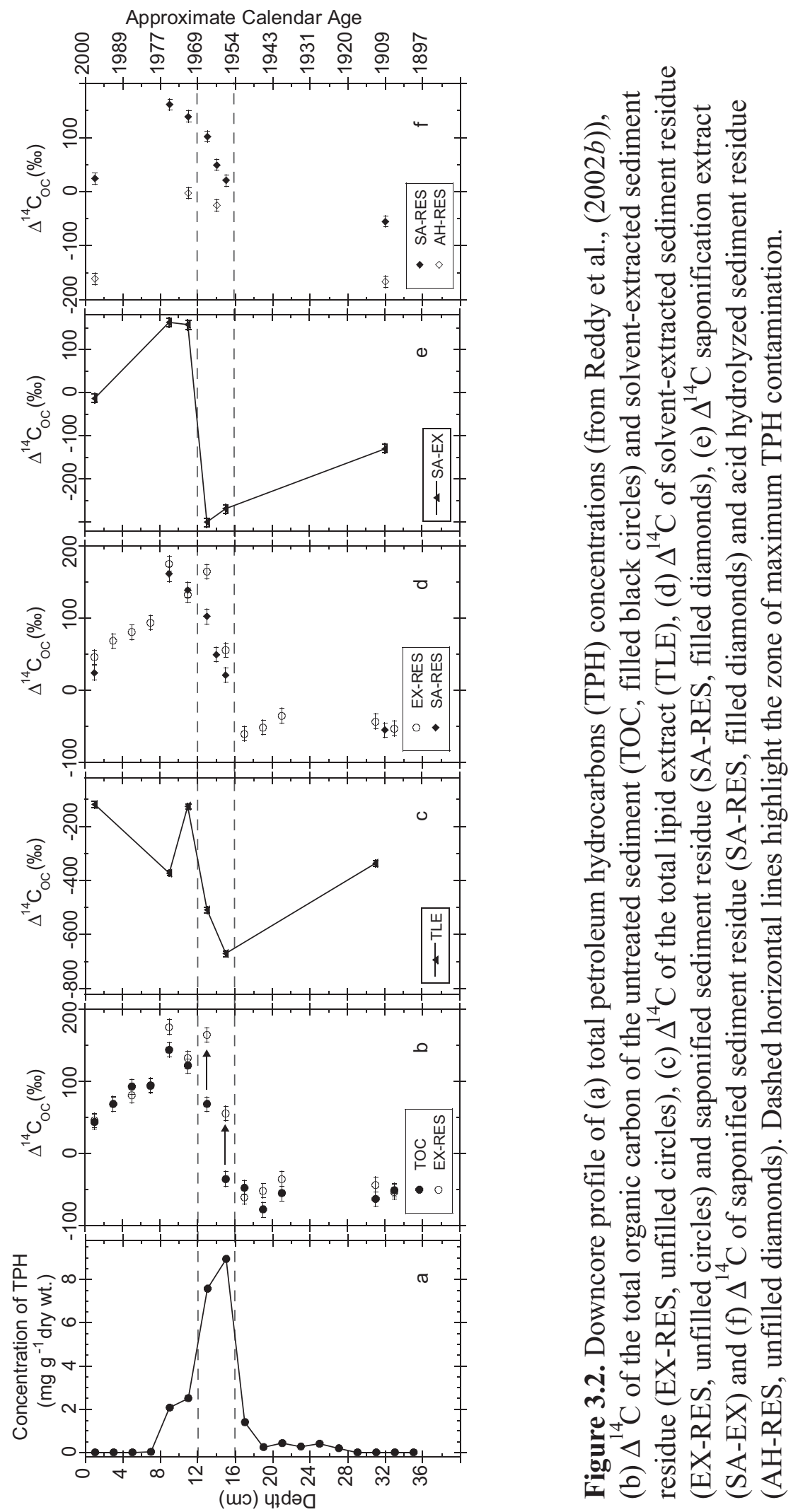
spill. Minimum values of $\sim 0-2 \mathrm{mg} \mathrm{g}^{-1}$ are observed throughout the rest of the core (0-12 $\mathrm{cm}$ and 16-34 cm). Other significant observations from the downcore profiles include the $\Delta^{14} \mathrm{C}$ values of the sediments, residues and extracts from the sequential chemical treatments. These display very similar profiles with a maximum in ${ }^{14} \mathrm{C}$ levels at a depth of 8-10 cm, corresponding to the well established "bomb ${ }^{14} \mathrm{C}$ spike" resulting from aboveground thermonuclear weapons testing in the late 1950s and early 1960s (Levin et al., 1985) (Figure 3.2b, c, d, e). Significant offsets are observed, however, between the different sediment residues and these coincide with the maximum TPH content. The implications of these isotopic variations will be discussed further.

\subsubsection{Radiocarbon as an Inverse Tracer}

Radiocarbon abundances $\left(\Delta^{14} \mathrm{C}\right)$ of the organic carbon from untreated sediments, residues and corresponding extracts were measured from horizons throughout the sediment core (Table 3.1 and Figure 3.2). In the most heavily contaminated horizons (12$16 \mathrm{~cm}$ ) (Figure 3.2a), a significant offset is observed between the unextracted and solvent extracted sediments (indicated by arrows in Figure 3.2b). This is due to the influence of ${ }^{14} \mathrm{C}$-free petroleum from the oil spill. The unextracted sediments contain significantly less ${ }^{14} \mathrm{C}$ than the extracted sediments. Correspondingly, the ${ }^{14} \mathrm{C}$ content of the TLE is significantly lower than that from the uncontaminated horizons (Figure 3.2c). The TLEs from the contaminated horizons of the core are comprised of a mixture of fossil carbon $\left(\Delta^{14} \mathrm{C}=-1000 \%\right)$ and biogenic hydrocarbons $\left({ }^{14} \mathrm{C} \sim+100 \%\right)$ and this is reflected in the $\Delta{ }^{14} \mathrm{C}$ values of these extracts. This is supported by GC/MS analysis of TLEs throughout the entire core, which indicate the presence of biogenic hydrocarbons including higher plant wax-derived $n$-alkanes from $n-C_{25}$ to $n-C_{33}$ with a strong odd/even dominance, alkanoic acids from $n-\mathrm{C}_{16}$ to $n-\mathrm{C}_{34}$ with an even/odd dominance, $n$-alkanols from $n-\mathrm{C}_{22}$ to $n-\mathrm{C}_{36}$ with even/odd dominance, and the $\mathrm{C}_{29}$ sterols $\beta$-sitosterol and stigmasterol, which are major sterols in higher plants. The higher plant triterpenoid lupeol was also observed. The contaminated sections $(8-16 \mathrm{~cm})$ are, however, dominated by an unresolved complex mixture (UCM) of hydrocarbons in the boiling range of $n-\mathrm{C}_{13}$ to $n-\mathrm{C}_{24}$ alkanes, consistent 


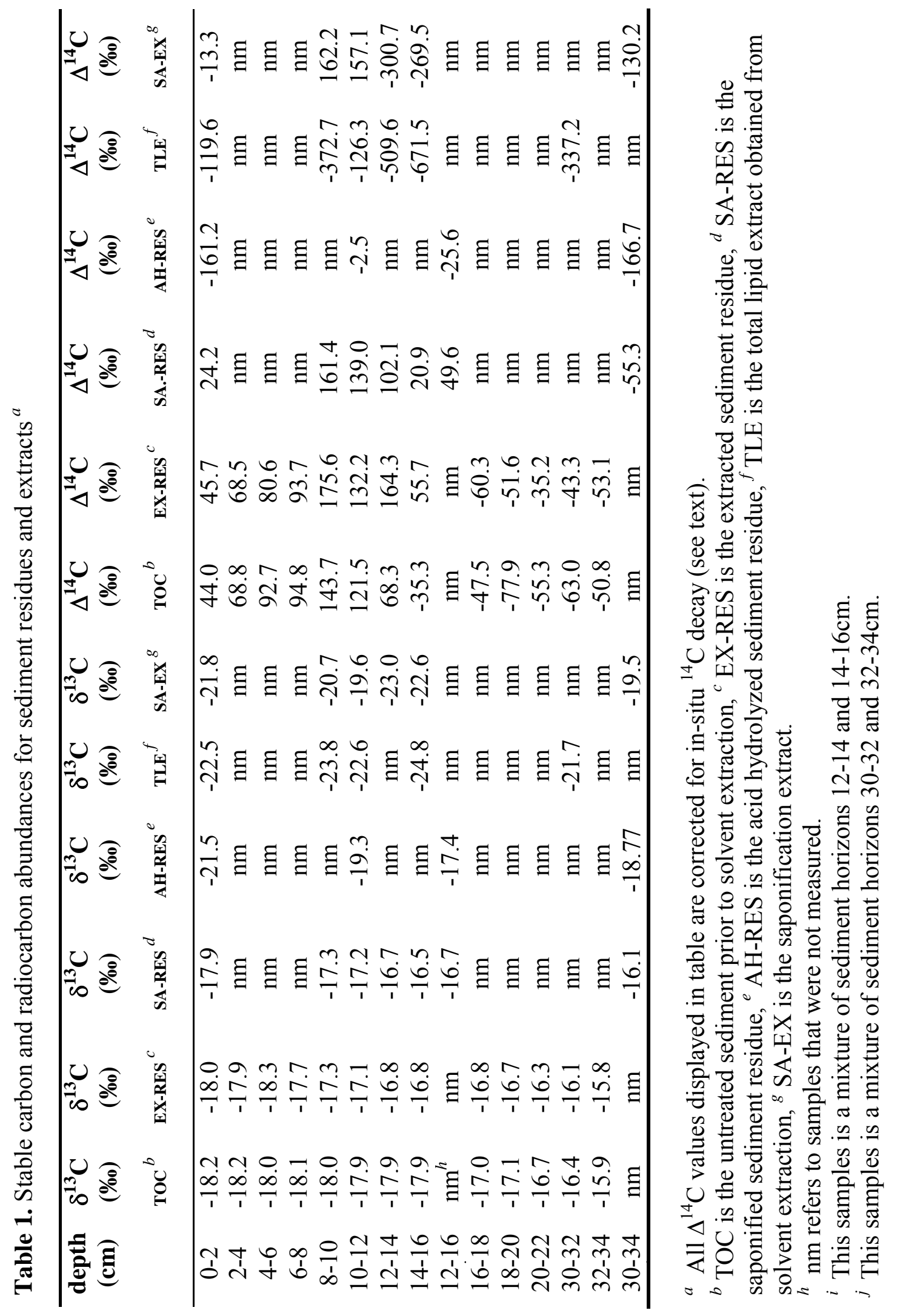


with a biodegraded No.2 fuel oil source (Reddy et al., 2002c; Frysinger et al., 2003).

Comparison of the ${ }^{14} \mathrm{C}$ contents of the solvent extracted and saponified sediments shows little difference, with the exception of the 12-14 cm horizon (Figure 3.2d). This shift and smaller changes downcore indicate less ${ }^{14} \mathrm{C}$ in the saponified residue than the extracted residue from which it originated. This suggests that the compounds liberated by the process of saponification in these sediments are more enriched in ${ }^{14} \mathrm{C}$ than the remaining saponified sediment residue. This is supported by the ${ }^{14} \mathrm{C}$ contents of the saponified extracts (Figure 3.2e), which display a modern signature reminiscent of the bomb spike unperturbed by petroleum contamination. Moreover, based on GC/MS analysis, the saponified extracts were similar in composition throughout the sediment core and indicate the presence of $n$-alkanols from $n-C_{22}$ to $n-C_{32}$ with even/odd dominance, alkanoic acids from $n-\mathrm{C}_{10}$ to $n-\mathrm{C}_{28}$ with even/odd dominance and sterols (as before). The extracts from the contaminated zone contained no evidence of additional components that could derive from hydrocarbons.

There are observable offsets in $\Delta^{14} \mathrm{C}$ between the saponified and hydriodic acid hydrolyzed sediment residues throughout the contaminated and uncontaminated horizons of the core (Figure $3.2 \mathrm{f}$ ). In all cases, the acid hydrolyzed residue is more depleted in ${ }^{14} \mathrm{C}$ than the saponified residue. This suggests that more recently synthesized material has been removed by this treatment. The remaining residue is significantly older and may be partially comprised of aliphatic biopolymers that are highly refractory and not hydrolysable by these chemical treatments (Hedges et al., 2000). In the contaminated horizon $(12-16 \mathrm{~cm})$ the effect of the bomb spike is evident by a more ${ }^{14} \mathrm{C}$ enriched acid hydrolysis sediment residue relative to the pre-bomb sediment residue in the $30-34 \mathrm{~cm}$ horizon (approximate date 1909) and the most recently deposited post-bomb material deposited in the 0-2 cm horizon. GC/MS analyses of the extracts indicate the presence of benzo $[b]$ thiophene and its alkylated derivatives as well as alkylated benzenes in all of the depth horizons examined. These compounds are unlikely to be natural products and instead may arise from alteration of natural compounds during the hydriodic acid hydrolysis treatment. The extract obtained from acid hydrolysis of the contaminated 
section of the core $(12-16 \mathrm{~cm})$, however, also displays a few compounds that are exclusive to this sample. These compounds may be related to the contamination in some way either directly or indirectly as a result of the oil spill. They could, for example, be due to a different natural source of organic matter related to a shift in the biological community structure in response to the spill. The structure of these compounds is currently unknown and their identification and source will be the focus of future work. For the present investigation, it is important to note that the abundance of these compounds is insufficient to influence the ${ }^{14} \mathrm{C}$ content of the sediment residues.

\subsubsection{Stable Carbon Isotopic Compositions of Sediments, Residues and Extracts}

Stable carbon isotopic compositions of the organic carbon from untreated sediments, as well as corresponding residues and extracts were measured from horizons throughout the sediment core (Table 3.1 and Figure 3.3). Patterns observed after each sequential chemical treatment are similar to those observed for $\Delta^{14} \mathrm{C}$. As before, an offset is observed between the unextracted and extracted sediments (Figure 3.3b) within the contaminated horizons (Figure 3.3a), which we attribute to the presence of ${ }^{13} \mathrm{C}$-depleted petroleum. The $\delta^{13} \mathrm{C}$ value of the remaining oil at this site is $\sim-27 \%$ (Reddy et al., 2002c) and thus contaminated sediments are shifted from the $\delta^{13} \mathrm{C}$ of the natural organic matter towards this end member. Organic carbon in salt marsh sediments containing Spartina alterniflora have previously been shown to have $\delta^{13} \mathrm{C}$ values between -17 and $-24 \%$ (Boshker et al., 1999). These values are proposed to reflect a variety of carbon inputs including those depleted in ${ }^{13} \mathrm{C}$ such as phytoplankton, benthic algae or $\mathrm{C}_{3}$ vascular plant material as well as the ${ }^{13} \mathrm{C}$ enriched Spartina alterniflora carbon. The $\delta^{13} \mathrm{C}$ of the uncontaminated TOC in the core top is more depleted $(\sim-18 \%)$ than the uncontaminated sediments lower in the core (-16\%). This $2 \%$ shift may reflect selective preservation of a

${ }^{13} \mathrm{C}$ enriched biomass source such as Spartina over the more ${ }^{13} \mathrm{C}$ depleted phytoplankton biomass. The observed shift in $\delta^{13} \mathrm{C}$ could alternatively indicate a non-steady state of carbon inputs to the salt marsh over time. Middleburg et al., (1997) suggest that an 

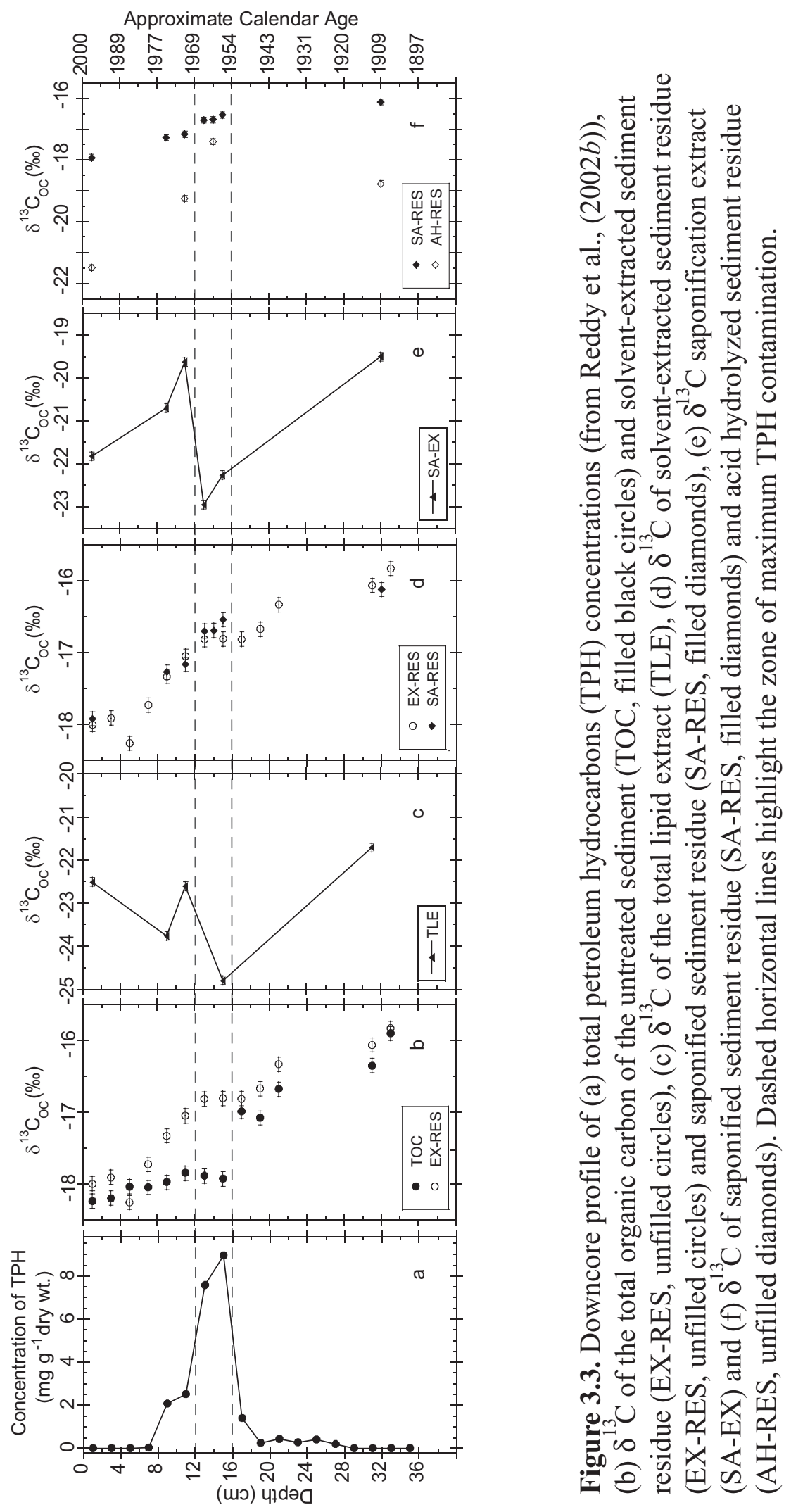
important mechanism affecting the $\delta^{13} \mathrm{C}$ of sedimentary TOC in salt marshes is the input of allochthonous organic matter, which includes organic matter sorbed on mineral matter as well as marine phytoplankton, microphytobenthos and non-local macrophytes. The TLE is also quite enriched (Figure 3.3c), and in the contaminated horizons shows more depleted $(-24 \%)$ values closer to that of petroleum $(-27 \%$, as before), which is to be expected. Very little difference is observed between the extracted and saponified sediment residues (Figure 3.3d) and saponified extract (Figure 3.3e). Differences in $\delta^{13} \mathrm{C}$ are, however, observed between the saponified and the acid hydrolyzed sediment residues (Figure 3.3f). In all cases the acid hydrolyzed residue is more ${ }^{13} \mathrm{C}$ depleted than the saponified residue, and this difference is most significant (3.5\%) in the $0-2 \mathrm{~cm}$ horizon. The smallest difference of $\sim 0.5 \%$ is observed in the contaminated horizon $12-16 \mathrm{~cm}$. The offsets observed between these two residues in the different sediment horizons could arise from isotopic fractionation associated with slightly different chemical conditions imposed on these sediments throughout the multi-step chemical treatment. Alternatively, these differences in $\delta^{13} \mathrm{C}$ may represent different sources of carbon to the marsh as previously discussed. As mentioned, the acid hydrolyzed sediment residues may contain refractory aliphatic biopolymers. The presence of these biopolymers, which are synthesized from lipids that are typically depleted relative to bulk biomass, may help to explain the more depleted $\delta^{13} \mathrm{C}$ signal of the acid hydrolyzed residues. It is evident from this data, however, that there is no significant manifestation of any remaining oil on the $\delta^{13} \mathrm{C}$ values of the residues.

\subsubsection{Isotope Mass Balance}

The fraction of TOC that is derived from petroleum in these sediments can be calculated based on isotope mass balance. TOC from the bulk, unextracted sediment is considered to be a mixture $(t)$ comprised of exogenous $(x)$ and endogenous $(n)$ components that can be represented by

$$
(\text { TOC }) t=(\text { TOC }) x+(\text { TOC }) n
$$

and the isotopic composition of the mixture is given by 


$$
F t=f F x+(1-f) F n
$$

where the Fs represent isotopic abundances and $f$ is the fraction of the mixture that is exogenous, in this case, derived from petroleum. In terms of radiocarbon abundances $(\Delta)$, we can write

$$
f=(\Delta t-\Delta n) /(\Delta x-\Delta n)
$$

The corrected $\Delta{ }^{14} \mathrm{C}$ values for the untreated sediments were used as $\Delta t$ and the corrected $\Delta^{14} \mathrm{C}$ values for the extracted sediment residues were used for $\Delta n$. Assuming $\Delta x$ to reflect an absence of ${ }^{14} \mathrm{C}$ (i.e., $\Delta^{14} \mathrm{C}=-1000 \%$ ), solutions of $f$ were obtained for the sediment horizons examined in this study. These are expressed as the percentage of TOC derived from solvent-extractable petroleum and are shown in Table 3.2 alongside values calculated by comparing TPH concentrations (measured by GC-FID) to TOC content (determined by elemental analysis). The mass of TPH was converted to carbon equivalents considering the mass contribution of hydrogen to the hydrocarbon, which in an alkane typical of the UCM ( $n-\mathrm{C}_{13}$ to $n-\mathrm{C}_{24}$ as before) is approximately $15 \%$ of the total. Potential errors could arise depending on the specific contribution of hydrogen to the TPH, which could range from $15 \%$ for the most saturated compounds such as the alkanes to $5 \%$ for the most unsaturated compounds such as the 3-ring aromatic hydrocarbons. If a 5\% contribution of hydrogen was used instead of $15 \%$, the \%TOC derived from petroleum values in Table 3.2 would increase by no greater than $1 \%$. The reported values (Table 3.2) show good agreement throughout the core indicating a maximum of $6-9 \%$ TOC derived from petroleum in the contaminated horizons (12-16 $\mathrm{cm})$. In the relatively uncontaminated horizons, above and below this, $\sim 0-2 \%$ of TOC is derived from the petroleum. There is a difference of $\sim 1-2 \%$ between the two methods and this is likely due to the error associated with the ${ }^{14} \mathrm{C}$ abundance measurements and/or the mass contribution of hydrogen to the TPH as previously discussed. It is clear, however, that within this error, the fraction of petroleum that is measurable by GC-FID is comparable with the isotope mass balance.

These results indicate that at the bulk level, the vast majority of petroleum appears to be solvent-extractable and not bound to the insoluble organic matter in the sediment. It 
is important to note that the TLE could contain soluble esterified contaminants. However, since the free contaminants quantified by GC-FID correspond well to the mass balance, the proportion that is bound must be extremely small. Given that the contaminant in this study consists of relatively inert hydrocarbons, it is not surprising that significant binding is not observed. For binding to occur, compounds must possess functional groups, and

Table 3.2 Elemental and Petroleum concentrations in West Falmouth sediments, 2000

\begin{tabular}{cccccc}
\hline $\begin{array}{c}\text { depth } \\
\text { (cm) }\end{array}$ & $\begin{array}{c}\text { approx } \\
\text { age }\end{array}$ & $\begin{array}{c}\text { TOC } \\
(\mathbf{\%})\end{array}$ & $\begin{array}{c}\text { TPH } \\
\left(\mathbf{m g ~ g}^{-1}\right)^{a}\end{array}$ & $\begin{array}{c}\text { \% TOC from petroleum measured by } \\
\text { mass balance }\end{array}$ & gas chromatography \\
\hline $0-2$ & 1997 & 8.42 & 0.00 & 0.16 & 0.00 \\
$2-4$ & 1991 & 9.78 & 0.00 & -0.03 & 0.00 \\
$4-6$ & 1986 & 12.0 & 0.00 & -1.12 & 0.00 \\
$6-8$ & 1980 & 12.8 & 0.04 & -0.10 & 0.03 \\
$8-10$ & 1974 & 10.8 & 2.08 & 2.71 & 1.63 \\
$10-12$ & 1969 & 12.8 & 2.51 & 0.95 & 1.67 \\
$12-14$ & 1963 & 11.6 & 7.57 & 8.25 & 5.56 \\
$14-16$ & 1957 & 11.7 & 8.95 & 8.62 & 6.52 \\
$16-18$ & 1951 & 11.2 & 1.41 & -1.36 & 1.07 \\
$18-20$ & 1946 & 10.5 & 0.24 & 2.77 & 0.19 \\
$20-22$ & 1940 & 11.1 & 0.44 & 2.09 & 0.34 \\
$30-32$ & 1911 & 10.0 & 0.00 & 2.06 & 0.00 \\
$32-34$ & 1906 & 8.09 & 0.00 & -0.25 & \\
\hline
\end{tabular}

${ }^{a}$ Data from Reddy et al., (2002b) where TPH is total petroleum hydrocarbons.

${ }^{b}$ To calculate the percent total organic carbon (\% TOC) derived from petroleum, the mass of TPH was converted to carbon equivalents considering a mass contribution of hydrogen to the hydrocarbons, which in an alkane typical of the UCM ( $n-\mathrm{C}_{13}$ to $n-\mathrm{C}_{24}$ as before) is approximately $15 \%$ of the total. 
whilst petroleum metabolites resulting from microbial degradation are chemically more reactive, we found no detectable evidence of any binding of degradation products. This may be because degradation at this site is slow or has ceased. Recent work by Slater et al., (2005), who have examined the ${ }^{14} \mathrm{C}$ content of lipid markers of microbial activity present in the sediments, supports this claim. The study by Slater et al. indicates that there is currently no measurable flow of petroleum carbon into the biomass and that the microbial population are preferentially utilizing the natural organic matter in the sediment as a carbon source. This conclusion, coupled to the findings of this study indicating the absence of significant binding or incorporation of the petroleum, leaves us to speculate on the reason(s) why hydrocarbon contamination persists in these sediments more than 30 years after the spill. It has been proposed that this persistence is due to the lack of sulfate, a necessary electron acceptor for anaerobic degradation of petroleum or that the residual compounds are structurally too complex for anaerobic degradation or are inaccessible to microbial attack (Reddy et al., 2002b). Further studies will explore these scenarios.

\subsubsection{Sensitivity of Isotopic Approach}

While it is clear from the present study that ${ }^{14} \mathrm{C}$ can be used as an intrinsic tracer of contaminants in environmental matrices; there are limitations to this approach. For example, it may be that contaminants are binding to sediments at this site, but not at concentrations observable using ${ }^{14} \mathrm{C}$ as an inverse tracer. Figure 3.4 details the expected change in $\Delta^{14} \mathrm{C}_{\mathrm{TOC}}$ as a function of the percentage of petroleum present in the sediment. Sediment containing $0.1 \%$ petroleum represents a relatively non-impacted $\Delta \Delta^{14} \mathrm{C}_{\mathrm{TOC}}$ of $+100 \%$, a value chosen to represent modern sediments. Previous work measuring ${ }^{14} \mathrm{C}$ content of discrete carbon pools in Buzzards Bay, MA, 1991 yielded $\Delta^{14} \mathrm{C}$ values of eel grass particulate organic carbon (POC) of 62\%, and Spartina alterniflora as 198\%o (McNichol et al., 1994). We assume that the bulk of the organic matter at our site is Spartina alterniflora as opposed to phytoplankton and therefore choose a post-bomb, heavily Spartina influenced value of $100 \%$. Potential errors inherent in assuming this isotopic end member value are shown in Figure 3.4. This figure clearly demonstrates that 


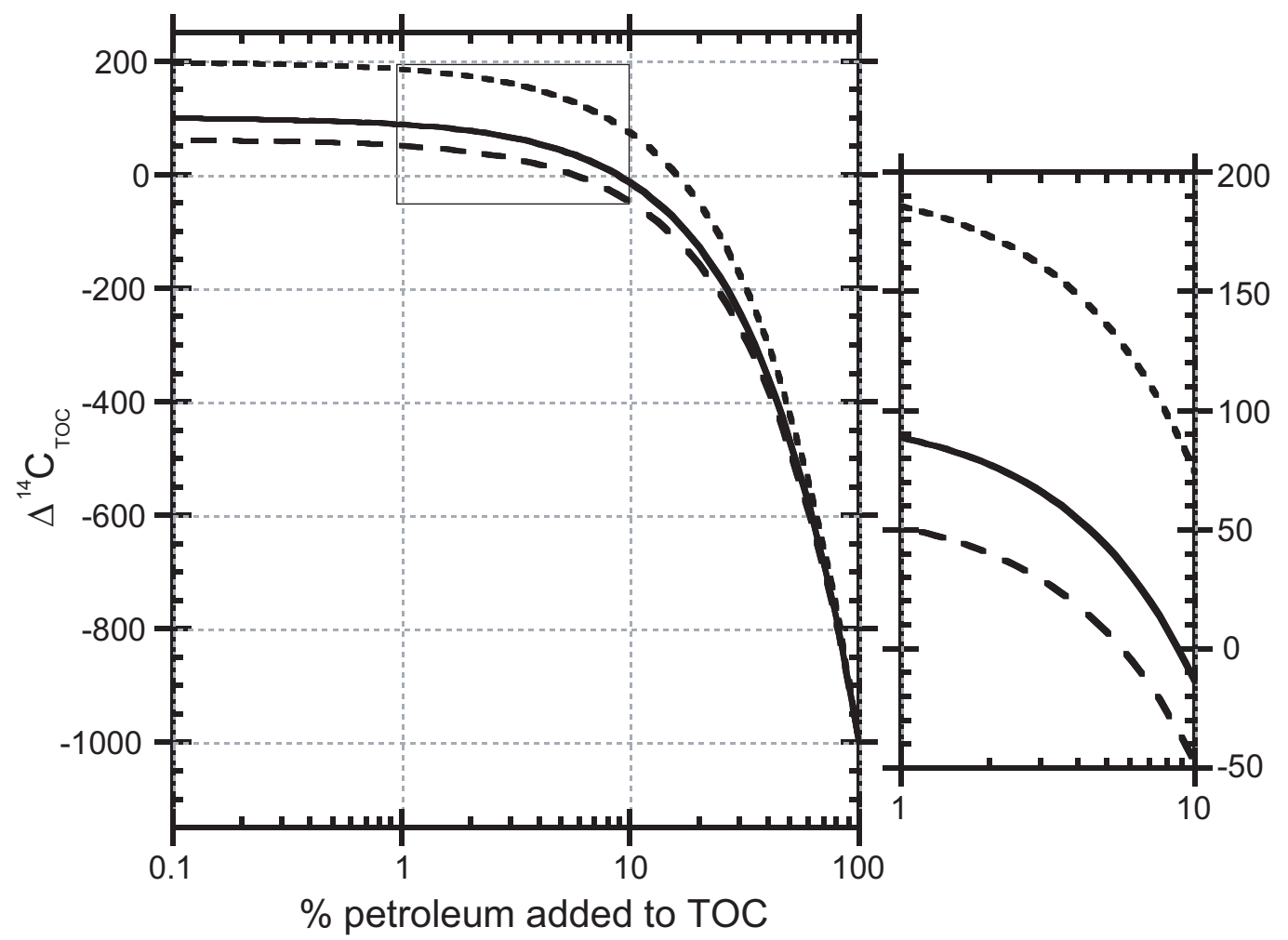

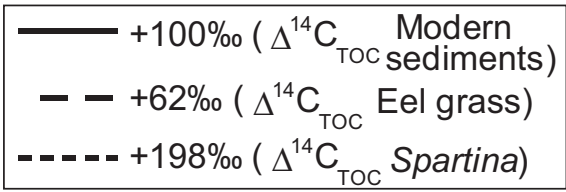

Figure 3.4. The sensitivity of $\Delta^{14} \mathrm{C}$ of total organic carbon $\left(\Delta^{14} \mathrm{C}_{\mathrm{TOC}}\right)$ to additions of petroleum $\left(\Delta^{14} \mathrm{C}=-1000 \%\right.$ o $)$ to sediments with varying $\Delta^{14} \mathrm{C}_{\mathrm{TOC}}$ values. Modern sediments are represented by a $\Delta^{14} \mathrm{C}_{\mathrm{TOC}}$ of $+100 \%$. Two other potential end members were chosen to represent the particulate organic carbon (POC) of the salt marsh. These were Eel grass and Spartina and are represented by $\Delta^{14} \mathrm{C}_{\mathrm{TOC}}$ values of $+62 \%$ and $+198 \%$ respectively, as in McNichol et al., (1994).

given an analytical precision of $10 \%$, at least $1 \%$ of petroleum $\left(\Delta^{14} \mathrm{C}=-1000 \%\right)$ must be present to significantly affect $\Delta \Delta^{14} \mathrm{C}_{\mathrm{TOC}}$. Further analysis of sediments on a molecular rather than bulk level would undoubtedly resolve petroleum-derived compounds that are bound, although it is clear from the isotope mass balance that such findings would not be quantitatively significant. It is also possible that bound compounds of petroleum origin could be present in the extracts obtained from each of the sequential chemical treatments, 
as mentioned previously, but this is likely an extremely small quantity as the percentage of fossil carbon determined by mass balance compares well to that measured by GC-FID. Future work will be directed at applying this approach to sediments and soils containing more reactive contaminants to determine the significance of binding, as well as molecular level ${ }^{14} \mathrm{C}$ studies to develop a more detailed understanding of the provenance and fate of contaminants in environmental samples.

\section{Acknowledgment}

We thank L.A. Houghton, D. Montluçon, J. Andrews, S. Sylva, and G. R. Hampson for their help with this project and J.M. Hayes and P.M. Gschwend for helpful discussions. This work was supported by funds from the National Science Foundation (CHE-0089172). This is WHOI contribution No. 11317.

\subsection{REFERENCES}

Alexander, M. 1995. How toxic are toxic chemicals in soil? Environmental Science and Technology 29, 2713-2717.

Beller, H.R., Simoneit, B.R.T. 1988. Hexachlorophene distributions in estuarine sediments. Bulletin of Environmental Contamination and Toxicology 41, 645-650.

Boshker, H.T.S., de Brouwer, J.F.C., Cappenberg T.E. 1999. The contribution of macrophyte-derived organic matter to microbial biomass in salt-marsh sediments: Stable carbon isotope analysis of microbial biomarkers. Limnology and Oceanography 44, 309-319.

Dec, J., Bollag, J. -M. 1997. Determination of covalent and noncovalent binding interactions between xenobiotic chemicals and soil. Soil Science 162, 858-874.

Eakins, J.D. ${ }^{210} \mathrm{~Pb}$ technique for dating sediments, and some applications. In: Radioisotopes in sediment studies; IAEA-TEC ROC 298, Vienna, 1983; pp. 31-47.

Farrington, J. W., Tripp, B. W. 1977. Hydrocarbons in western North Atlantic surface sediments. Geochimica et Cosmochimica Acta 41, 1627-1641.

Frysinger, G.S., Gaines, R.B., Xu, L., Reddy C.M. 2003. Resolving the unresolved complex mixture in petroleum-contaminated sediments. Environmental Science and Technology 37, 1653-1662.

Giger, W., Sturm, M., Sturm, H., Shaffner, C., Bonani, G., Balzer, R., Hofmann, H.J., Morenzoni, E., Nessi, M., Suter, M., Wölfi, W. $1984 .{ }^{14} \mathrm{C} /{ }^{12} \mathrm{C}$-Ratios in organic 
matter and hydrocarbons extracted from dated lake sediments. Nuclear Instruments and Methods in Physics Research B5, 394-397.

Hatcher, P.G., Bortiatynski, J.M., Minard, R.D., Dec, J., Bollag, J.M. 1993. Use of high resolution ${ }^{13} \mathrm{C}$ NMR to examine enzymatic covalent binding of ${ }^{13} \mathrm{C}$-labelled 2,4dichlorophenol to humic substances. Environmental Science and Technology 27, 2098-2103.

Hedges, J.I., Oades, J.M. 1997. Comparative organic geochemistries of soils and marine sediments. Organic Geochemistry, 27, 319-361.

Hedges, J.I., Eglinton, G., Hatcher, P.G., Kirchman, D.L., Arnosti, C., Derenne, S., Evershed, R.P., Kögel-Knabner, I., de Leeuw, J.W., Littke, R., Michaelis, W., Rullkötter, J. 2000. The molecularly-uncharacterized component of nonliving organic matter in natural environments. Organic Geochemistry 31, 945-958.

Hoefs, M.J.L., Schouten, S., de Leeuw, J.W., King, L.L., Wakeham, S.G., Sinninghe Damsté, J.S. 1997. Ether lipids of planktonic archae in marine water column. Applied and Environmental Microbiology 63, 3090-3095.

Höld, I.M., Brussee, N.J., Schouten, S., Sinninghe Damsté, J.S. 1998. Changes in the molecular structure of a Type II-S kerogen (Monterey Formation, U.S.A. during sequential chemical degradation. Organic Geochemistry 29, 1403-1417.

Levin, I., Kromer, B., Schoch-Fischer, H., Bruns, M., Münnich, M., Berdau, D., Vogel, J.C., Münnich, K.O. 1985. 25 Years of tropospheric ${ }^{14} \mathrm{C}$ observations in central Europe. Radiocarbon 27, 1-19.

McNichol, A.P., Osborne, E.A., Gagnon, A.R., Fry, B., Jones, G.A. 1994. TIC, TOC, DIC, DOC, PIC, POC-unique aspects on the preparation of oceanographic samples for ${ }^{14} \mathrm{C}$-AMS. Nuclear Instruments and Methods in Physics Research B92, 162-165.

Middleburg, J.J., Nieuwenhuize, J., Lubberts, R.K., van de Plassche, O. 1997. Organic carbon isotope systematics of coastal marshes. Estuarine, Coastal and Shelf Science 45, 681-687.

Reddy, C.M., Quinn J.G., King J. 2000. Free and bound benzotriazoles in marine and freshwater sediments. Environmental Science and Technology 34, 973-979.

Reddy, C.M., Xu, L., Eglinton, T.I., Boon, J.P., Faulkner, D.J. 2002a. Radiocarbon content of synthetic and natural semi-volatile halogenated organic compounds. Environmental Pollution 120, 163-168.

Reddy, C.M., Eglinton, T.I., Hounshell, A.H., White, H.K., Xu, L., Gaines, R.B., Frysinger, G.S., 2002b. The West Falmouth oil spill after thirty years: The persistence of petroleum hydrocarbons in marsh sediments. Environmental Science and Technology 36, 4754-4760.

Reddy, C.M., Xu, L., Quinn, J.G., Hartmann, P.C. 2002c. Investigating the radiocarbon content of the unresolved complex mixture. Abstracts of the American Chemical Society, Division of Environmental Chemistry 224, 32.

Richnow, H.H., Seifert, R., Hefter, J., Kästner, M., Mahro, B., Michaelis, W. 1994. Metabolites of xenobiotica and mineral oil constituents linked to macromolecular organic matter in polluted environments. Organic Geochemistry 22, 671-681. 
Richnow, H.H., Seifert, R., Hefter, J., Link, M., Francke, W., Schaefer G., Michaelis W. 1997. Organic pollutants associated with macromolecular soil organic matter - a mode of binding. Organic Geochemistry 26, 745-758.

Richnow, H.H., Eschenbach, A., Seifert, R., Wehrung, P., Albrecht P. Michaelis W. 1998. The use of 13-C-labelled polycyclic aromatic hydrocarbons for the analysis of their transformation in soils. Chemosphere 36, 2211-2224.

Richnow, H.H., Annweiler, E., Koning, M., Lüth, J.-C., Stegmann, R., Garms, C., Francke W., Michaelis W. 2000. Tracing the transformation of labeled [113C]phenanthrene in a soil bioreactor. Environmental Pollution 108, 91-101.

Schouten, S., Hoefs, M.J.L., Sinninghe Damsté, J.S. 2000. A molecular and stable carbon isotopic study of lipids in late Quaternary sediments from the Arabian Sea. Organic Geochemistry 31, 509-521.

Schwarzbauer, J., Ricking, M., Littke, R. 2003. DDT-Related compounds bound to the nonextractable particulate matter in sediments of the Teltow Canal, Germany. Environmental Science and Technology 37, 488-495.

Slater, G., White, H. K., Eglinton, T. I., Reddy, C.M. 2005. Determination of microbial carbon sources in petroleum contaminated sediments using molecular 14C analysis. Environmental Science and Technology 39, 2552-2558.

Steinberg, S.M., Pignatello, J.J., Sawhney, B.L. 1987. Persistence of 1,2-dibromoethane in soils: Entrapment in intraparticle micropores. Environmental Science and Technology 21, 1201-1208.

Stuiver, M., Polach, H.A., 1977. Discussion: reporting of 14C data. Radiocarbon 19, 355363.

Wakeham, S.G., Forrest, J., Masiello, C.A., Gélinas, Y., Alexander, C.R., Leavitt, P.R. 2004. Hydrocarbons in Lake Washington Sediments. A 25-year retrospective in an urban lake. Environmental Science and Technology 38, 431-439.

Zafiriou, O. C. 1973. Petroleum hydrocarbons in Narragansett Bay, II. Chemical and isotopic analysis. Estuarine, Coastal and Marine Science 1, 81-87. 
3.5 APPENDIX 


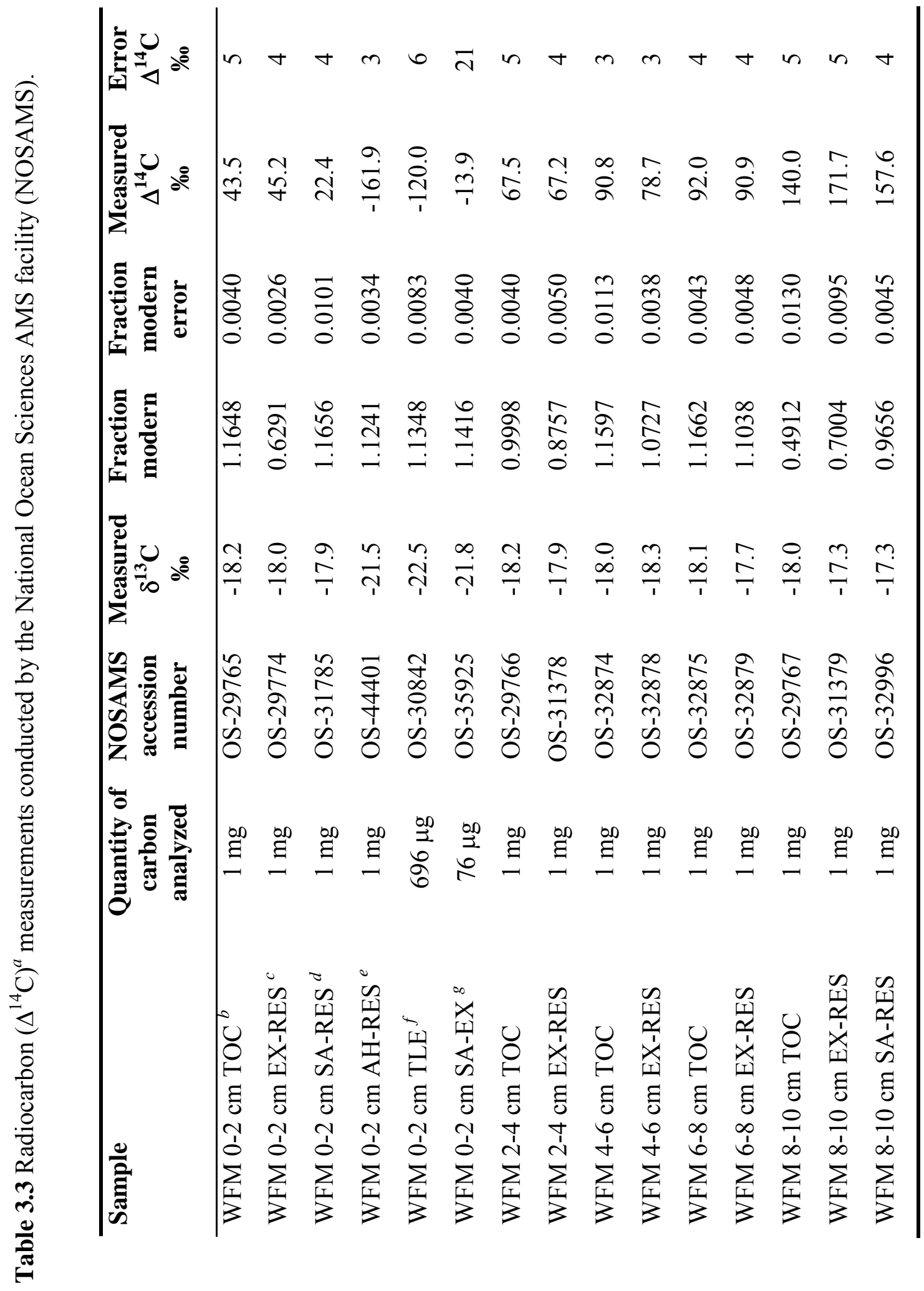




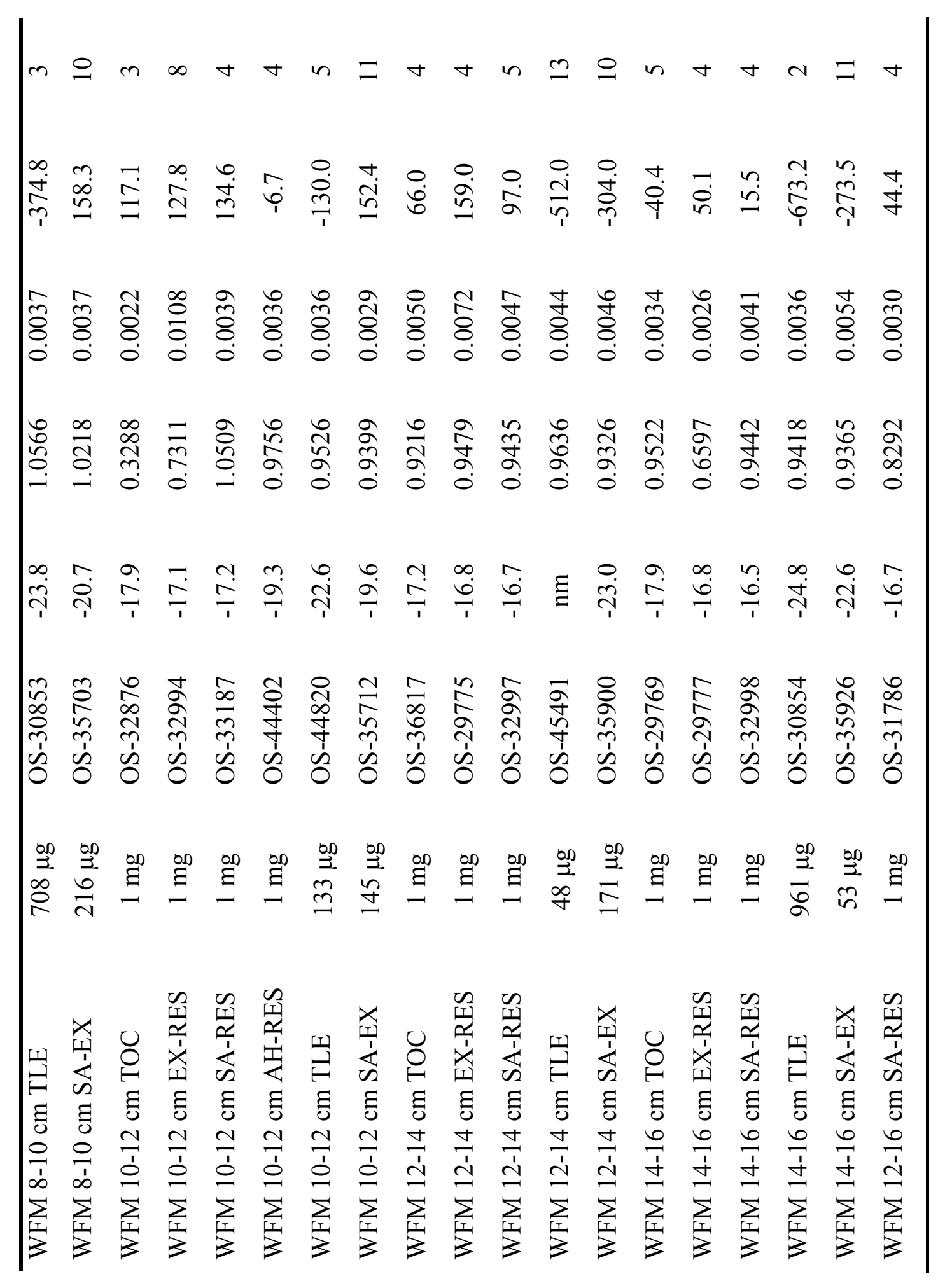




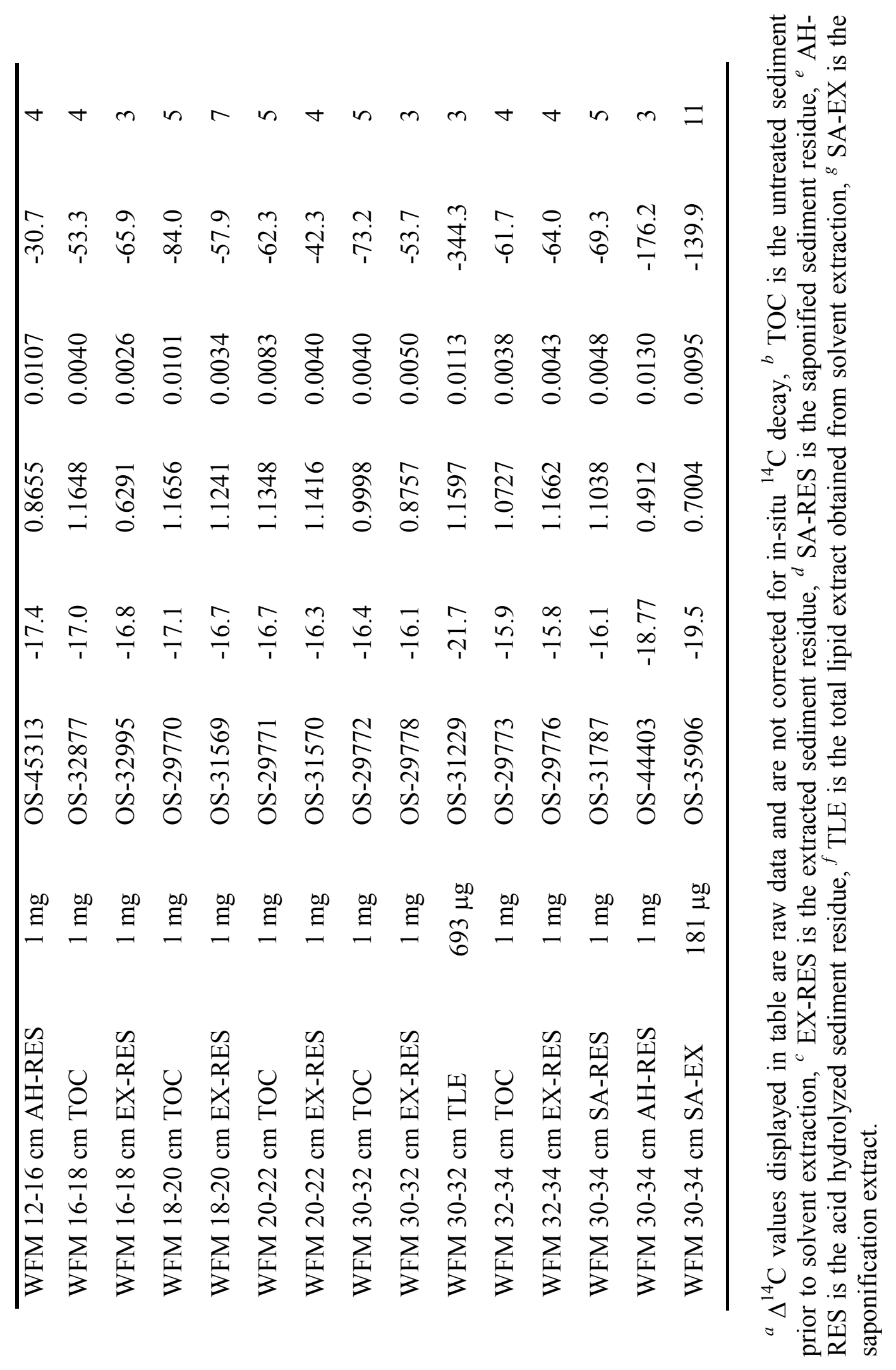




\title{
CHAPTER 4
}

\section{RELATIONSHIPS BETWEEN RADIOCARBON CONTENT AND MODES OF ASSOCIATION OF NATURAL ORGANIC MATTER IN COASTAL AND CONTINENTAL MARGIN SEDIMENTS}

\begin{abstract}
We have investigated the relationships between radiocarbon $\left({ }^{14} \mathrm{C}\right)$ and stable carbon $\left({ }^{13} \mathrm{C}\right)$ isotopic composition and the different modes of association of organic matter $(\mathrm{OM})$ present in surficial sediments from near-shore and continental margin sites that range in terms of inputs and depositional conditions. Our aim is to gain insight into the sources and sinks of $\mathrm{OM}$ in the marine environment, and to enhance our understanding of the nature and distribution of $\mathrm{OM}$ in sediments. Radiocarbon is a particularly sensitive tracer of $\mathrm{OM}$ provenance, with variations in its natural abundance reflecting age and pre- and post-depositional history. In order to investigate isotopic variability within different sedimentary OM pools, sediments were sequentially treated first by solvent extraction to examine non-covalently associated compounds followed by saponification to cleave ester-linked moieties. Radiocarbon analysis was performed on the bulk sediment and resulting sediment residues. The molecular composition of the extracts was examined using gas chromatography/mass spectrometry (GC/MS), and the relative contributions of terrestrial and marine biomarkers released from the sequential chemical treatments were assessed. For select sites, pre-industrial sediment horizons were also studied to examine diagenetic influences on the relationships between age, chemical association and reactivity of sedimentary OM. Radiocarbon abundances $\left(\Delta^{14} \mathrm{C}\right)$ of the bulk sediment reflect a mixture of modern, pre-aged and fossil (i.e. ${ }^{14} \mathrm{C}$-“dead”) OM of marine and terrestrial origin with little difference in $\Delta^{14} \mathrm{C}$ between the unextracted (TOC)
\end{abstract}


and solvent extracted sediments (EX-RES). Distinct offsets in $\Delta^{14} \mathrm{C}$ between EX-RES and saponified sediment residues (SA-RES) observed at most sites indicate the removal of

more ${ }^{14} \mathrm{C}$ enriched material by this treatment. Saponification extracts (SAE) are mainly composed of short-chain ( $n-\mathrm{C}_{12}$ to $\left.n-\mathrm{C}_{24}\right)$ alkanoic acids with an even/odd dominance indicating a predominantly marine algal or microbial source. These observations provide evidence for the protection of labile marine carbon by chemical binding. Exceptions to these overall patterns exist and are attributed to either fossil carbon inputs and/or the impact of diagenetic processes.

\subsection{INTRODUCTION}

The burial of organic matter $(\mathrm{OM})$ in recent marine sediments plays a critical role in the global organic carbon cycle. Quantitatively, there is more organic carbon (OC) derived from non-living organic molecules occurring in recent marine sediments, soil humus and dissolved in seawater than in all living land plants and marine organisms combined (Hedges et al., 2000). Approximately $90 \%$ of OC buried globally in the ocean is sequestered in shelf and slope sediments (Hedges and Keil, 1995 and references therein), and removal of organic carbon from the biosphere and storage in sediments affects many key processes such as global carbon budgets and long term controls on atmospheric $\mathrm{CO}_{2}$ and $\mathrm{O}_{2}$.

To understand the sources, transport and degradation of OC in the oceans, the nature and distribution of $\mathrm{OM}$ in marine sediments must be studied. In addition to the intrinsic reactivity of organic molecules, interactions between individual organic compounds and macromolecular organic matter (MOM) are important as they have the potential to influence the overall fate of specific organic compounds, including contaminants (Farrington and Quinn, 1971; Lee, 1977; Zegouagh et al., 1996). For example, compounds which are "free" and non-covalently associated with MOM may be more easily degraded than those that are "bound" and covalently linked by an ester, ether or C-C bond. Compounds defined as "free" are those that are solvent extractable, whereas 
those released only by harsher chemical treatments, are considered "non-extractable" or "bound". It is important to note that not all "non-extractable" compounds are covalently bound to $\mathrm{OM}$ and some may be physically entrapped in OM or mineral matrices (Knicker and Hatcher, 1997 and references therein) and only released when the matrices themselves are altered by chemical treatments. Conversely, the extractability of a compound does not necessarily imply that it is susceptible to degradation. For example, organic compounds sorbed to mineral surfaces may be readily extractable, but physically protected from degradation (Keil and Hedges, 1993). Nevertheless these different associations may exert strong controls on the preservation of labile organic compounds (Wakeham, 1999), as well as their residence times in different carbon reservoirs. Binding to $\mathrm{OM}$, for example, may slow the delivery of a terrestrial derived organic compound to the ocean through association with relatively immobile particulate phases (e.g. soils).

Complex mixing of autochthonous and allochthonous materials occur on continental margins. To assess the relative contributions of marine, terrestrial and fossil OC to marine sediments, abundances and distributions of molecular markers, such as hydrocarbons, $n$-alkanoic acids and alkanols are typically examined. Specific characteristics of these markers are studied and include carbon preference and carbon isotopic compositions. For example, short chain $\left(n-\mathrm{C}_{12}\right.$ to $\left.n-\mathrm{C}_{22}\right) n$-alkanoic acids and alkanols with an even-over-odd predominance are considered to be derived predominantly from marine algae, bacteria or zooplankton whereas their longer chain ( $n$ $\mathrm{C}_{24}$ to $n-\mathrm{C}_{34}$ ) counterparts have terrestrial origins from higher plant epicuticular waxes. Alkanoic acids derived from sedimentary microbial biomass may also contribute significantly (Hollander and Smith, 2001). For $n$-alkanes, an odd-over-even predominance in carbon chain length $>n-\mathrm{C}_{23}$ is typical of higher plants and is numerically represented by the carbon preference index (CPI, $=\Sigma$ [odd numbered alkane abundances from $n-\mathrm{C}_{23}$ to $\left.n-\mathrm{C}_{35}\right] / \Sigma$ [even numbered alkane abundances from $n-\mathrm{C}_{22}$ to $\left.n-\mathrm{C}_{34}\right]$ ). Initial plant wax CPI values are high (CPI = 4-40; Collister et al., 1994), but tend towards 1 with increasing degradation, as well as increasing thermal maturity for sources such as 
petroleum, petroleum source rocks and continental rocks of intermediate thermal maturity (Brassell and Eglinton, 1980).

Stable carbon isotope $\left(\delta^{13} \mathrm{C}\right)$ compositions of $\mathrm{OM}$ can be used as indicators of both source and carbon flow. Sedimentary bulk OM is comprised of contributions from marine, terrestrial and bacterial sources, and this is reflected in the isotope ratios obtained. Terrestrial sources derived from $C_{3}$ vegetation typically exhibit $\delta^{13} \mathrm{C}$ values 26\%o whereas marine sources are more enriched ( $-21 \%$; Fry and Sherr, 1984; Prahl et al., 1994). Natural abundance radiocarbon $\left(\Delta^{14} C\right)$ measurements are also informative as ${ }^{14} \mathrm{C}$ serves as a sensitive tracer of $\mathrm{OM}$ inputs. All recently photosynthesized carbon contains significant amounts of ${ }^{14} \mathrm{C}$, which is produced in the Earth's atmosphere by cosmic ray interactions, and makes its way into the biosphere mainly via photosynthetic fixation of $\mathrm{CO}_{2}$. Additionally, any natural product derived from carbon reservoirs in communication with the atmosphere since 1952 contains an excess quantity of ${ }^{14} \mathrm{C}$ due to incorporation of ${ }^{14} \mathrm{C}$ produced by the above-ground testing of thermonuclear weapons. The 5730 year half life of ${ }^{14} \mathrm{C}$ allows compounds of geologic age to be easily distinguished as they contain no ${ }^{14} \mathrm{C}$. Continental margin sediments contain significant quantities of both modern and "pre-aged" terrestrial organic carbon (Eglinton et al., 1997; Masiello and Druffel 2001; Blair et al., 2003; Goñi et al., 2005; Drenzek et al., submitted) with potential sources of "pre-aged" carbon arising from remobilization of soil carbon, weathering of sedimentary rock and resuspension and redistribution of marine organic matter (Mollenhauer et al., 2005).

In this study, $\Delta^{14} \mathrm{C}$ and $\delta^{13} \mathrm{C}$ measurements of bulk sediments and residues resulting from sequential chemical treatments are combined with analyses of the molecular composition of extracts released by these treatments. By examining the nature and distribution of $\mathrm{OM}$ in marine sediments, we aim to gain insight not only into the varied sources of OM, but also by understanding their associations we hope to make predictions concerning their overall fate. 


\subsection{MATERIALS AND METHODS}

\subsubsection{Study Area and Samples}

Geographic locations, dates, depths and details of the sites examined in this study are detailed in Table 4.1 and Figure 4.1. These samples represent a variety of coastal and continental margin settings, many of which have previously been subjected to molecular isotopic studies (see references, Table 4.1). The samples are divided into five general groups determined by their depositional settings. Group ' $a$ ' includes organic-rich marine sediments from Guaymas basin (GB), a hydrothermal system with active petroleum production in the sediment; sediments from the upwelling systems of the Peru Margin $(\mathrm{PM})$; and surface $(0-1 \mathrm{~cm})$ and pre-industrial sediments $(13-15 \mathrm{~cm})$ from the Benguela upwelling (BU) system off of the coast of Namibia, Africa. Santa Monica Basin (SMB) sediments were examined from the periphery of the basin which has oxygenated bottom waters (Station 1), and from the less oxygenated depocenter (Station 2) from surface (0-1 $\mathrm{cm})$, pre-bomb $(10-11 \mathrm{~cm})$ and pre-industrial $(30-32 \mathrm{~cm})$ sediments. Group ' $\mathrm{b}$ ' is comprised of open shelf and river dominated sediments from the New England Margin (NEM); the Washington Margin (WM), including a site from the inner shelf (Station 1) and surface $(0-1 \mathrm{~cm})$ and pre-industrial $(34-36 \mathrm{~cm})$ sediments from further offshore (Station 4), as well as surface $(0-2 \mathrm{~cm})$ and pre-industrial $(100-101 \mathrm{~cm})$ sediments from the Eel River Margin (ERM) which has a narrower flood plain than WM. Group 'c' encompasses coastal sites where sediments were recovered from shallow $(<10 \mathrm{~cm})$ or intertidal zones. These include anoxic sediments from the Pettaquamscutt River (PR), sediments from Penobscot Bay (PB); sediments from Lowes Cove (LC), which is an intertidal mudflat; marine sediments from Blakely Harbor $(\mathrm{BH})$; and salt marsh sediments from West Falmouth (WF). Group 'd' includes river-dominated sediments from the Mackenzie shelf (MS) and Beaufort slope (BS) in the Canadian Arctic. Group ' $\mathrm{e}$ ' is comprised of surface $(0-2 \mathrm{~cm})$ sediments from the Ross Sea (RS), Antarctica and one deeper sediment horizon $(12-15 \mathrm{~cm})$. Significant inputs of pre-aged OC to sediments 


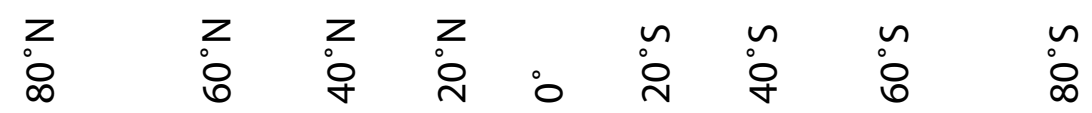

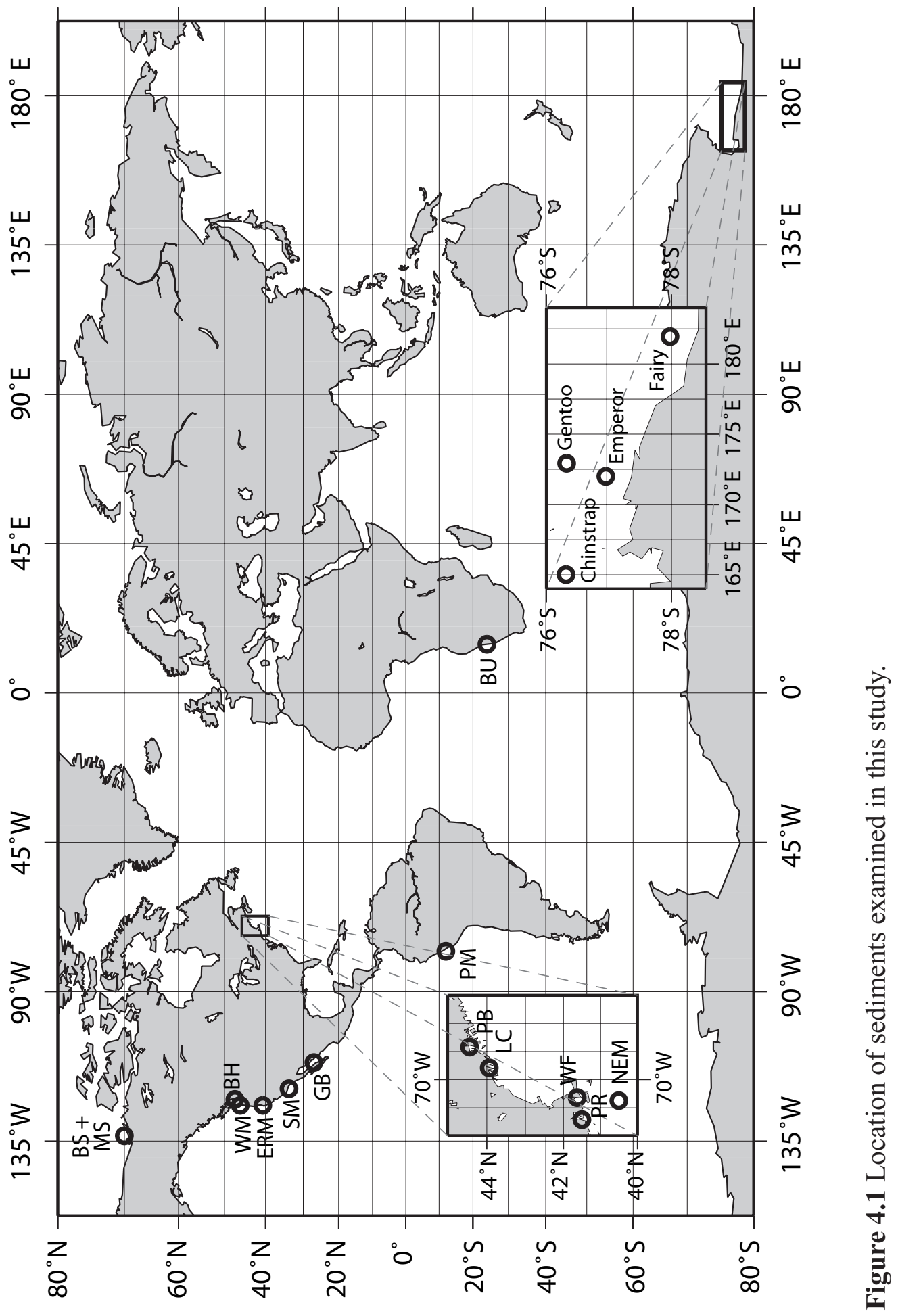




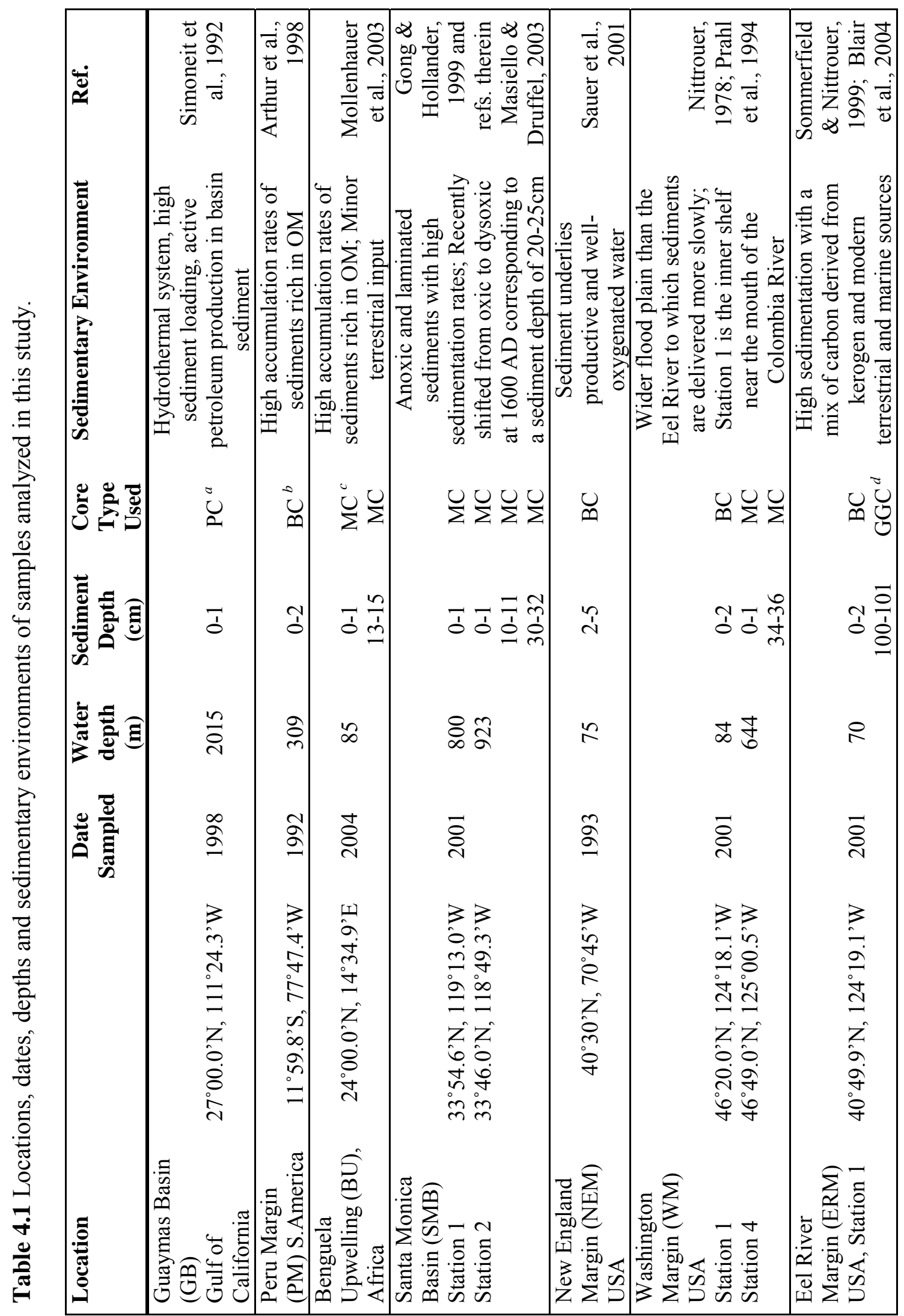



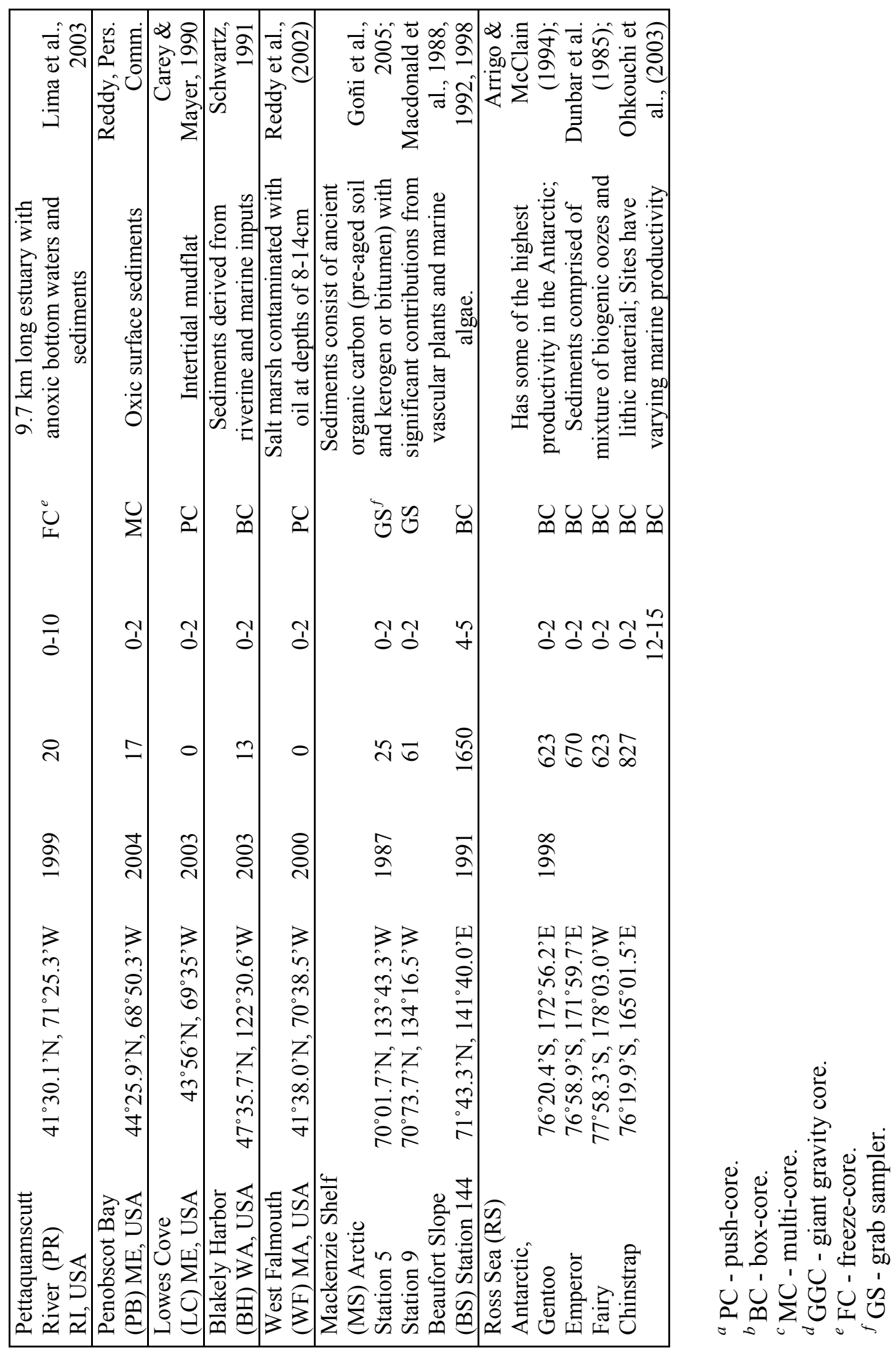
from groups ' $d$ ' and 'e' have previously been observed (Ohkouchi et al., 2003; Goñi et al., 2005; Drenzek et al., submitted).

All groups include various end-members in terms of depositional environments, and include sediments deposited under both oxic and anoxic bottom waters with variable contributions from marine, terrestrial, ancient and petroleum carbon sources. This enables an assessment of the potential affects of diagenesis and different oxidation states on the nature and distribution of $\mathrm{OM}$ in marine sediments and enables predictions to be made about more complex sediments that are a mixture of the end-member environments examined here.

\subsubsection{Sequential Lipid Extraction}

Sediments were air-dried and homogenized with a mortar and pestle before passing through a $1 \mathrm{~mm}$ sieve. Depending on the OC content and quantity of sediment available, two to twenty grams of each sediment sample were taken and sequentially treated as previously described (White et al., 2005). Briefly, the sediments were extracted with dichloromethane (DCM) and methanol $(\mathrm{MeOH})(9: 1)$ by pressurized fluid extraction $\left(100^{\circ} \mathrm{C}, 1000 \mathrm{psi}\right)$. The resulting total lipid extracts (TLE) were reduced in volume by rotary evaporation and percolated through a copper column plugged with combusted glass wool to remove sulfur and any entrained particulate matter prior to further analysis. The solvent extraction step was not performed in this study for GB, MS and BS samples because the sediments had already been solvent extracted using a Soxhlet apparatus as part of previous investigations (Pearson et al., 2005; Drenzek et al., submitted). Aliquots of the TLE from these sediments were provided for GC/MS analysis. Solvent extracted sediment from all samples was refluxed at $70^{\circ} \mathrm{C}$ for $2 \mathrm{~h}$ with a solution of $0.5 \mathrm{~N}$ potassium hydroxide $(\mathrm{KOH})$ (in $\mathrm{MeOH}, 100 \mathrm{~mL}$ ) and water $\left(\mathrm{H}_{2} \mathrm{O}\right)(20 \mathrm{~mL})$. After cooling, the reaction mixture was separated by centrifugation $(1500 \mathrm{rpm})$, the supernatant removed, and the remaining sediment rinsed with $\mathrm{MeOH}$, followed by DCM, and then hexane. These extracts were combined with the supernatant in a separatory funnel. The alkaline extract (supernatant) was back-extracted with hexane $(3 \times 50 \mathrm{~mL})$ to obtain a 
neutral fraction before acidification with $4 \mathrm{~N}$ hydrochloric acid $(\mathrm{HCl})$ to $\mathrm{pH} 2$ and extraction with DCM (3 x $50 \mathrm{~mL})$ to obtain an acidic fraction. Both fractions were reduced in volume by rotary evaporation and dried by passing through a small glass pipette column of anhydrous $\mathrm{Na}_{2} \mathrm{SO}_{4}$ plugged with glass wool (this also served to remove any particles from the extracts).

\subsubsection{Bulk Sediment Analyses}

Aliquots of dried unextracted (TOC), extracted (EX-RES) and saponified sediment residues (SA-RES) were treated with $10 \% \mathrm{HCl}$ to remove any carbonates. The sediments and residues were then analyzed for organic carbon content with a Carlo Erba 1108 elemental analyzer. The stable carbon isotope ratio $\left(\delta^{13} \mathrm{C}\right)$ and radiocarbon abundance $\left(\Delta^{14} \mathrm{C}\right)$ of the sediments were measured on purified carbon dioxide $\left(\mathrm{CO}_{2}\right)$ after their combustion in the presence of cupric oxide $(\mathrm{CuO})$. Stable carbon values were determined by isotope ratio mass spectrometry (irMS), and ${ }^{14} \mathrm{C}$ content by accelerator mass spectrometry (AMS) at the National Ocean Sciences Accelerator Mass Spectrometry (NOSAMS) facility at Woods Hole Oceanographic Institution (WHOI), Woods Hole, MA, after conversion of the $\mathrm{CO}_{2}$ to graphite (McNichol et al., 1994). All

${ }^{14} \mathrm{C}$ measurements are normalized to $\delta^{13} \mathrm{C}$ values of $-25 \%$ and expressed as $\Delta^{14} \mathrm{C}$ values, which is the per mille (\%) deviation from the international standard for ${ }^{14} \mathrm{C}$ dating, Standard Reference Material 4990B “Oxalic Acid". Precision for $\delta^{13} \mathrm{C}$ and $\Delta^{14} \mathrm{C}$ measurements are $\sim 0.1$ and 2-5\%o (see Appendix for errors specific to each sample analyzed), respectively. For our samples, the reported $\Delta^{14} \mathrm{C}=\left[f_{\mathrm{m}} e^{(1950-x) \lambda}-1\right] 1000$ (Stuiver and Polach, 1977), where $\lambda=1 / 8267$ (year ${ }^{-1}$ ), $f_{\mathrm{m}}=$ fraction modern ${ }^{14} \mathrm{C}$ (corrected for isotopic fractionation using $\delta^{13} \mathrm{C}$ ), and " $x$ " equals the year of collection (see Table 4.1). This corrects for decay of ${ }^{14} \mathrm{C}$ since time of collection to time of measurement. Isotopic and elemental analysis of the TOC, EX-RES and SA-RES from WF, and the TOC from the ERM (100-101 cm sample only), GB, BU, RS, MS and BS had previously been performed (see Table 4.2), and were not repeated for this study. 


\subsubsection{Gas Chromatography-Mass Spectrometry (GC/MS) Analysis}

Aliquots of TLEs and saponified neutral and acidic extracts were spiked with an internal standard ( $n-\mathrm{C}_{36}$ alkane, $4 \mu \mathrm{g}$ ), prior to derivatization with bis-(trimethylsilyl)trifluoroacetamide (BSTFA) and pyridine to improve chromatography. For compound identification, electron ionization (EI) spectra were acquired on an Agilent 6890 series gas chromatograph interfaced to an Agilent 5973 mass selective detector (MSD). A post column split to a flame ionization detector allowed for quantification of compounds of interest relative to the internal standard. Compounds were separated on a J\&W DB-5MS capillary column (60 m x $0.32 \mathrm{~mm}$ ID, $0.25 \mu \mathrm{m}$ film thickness) with helium carrier gas at a constant flow of $1 \mathrm{ml} \mathrm{min}{ }^{-1}$. The initial GC oven temperature was $40^{\circ} \mathrm{C}$ ( 1 minute hold) and was ramped at $20^{\circ} \mathrm{C} \mathrm{min}^{-1}$ until $130^{\circ} \mathrm{C}$ and then at $2^{\circ} \mathrm{C} \mathrm{min}^{-1}$ until $320^{\circ} \mathrm{C}(30$ minute hold). Spectra were acquired between $\mathrm{m} / \mathrm{z} 40-650$ at a scan rate of 1 cycle $\mathrm{s}^{-1}$. Compounds present in the extracts were identified from mass spectra and gas chromatographic retention characteristics. The flame ionization detector response was calibrated regularly by injection of $n$-alkane, $n$-alkanoic and $n$-alkanol standards.

\subsection{RESULTS AND DISCUSSION}

\subsubsection{General Trends in Surface Sediments}

For the majority of surface sediments examined in this study, the $\Delta^{14} \mathrm{C}$ of the bulk untreated sediment prior to solvent extraction (TOC) have $\Delta^{14} \mathrm{C}$ values that range from -300 to $-50 \%$ (Table 4.2 and Figure 4.2 a, b and c), reflecting a mixture of modern, preaged and fossil OM of marine and terrestrial origin. These $\Delta^{14} \mathrm{C}$ values compare well with those obtained for other core-top sediments previously reported in the literature (e.g., McNichol et al., 1993; Wang et al., 1996; Eglinton et al., 1997; Masiello and Druffel, 2003; Hwang et al., 2005; Komada et al., 2005). Salt marsh sediments from WF are, however, more enriched ( $+44 \%$, Figure $4.2 \mathrm{c})$, likely due to incorporation of recently synthesized vascular plant biomass from the roots of the marsh grass Spartina 


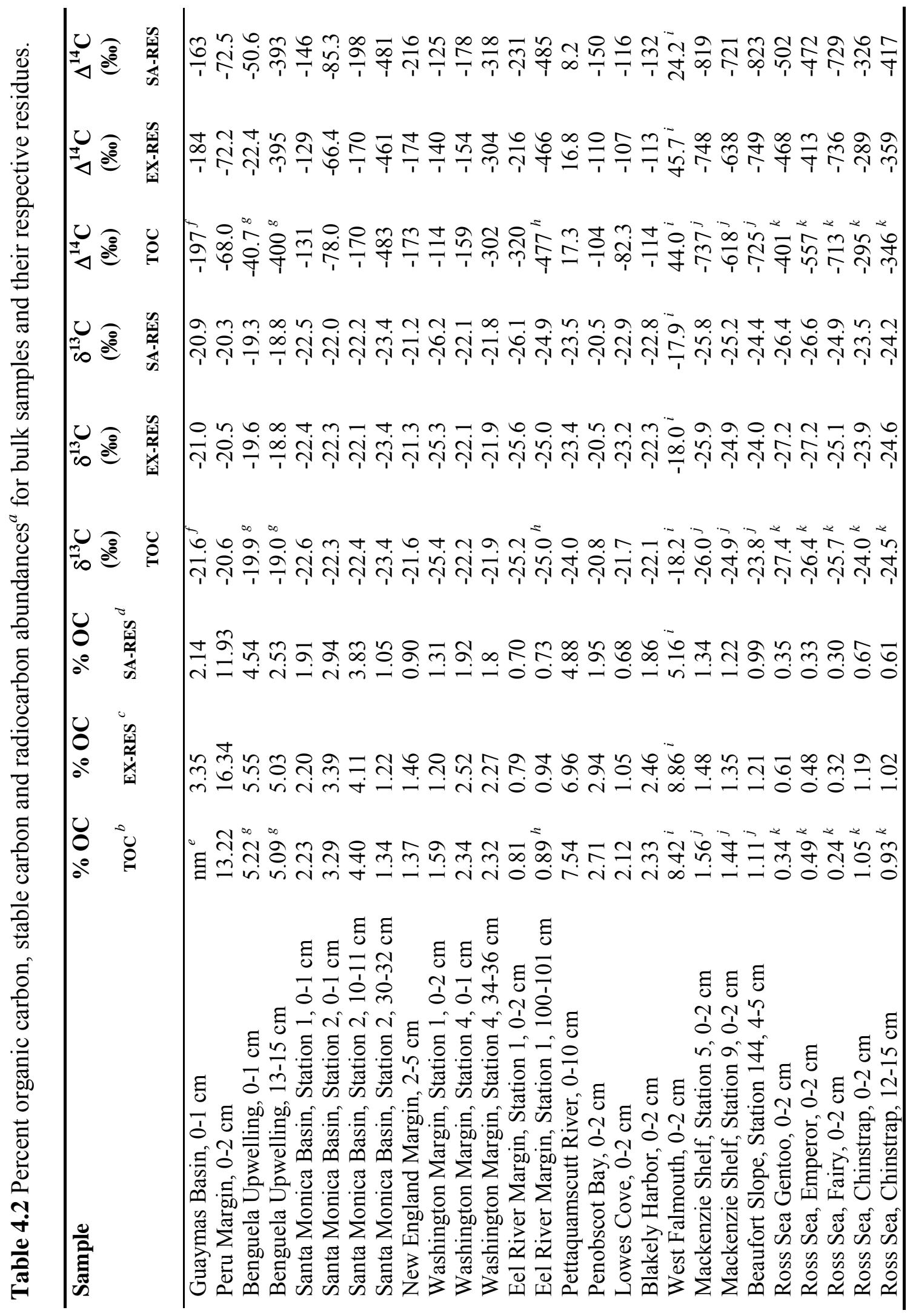




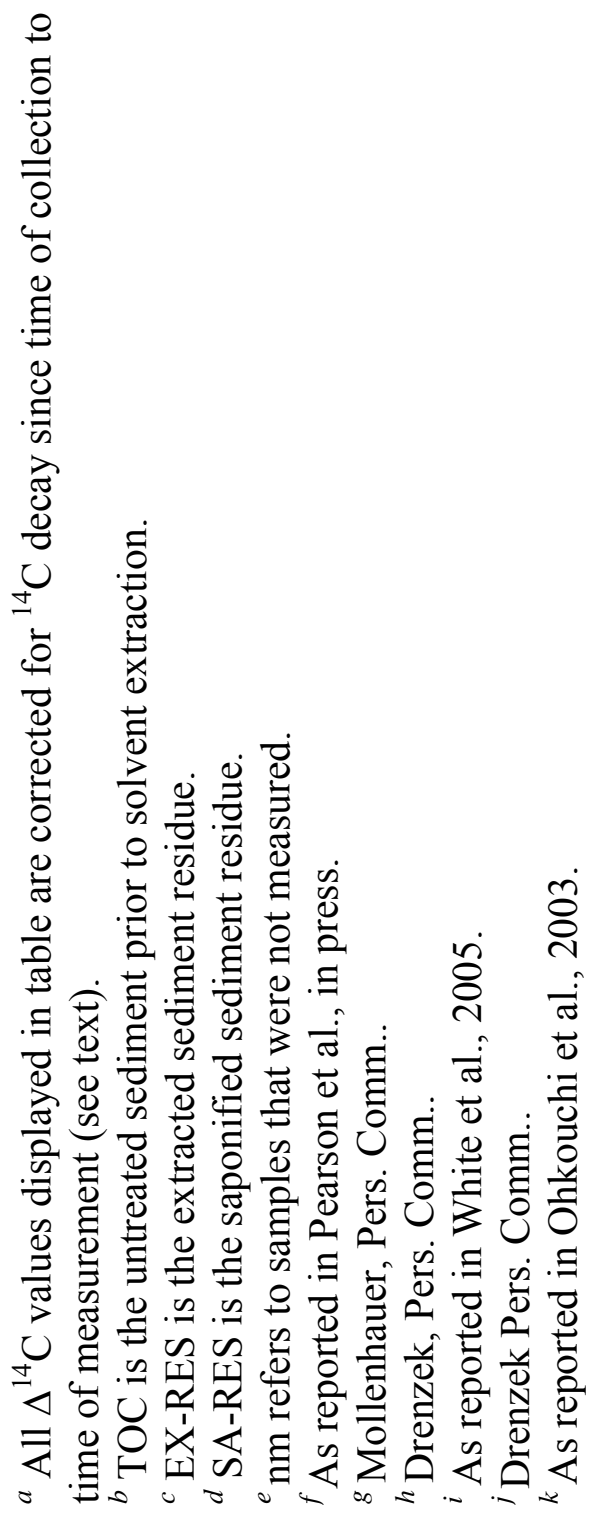



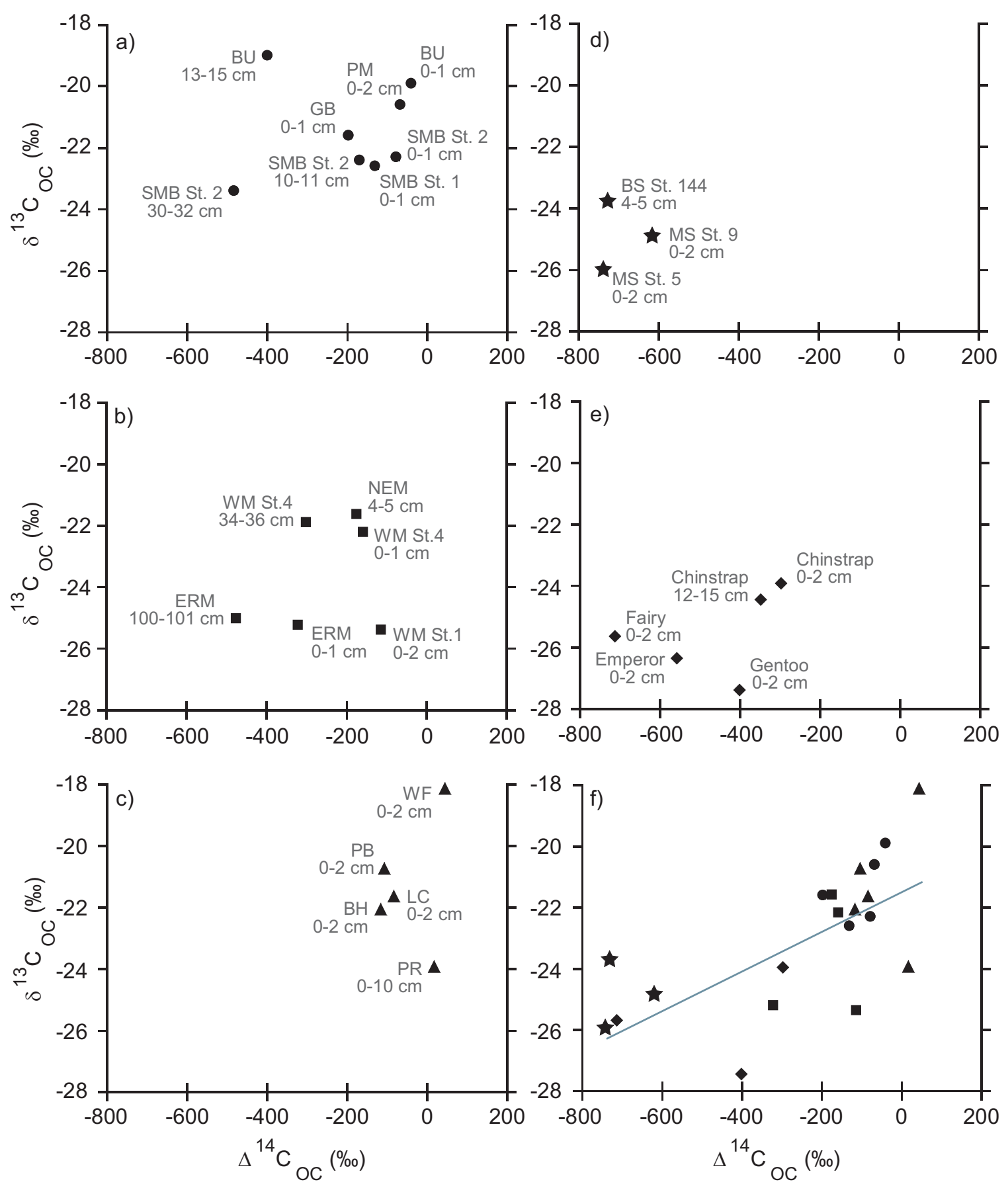

Figure 4.2 $\Delta^{14} \mathrm{C}$ and $\delta^{13} \mathrm{C}$ of unextracted sediment residues (TOC) for (a) organic-rich marine sediments; (b) open shelf and river dominated sites; (c) near-coast sediments; (d) Arctic sediments; (e) Antarctic sediments and (f) all core-top samples compared. Error bars for $\Delta^{14} \mathrm{C}$ and $\delta^{13} \mathrm{C}$ are $10 \%$ and $0.1 \%$ respectively and are smaller than the symbols shown in the figure and thus are not visible. 
alterniflora into the sedimentary matrix. Other exceptions include sediments from ERM, RS, MS and BS which are all significantly depleted $\left(\Delta^{14} \mathrm{C} \sim-750\right.$ to $-300 \%$; Figure $4.2 \mathrm{~b}$, $\mathrm{d}$ and e) due to varying contributions of fossil organic carbon. This fossil carbon is derived from kerogen from bedrock in the case of ERM sediments (Blair et al., 2004); pre-aged soil material and bitumen or kerogen in MS and BS sediments (Goñi et al., 2005; Drenzek et al., 2005) and from relict organic carbon from the Antarctic continent in the case of RS sediments (Ohkouchi et al., 2003).

The $\delta^{13} \mathrm{C}$ values of the bulk TOC for all sites range from -28 to $-18 \%$ (Table 4.2 , Figure 4.2), but within each group of sediments, it does not vary by more than 6\%. In general, the organic-rich marine sediments (Figure 4.2a) are the most ${ }^{13} \mathrm{C}$-enriched $(-23.4$ to $-19 \%$ ), and the Arctic and Antarctic sediments (Figure 4.2d and e) are the most depleted (-27.4 to $-23.8 \%$ ), likely reflecting significant contributions of enriched marine carbon in the former and ${ }^{13} \mathrm{C}$-depleted marine carbon and/or fossil carbon in the latter. Sediments from near-coast and open shelf and river dominated sites lie between these two extremes with $\delta^{13} \mathrm{C}$ of the bulk TOC ranging from -25.4 to $-20.8 \%$ (Figure $4.2 \mathrm{~b}$ and c). The WF sample is the exception. It's more enriched $(-18.2 \%) \delta^{13} \mathrm{C}$ value consistent with those of other salt marsh systems where the $\mathrm{C}_{4}$ plant Spartina alterniflora is the dominant macrophyte (Middleburg et al., 1997). A weak positive correlation between isotopic compositions $\left(\delta^{13} \mathrm{C}\right.$ vs. $\left.\Delta^{14} \mathrm{C}\right)$ of the TOC of all sediments examined is apparent (Figure 4.2e; $\mathrm{r}^{2}=0.5, \mathrm{p}=0.0004$ ) indicating that $\Delta^{14} \mathrm{C}$ as well as $\delta^{13} \mathrm{C}$ can be used to indicate the source of organic matter. It is worth noting that this correlation improves $\left(r^{2}=0.6\right)$ if the sediments with significant fossil contributions (MS, BS and RS Fairy and Emperor) are considered outliers.

In general, there is little difference between the $\Delta^{14} \mathrm{C}$ value of the TOC and the corresponding solvent extracted sediment residue (EX-RES) for the majority of sites examined (Table 4.2). This concurs with previous work on sediments from NEM that demonstrated the $\Delta^{14} \mathrm{C}$ of individually isolated, extractable alkenones, which are biomarkers derived from marine algae, are similar to that of bulk OM (Ohkouchi, Pers. Comm.). GC/MS analysis of TLE (Figure 4.3 i) from each sample provides insights into 
the composition and source of materials removed by solvent extraction. It should be borne in mind, however, that much of the TLE is not amenable to GC, so interpretations should be made with caution. In each case, varying proportions of short $\left(n-C_{12}\right.$ to $\left.n-C_{22}\right)$ and long $\left(n-\mathrm{C}_{24}\right.$ to $\left.n-\mathrm{C}_{34}\right)$ chain alkanoic acids and alkanols with-even-over-odd predominance (Figure 4.4-4.8), reflect inputs from marine and terrestrial sources, respectively. There are also significant contributions from $n$-alkanes, which are predominantly odd carbon numbered. In samples where they contribute $<5 \%$ to the GCamenable portion the even $n$-alkanes concentrations are below the detection limit. Generally, CPI values range from 1.6 (predominantly fossil-derived) to 13.3 (predominantly plant-wax derived). There are also significant contributions from sterols for which the assignment of sources is less straightforward (Volkman 2005), but is dominated by those with carbon numbers from $\mathrm{C}_{27}-\mathrm{C}_{29}$.

At the majority of sites, systematic offsets in $\Delta^{14} \mathrm{C}$ between the EX-RES and SARES are observed (Table 4.2). With the exception of WM St. 1 and GB (discussed later) the SA-RES is always more depleted than that of the EX-RES indicating removal of more ${ }^{14} \mathrm{C}$ enriched material by the process of saponification. GC/MS analysis indicates that the GC-amenable fraction of the saponification extracts (SAE) is mainly composed of shortchain alkanoic acids $\left(n-\mathrm{C}_{12}\right.$ to $n-\mathrm{C}_{22}$ ) (Figure 4.3 ii) with strong even-over-odd predominance (Figure 4.9-4.13), indicating a marine algal or bacterial source. This is supported in a study by Ohkouchi et al. (2003) that demonstrated relatively uniform $\Delta^{14} \mathrm{C}$ values for ester-bound short chain alkanoic acids in surface sediments from the Ross Sea that were more enriched relative to the bulk sediment and reflected the post-bomb dissolved inorganic carbon (DIC) reservoir. Such observations provide evidence for the protection of labile marine carbon by chemical binding with the sedimentary matrix. Free $n$-alkanoic acids are especially susceptible to degradation if they are short-chain and unsaturated (Sun and Wakeham, 1994; Zegouagh et al., 1996) and although they are also derived from bacterial communities responsible for this degradation, these would most likely be present in the TLE (as intact phospholipids) as opposed to the SAE. Long chain 
a) i)

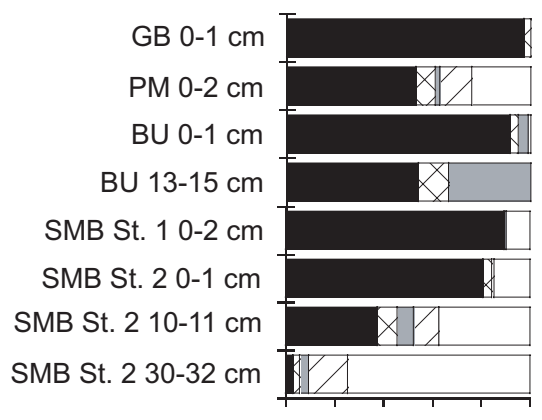

b) i)

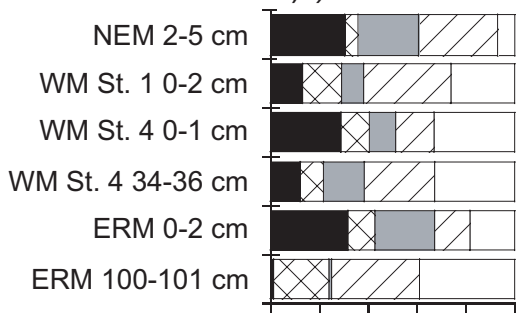

c) i)

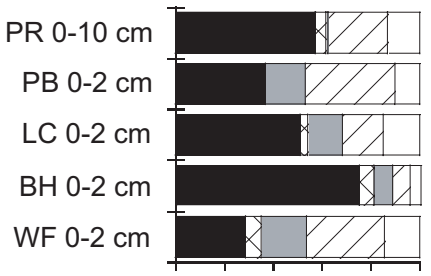

d) i)

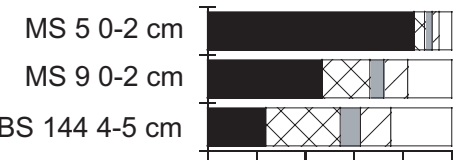

e) i)

\section{Gentoo 0-2 cm \\ Emperor 0-2 cm \\ Fairy $0-2 \mathrm{~cm}$ \\ Chinstrap 0-2 cm}

Chinstrap $12-15 \mathrm{~cm}$

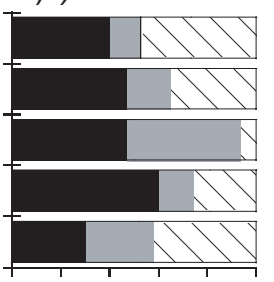

020406080100020406080100

$\%$ contribution to TLE \% contribution to SAE ii)

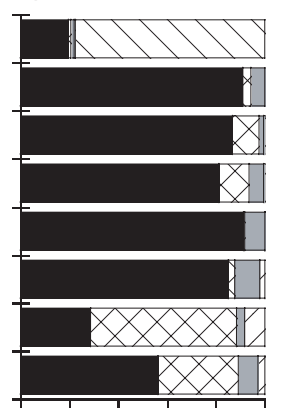

ii)

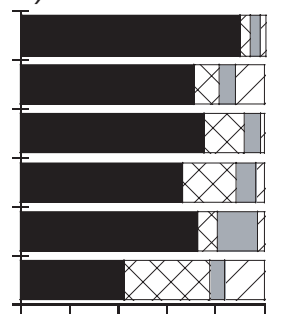

ii)

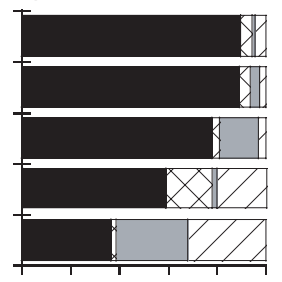

ii)

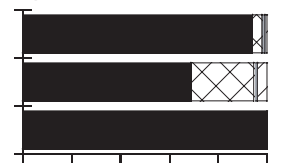

ii)

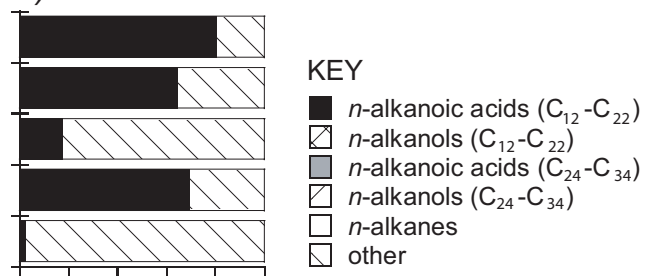

Figure 4.3 Relative contribution of $n$-alkanoic acids, $n$-alcohols and alkanes for a) organic-rich marine sediments; b) open shelf and river dominated sediments; c) nearcoast sediments; d) Arctic sediments and e) Antarctic sediments to $i$ ) the total lipid extract (TLE) and (ii) the saponification extract (SAE). See text for description of 'other'. 


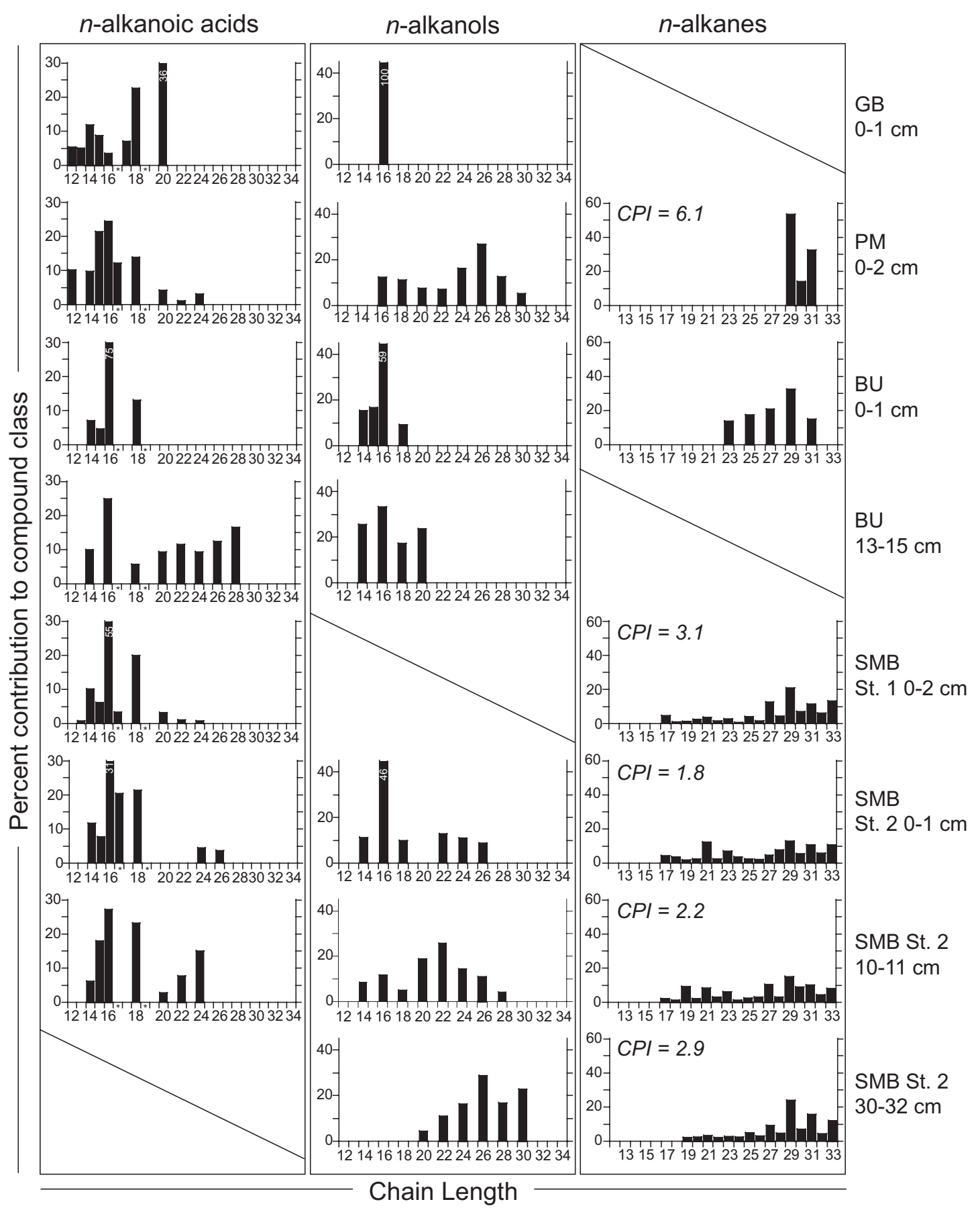

Figure 4.4 Percent contribution to compound class for individual $n$-alkanoic acids, $n$-alkanols and $n$-alkanes in the total lipid extract (TLE) in organic-rich marine sediments. ' $*$ ' represents the unsaturated counterpart of the previous $n$-alkanoic acid. Values superimposed on histogram bars represent those that are off scale and odd over even predominance (OEP) for $n$-alkanes is indicated. Diagonal lines are present where compounds are below detection limits. 


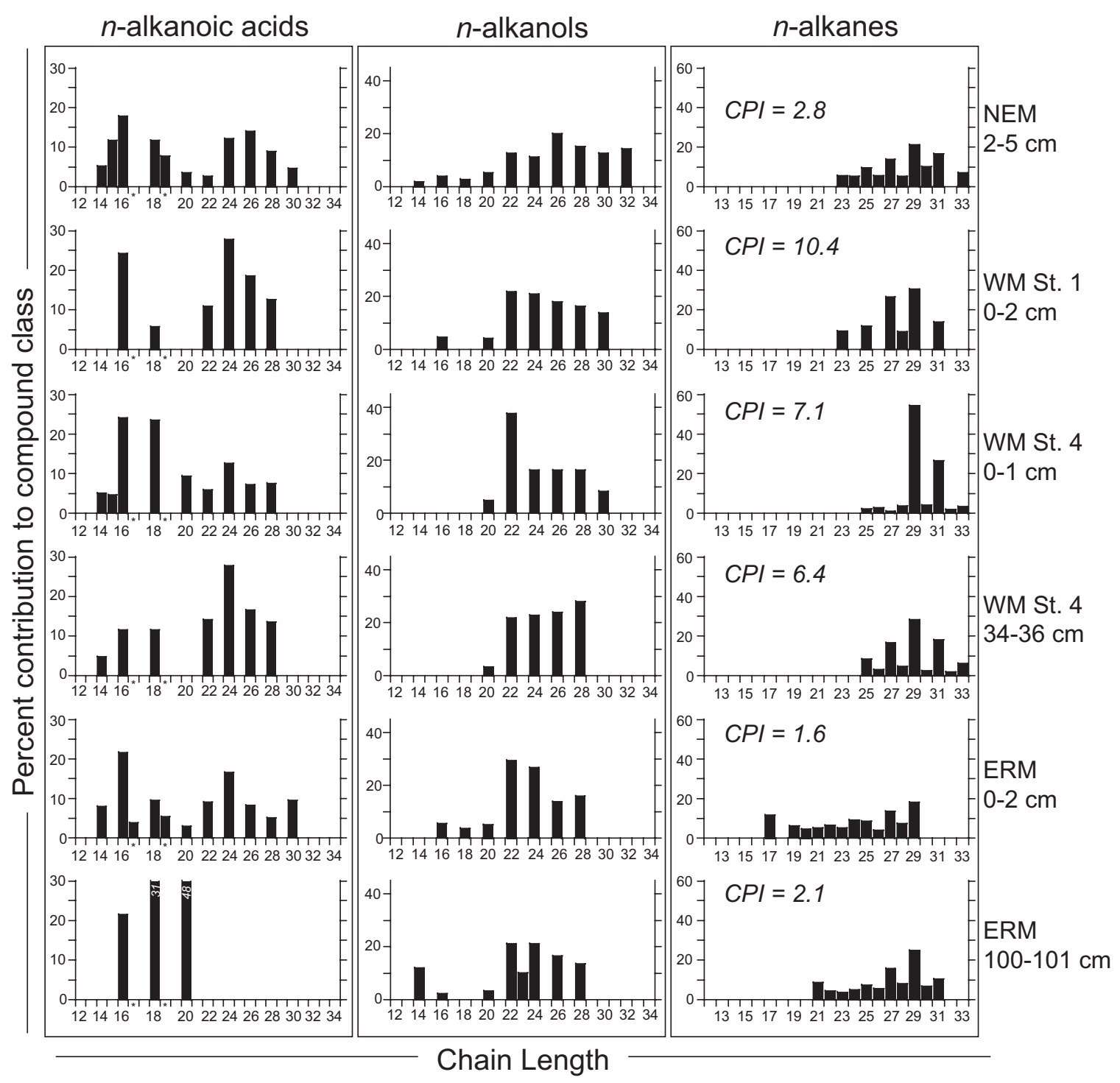

Figure 4.5 Percent contribution to compound class for individual $n$-alkanoic acids, $n$ alkanols and $n$-alkanes in the total lipid extract (TLE) to open shelf and river dominated sediments. ' $*$ ' represents the unsaturated counterpart of the previous $n$-alkanoic acid. Values superimposed on histogram bars represent those that are off scale and odd over even predominance (OEP) for $n$-alkanes is indicated. 


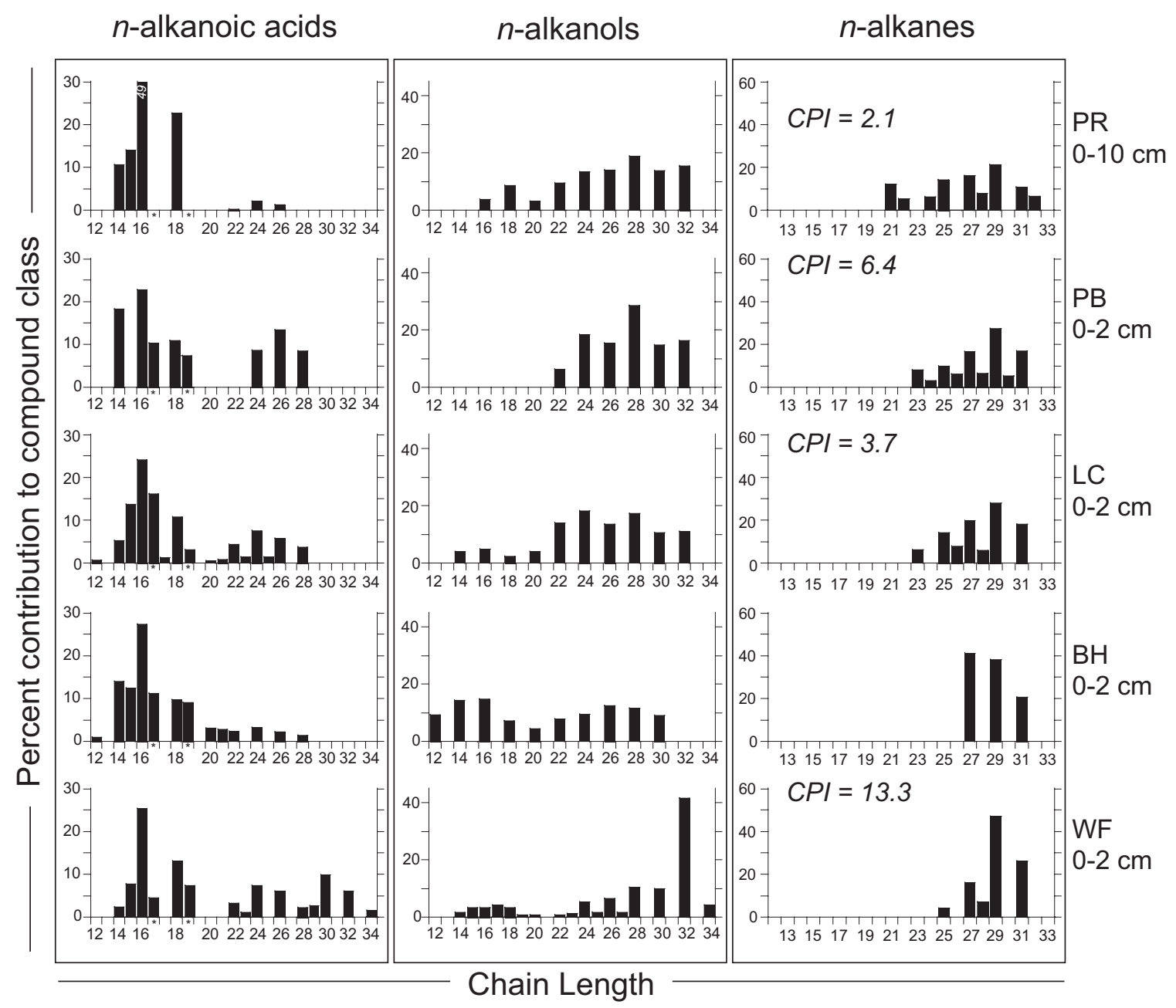

Figure 4.6 Percent contribution to compound class for individual $n$-alkanoic acids, $n$ alkanols and $n$-alkanes in the total lipid extract (TLE) to Near-coast sediments. '*' represents the unsaturated counterpart of the previous $n$-alkanoic acid. Values superimposed on histogram bars represent those that are off scale and odd over even predominance (OEP) for $n$-alkanes is indicated. 


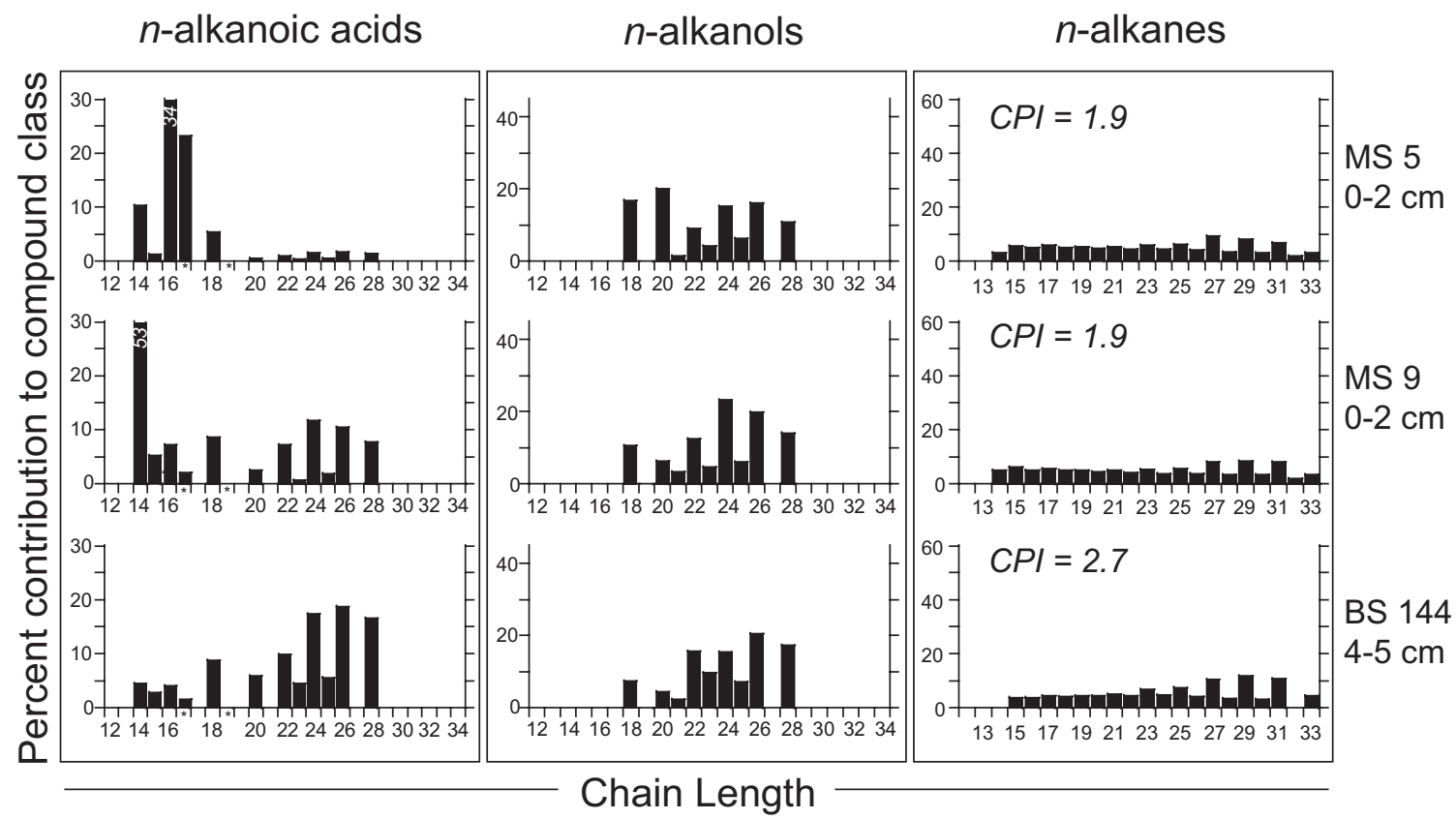

Figure 4.7 Percent contribution to compound class for individual $n$-alkanoic acids, $n$ alkanols and $n$-alkanes in the total lipid extract (TLE) to Arctic sediments. '*' represents the unsaturated counterpart of the previous $n$-alkanoic acid. Values superimposed on histogram bars represent those that are off scale and odd over even predominance (OEP) for $n$-alkanes is indicated. 


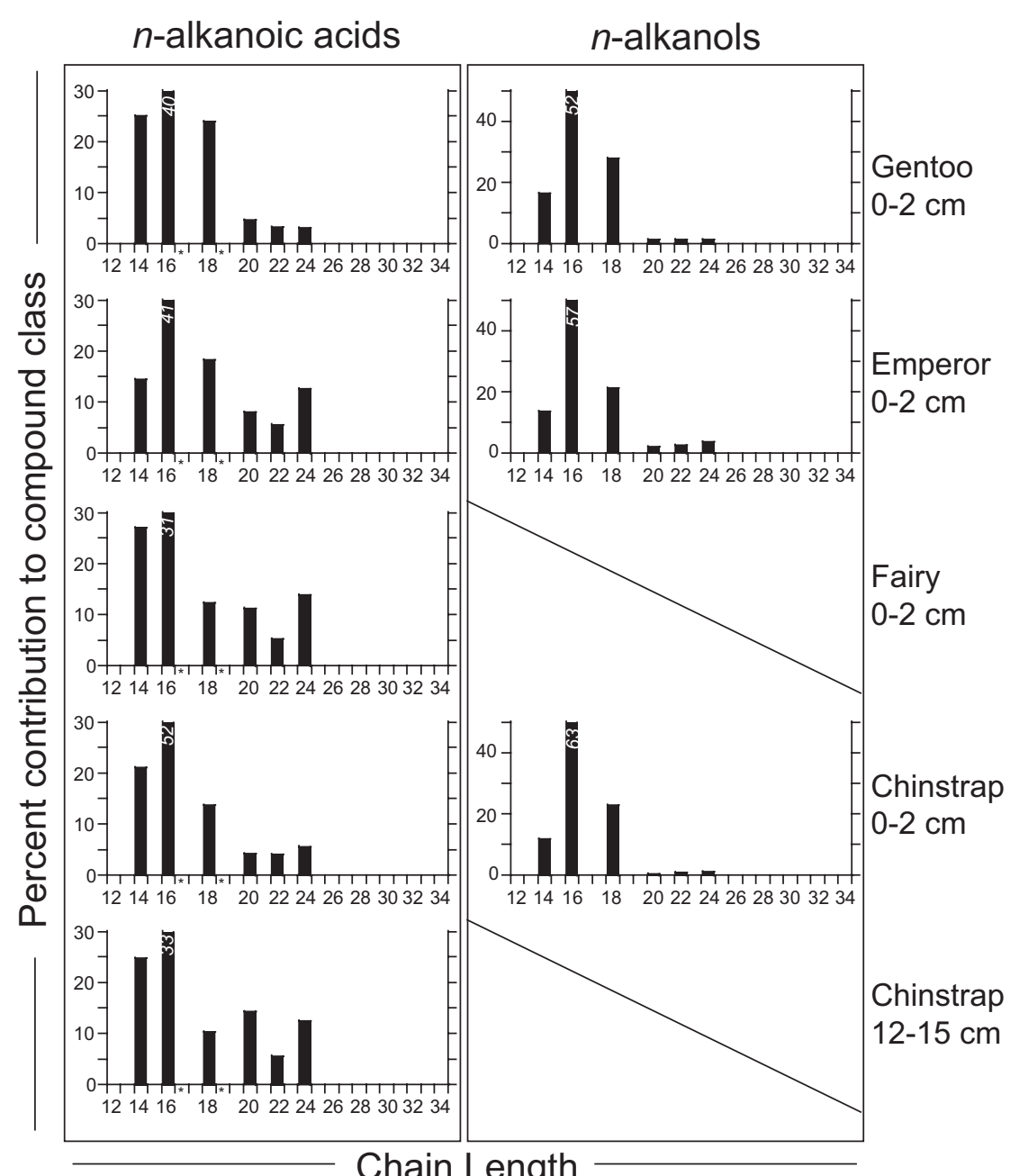

Figure 4.8 Percent contribution to compound class for individual $n$-alkanoic acids and $n$ alkanols in the total lipid extract (TLE) to Antarctic sediments. '*' represents the unsaturated counterpart of the previous $n$-alkanoic acid. Values superimposed on histogram bars represent those that are off scale. Diagonal lines are present where compounds are below detection limits. 


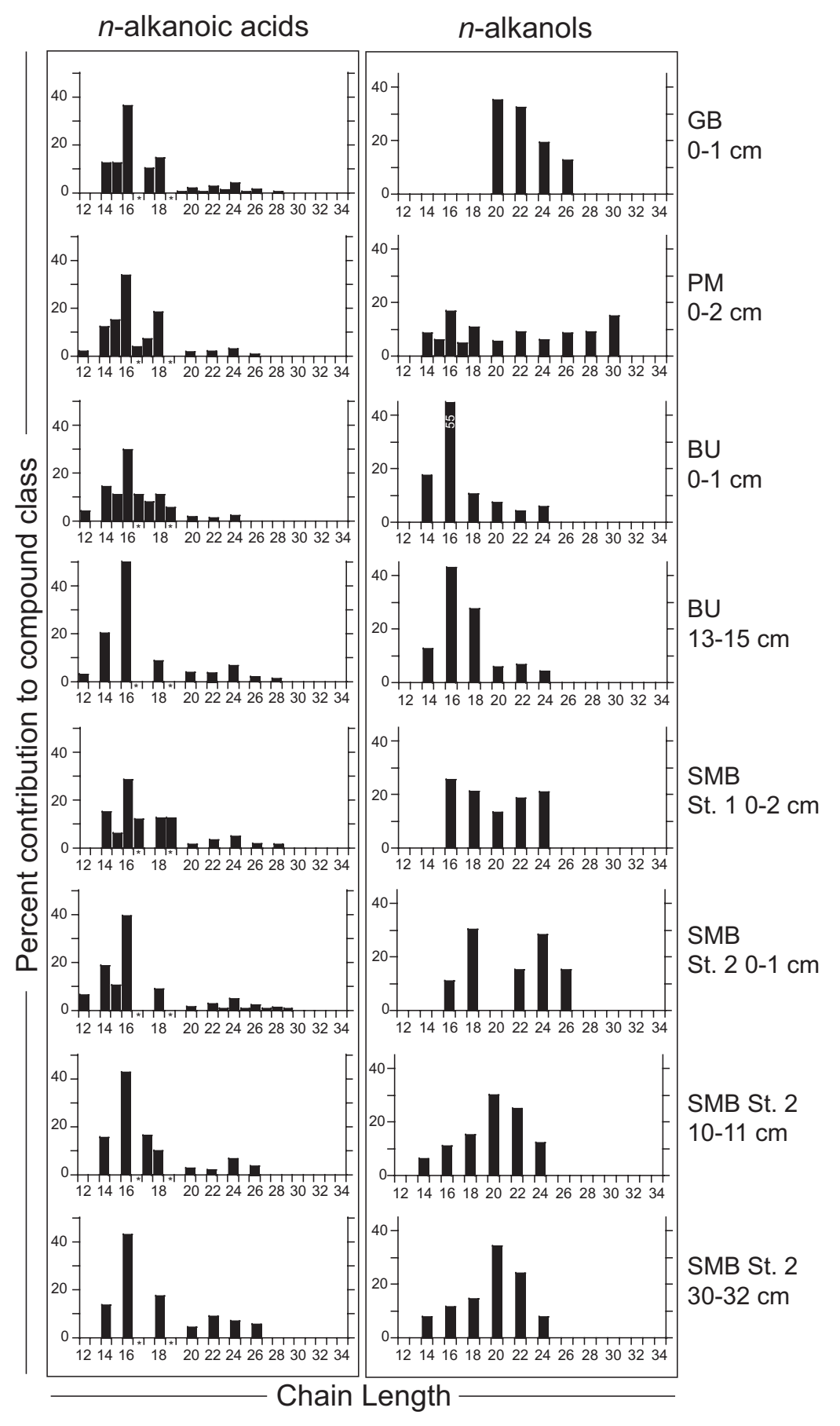

Figure 4.9 Percent contribution to compound class for individual $n$-alkanoic acids and $n$ alkanols in the saponification extract (SAE) for organic-rich marine sediments. '*' represents the unsaturated counterpart of the previous $n$-alkanoic acid. Values superimposed on histogram bars represent those that are off scale. 


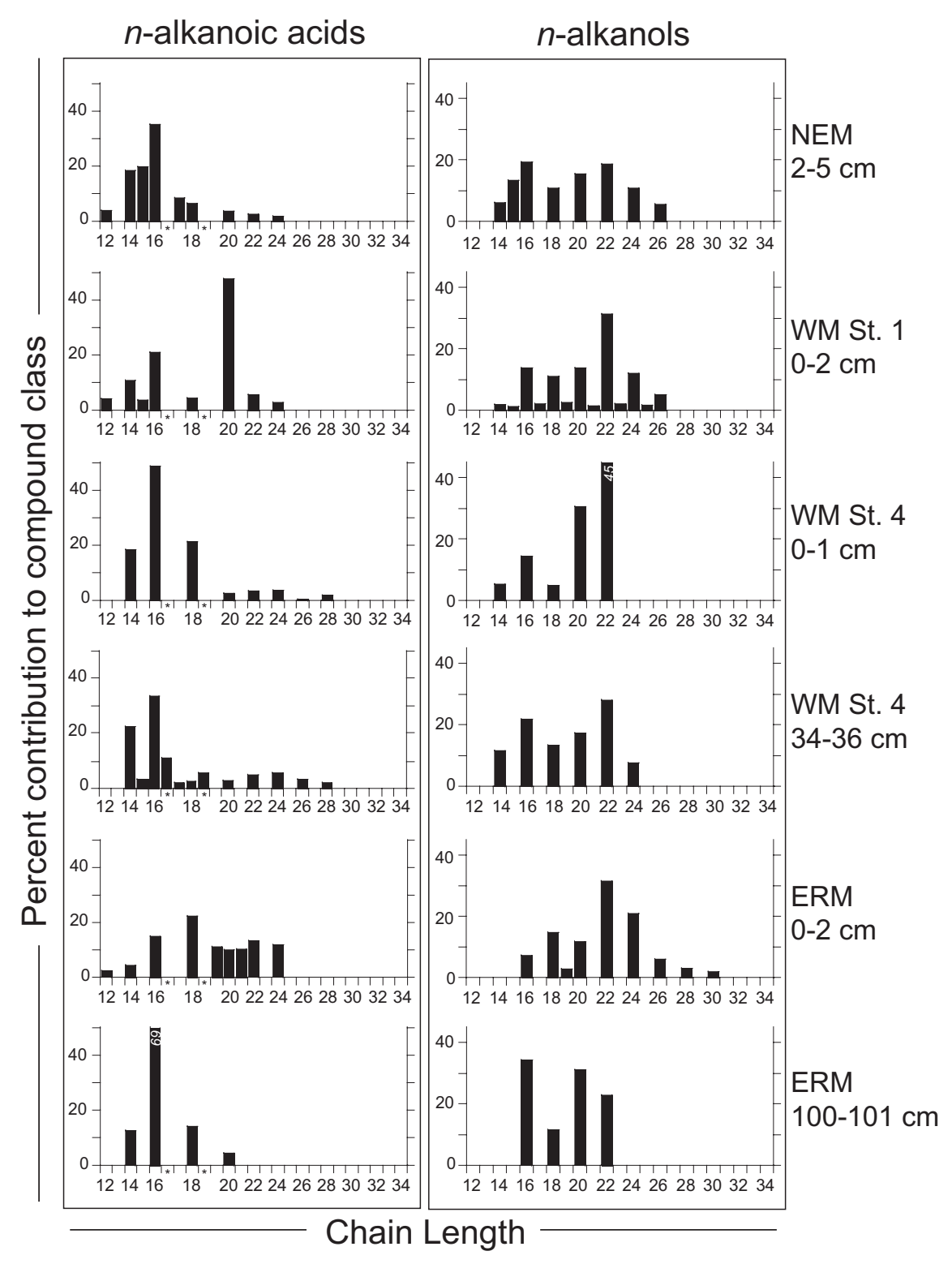

Figure 4.10 Percent contribution to compound class for individual $n$-alkanoic acids and $n$-alkanols in the saponification extract (SAE) for open shelf and river dominated sediments. ' $*$ ' represents the unsaturated counterpart of the previous $n$-alkanoic acid. Values superimposed on histogram bars represent those that are off scale. 


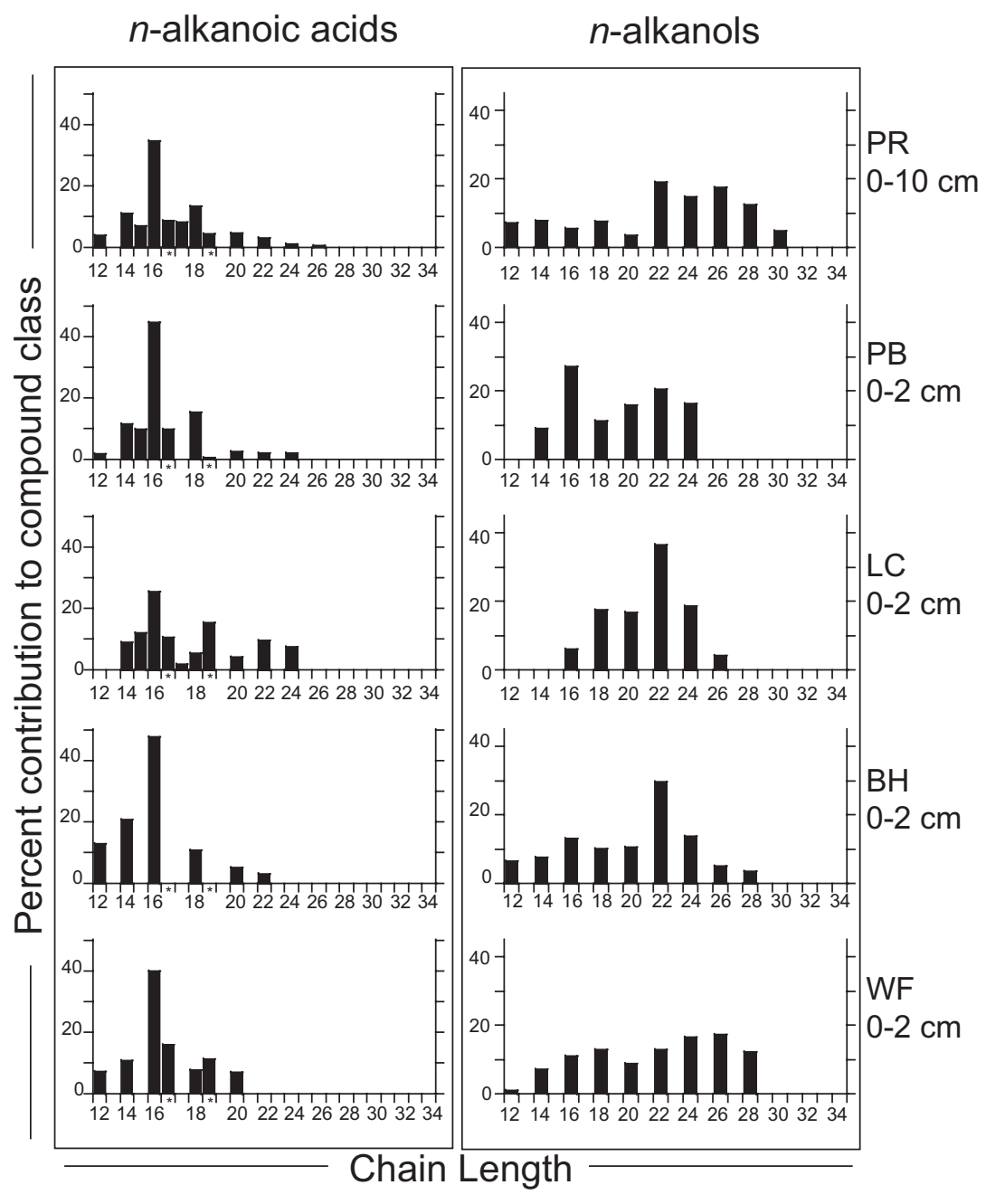

Figure 4.11 Percent contribution to compound class for individual $n$-alkanoic acids and $n$-alkanols in the saponification extract (SAE) for near-coast sediments. '*' represents the unsaturated counterpart of the previous $n$-alkanoic acid. 


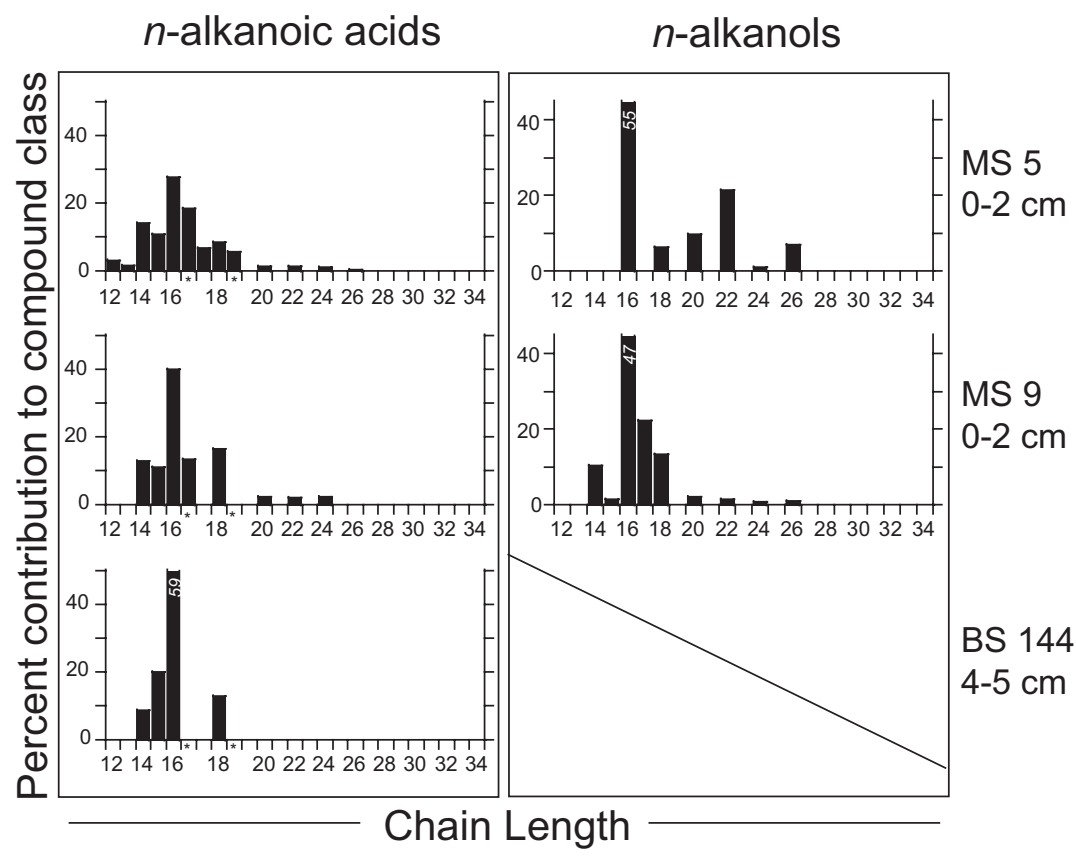

Figure 4.12 Percent contribution to compound class for individual $n$-alkanoic acids and $n$-alkanols in the saponification extract (SAE) for Arctic sediments. '*' represents the unsaturated counterpart of the previous $n$-alkanoic acid. Values superimposed on histogram bars represent those that are off scale. Diagonal lines are present where compounds are below detection limits. 
n-alkanoic acids originating from higher plants are, however, more resistant to degradation most likely due to a protective matrix association (Zegouagh et al., 1996).

To determine the significance of the contributions of different biomarkers observed in the TLE and SAE, the proportion of TOC that is solvent extractable and saponifiable as well as the quantity of this material that is GC amenable was calculated (Table 4.3). To calculate the percentage of TOC that was extractable, portions of the extracts were weighed and converted to carbon equivalents considering contributions from hydrogen and oxygen (an average of $80 \%$ of biogenic compounds examined here are carbon derived). This value was then divided by the amount of organic carbon in the bulk unextracted sediment (TOC, Table 4.2). The fact that only GC-amenable compounds are discussed is a limitation of this study, but, this highlights the strengths of the isotopic approach as differences in isotopic compositions between sediments and residues provides information about the carbon pools that are not GC-amenable. Examination of $\Delta{ }^{14} \mathrm{C}$ shifts between bulk residues and the $\Delta{ }^{14} \mathrm{C}$ of the extracts removed that lead to these shifts has been performed in one case (WF) and these values are consistent with one another (White et al., 2005).

In the context of these overall aforementioned trends, the isotopic abundances of sediments and their residues as well as their compound distributions in "free" (TLE) and "bound" (SAE) pools, will be discussed in more detail. The difference in isotope abundances $\left(\Delta^{14} \mathrm{C}\right.$ and $\left.\delta^{13} \mathrm{C}\right)$ of the residues (EX-RES represented by grey filled circles; SA-RES represented by open circles) from the bulk TOC (black filled circle at the origin of the plot) are shown for core-top sediments in figures 4.13-4.17. These will also be discussed for sediment samples below the mixed layer (Figure 4.18). Where present, arrows indicate significant offsets between the residues as a result of the chemical treatments. 


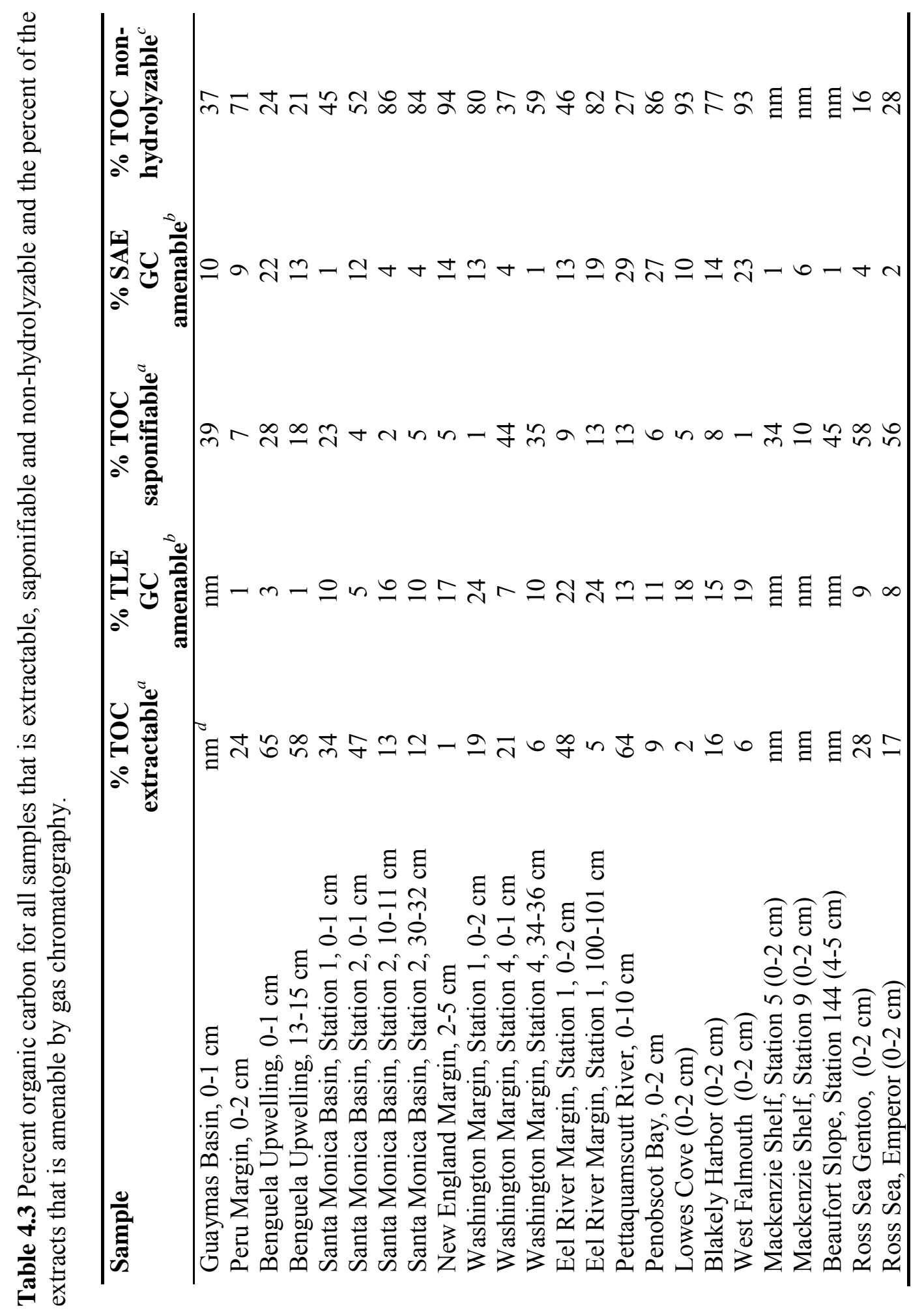




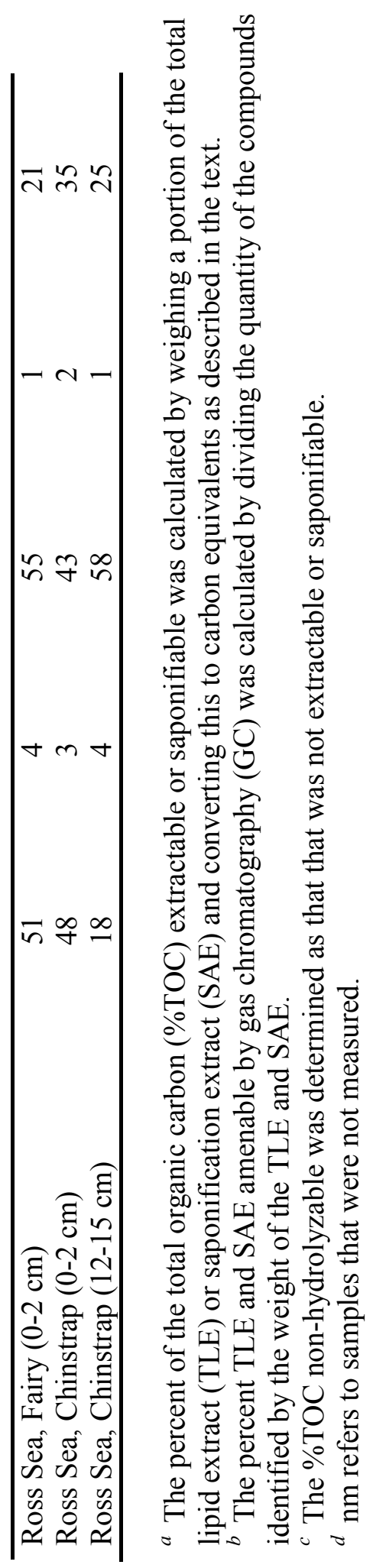




\subsubsection{Organic-Rich Marine Sediments}

Isotopic abundances of the TOC for organic-rich marine sediments from surface sediments, display relatively small offsets between bulk sediments and their respective residues as a result of the chemical treatments. This is demonstrated by the clustering of the EX-RES and SA-RES in both $\Delta^{14} \mathrm{C}$ and $\delta^{13} \mathrm{C}$ space around the origin, which represents the isotopic composition of the TOC (Figure 4.13). This indicates that the organic carbon removed by the sequential treatments is isotopically similar to that in the original bulk sediment as well as that remaining in the residues. Analysis of organic phosphorus in sediments of the Peru Margin by sequential treatment also indicated little variance in organic phosphorus between different pools of OM suggesting that the different pools of OM have similar compositions (Laarkamp, 2000). This is likely due to the fact that these organic-rich sediments are predominantly derived from a marine source. Although the isotopic offsets between the residues are small, some general patterns are evident. Excluding the GB sample, the mean offset in $\Delta \Delta^{14} \mathrm{C}$ and $\Delta \delta^{13} \mathrm{C}$ between the EX-RES and TOC is 7 and $0.2 \%$ respectively indicating a slight enrichment in EX-RES in both isotopes relative to the TOC. This is consistent with previous work by Eglinton et al. (1997) which observed a ${ }^{14} \mathrm{C}$-depleted TLE relative to the TOC in surface sediments from the Black Sea. Other work by Hwang et al. (2005), consistently demonstrates lipid that are depleted in $\Delta^{14} \mathrm{C}$ and $\delta^{13}$ relative to bulk sediment. Excluding the GB sample again, the mean offset in $\Delta \Delta^{14} \mathrm{C}$ and $\Delta \delta^{13} \mathrm{C}$ between the SA-RES and TOC can be calculated and is -9 and $0.3 \%$ respectively. The SA-RES is enriched in $\delta^{13} \mathrm{C}$ similarly to the EX-RES, but is slightly depleted in $\Delta^{14} \mathrm{C}$ relative to the bulk TOC, indicating the removal of ${ }^{14} \mathrm{C}$-enriched material by saponification.

Comparisons between sediments from the SMB depocenter (Station 2) where bottom water oxygen contents are $\leq 0.1 \mathrm{ml} \mathrm{l}^{-1}$ (Hickey, 1992) and the periphery (Station 1) where bottom water oxygen contents are higher, have previously been made to examine the differential degradation of alkenones and differences in fatty acid composition (Gong and Hollander, 1997, 1999; Mollenhauer and Eglinton, in preparation). Alkenone contents were observed to be lower in sediments from the 
periphery than those from the depocenter, but at depths corresponding to deposition under anoxic conditions in the depocenter, the alkenone contents were of equal abundance, indicating the control of post-depositional oxidative degradation on these compounds. In this study, surface sediment OC contents of the periphery were lower (2.2\%, Table 4.2) compared to the depocenter supporting these previous findings $(3.2 \%$, Table 4.2). Several experiments examining surface water primary production, physical

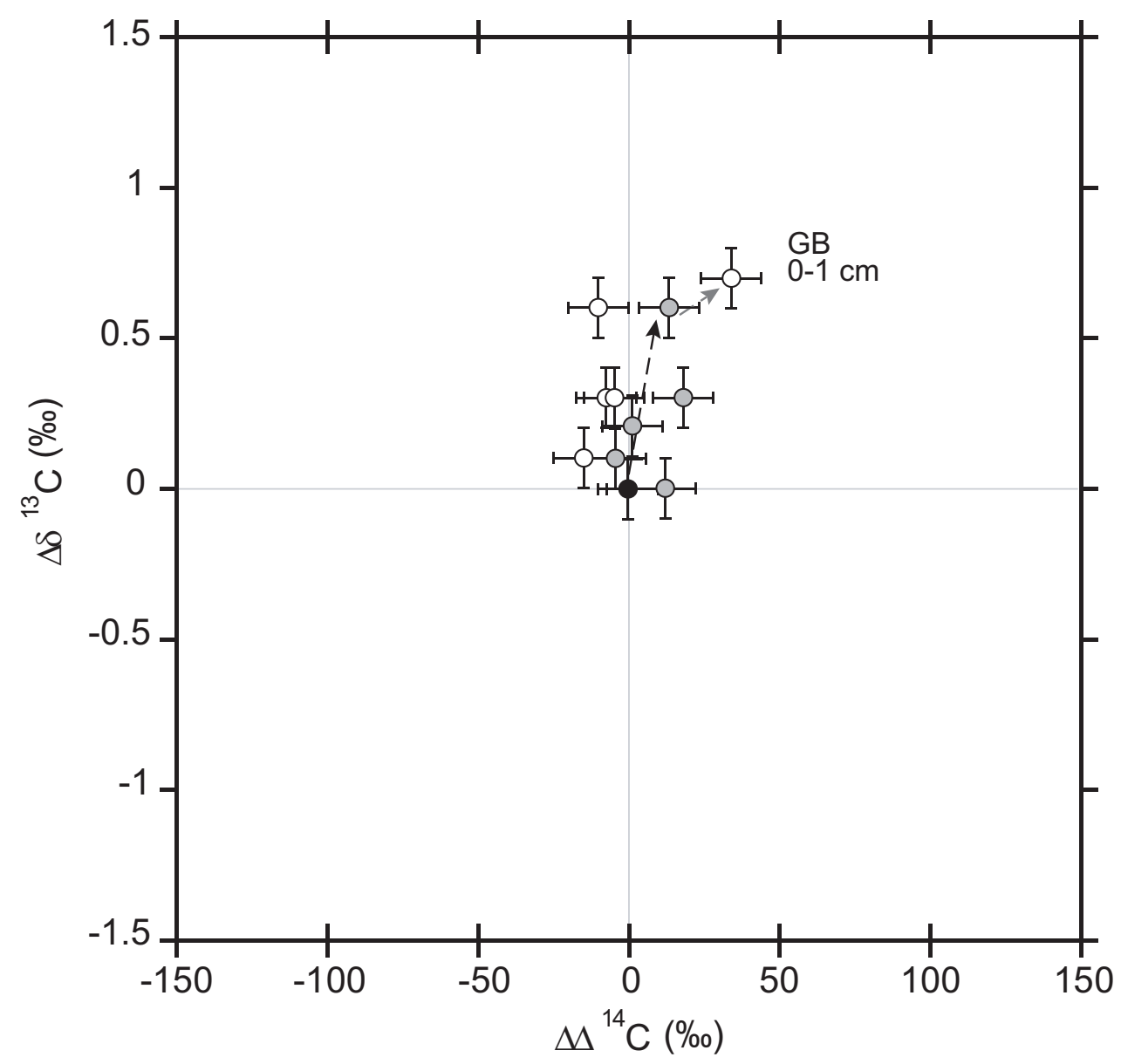

Figure 4.13 Differences in $\delta^{13} \mathrm{C}$ of the extracted residue (EX-RES; filled grey symbols) and saponified residue (SA-RES; open symbols) from $\delta^{13} \mathrm{C}$ of bulk sediment (TOC; filled black symbol) expressed as $\Delta \delta^{13} \mathrm{C} \%$ vs. the differences in $\Delta{ }^{14} \mathrm{C}$ of the EX-RES and SARES from the TOC expressed as $\Delta \Delta^{14} \mathrm{C} \%$ for organic-rich marine sediments (core-top samples only). Error bars represent $0.1 \%$ error for $\delta^{13} \mathrm{C}$ values and $10 \%$ error for $\Delta^{14} \mathrm{C}$. 
and chemical properties of the upper water column and sedimentation processes have been performed to demonstrate that the primary difference between the sediments of the depocenter and the periphery was the oxygen content (Gong and Hollander, 1999). Very similar distributions of extractable and saponifiable biomarkers are observed in the surface sediments from the two stations (Figures 4.3a, 4.4 and 4.9), with the only significant difference being the absence of short chain alkanols $\left(n-\mathrm{C}_{12}-\mathrm{C}_{22}\right)$ in the periphery sediments (Station 1) suggesting enhanced degradation of these compounds in the presence of oxygen. Overall, the surface bulk sediment and corresponding residues from the depocenter are more enriched (-85 to $-66 \%)$ than those from the periphery (-146 to $-129 \%$; Table 4.2 ), indicating that ${ }^{14} \mathrm{C}$ rich organic material that is younger and likely more labile, is preferentially degraded at the periphery.

Sediments from GB behave very differently than the other organic-rich marine sediments (Figure 4.13) and the residues become successively more enriched in ${ }^{14} \mathrm{C}$ as the sequential treatments are performed. The TOC is the most depleted (-197\%) followed by the EX-RES (-184\%) and the SA-RES (-163\%). Guaymas Basin is an unusual environment in which hydrothermal petroleum is produced in the sediments as a result of magmatic heating. The successive enrichment of residues observed results from the removal of relatively ${ }^{14} \mathrm{C}$ depleted material at each step. Solvent-extractable $n$-alkanoic acids isolated from the microbial mat of Beggiotoa, exhibit depleted $\Delta{ }^{14} \mathrm{C}$ values (-418\%o to $-227 \%$ ) that are similar to that of hydrothermal petroleum, indicating the consumption of pre-aged carbon by the entire bacterial assemblage (Pearson et al., 2005). For this study, we have examined the sediment underlying the microbial mat, and our results are consistent with Pearson et al. suggesting that solvent extraction removes compounds that are relatively depleted in ${ }^{14} \mathrm{C}$. Notably, the TLE in this study is comprised predominantly of short chain $n$-alkanoic acids ( $80 \%$, Figure $4.3 \mathrm{a})$. The SAE reveals a significant $(\sim 70 \%)$ contribution of polycyclic aromatic hydrocarbons (PAHs) including naphthalenes, phenanthrenes and their alkylated derivatives, fluoranthene, anthracene and fluorene (shown as "other" in Figure 4.3a). These PAHs are apparently nonextractable, but are unlikely to be covalently bonded to the $\mathrm{OM}$ as they are not functionalized. 
Instead, they may be encapsulated in the sedimentary matrix, possibly via association with organic matter or mineral grains. These compounds are directly derived from the ${ }^{14} \mathrm{C}$-depleted hydrothermal petroleum, thus explaining the remaining enriched residue.

\subsubsection{Open Shelf and River-Dominated Sediments}

Significant offsets in $\Delta^{14} \mathrm{C}$ are observed between TOC and EX-RES of surface sediments from WM St. 1 and ERM and to a lesser extent NEM (Figure 4.14). These offsets are, however, in opposite directions. In the case of WM St.1, the $\Delta^{14} \mathrm{C}$ EX-RES is significantly more depleted than that of the TOC. For this latter sample, the offset may reflect the weak association and facile removal of more recently synthesized material by solvent extraction, leaving behind a more depleted residue. This interpretation is supported by the molecular-level composition of the TLE (Figure 4.3b), which has significant contributions from long-chain $\left(n-\mathrm{C}_{24}\right.$ to $\left.n-\mathrm{C}_{34}\right)$ alkanols $(\sim 20 \%)$ and alkanoic acids $(\sim 5 \%)$ with an even over odd predominance as well as long chain $\left(n-\mathrm{C}_{23}\right.$ to $\left.n-\mathrm{C}_{31}\right)$ alkanes $(\sim 15 \%)$ with an odd-over-even predominance (CPI $=10.4$; Figure 4.5$)$. These biomarker compounds are characteristic of vascular plant biomass and are particularly abundant at WM St. 1, which is on the inner shelf. Absolute abundances of $n$-alkanes on the WM continental shelf average $165 \mu \mathrm{g} \mathrm{g}^{-1}$ carbon (C) (Prahl et al., 1994). Radiocarbon analysis of individual terrestrial biomarkers for a site proximal to St. 1 determined that they are younger than the TOC (Eglinton, Pers. Comm.) supporting these bulk level observations. No significant offset in $\Delta{ }^{14} \mathrm{C}$ between TOC and EX-RES (Table 4.2) is observed at WM St. 4, which is further offshore than St. 1 (upper continental slope) for surface sediments, or those at a depth of 34-36 cm corresponding to $\sim 318 \mathrm{yr}$ bp (M. Uchida, Pers. Comm.). This is likely due to a decrease in the contribution of terrestrial plant material, which is not particularly evident in the composition of the TLE (Figure 4.3), but previous research has indicated decreasing concentrations in this material with increasing distance offshore, for example, absolute abundances of $n$-alkanes on the slope are $91 \mu \mathrm{g} \mathrm{g}^{-1} \mathrm{C}$ and $52 \mu \mathrm{g} \mathrm{g}^{-1} \mathrm{C}$ in basin sediments (Prahl et al., 1994). 
In sharp contrast to WM1, the radiocarbon content of TOC from ERM $0-2 \mathrm{~cm}$ is considerably more depleted ( 100\%) than the EX-RES (Figure 4.14). Analysis of the $n$ alkanes, which comprise $\sim 20 \%$ of the GC-resolvable TLE (Figure $4.3 \mathrm{~b}$ ) reveals a low CPI (1.6; Figure 4.5), betraying the presence of petrogenic hydrocarbons associated with the supply of OM from erosion of ancient sedimentary rocks on the adjacent continent (Blair et al., 2004). Large quantities of unaltered bedrock containing predominantly a

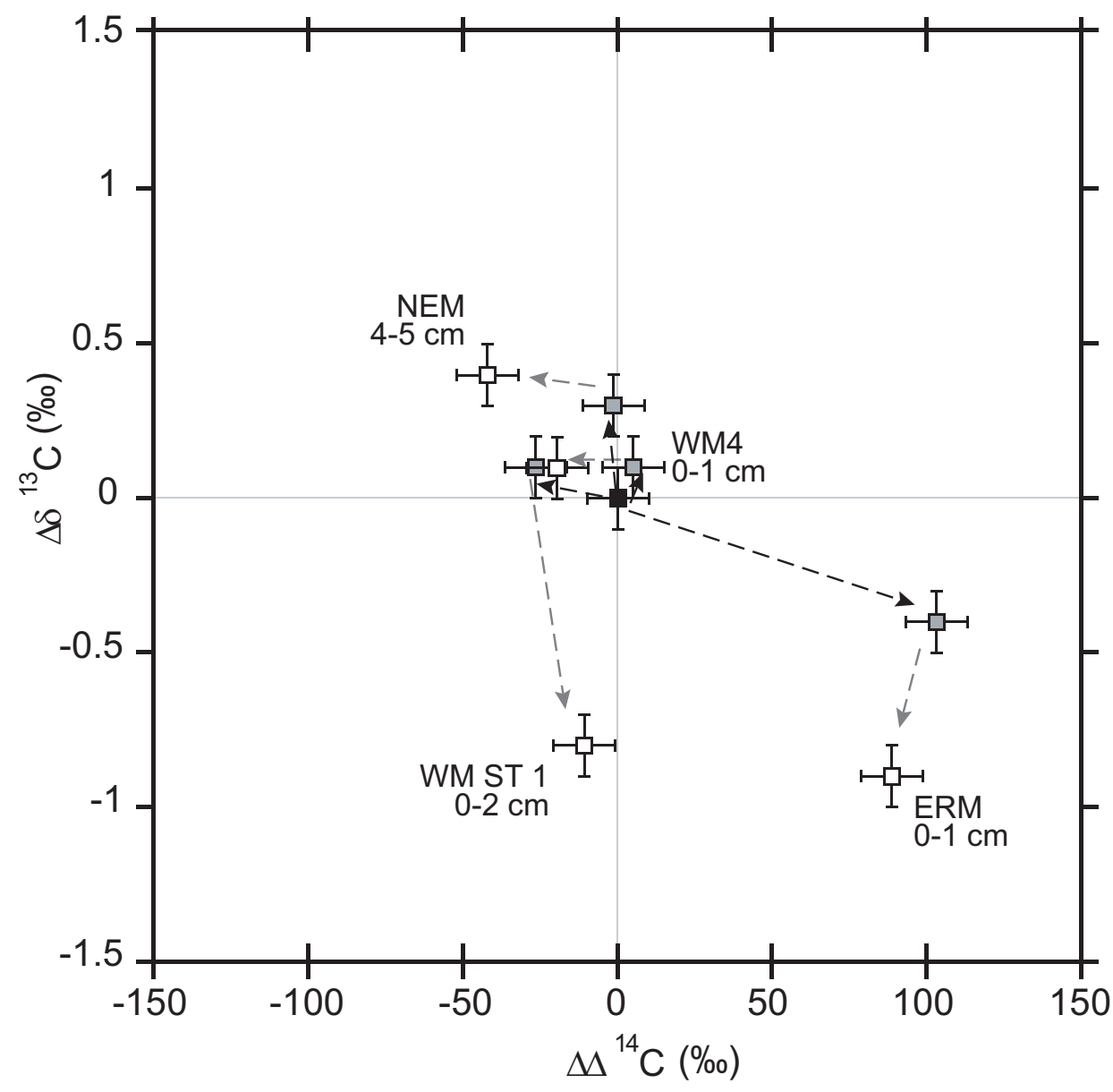

Figure 4.14 Differences in $\delta^{13} \mathrm{C}$ of the extracted residue (EX-RES; filled grey symbols) and saponified residue (SA-RES; open symbols) from $\delta^{13} \mathrm{C}$ of bulk sediment (TOC; filled black symbol) expressed as $\Delta \delta^{13} \mathrm{C} \%$ vs. the differences in $\Delta{ }^{14} \mathrm{C}$ of the EX-RES and SARES from the TOC expressed as $\Delta \Delta^{14} \mathrm{C} \%$ for open shelf and river dominated sediments (core-top samples only). Error bars represent $0.1 \%$ error for $\delta^{13} \mathrm{C}$ values and $10 \%$ error for $\Delta{ }^{14} \mathrm{C}$. 
type III kerogen and plant debris-rich surface soils are delivered from the continent as a result of large scale flood events. As a consequence, widespread and rapid (0.2-0.4 cm $\mathrm{yr}^{-1}$ ) accumulation of modern sediment occurs along the shelf break (Sommerfield and Nittrouer, 1999). The sediments examined in this study are from the middle of the flood depocenter on the shelf.

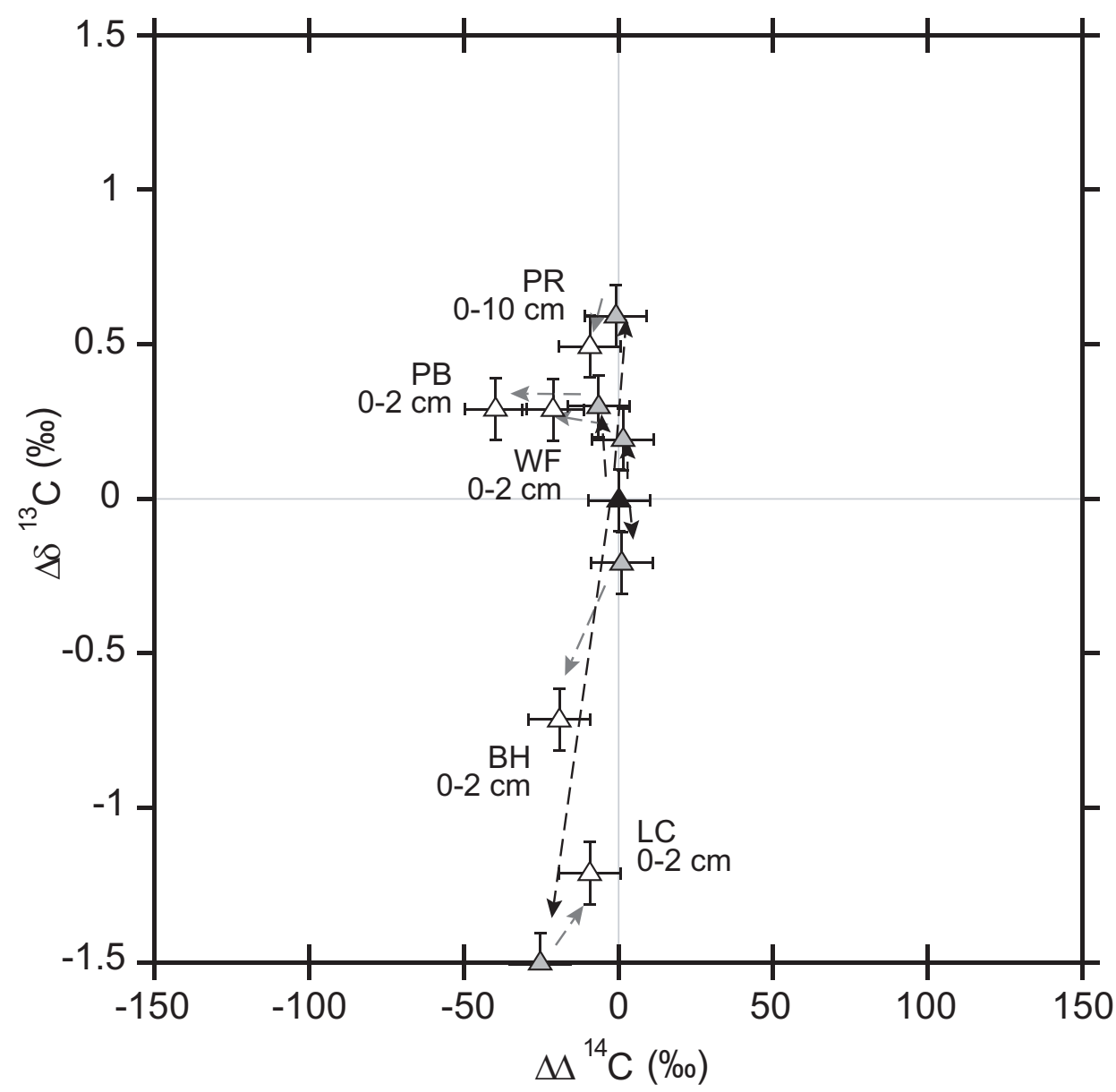

Figure 4.15 Differences in $\delta^{13} \mathrm{C}$ of the extracted residue (EX-RES; filled grey symbols) and saponified residue (SA-RES; open symbols) from $\delta^{13} \mathrm{C}$ of bulk sediment (TOC; filled black symbol) expressed as $\Delta \delta^{13} \mathrm{C} \%$ vs. the differences in $\Delta^{14} \mathrm{C}$ of the EX-RES and SARES from the TOC expressed as $\Delta \Delta^{14} \mathrm{C} \%$ for near-coast sediments. Error bars represent $0.1 \%$ error for $\delta^{13} \mathrm{C}$ values and $10 \%$ error for $\Delta^{14} \mathrm{C}$. 


\subsubsection{Near-Coast Sediments}

Near-coast sediments (Figure 4.15) display similar isotopic shifts to the general trends observed except for LC, which exhibits a more ${ }^{14} \mathrm{C}$ enriched TOC relative to the EX-RES (-82 and $-107 \%$ respectively; Table 4.2$)$. This is likely due to the removal of

${ }^{14} \mathrm{C}$-enriched terrestrial biomass as indicated by the abundance of long chain $n$-alkanoic acids and $n$-alkanols with even/odd dominance as well as $n$-alkanes with a CPI of 3.7 (Figures 4.3c and 4.6). A significant shift in $\delta^{13} \mathrm{C}$ and $\Delta^{14} \mathrm{C}$ space is also observed for $\mathrm{BH}$ between the EX-RES and SA-RES (Figure 4.15), which becomes more depleted in both $\delta^{13} \mathrm{C}$ and $\Delta^{14} \mathrm{C}$ due to the removal of relatively ${ }^{13} \mathrm{C}$ and ${ }^{14} \mathrm{C}$ enriched material that is likely marine derived as indicated by short chain $n$-alkanoic acids and alkanols that dominate the SAE (Figure 4.3c).

\subsubsection{Arctic Sediments}

Surface sediments and residues from MS and BS exhibit the most depleted $\Delta^{14} \mathrm{C}$ values (-823 to $-618 \%$ ) observed in this study (Table 4.2 ). Similar shifts in $\Delta^{14} \mathrm{C}$ are observed in all sediments (Figure 4.16), with the TOC being the most enriched in ${ }^{14} \mathrm{C}$ and the SA-RES the most depleted resulting from the removal of OC that is increasingly enriched in ${ }^{14} \mathrm{C}$ as the sequential treatments progress. This offset is greatest $(\sim-100 \%)$ between the EX-RES and SA-RES (Figure 4.16) likely due to the SAE being composed predominantly ( $\sim 60-100 \%)$ of fresh marine biomarkers such as short chain $n$-alkanoic acids (as in Zegouagh et al., 1996) and $n$-alkanols (Figure $4.3 \mathrm{~d}$ ii)). The TLEs, are dominated by short chain $n$-alkanoic acids, which have previously been shown to have modern ${ }^{14} \mathrm{C}$ values (Drenzek et al., submitted) with lesser contributions from long chain $n$-alkanoic acids and short and long chain $n$-alkanols. There are also varying contributions from $n$-alkanes (5-25\%) with OEP ranging from 1.9-2.7 previously shown to be derived from a mixture of higher plant leaf waxes and erosion of sedimentary rocks in the drainage basin (Yunker et al., 1993; Drenzek et al., submitted). What remains as the non-hydrolyzable portion of the TOC is extremely depleted in ${ }^{14} \mathrm{C}$ (-823 to $-721 \%$ ). These values are consistent with $\Delta{ }^{14} \mathrm{C}$ compositions of pyrolysate alkanes from Station 5 
(as in Drenzek et al., submitted) that are thought to be derived from kerogen and/or vascular plant cutan that is pre-aged on the continent prior to delivery to the Beaufort Sea.

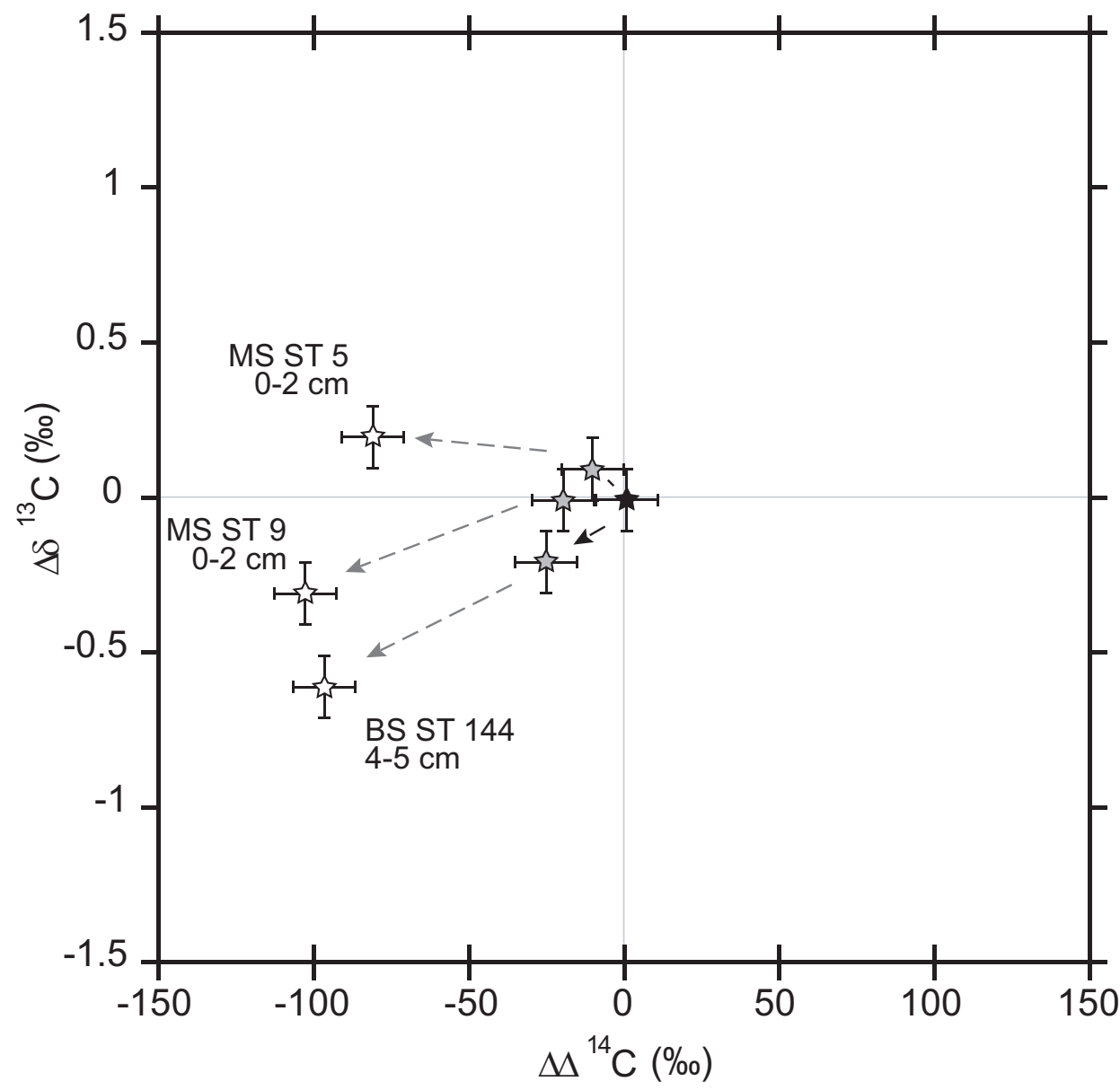

Figure 4.16 Differences in $\delta^{13} \mathrm{C}$ of the extracted residue (EX-RES; filled grey symbols) and saponified residue (SA-RES; open symbols) from $\delta^{13} \mathrm{C}$ of bulk sediment (TOC; filled black symbol) expressed as $\Delta \delta^{13} \mathrm{C} \%$ vs. the differences in $\Delta^{14} \mathrm{C}$ of the EX-RES and SARES from the TOC expressed as $\Delta \Delta^{14} \mathrm{C} \%$ for Arctic sediments. Error bars represent $0.1 \%$ error for $\delta^{13} \mathrm{C}$ values and $10 \%$ error for $\Delta^{14} \mathrm{C}$. 


\subsubsection{Antarctic Sediments}

Significant offsets in $\Delta^{14} \mathrm{C}$ and $\delta^{13} \mathrm{C}$ are observed between sediments and corresponding residues in Antarctic sediments from the Ross Sea (Figure 4.17). These sites are the same as those examined by Ohkouchi et al. (2003). The Emperor and Gentoo sites are in regions with extensive blooms of haptophyte algae; Chinstrap represents a region where diatoms bloom during the austral summer. In contrast, large algal blooms have not been observed at the Fairy site which is the most proximal to the Ross ice shelf

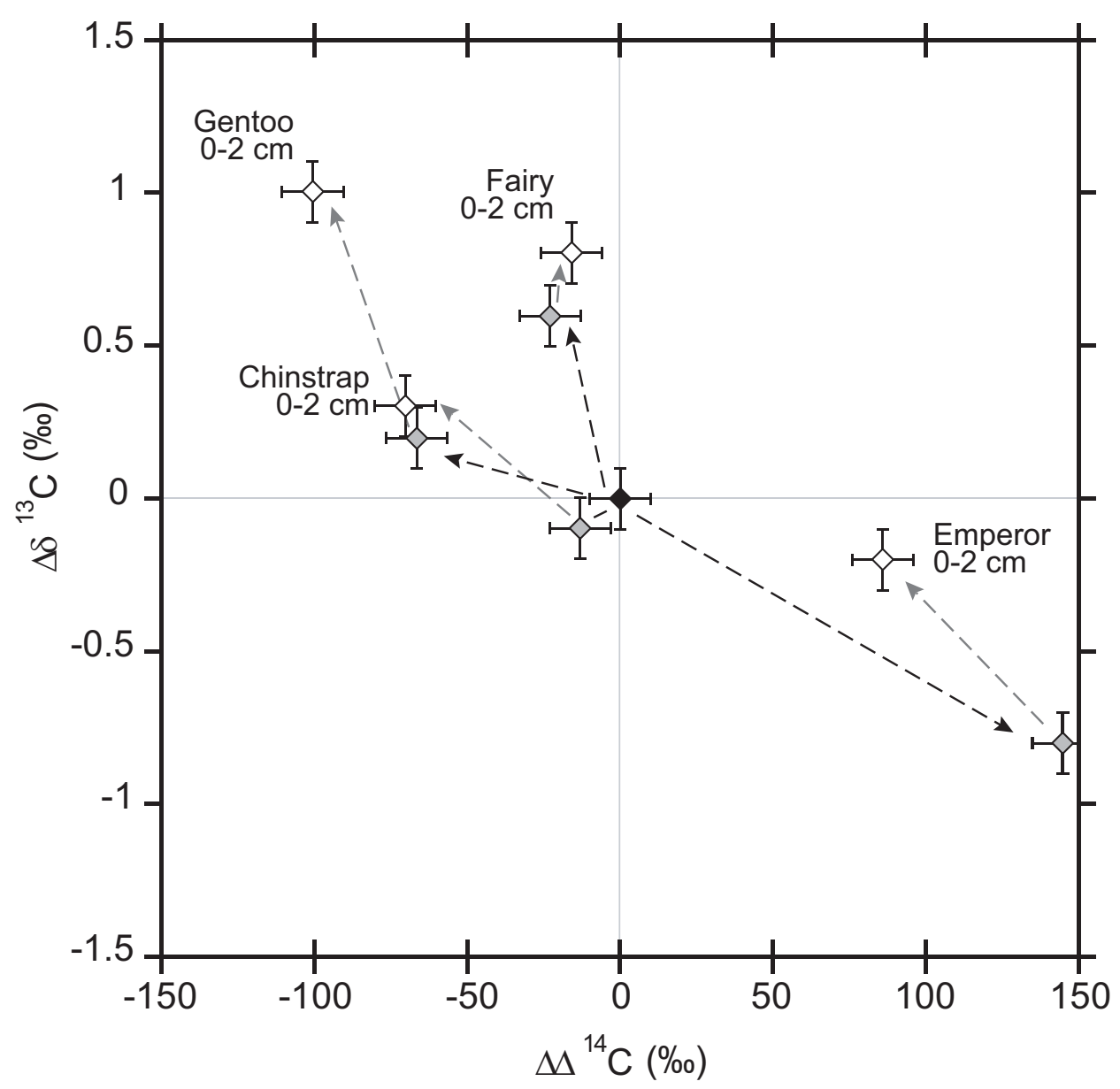

Figure 4.17 Differences in $\delta^{13} \mathrm{C}$ of the extracted residue (EX-RES; filled grey symbols) and saponified residue (SA-RES; open symbols) from $\delta^{13} \mathrm{C}$ of bulk sediment (TOC; filled black symbol) expressed as $\Delta \delta^{13} \mathrm{C} \%$ vs. the differences in $\Delta^{14} \mathrm{C}$ of the EX-RES and SARES from the TOC expressed as $\Delta \Delta^{14} \mathrm{C} \%$ for Antarctic sediments (core-top samples only). Error bars represent $0.1 \%$ error for $\delta^{13} \mathrm{C}$ values and $10 \%$ error for $\Delta^{14} \mathrm{C}$. 
(Dunbar et al., 1985). For all sites except Emperor, the TOC is similar to, or more enriched in ${ }^{14} \mathrm{C}$ than the EX-RES and significant variation in $\delta^{13} \mathrm{C}$ is not observed between fractions. Where observed, this difference between TOC and EX-RES represents the extraction of $\mathrm{OC}$ that is relatively enriched in ${ }^{14} \mathrm{C}$ as reflected in TLEs that are dominated by short chain $n$-alkanoic acids (30-60\%, Figure $4.3 \mathrm{e}$ i)). The latter have been shown to be significantly enriched in ${ }^{14} \mathrm{C}$ relative to the TOC, exhibiting $\Delta^{14} \mathrm{C}$ values corresponding to that of post-bomb surface ocean dissolved inorganic carbon in this region (Ohkouchi et al., 2003). The Emperor site, however displays a significantly more depleted $\Delta^{14} \mathrm{C}$ of TOC (-557\%) relative to EX-RES (-413\%; Table 4.2), implying removal of ${ }^{14} \mathrm{C}$-depleted OC. Analysis of the TLE (Figure 4.3e, where other represents the contribution of sterols) does not reveal significant differences in biomarker contributions in Emperor compared to the other sites, but the fraction of OC that is extractable is less (17\%) than that observed in the other Ross Sea surface sediments (2851\%; Table 4.3). Long chain $n$-alkanoic acids at the Emperor and Fairy sites are relatively depleted in ${ }^{14} \mathrm{C}$ (e.g. $n-\mathrm{C}_{28} \mathrm{FA}=-375 \%$; Ohkouchi, et al., 2003) compared to their short chain counterparts, and these depleted values may have a larger impact on the isotopic signature at the Emperor site where the \%TOC extractable is less. Fairy sediments and residues exhibit the most depleted $\Delta^{14} \mathrm{C}$ values (-736 to $-713 \%$ ) of all of the Ross Sea sediments examined here, and differences in contributions of biomarkers to the TLE and SAE are observed at the Fairy site compared to the other Ross Sea sediments. The contribution of sterols to the TLE is much less than at other sites $(\sim 10 \%$ compared to 26-46\%; Figure 4.3e) and the remainder of the GC-amenable components of the TLE are comprised of equal contributions of short and long chain $n$-alkanoic acids whereas at other sites, short chain $n$-alkanoic acids contribute twice as much as their long chain counterparts. This lesser contribution of sterols and short chain $n$-alkanoic acids at the Fairy site may result from either a deficit in the delivery of fresh marine organic carbon from the photic zone (due to the absence of large algal blooms at the Fairy site), preferential degradation of sedimentary biomarkers, dilution of the signal by OM from a different source with a different composition from lateral transport (Villinski and Hayes, 
2005) or fossil OC inputs (Ohkouchi and Eglinton, 2005). Either way, these inputs result in an overall decrease in the proportion of easily extractable, fresh ${ }^{14} \mathrm{C}$ enriched material in the sediments, and thus give rise to only a small offset in $\Delta^{14} \mathrm{C}$ TOC and EX-RES.

Differences in $\Delta^{14} \mathrm{C}$ and $\delta^{13} \mathrm{C}$ for EX-RES and SA-RES from Fairy, Gentoo and Chinstrap indicated by similar vectors observed (symbolized by grey dashed arrows between grey filled diamonds and open diamonds) in Figure 4.17. The SA-RES are significantly more depleted resulting from the removal of relatively ${ }^{14} \mathrm{C}$ enriched biomarkers dominated by short chain $n$-alkanoic acids and sterols (Figure 4.3 e ii). The Fairy site is the anomaly and this offset is much smaller and in the opposite direction. The SAE indicates less of a contribution of short chain $n$-alkanoic acids $(\sim 20 \%)$ compared to the other Ross Sea surface sediments ( $\sim 60-80 \%$; Figure $4.3 \mathrm{e}$ i)), which may cause this difference.

\subsubsection{Diagenetic Considerations}

The effects of diagenesis on the nature and distribution of $\mathrm{OM}$ in marine sediments was examined for select samples. In general, the significant offsets in ${ }^{14} \mathrm{C}$ and ${ }^{13} \mathrm{C}$ between bulk sediments and residues observed in surface sediments diminish at depth (e.g. ERM and WM4; Figure 4.18). In some samples, however, small isotopic offsets observed in the surface sediments are preserved with depth (SMB St. 2 and Chinstrap). Changes in the relative contributions of biomarkers with depth are also observed in some samples and help explain the isotopic offsets observed.

For organic-rich marine sediments from $\mathrm{BU}$, offsets in $\Delta{ }^{14} \mathrm{C}$ values between bulk sediment and residues observed in the surface sediment (Figure 4.13), are not observed at depth (13-15 cm; Figure 4.18) and instead the EX-RES and SA-RES are similarly depleted in ${ }^{14} \mathrm{C}$ and ${ }^{13} \mathrm{C}$ from the TOC. Analysis of the TLE indicates smaller relative contributions of short chain $n$-alkanoic acids at $13-15 \mathrm{~cm}$, and a corresponding increase of long chain $n$-alkanoic acids (Figure 4.3a) reflecting the increased lability of the former. The quantity of TOC that is extractable and saponifiable is also less at depth (Table 4.3), 
and thus removal of these pools of organic carbon (TLE and SAE) has less of an impact on the isotopic composition of the bulk organic carbon pool.

Pre-bomb sediments deposited in the depocenter $(10-11 \mathrm{~cm}$ interval, $185 \mathrm{yr} \mathrm{bp}$; Mollenhauer and Eglinton, 2004) of the SMB display a similar offset in $\Delta{ }^{14} \mathrm{C}$ between EX-RES and SA-RES to that observed in the surface sediment (Figure 4.13 and 4.18), again most likely due to the absence of easily extractable younger material (Table 4.2).

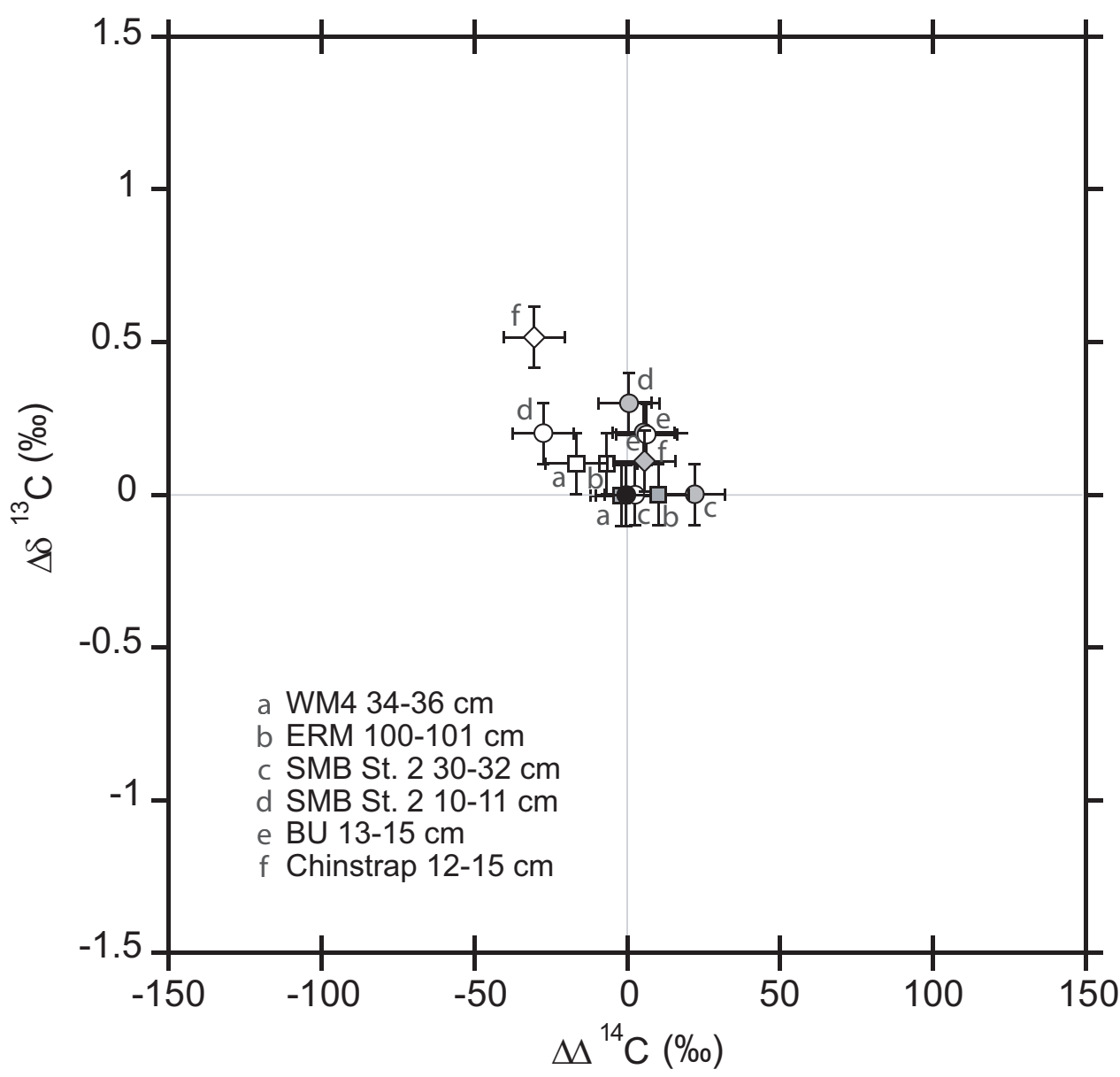

Figure 4.18 Differences in $\delta^{13} \mathrm{C}$ of the extracted residue (EX-RES; filled grey symbols) and saponified residue (SA-RES; open symbols) from $\delta^{13} \mathrm{C}$ of bulk sediment (TOC; filled black symbol) expressed as $\Delta \delta^{13} \mathrm{C} \%$ vs. the differences in $\Delta^{14} \mathrm{C}$ of the EX-RES and SARES from the TOC expressed as $\Delta \Delta^{14} \mathrm{C} \%$ for sediment horizons below the surface mixed layer. Error bars represent $0.1 \%$ error for $\delta^{13} \mathrm{C}$ values and $10 \%$ error for $\Delta^{14} \mathrm{C}$. 
Short chain $n$-alkanoic acids contribute less to the TLE and SAE $(\sim 20 \%)$ at $10-11 \mathrm{~cm}$ compared to $0-1 \mathrm{~cm}(\sim 60 \%$ and $\sim 70 \%$ respectively) and instead there is a greater contribution of alkanes to the TLE ( $20 \%)$ and sterols to the SAE ( 70\%; Figure 4.3a i)). This decrease in contribution of the short chain $n$-alkanoic acids, indicates that there may be some post depositional degradation occurring, although this is not conclusive without comparison to an equivalent periphery sediment horizon. It is also possible that changes in source function may give rise to these differences.

Sediments from the depocenter deposited under oxic conditions prior to the switch to dysoxia were also examined (30-32 cm interval, corresponding to $545 \mathrm{yr} \mathrm{bp}$; Mollenhauer and Eglinton, 2004) and show significantly lower contributions of short chain $n$-alkanoic acids $(\sim 3 \%)$ and higher proportions of plant wax $n$-alkanes $(\sim 70 \%$; Figure 4.3a), the latter having a CPI of 2.9 (Figure 4.4). This decrease in $n$-alkanoic acids may be due to either diagenesis and/or the higher bottom water concentrations of oxygen when these sediments were deposited that would result in enhanced degradation of these compounds. Compared to the periphery sediments, however, the contribution of short chain $n$-alkanoic acids is still very low suggesting that this difference has to be due to significantly higher bottom water oxygen at the depocenter relative to the periphery. The isotopic offset between the EX-RES and TOC at 30-32 is similar to that observed in the surface sediment (Figure 4.13 and 4.18) and the EX-RES is more ${ }^{14} \mathrm{C}$-enriched relative to the TOC, although no accompanying enrichment in $\delta^{13} \mathrm{C}$ is observed. There is also no significant offset in either $\delta^{13} \mathrm{C}$ or $\Delta^{14} \mathrm{C}$ between SA-RES and TOC at this depth.

There are subtle shifts in biomarker contributions in the extracts of WM4 0-1 cm compared to $34-36 \mathrm{~cm}$ sediments (Figure 4.3b) and the contribution of short chain $n$ alkanoic acids halves from $\sim 40$ to $\sim 20 \%$ with depth whereas long chain $n$-alkanoic acids and $n$-alkanols contribute more significantly. Sterol contributions also decrease with depth from $\sim 35$ to $\sim 15 \%$ in the TLE, but increase in the bound pool from 40 to $60 \%$. Significant offsets in isotopic composition are not observed between TOC and EX-RES, but the SA-RES is relatively more ${ }^{14} \mathrm{C}$-depleted relative to the TOC similar to general observations for the surface sediment (Figure 4.14$)$. The $\delta^{13} \mathrm{C}$ is invariant $(\sim-22 \%$ ) 
between WM4 sediment residues and with depth (Figure 4.18), and thus we can infer that diagenesis does not appear to have a significant effect on the isotopic composition of the sediments at this site. It is of interest to note that WM4 is positioned at the depocenter of the slope and the main degradation may have taken place during lateral transport to this site.

The large offset between TOC and EX-RES observed in the surface sediment of ERM is not observed at depths of 100-101 cm (Figure 4.18), corresponding to circa 1830 a.d. (N. Drenzek, Pers. Comm.). The distribution of $n$-alkanes at 100-101 cm suggests a larger terrestrial and smaller contribution of petrogenic hydrocarbons relative to that contributing to the surface sediment, and this is reflected in the CPI (2.1; Figure 4.5). A relative decrease in the contribution of short chain $n$-alkanoic acids is also observed with depth ( $2 \%$ compared to $35 \%$ in the surface sediment), but significant differences are not observed for the SAE with depth (Figure 4.3b ii). Less material is solvent extractable at 100-101 cm compared to the surface sediment ( $\sim 5$ and 50\% respectively; Table 4.3$)$ and this, coupled with differences in biomarker contributions, may reflect a change in the type of OM supplied from the Eel River as opposed to a diagenetic trend. Increased sediment accumulation rates, finer sediments and increased preservation of flood-layers have been observed for the Eel shelf since AD 1950 and attributed to climate, specifically increases in flood magnitude and frequency (Sommerfield et al., 2002). More recently, it has been suggested that these differences are due to wet conditions coupled with increased sediment supply as a result of timber harvesting (Leithold and Blair, 2001). Considering all major OC sources to the ERM (terrestrial, kerogen and marine), only the terrestrial source has been found to consistently change over time and the pre-1950s contribution of terrestrial material relative to bedrock was found to be greater (Leithold and Blair, 2001). This supports observations from the $n$-alkane data in this study. It therefore appears likely that in this instance the absence of isotopic offset between TOC and EX-RES at 100-101 $\mathrm{cm}$ may be due to a shift in OM type.

For Antarctic sediments from the Chinstrap site, differences in $\delta^{13} \mathrm{C}$ and $\Delta{ }^{14} \mathrm{C}$ between sediments and residues for sediment from 12-15 cm (Figure 4.18) are similar to 
those observed for $0-2 \mathrm{~cm}$ (Figure 4.17). Analysis of the extracts released by the sequential treatments indicates a significant increase in the relative contribution of sterols at $12-15 \mathrm{~cm}$ to the SAE (Figure 4.3). This suggests that sediments deposited at this depth likely have a more significant input from fresh marine organic matter than those deposited at 0-2 cm, which are likely more diluted by allochthonous inputs.

\subsection{CONCLUSIONS}

Differences in $\Delta^{14} \mathrm{C}$ and molecular composition of different $\mathrm{OM}$ fractions in sediments are evident at a variety of sites with different depositional settings. Only a small fraction of $\mathrm{OM}$ present in sediments is GC-amenable, and thus differences in isotopic compositions between bulk sediments and residues provides information regarding the composition of pools of OC that are undetectable by conventional geochemical techniques.

The findings of this study compare well with previous work that has examined the $\Delta^{14} \mathrm{C}$ of different $\mathrm{OM}$ fractions. Analysis of detrital aggregates, sediment floc and sediments, revealed ${ }^{14} \mathrm{C}$-depleted total lipids pools relative to individual amino acid and carbohydrate fractions (Wang and Druffel, 1996; Wang et al., 1998). This is similar to observations in organic-rich marine sediments where in general, the EX-RES is more enriched relative to the TOC as a result of the removal of labile, ${ }^{14} \mathrm{C}$-depleted lipids. A comparative study between sediments from the Southern Ocean and NE Pacific indicates that a 'younger' more labile organic matter pool consisting of amino acids and carbohydrates was being preserved with depth at the NE Pacific site where sedimentation rates and TOC contents were higher suggesting protection of these more labile compounds by sorption onto particle surfaces (Wang and Druffel, 2001). This is similar to the findings of this study that provides evidence for the protection of ${ }^{14} \mathrm{C}$-enriched labile marine organic carbon (predominantly short chain $n$-alkanoic acids) that are associated with insoluble sediment residues. 
It is important to reiterate that systematic variations in isotopic compositions are not only observed within specific depositional settings, such as organic-rich marine sediments, but also between these groupings. The two most obvious examples of this are the similarities observed between Arctic and Antarctic samples (excluding Emperor) and between ERM (0-1 cm), Guaymas basin and the Emperor site. The former group is characterized by the presence of non-hydrolyzable fossil carbon that gives rise to extremely depleted $\Delta{ }^{14} \mathrm{C}$ values for the bulk unextracted sediment. These $\Delta{ }^{14} \mathrm{C}$ values become successively more depleted as relatively ${ }^{14} \mathrm{C}$ - enriched material is removed by the sequential chemical treatments at each step. The latter group are also controlled by the presence of fossil carbon, but in these environments it is solvent-extractable and the depleted $\Delta^{14} \mathrm{C}$ of the bulk unextracted sediment becomes more enriched as this fossil carbon is removed by the sequential chemical treatments. Comparisons such as this across different depositional settings are extremely valuable and increase our understanding of the nature and distribution of organic matter in marine sediments.

To summarize this broad array of data, it is important to consider the global significance of this work. The majority of OC burial in the contemporary marine environment occurs on open shelf and slope margins $(\sim 45 \%)$ as well as deltaic sediments ( $44 \%$; Hedges and Keil 1995). No significant offset in $\Delta{ }^{14} \mathrm{C}$ between the TOC and the EX-RES is observed for the majority of surface sediments from these environments examined in this study $(n=7)$. The EX-RES from other surface sediments from these environments ( $\mathrm{n}=6$ ) can, however, be relatively ${ }^{14} \mathrm{C}$-depleted compared to the TOC due to the removal of relatively ${ }^{14} \mathrm{C}$-enriched material that has been more recently synthesized and may be terrestrial in origin, as in WM sediments. These observations in $\Delta{ }^{14} \mathrm{C}$ offsets between TOC and EX-RES are by far the most common observed in this study, and can be expected to apply for $\sim 90 \%$ of organic carbon buried in contemporary marine sediments. The main exception arises from inputs of fossil carbon and in sediments from ERM, GB and RS Emperor, the EX-RES is more ${ }^{14} \mathrm{C}$-enriched relative to the TOC due to the removal of fossil-derived carbon that contains no ${ }^{14} \mathrm{C}$. Organic-rich marine sediments either display no offset in ${ }^{14} \mathrm{C}$ between the TOC and EX-RES ( $\left.\mathrm{n}=2\right)$ or the EX-RES is 
slightly enriched relative to the TOC $(n=2)$ due to the removal of material slightly depleted in ${ }^{14} \mathrm{C}$. These highly productive environments are, however, not as significant as shelf, slope and deltaic systems and are only responsible for $\sim 5 \%$ of global organic carbon burial (Hedges and Keil, 1995). For the majority $(n=13)$ of surface sediments examined in this study, independent of depositional setting, the SA-RES is more ${ }^{14} \mathrm{C}$ depleted compared to the EX-RES. This indicates that the protection of relatively ${ }^{14} \mathrm{C}$ enriched material of predominantly marine algal origin, is a widespread phenomenon. It is clear that ${ }^{14} \mathrm{C}$ analysis provides a powerful tool for determining both the source and fate of marine, terrestrial and fossil organic carbon in the marine environment as well as enhancing our understanding of the general distribution of organic carbon in contemporary marine sediments.

\subsection{REFERENCES}

Arrigo, K.R., McClain, C.R., 1994. Spring phytoplankton production in the western Ross Sea. Science 266, 261-263.

Arthur, M.A., Dean, W.E., Laarkamp, K., 1998. Organic carbon accumulation and preservation in surface sediments on the Peru margin. Chemical Geology 152, 273286.

Blair, N. E., Leithold, E.L., Ford, S.T., Peeler, K.A., Holmes, J.C., Perkey, D.W. 2003. The persistence of memory: The fate of ancient sedimentary organic carbon in a modern sedimentary system. Geochimica et Cosmochimica Acta 67, 63-73.

Blair, N.E., Leithold, E.L., Aller, R.C., 2004. From bedrock to burial: the evolution of particulate organic carbon across coupled watershed-continental margin systems. Marine Chemistry 92, 141-156.

Brassell, S.C., Eglinton, G., 1980. Environmental Chemistry; an interdisciplinary subject; natural and pollutant organic compounds in contemporary aquatic environments. In: Albaiges, J. (Ed.), Analytical Techniques in Environmental Chemistry, Pergamon series on Environmental Science, vol. 3, pp. 1-22.

Carey, D.A., Mayer, L.M., 1990. Nutrient uptake by deposit-feeding enteropneust: nitrogenous sources. Marine Ecology Progress Series 63, 79-84.

Collister, J.W., Rieley, G., Stern, B., Eglinton, G., Fry, B., 1994. Compound-specific $\delta^{13} \mathrm{C}$ analyses of leaf lipids from plants with different carbon dioxide metabolisms. Organic Geochemistry 21, 619-627. 
Drenzek, N.J., Montluçon, D.B., Yunker, M.B., Macdonald, R.W., Eglinton, T.I. 2005. A coupled molecular isotope approach to constraining the origin of sedimentary organic carbon in the Beaufort Sea. Submitted.

Dunbar, R.B., Anderson, J.B., Domack, E.W., 1985. Antarctic Research Series: Oceanology of the Antarctic Continental Shelf. AGU, pp. 291-312.

Eglinton, T. I., Benitez-Nelson, B.C., Pearson, A., McNichol, A.P., Bauer, J.E., Druffel, E.R.M. 1997. Variability in radiocarbon ages of individual organic compounds from marine sediments. Science 277, 796-799.

Farrington, J.W., Quinn, J.G., 1971. Comparison of sampling and extraction techniques for fatty acids in recent sediments. Geochimica et Cosmochimica Acta 35, 735-741.

Fry, B., Sherr, E.B. 1984. $\delta^{13}$ C measurements as indicators of carbon flow in marine and freshwater ecosystems. Contributions in Marine Science 27, 13-47.

Gong, C., Hollander, D.J. 1997. Differential contribution of bacteria to sedimentary organic matter in oxic and anoxic environments, Santa Monica Basin, California. Organic Geochemistry 26, 545-563.

Gong, C., Hollander, D.J. 1999. Evidence for differential degradation of alkenones under contrasting bottom water oxygen conditions: Implication for paleotemperature reconstruction. Geochimica et Cosmochimica Acta 63, 405-411.

Goñi, M.A., Yunker, M.B., Macdonald, R.W., Eglinton, T.I. 2005. The supply and preservation of ancient and modern components of organic carbon in the Canadian Beaufort Shelf of the Arctic Ocean. Marine Chemistry 93, 53-73.

Hedges, J. I., Keil, R. G. 1995. Sedimentary organic matter preservation: an assessment and speculative synthesis. Marine Chemistry 49, 81-115.

Hedges, J. I., Eglinton, G., Hatcher, P.G., Kirchman, D.L., Arnosti, C., Derenne, S., Evershed, R.P., Kögel-Knaber, I., de Leeuw, J.W., Littke, R., Michaelis, W., Rullkötter, J. 2000. The molecularly-uncharacterized component of nonliving organic matter in natural environments. Organic Geochemistry 31, 945-958.

Hickey, B.M. 1992. Circulation over the Santa Monica-San Pedro Basin and Shelf. Journal of Geophysical Research 96, 16,689-16,708.

Hollander, D.J., Smith, M.A. 2001. Microbially mediated carbon cycling as a control on the $\delta^{13} \mathrm{C}$ of sedimentary carbon in eutrophic Lake Mendota (USA): New models for interpreting isotopic excursions in the sedimentary record. Geochimica et Cosmochimica Acta 64, 4321-4337.

Hwang, J., Druffel, E.R.M., Komada, T. 2005. Transport of organic carbon from the California coast to the slope region: A study of $\Delta^{14} \mathrm{C}$ and $\delta^{13} \mathrm{C}$ signatures of organic compound classes. Global Biogeochemical Cycles 19, GB2018.

Keil, R.G., Hedges, J.I. 1993. Sorption of organic matter to mineral surfaces and the preservation of organic matter in coastal marine sediments. Chemical Geology 107, 385-388.

Knicker, H., Hatcher, P.G. 1997. Survival of protein in an organic-rich sediment: Possible protection by encapsulation in organic matter. Naturwissenschaften 84, 231234. 
Laarkamp, K. 2000. Organic phosphorous in marine sediments: Chemical structure, diagenetic alteration and mechanisms of preservation. Ph.D., Massachusetts Institute of Technology / Woods Hole Oceanographic Institution.

Lee, C., Gagosian, R.B., Farrington, J.W. 1977, Sterol diagenesis in recent sediments from Buzzards Bay, Massachusetts. Geochimica et Cosmochimica Acta 41, 985-992.

Leithold, E.L., Perkey, D.W., Blair, N.E., Creamer, T.N. 2005. Sedimentation and carbon burial on the northern California continental shelf: the signatures of land-use change. Continental Shelf Research 25, 349-371.

Lima, A.L.C., Eglinton, T.I., Reddy, C.M., 2003. High-resolution record of pyrogenic polycyclic aromatic hydrocarbon deposition during the $20^{\text {th }}$ century. Environmental Science and Technology 37, 53-61.

Macdonald, R.W., Iseki, K., O'Brien, M.C., McLaughlin, F.A., McCullough, D., Macdonald, D.M., Carmack, E.C., Adams, H., Yunker, M.B., Miskulin, G., Buckingham, S., 1988. NOGAP B.6; Volume 4: Chemical data collected in the Beaufort Sea, Summer, 1987. Canadian Data Report of Hydrography and Ocean Sciences, 60, 1-103.

Macdonald, R.W., Sieberg, D., Pearson, R., Paton, D., O'Brien, M.C., McLaughlin, F.A., Carmack, E.C., 1992. Oceanographic data collected from the Henry Larsen in the Beaufort Sea, September 1991. Canadian Data Report of Hydrography and Ocean Sciences, 112, 1-108.

Macdonald, R.W., Solomon, S.M., Cranston, R.E., Welch, H.E., Yunker, M.B., Gobeil, C., 1998. A sediment and organic carbon budget for the Canadian Beaufort shelf. Marine Geology 144, 255-273.

Masiello, C.A., Druffel, E.R.M., 2001. Carbon isotope geochemistry of the Santa Clara River. Global Biogeochemical Cycles 15, 407-416.

Masiello, C.A., Druffel, E.R.M., 2003. Organic and black carbon C-13 and C-14 through the Santa Monica Basin sediment oxic-anoxic transition. Geophysical Research Letters 30, 1185.

McNichol, A.P., Osborne, E.A., Gagnon, A.R., Fry, B., Jones, G.A. 1994. TIC, TOC, DIC, DOC, PIC, POC-unique aspects on the preparation of oceanographic samples for ${ }^{14} \mathrm{C}$-AMS. Nuclear Instruments and Methods in Physics Research B92, 162-165.

Middleburg, J.J., Nieuwenhuize, J., Lubberts, R.K., van de Plassche, O. 1997. Organic carbon isotope systematics of coastal marshes. Estuarine, Coastal and Shelf Science 45, 681-687.

Mollenhauer, G., Eglinton, T.I., Ohkouchi, N., Schneider, R.R., Müller, P.J., Grootes, P.M., Rullkötte, J. 2003. Asynchronous alkenone and foraminifera records from the Benguela Upwelling system. Geochimica et Cosmochimica Acta 67, 2157-2171.

Mollenhauer, G., Eglinton, T.I. 2004. Radiocarbon content of alkenones, foraminifera and bulk organic carbon in oxic and anoxic sediments from the California Borderland basins. Gordon Conference, Portsmouth, NH, August 2004.

Mollenhauer, G., Kienast, M., Lamy, F., Meggers, H., Schneider, R.R., Hayes, J.M., Eglinton, T.I. 2005. An evaluation of ${ }^{14} \mathrm{C}$ age relationships between co-occurring foraminifera, alkenones, and total organic carbon in continental margin sediments. Paleoceanography 20, PA1016. 
Nittrouer, C.A., 1978. The Process of Detrital Sediment Accumulation in a Continental Shelf Environment: An Examination of the Washington Shelf. Ph.D. dissertation, University of Washington, pp. 243.

Ohkouchi, N., Eglinton, T.I., Hayes, J.M., 2003. Radiocarbon dating of individual fatty acids as a tool for refining Antarctic margin sediment chronologies. Radiocarbon 45, $17-24$.

Pearson, A., Eglinton, T.I., 2000. The origin of $n$-alkanes in Santa Monica Basin surface sediment: a model based on compound-specific $\Delta^{14} \mathrm{C}$ and $\delta{ }^{13} \mathrm{C}$ data. Organic Geochemistry 31, 1103-1116.

Pearson, A., Seewald, J.S., Eglinton, T.I., 2005. Bacterial incorporation of relict carbon in the hydrothermal environment of Guaymas Basin. Geochimica et Cosmochimica Acta 69, 5477-5486.

Prahl, F.G., Ertel, J.R., Goni, M.A., Sparrow, M.A., Eversmeyer, B., 1994. Terrestrial organic carbon contributions to sediments on the Washington Margin. Geochimica et Cosmochimica Acta 58, 3035-3048.

Reddy, C.M., Eglinton, T.I., Hounshell, A.H., White, H.K., Xu, L., Gaines, R.B., Frysinger, G.S., 2002. The West Falmouth oil spill after thirty years: The persistence of petroleum hydrocarbons in marsh sediments. Environmental Science and Technology 36, 4754-4760.

Sauer, P.E., Eglinton, T.I., Hayes, J.M., Schimmelmann, A., Sessions, A.L., 2001. Compound-specific $\mathrm{D} / \mathrm{H}$ ratios of lipid biomarkers from sediments as a proxy for environmental and climatic conditions. Geochimica et Cosmochimica Acta 65, 213222.

Schwartz, M. L., 1991. Net Shore-Drift in Washington State: Volume 3, Central Puget Sound Region. Shorelands and Coastal Zone Management Program, Washington State Department of Ecology, Olympia, WA.

Simoneit, B.R.T., Leif, R.N., Sturz, A.A., Sturdivant, A.E., Gieskes J.M., 1992. Geochemistry of shallow sediments in Guaymas Basin, Gulf of California: Hydrothermal gas and oil migration and effects of mineralogy. Organic Geochemistry $18,765-784$.

Sommerfield, C.K., Nittrouer, C.A., 1999. Modern accumulation rates and a sediment budget for the Eel shelf: a flood-dominated depositional environment. Marine Geology 154, 227-241.

Sommerfield, C.K., Drake, D.E., Wheatcroft, R.A. 2002. Shelf record of climatic changes in flood magnitude and frequency, north-coastal California. Geology 30, 395-398.

Stuiver, M., Polach, H.A., 1977. Discussion: reporting of 14C data. Radiocarbon 19, 355363.

Sun, M-Y., Wakeham, S.G. 1994. Molecular evidence for degradation and preservation of organic matter in the anoxic Black Sea basin. Geochimica et Cosmochimica Acta 58, 3395-3406.

Volkman J.K. 2005. Sterols and other triterpenoids: source specificity and evolution of biosynthetic pathways. Organic Geochemistry 36, 139-159. 
Wang, X.-C., Druffel, E.R.M. 1996. Radiocarbon in organic compound classes in particulate organic matter and sediment in the deep northeast Pacific Ocean. Geophysical Research Letters 23, 3583-3586.

Wakeham, S.G., 1999. Monocarboxylic, dicarboxylic and hydroxy acids released by sequential treatments of suspended particles and sediments of the Black Sea. Organic Geochemistry 30, 1059-1074.

White, H.K., Reddy, C.M., Eglinton, T.I., 2005. Isotopic constraints on the fate of petroleum residues sequestered in salt marsh sediments. Environmental Science and Technology 39, 2545-2551.

Yunker, M.B., Macdonald, R.W., Cretney, W.J., Fowler, B.R., McLaughlin, F.A. 1993. Alkane, terpene and polycyclic aromatic hydrocarbon geochemistry of the Mackenzie River and Mackenzie shelf: Riverine contributions to Beaufort Sea coastal sediment. Geochimica et Cosmochimica Acta 57, 3041-3061.

Zegouagh, Y., Derenne, S., Largeau, C., Saliot, A., 1996. Organic matter sources and early diagenetic alterations in Arctic surface sediments (Lena River delta and Laptev Sea, Eastern Siberia) - I. Analysis of the carboxylic acids released via sequential treatments. Organic Geochemistry 24, 841-857. 


\subsection{APPENDIX}




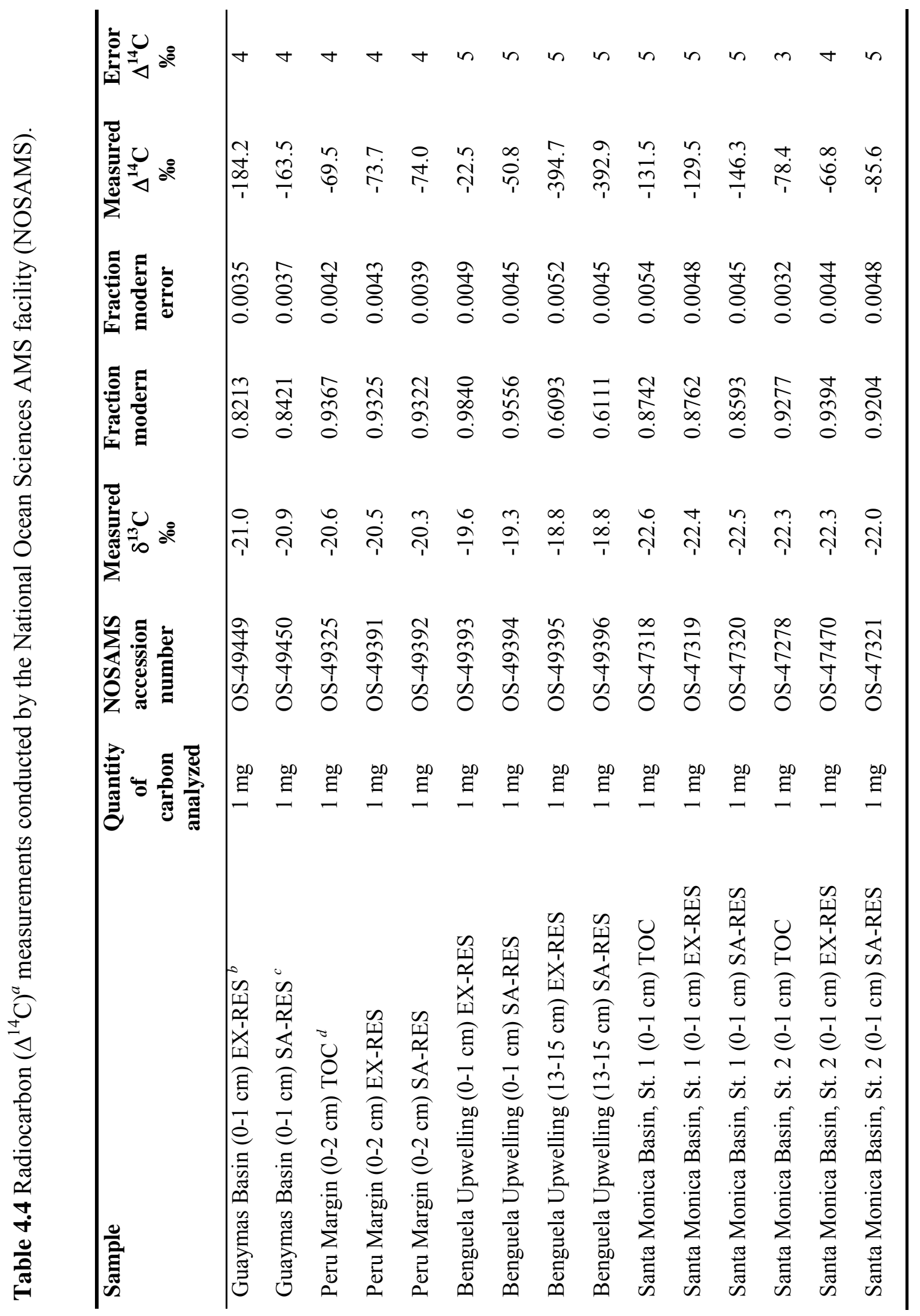




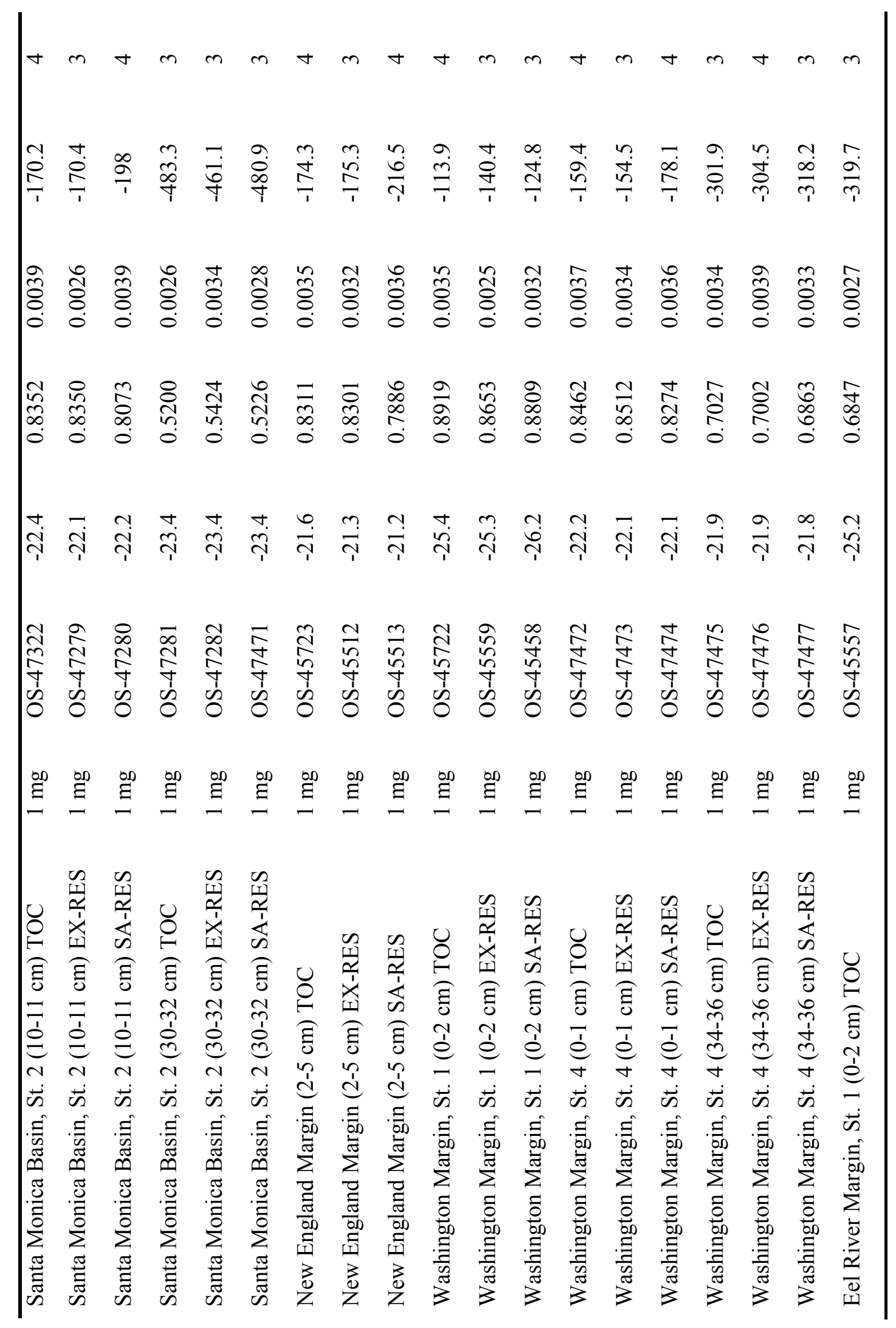




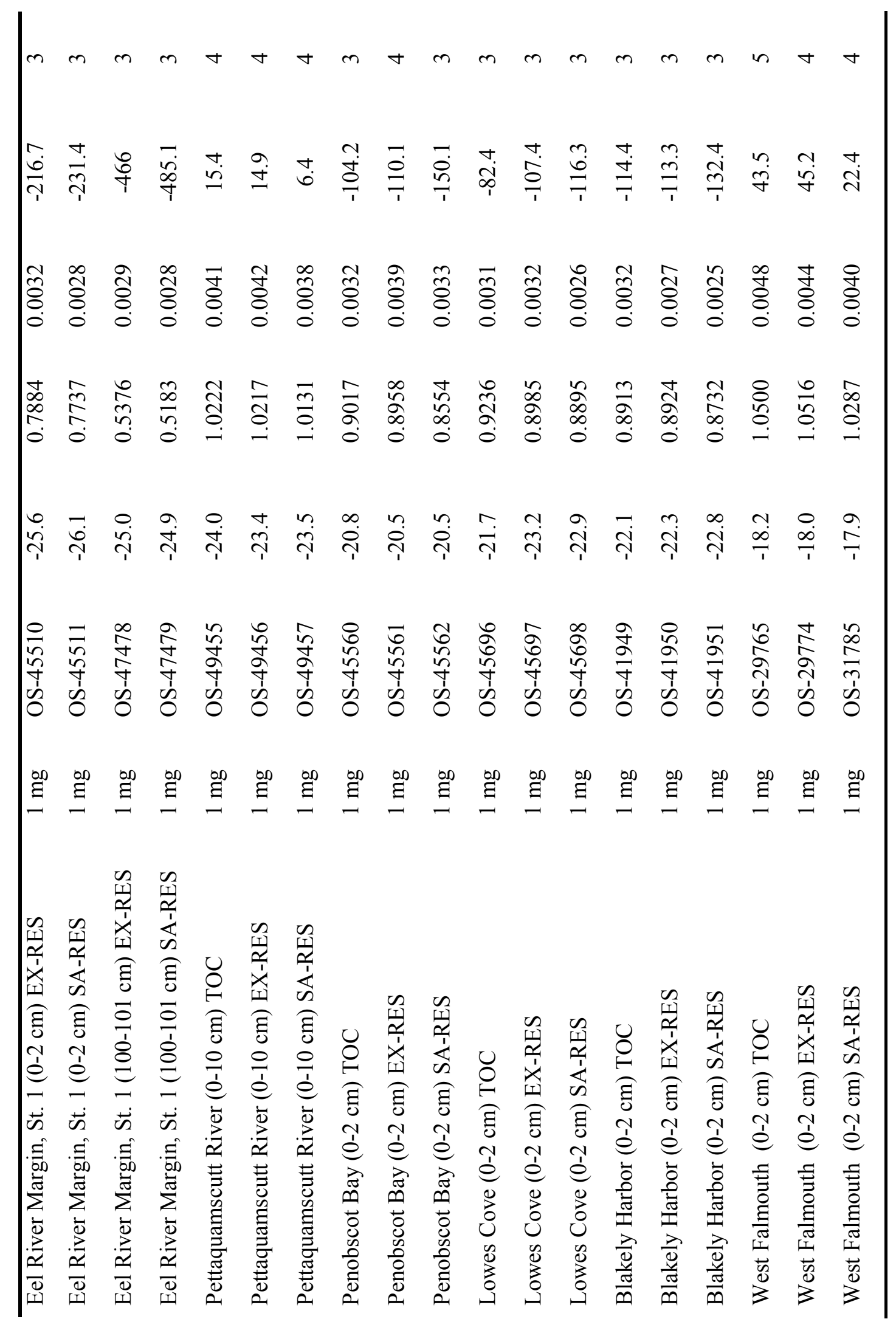




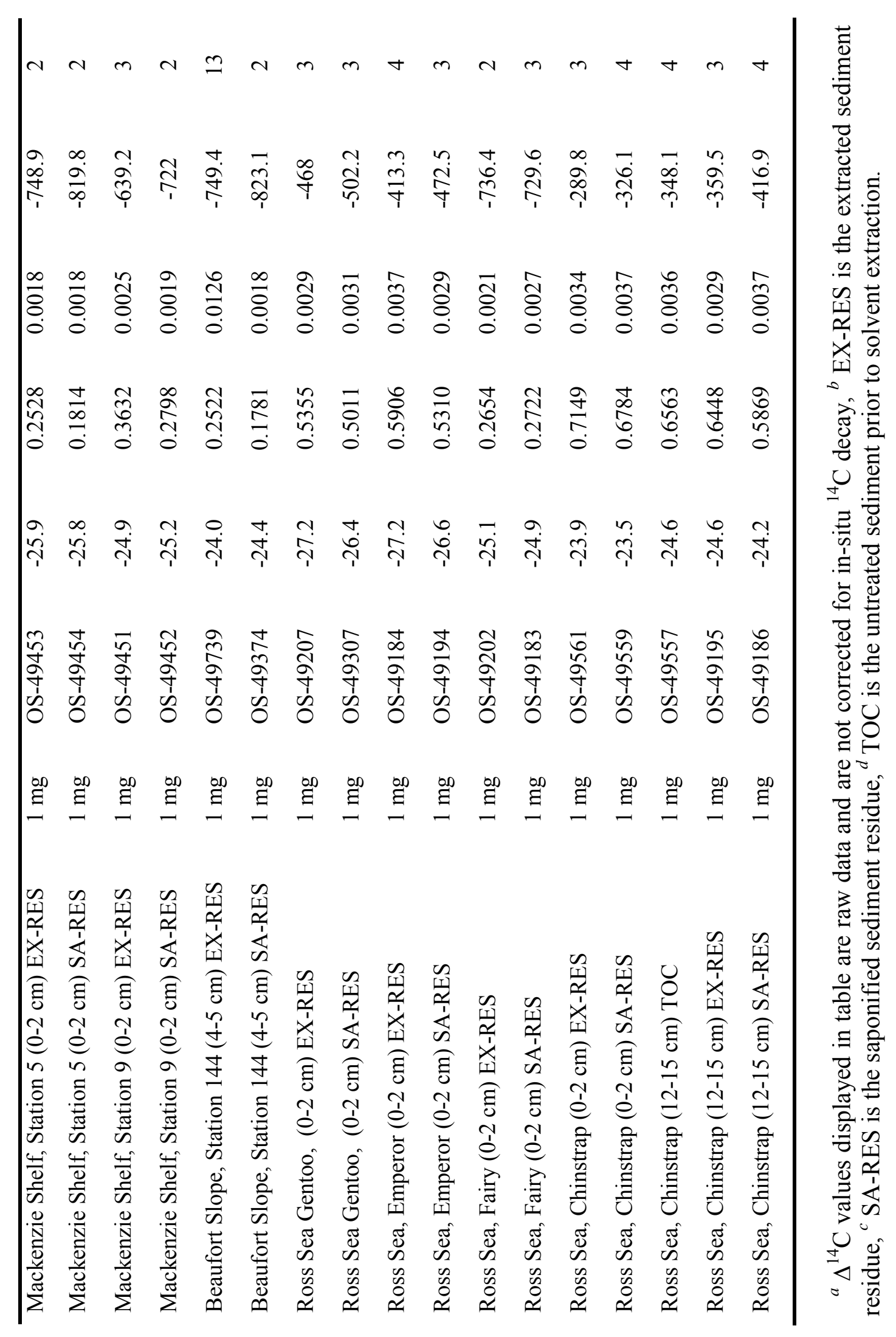




\title{
CHAPTER 5
}

\section{RADIOCARBON AS AN INVERSE TRACER OF FOSSIL FUEL-DERIVED CONTAMINANTS IN SEDIMENTS}

\begin{abstract}
We have exploited natural abundance variations in radiocarbon $\left({ }^{14} \mathrm{C}\right)$ as an inverse tracer of fossil fuel-derived contaminants $\left({ }^{14} \mathrm{C}\right.$ free) within different chemically defined fractions of contemporary organic materials (OM) (modern ${ }^{14} \mathrm{C}$ content) from select marine and freshwater sediments. Hydrophobic organic contaminants (HOCs) are known to interact with $\mathrm{OM}$, but these processes are difficult to follow and quantitatively constrain. Using natural abundance ${ }^{14} \mathrm{C}$ measurements it is possible to make quantitative assessments through the principle of isotope mass balance. This study focuses on sediments impacted by various fossil fuel-derived HOCs including petroleum, creosote, coal tar, polychlorinated biphenyls (PCBs), benzotriazoles (BZTs), 2,2bis(chlorophenyl)-1,1,1-trichlorethane (DDT) and other chlorinated pesticides. A mineral oil contaminated soil and an urban aerosol sample have also been examined. The samples were sequentially chemically treated, first by solvent extraction and then saponification to examine the quantity of HOC and/or its derivatives present in both the extractable and unextractable fractions. Radiocarbon analysis of the original bulk sample and residues resulting from the sequential treatments was performed to trace HOCs and their metabolites in the different pools of OM. The resulting extracts were examined using gas chromatography/mass spectrometry (GC/MS) to identify and quantity HOCs and/or metabolites released from the sequential treatments. For most samples, the majority of fossil fuel-derived carbon is solvent extractable, but at a few sites either chemical or isotopic evidence indicates varying quantities of HOCs and/or derivatives present within the insoluble residues. The quantities of these nonextractable HOCs are for the most part,
\end{abstract}


not significant, and thus incorporation of HOCs into insoluble sediment residues cannot be considered an important sink in aquatic sediments. This suggests that the ability of HOCs to persist in the environment is likely controlled by physical associations as opposed to chemical linkages. In this form, HOCs may be more available to biota and more likely to be subjected to transport processes, especially if sediment conditions change e.g. if the sediment is resuspended and remobilized. Overall, the lack of significant incorporation of HOCs into nonextractable residues suggests that these compounds have a greater potential to exert longer-term adverse affects on the sedimentary environment in which they persist.

\subsection{INTRODUCTION}

Elucidating the nature of interactions between hydrophobic organic contaminants (HOCs) and organic matter (OM) is of great importance for determining the fate of xenobiotics in the environment. Much of the work to date has focused on soils contaminated with polycyclic aromatic hydrocarbons (PAHs) (Richnow et al., 1994, 1995, 1997, 1998, 1999 and 2000) and other HOCs such as pesticides (Gevao et al., 2000 and references therein), fumigants (Xu et al., 2003), the fungicide cyprodinil (Dec et al., 1997), 2,4,6-trinitrotoluene (TNT) (Eriksson et al., 2004), and polychlorinated biphenyls (PCBs) (Kohl and Rice, 1998). Experimental and analytical techniques for determining the presence of bound HOCs and their residues vary (Northcott and Jones, 2000 and references therein), but in most instances, specific interactions are determined by sequential chemical treatments. Typically, samples are first solvent extracted to isolate compounds with non-covalent associations to OM, such as hydrophobic sorption, charge transfer complexes and hydrogen bonding. The HOCs and residues released from this process are referred to as "free" or "unbound" and those that remain associated with the $\mathrm{OM}$ are defined as "nonextractable" or "bound". Subsequent chemical treatments performed on the remaining extracted soil residues or humic fractions target linkages by specific types of covalent bond between HOCs and OM. Alkaline or acid hydrolysis 
methods are specifically aimed at cleaving ester bonds (Richnow et al., 1994, 1997, 1998 and 2000), and harsher degradation techniques such as boron trichloride degradation and hydrogenolysis with rhodium-on-charcoal target ether as well as ester linkages (Richnow et al., 1994). Analytical pyrolysis and thermal desorption methods have also been employed to release compounds associated by carbon-carbon bonds as well as other bonds (Richnow et al., 1995; Northcott and Jones 2000, and references therein). It is important to note that not all nonextractable residues are covalently associated to OM and some may be physically entrapped in OM or mineral matrices (Gevao et al., 2000 and references therein) and only released when the matrices themselves are altered by chemical treatments.

For covalent binding to occur, the contaminant or its metabolic intermediate must possess a functional group, such as hydroxyl, carboxyl, nitro, amino or phosphate group or other reaction center. The functional group of a contaminant will largely determine its reactivity towards $\mathrm{OM}$, and it has been demonstrated in soils that phenolic and aniline compounds have the greatest tendency to form bound residues (Roberts, 1984). Simple hydrocarbons, however, are relatively inert and undergo the same fate only after a preliminary attack and oxidation by microorganisms (Northcott and Jones, 2000).

The formation of nonextractable residues in soils can be quantitatively significant, and as much as $70 \%$ of anthracene and/or its metabolites have been demonstrated to bind to soil OM in aerobic microcosm experiments (Richnow et al., 1998). This quantity, however, is highly variable and in a separate incubation of phenanthrene, only $\sim 6 \%$ of the corresponding metabolites became bound (Richnow et al., 2000). This difference is likely due to variations in soil microflora and the efficiency of microorganisms to metabolize different PAHs into more reactive metabolites that can subsequently bind to OM. Bound residue formation, however, has been proposed as a major sink for HOCs in soils and has been considered as a bioremediation strategy (Dec and Bollag, 1997). Interactions between HOCs and OM have not been examined as extensively in aquatic sediments, but initial studies suggest that binding is a potentially important sink (Beller and Simoneit, 1988; Richnow et al., 1994; Reddy et al., 2000a; Schwarzbauer et al., 2003). Aquatic 
sediments, however, provide a very different chemical and microbial environment to that found in soils (White et al., 2005) and it is therefore of interest to determine whether the significance of binding in soils can be extrapolated to sediments.

Natural abundance variations in radiocarbon content $\left(\Delta^{14} \mathrm{C}\right)$ have previously been used to trace fossil fuel or petrochemical-derived HOCs into various pools of organic matter (Reddy et al., 2002a; White et al., 2005) as well as enabling quantitative assessments of fossil carbon contributions through the principle of isotope mass balance (Pearson and Eglinton, 2000; Petsch et al., 2001). The absence of ${ }^{14} \mathrm{C}$ in fossil-fuelderived contaminants serves as an inverse tracer intrinsic to the contaminant, thereby negating the need to use a labeled derivative that may not accurately reflect in situ processes (Steinberg et al., 2003). The sensitivity of this approach is an important consideration and in general, with a conservative estimate of analytical error of $10 \%$, at least $1 \%$ of organic carbon in a particular organic matter pool of interest must be fossil fuel derived for it to significantly influence the overall $\Delta^{14} \mathrm{C}$ (White et al., 2005). The inverse tracer approach has been previously applied to anaerobic salt marsh sediments to determine the fate of petroleum residues persisting in sediments for over 30 years (White et al., 2005). At this site, significant binding to $\mathrm{OM}$ was not observed, and this was attributed to the relatively inert nature of the petroleum residues and the lack of more reactive metabolites resulting from the absence of active biodegradation at the site (Slater et al., 2005). Understanding whether more reactive HOCs, or HOCs in more reactive sediments (e.g. aerobic as opposed to anaerobic), would give rise to more significant binding of HOCs to OM is therefore of interest. To explore this, we have collected surface sediments from a variety of locations contaminated with petroleum, creosote, coal tar, polychlorinated biphenyls (PCBs), benzotriazoles (BZTs), 2,2-bis(chlorophenyl)1,1,1-trichloroethane (DDT) and other chlorinated pesticides.

In petroleum contaminated sediments, PAHs such as naphthalene and phenanthrene and their alkylated derivatives are of interest due to their toxicity to organisms, as well as the potential of their corresponding metabolic intermediates to bind to OM (Richnow et al., 1994, 1995, 1997, 1998, 1999, 2000). The structure of the parent 


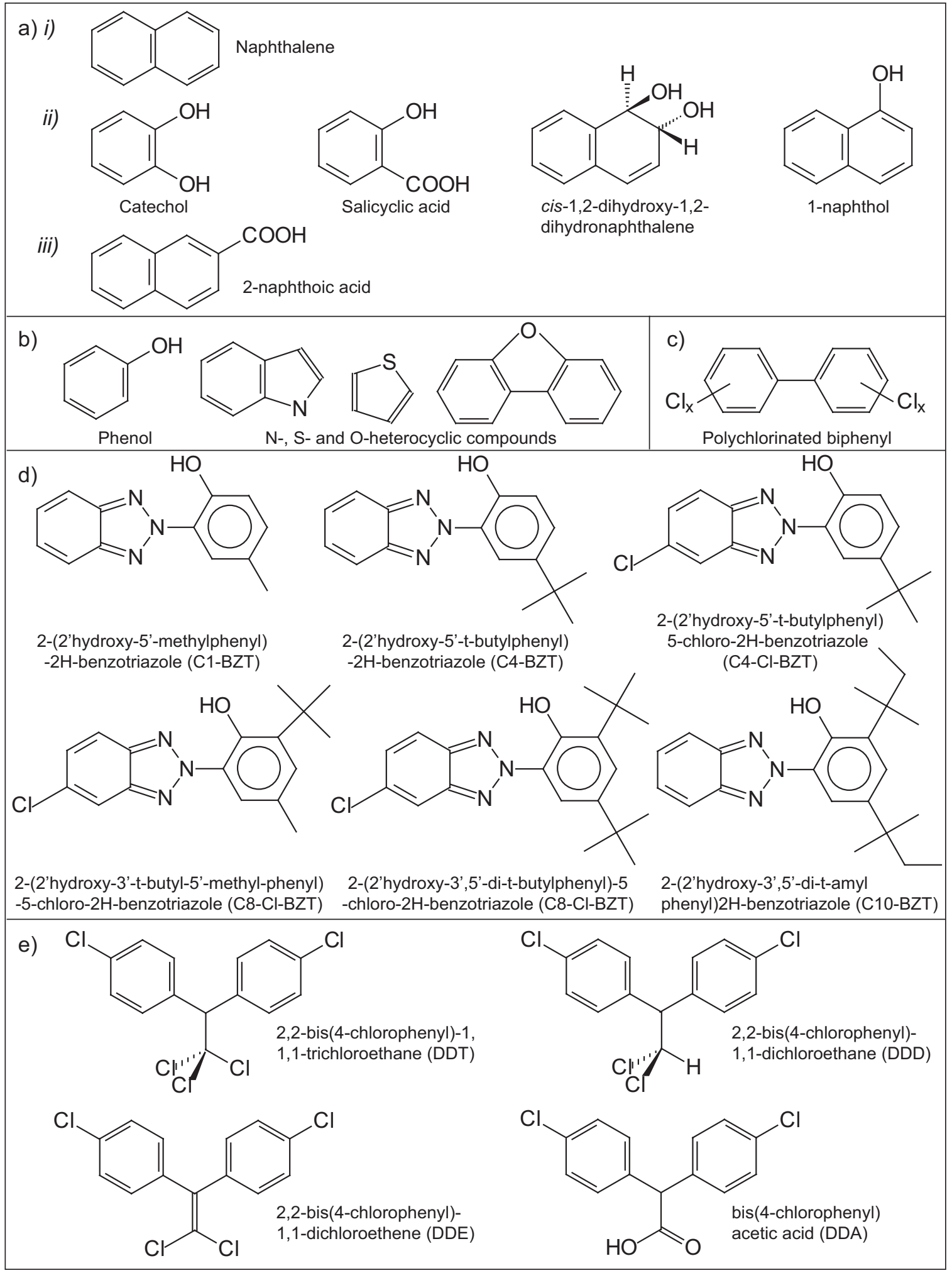

Figure 5.1 Structures of hydrophobic organic contaminants examined in this study. 
PAH naphthalene (Figure 5.1a i)) and its metabolites identified from aerobic (Figure 5.1a ii; Heitkamp et al., 1997) and anaerobic degradation (Figure 5.1a iii; Zhang and Young 1997) in sediments are shown as an example. Creosote and coal tar are composed of approximately $85 \%$ PAHs, $10 \%$ phenolic and 5\% N-, S-, and O-heterocyclic compounds, and examples of these compounds are also presented (Figure 5.1b). Polychlorinated biphenyls are mixtures of up to 209 individual chlorinated compounds known as congeners with the general structure $\mathrm{C}_{12} \mathrm{H}_{10-\mathrm{x}} \mathrm{Cl}_{\mathrm{x}}$ where $\mathrm{x}=1-10$ (Figure 5.1c). Structures of the most abundant BZTs (Figure 5.1d), and DDT and its common metabolites 2,2bis(4-chlorophenyl)-1,1-dichloroethane (DDD), 2,2-bis(4-chlorophenyl)-1,1-dichloroethene (DDE) and bis(4-chlorophenyl)acetic acid (DDA), are also shown (Figure 5.1e). All of these HOCs and/or their metabolites, have a variety of functional groups and therefore potential reactive sites ("chemical handles") to bind to OM.

\subsection{MATERIALS AND METHODS}

\subsubsection{Study Area and Samples}

Geographic locations, dates, depths and details of the sites examined in this study are provided in Table 5.1 and Figure 5.2. To test the inverse tracer approach on a sample known to contain bound HOCs, soil contaminated with mineral oil from a site near Hamburg, Germany (SS), previously examined by Richnow et al., (1994) was obtained. Sediments where bound HOCs had previously been reported were also examined. These included, freshwater sediments contaminated with BZTs from the Pawtuxet River (PR) (Reddy et al., 2000a) and from a control site (Station 3), upstream of the chemical plant that released the BZTs into the river (Figure 5.2 insert), and freshwater sediments contaminated with DDT from Teltow Canal (TC) (Schwarzbauer et al., 2003). The Palos Verdes (PV) shelf is a coastal marine site that also has a history of DDT contamination (Eganhouse et al., 2000) and thus for comparison, sediments from this site were analyzed. Creosote contaminated sediments from both a marine site, Eagle Harbor (EH), and freshwater site, Chattanooga Creek (CC), as well as PCB contaminated sediments from 


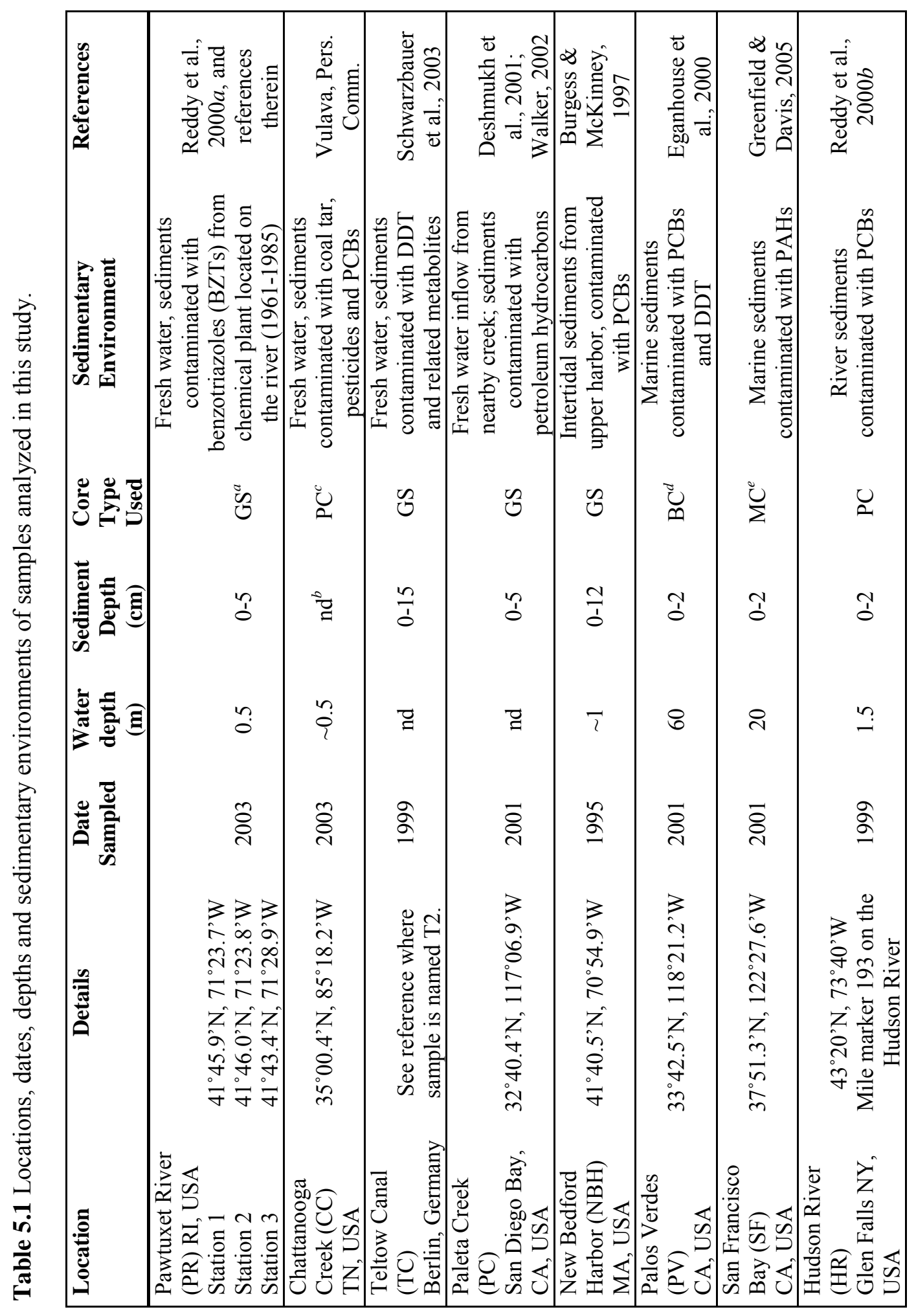




\begin{tabular}{|c|c|c|c|c|c|c|}
\hline 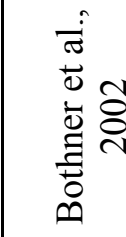 & 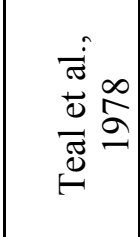 & 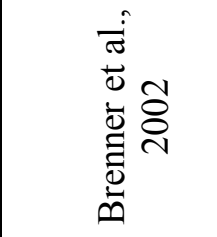 & 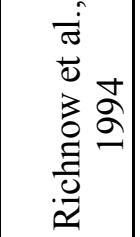 & 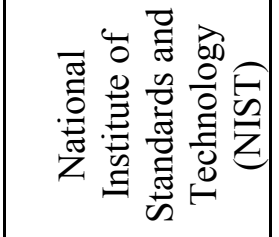 & 㫐 & \\
\hline 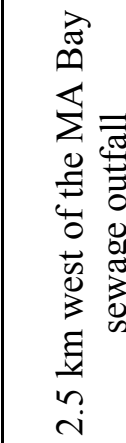 & 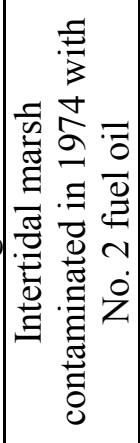 & 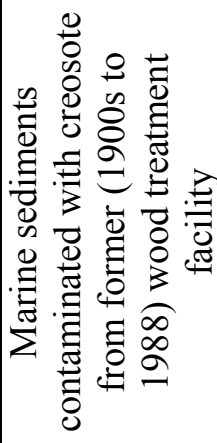 & 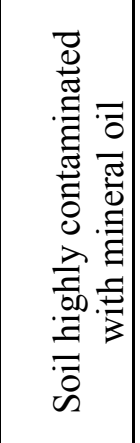 & 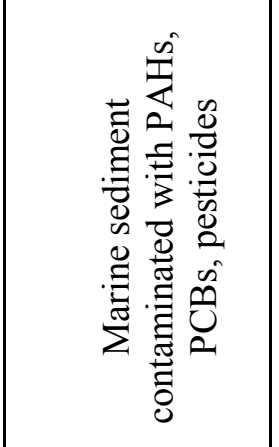 & 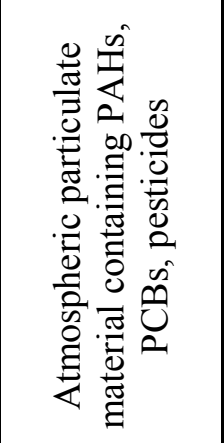 & \\
\hline$\widetilde{J}$ & U & U & $\stackrel{\Xi}{\Xi}$ & $\mathscr{J}$ & $\underset{\Xi}{\mathcal{J}}$ & \\
\hline $\bar{o}$ & $\tilde{o}$ & ơ & $\Xi$ & 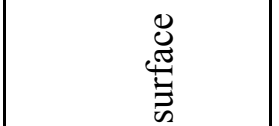 & $\stackrel{\Xi}{\Xi}$ & \\
\hline అల & 0 & in & 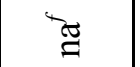 & $\bar{Z}$ & $\stackrel{\widetilde{Z}}{\Xi}$ & \\
\hline$\stackrel{0}{8}$ & $\stackrel{n}{8}$ & $\stackrel{\text { }}{\stackrel{8}{0}}$ & 1 & $\stackrel{\infty}{\curvearrowright}$ & 응 & \\
\hline 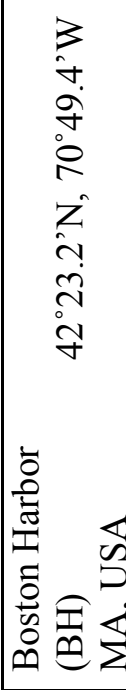 & 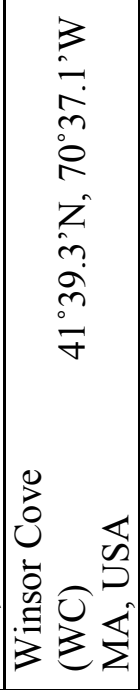 & 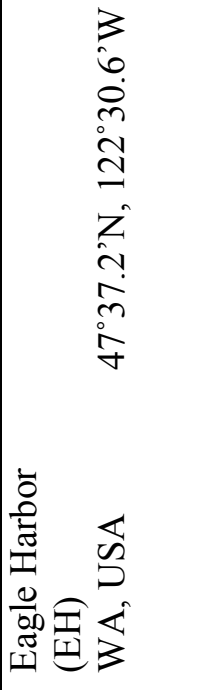 & 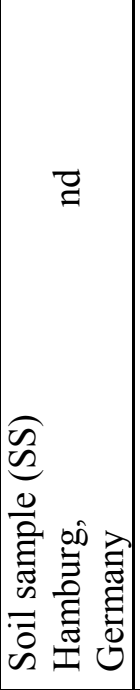 & 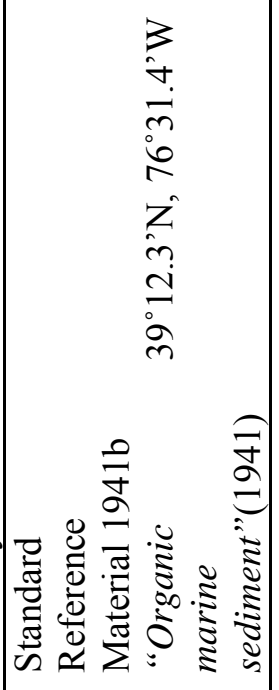 & 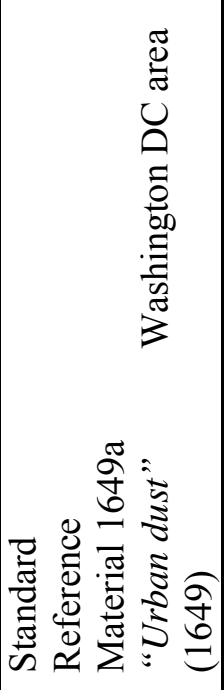 & 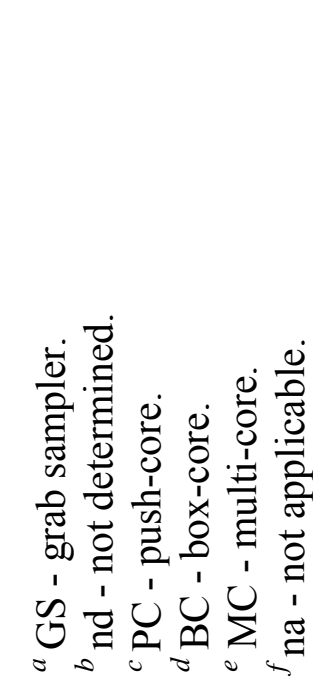 \\
\hline
\end{tabular}



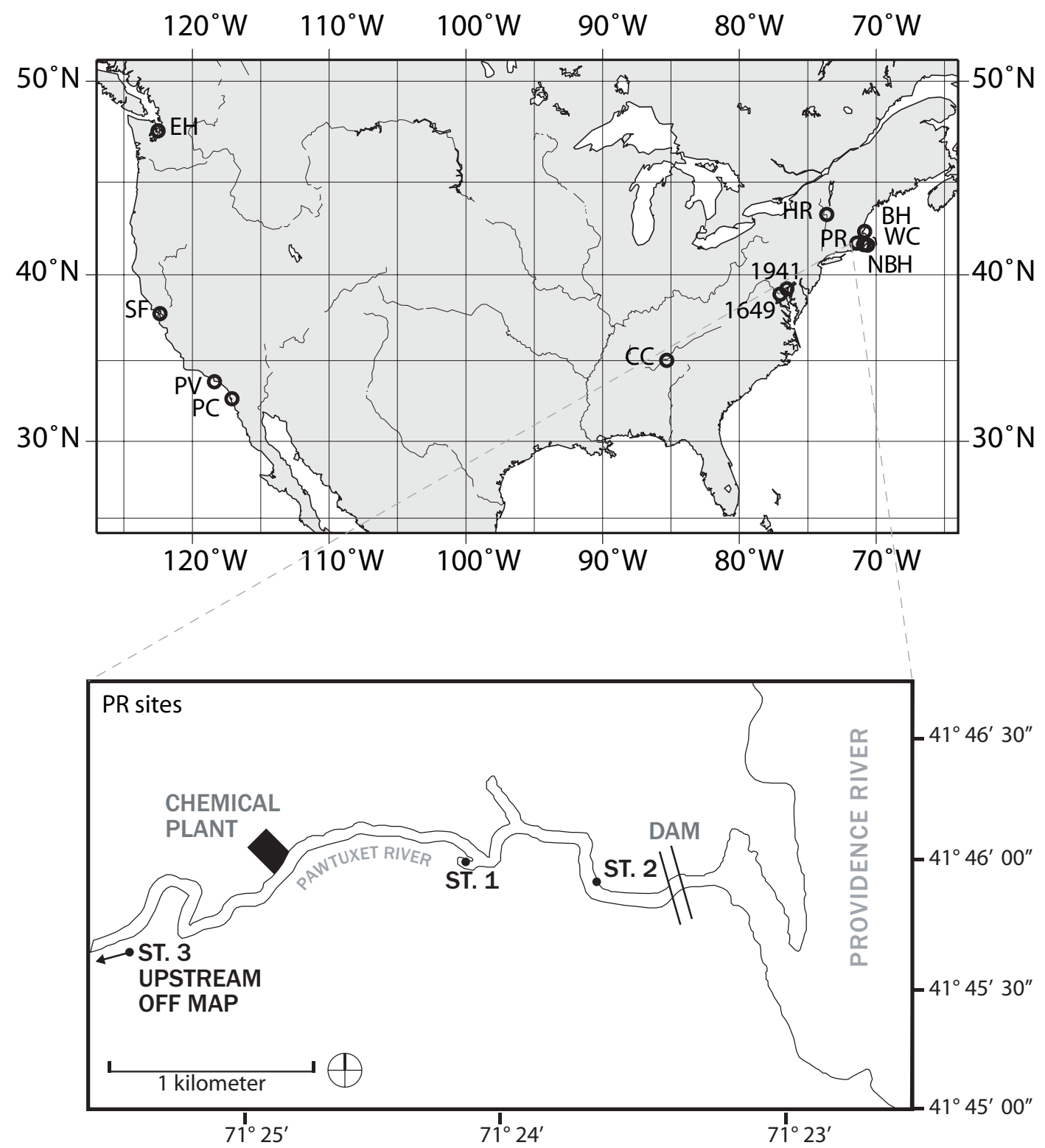

Figure 5.2 Location of sediments examined in this study.

New Bedford Harbor (NBH) and Hudson River (HR) were examined. Sites contaminated with petroleum and PAHs were sampled, but unlike the previous investigation of anoxic sediments from West Falmouth (White et al., 2005), oxic sediments from Paleta Creek 
(PC), San Francisco Bay (SF), Boston Harbor (BH) and Winsor Cove (WC) were also analyzed. Standard Reference Materials 1941b "Organics in marine sediment" and 1649a "Urban dust" from the National Institute of Standards and Technology (NIST) were selected for study because of the extensive information regarding their compositions and broad contamination from PAHs, PCBs and pesticides, as well as providing the opportunity with the "Urban dust" sample to examine the significance of binding in a different environmental matrix (atmospheric particulates). Data from West Falmouth sediments impacted by No. 2 fuel oil as previously described (White et al., 2005), are also included in this study for comparison.

\subsubsection{Sequential Chemical Treatment}

Samples were air-dried and homogenized with a mortar and pestle before passing through a $1-\mathrm{mm}$ sieve. Depending on the quantity available, 1 to 10 grams of each sample was extracted with a mixture of dichloromethane (DCM), methanol $(\mathrm{MeOH})$ and water $\left(\mathrm{H}_{2} \mathrm{O}\right)(89: 10: 1)$ by pressurized fluid extraction $\left(100{ }^{\circ} \mathrm{C}, 1000 \mathrm{psi}\right)$. The resulting total lipid extracts (TLE) were acidified with $4 \mathrm{~N}$ hydrochloric acid $(\mathrm{HCl})$ to $\mathrm{pH} 4$ to ensure that any anionic metabolites would be protonated before back-extracting into DCM. The TLE was then reduced in volume by rotary evaporation, dried over $\mathrm{Na}_{2} \mathrm{SO}_{4}$ and percolated through a copper column plugged with glass wool to remove sulfur and any particulate matter prior to further analysis. The remaining solvent extracted residues (EXRES) from all samples were then refluxed for $2 \mathrm{~h}$ with a solution of $0.5 \mathrm{~N}$ potassium hydroxide $(\mathrm{KOH})$ in $\mathrm{MeOH},(100 \mathrm{~mL})$ and $\mathrm{H}_{2} \mathrm{O}(20 \mathrm{~mL})$. After cooling, the reaction mixture was separated by centrifugation and the remaining saponified residue (SA-RES) rinsed with $\mathrm{MeOH}$, followed by DCM, and then hexane. The alkaline solution was back extracted with hexane $(3 \times 50 \mathrm{~mL})$ to obtain a neutral fraction before acidification with $4 \mathrm{~N} \mathrm{HCl}$ to $\mathrm{pH} 2$ and extraction with DCM $(3 \times 50 \mathrm{~mL})$ to obtain an acidic fraction. Both fractions were reduced in volume by rotary evaporation and dried over $\mathrm{Na}_{2} \mathrm{SO}_{4}$. Combined, these fractions comprise the saponification extract (SAE). 


\subsubsection{Demineralization of Pawtuxet River Sediments}

BZTs had previously been shown to be present in the nonextractable fraction of Pawtuxet River sediments, and were hypothesized to be linked to OM via an ester bond (Reddy et al., 2000a). To examine this further and explore the role of minerals interactions with HOCs, 10 gram aliquots of the solvent-extracted sediment residues were demineralized. To remove carbonate minerals, the extracted sediments were placed in $60 \mathrm{~mL}$ acid-cleaned Teflon test tubes with $5 \mathrm{~mL}$ of $12 \mathrm{~N} \mathrm{HCl}$ before capping the tubes and agitating for $1 \mathrm{hr}$. Following centrifugation, the supernatant was removed and this was repeated twice more. Silicate minerals were then removed by addition of $10 \mathrm{~mL}$ of concentrated hydrofluoric acid (HF) and $4 \mathrm{~mL}$ of $\mathrm{HCl}$. The tubes were agitated for $12 \mathrm{hrs,}$ centrifuged and the supernatant removed. This was repeated twice more before salting out the remaining HF with boric acid and several water rinses. The demineralized sediments were then allowed to dry before adding pyridine $(5 \mathrm{~mL})$ to swell the sediments, followed by sonication for 30 minutes. The tubes were then centrifuged and the pyridine extract, which was now a dark brown color, was decanted reduced in volume and dried over $\mathrm{Na}_{2} \mathrm{SO}_{4}$. The demineralized sediment was then saponified with $\mathrm{KOH}$ in $\mathrm{MeOH}$ as previously described in section 3.1 .

\subsubsection{Bulk Sediment Analyses}

Aliquots of the total samples prior to solvent extraction (TOC), and the respective EX-RES and SA-RES for each sample were treated with $10 \% \mathrm{HCl}$ to remove any carbonates. These bulk samples and residues were then analyzed for organic carbon content with a Carlo Erba 1108 elemental analyzer. The stable carbon isotope ratio $\left(\delta^{13} \mathrm{C}\right)$ and radiocarbon abundance $\left(\Delta{ }^{14} \mathrm{C}\right)$ of the samples and respective residues were measured on purified carbon dioxide $\left(\mathrm{CO}_{2}\right)$ after their combustion in the presence of cupric oxide $(\mathrm{CuO})$. Stable carbon values were determined by isotope ratio mass spectrometry (irMS) and ${ }^{14} \mathrm{C}$ content by accelerator mass spectrometry (AMS) at the National Ocean Sciences Accelerator Mass Spectrometry (NOSAMS) facility at Woods Hole Oceanographic Institution (WHOI), Woods Hole, MA. Radiocarbon analyses were performed after 
conversion of the $\mathrm{CO}_{2}$ to graphite (McNichol et al., 1994) and all samples were run as conventional targets. All ${ }^{14} \mathrm{C}$ measurements are normalized to $\delta^{13} \mathrm{C}$ values of $-25 \%$ and expressed as $\Delta^{14} \mathrm{C}$ values, which is the per mille (\%) deviation from the international standard for ${ }^{14} \mathrm{C}$ dating, Standard Reference Material 4990B "Oxalic Acid". Precision for $\delta^{13} \mathrm{C}$ and $\Delta^{14} \mathrm{C}$ measurements are $\sim 0.1$ and $1-5 \%$ (see Appendix for errors specific to each sample analyzed), respectively. For each sample, the reported $\Delta{ }^{14} \mathrm{C}=\left[f_{\mathrm{m}} e^{(1950-\mathrm{x}) \lambda}-1\right] 1000$ (Stuiver and Polach, 1977), where $\lambda=1 / 8267$ (year ${ }^{-1}$ ), $f_{\mathrm{m}}=$ fraction modern ${ }^{14} \mathrm{C}$, corrected for isotopic fractionation using $\delta^{13} \mathrm{C}$, and “ $\chi$ ” equals the year of collection (see Table 5.1).

\subsubsection{Gas Chromatography-Mass Spectrometry (GC/MS) Analysis}

Pawtuxet River sediment extracts were acetylated with acetic anhydride and pyridine and the resulting product was solvent exchanged into hexane before placing on a $0.5 \mathrm{~cm}$ (i.d.) $\times 15 \mathrm{~cm}$ column containing activated silica gel. The first fraction was eluted with $15 \mathrm{~mL}$ of a mixture of hexane and DCM (4:1) and the second fraction containing BZT-acetates was eluted with $15 \mathrm{~mL}$ of a mixture of DCM and acetonitrile (1:1). These fractions were reduced in volume by rotary evaporation prior to further analysis. All other extracts were derivatized with bis-(trimethylsilyl)-trifluoroacetamide (BSTFA) and pyridine to improve chromatography. Aliquots of extracts from all samples were spiked with an internal standard of $n-\mathrm{C}_{36}$ alkane $(4 \mu \mathrm{g})$. For compound identification, electron ionization (EI) spectra were acquired on an Agilent 6890 series gas chromatograph (GC) interacted to an Agilent 5973 mass selective detector (MSD). A post column split to a flame ionization detector (FID) allowed for quantification of compounds of interest relative to the internal standard. Extracts were separated on a J\&W DB-5MS capillary column (60 m x $0.32 \mathrm{~mm}$ ID, $0.25 \mu \mathrm{m}$ film thickness) with helium carrier gas at a constant flow of $1 \mathrm{ml} \mathrm{min}{ }^{-1}$. The GC oven had an initial temperature of $40^{\circ} \mathrm{C}(1$ minute hold) and was ramped at $20^{\circ} \mathrm{C} \min ^{-1}$ until $130^{\circ} \mathrm{C}$ and then at $2^{\circ} \mathrm{C} \min ^{-1}$ until $320^{\circ} \mathrm{C}(30$

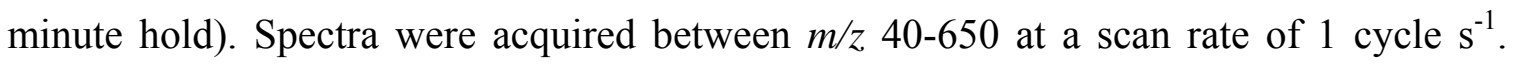
Compounds present in the extracts were identified from both mass spectra and gas chromatographic retention characteristics. Contributions of an unresolved complex 
mixture (UCM) to some of the extracts were quantified by integrating the total FID area of the UCM and using response factors determined from No. 2 fuel oil standards from the Marine Ecosystem Research Laboratory (MERL) as in Peacock et al., (2005). Saponification extracts from HR were also analyzed by electron capture negative ionization (ECNI) with methane as a reagent gas and using an Agilent 6890 series gas chromatograph interfaced to an Agilent 5973 mass selective detector (MSD), with a J\&W Scientific DB-XLB column (60 $\mathrm{m} \times 0.25 \mathrm{~mm}$ ID, $0.25 \mu \mathrm{m}$ film thickness $)$. The GC oven had an initial temperature of $50^{\circ} \mathrm{C}(1$ minute hold $)$ and was ramped at $30^{\circ} \mathrm{C} \mathrm{min}{ }^{-1}$ until $120^{\circ} \mathrm{C}$ and then at $8^{\circ} \mathrm{C} \mathrm{min}^{-1}$ to $300^{\circ} \mathrm{C}$ (30 minute hold). Spectra were acquired

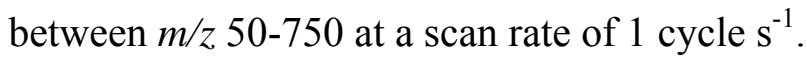

\subsection{RESULTS AND DISCUSSION}

\subsubsection{Solvent-Extractable Contaminants}

Variable quantities of HOCs were extracted from the samples examined in this study (Table 5.2). Several BZT compounds including C1-BZT, C4-BZT, C4-Cl-BZT, C5-Cl-BZT, C8-BZT and C10-BZT (Figure 5.1d) were isolated from Pawtuxet River sediments from Stations 1 and 2. Extracts from both sediments were dominated by $\mathrm{C} 1-$ BZT with maximum concentrations of $6 \mu \mathrm{g} \mathrm{g}^{-1}$ dry weight $(\mathrm{dw})$ sediment $\left(0.33 \mathrm{mg} \mathrm{g}^{-1}\right.$ organic carbon (OC)) in Station 1, and $100 \mu \mathrm{g} \mathrm{g}^{-1} \mathrm{dw}\left(1.9 \mathrm{mg} \mathrm{g}^{-1} \mathrm{OC}\right)$ in Station 2. No BZT compounds were identified in Station 3 sediments due to it being upstream from the chemical plant that originally released the BZTs into the river (Figure 5.2), and it was therefore used as a control site. Sediment extracts contaminated with PCBs from NBH were dominated by di-, tri- and tetrachlorobiphenyls, but also contained penta- and hexachlorobiphenyls with a summed concentration of $4200 \mu \mathrm{g} \mathrm{g}^{-1} \mathrm{dw}\left(37.5 \mathrm{mg} \mathrm{g}^{-1}\right.$ OC). Sediments from HR, however were less contaminated and mono-, di-, tri- and tetrachlorobiphenyls with summed concentrations of $170 \mu \mathrm{g} \mathrm{g}^{-1} \mathrm{dw}\left(7.7 \mathrm{mg} \mathrm{g}^{-1}\right.$ OC) were present in the TLE. Sediments from TC contained a variety of extractable DDT metabolites including DDE, DDD and DDA (Figure 5.1e) with a summed concentration 


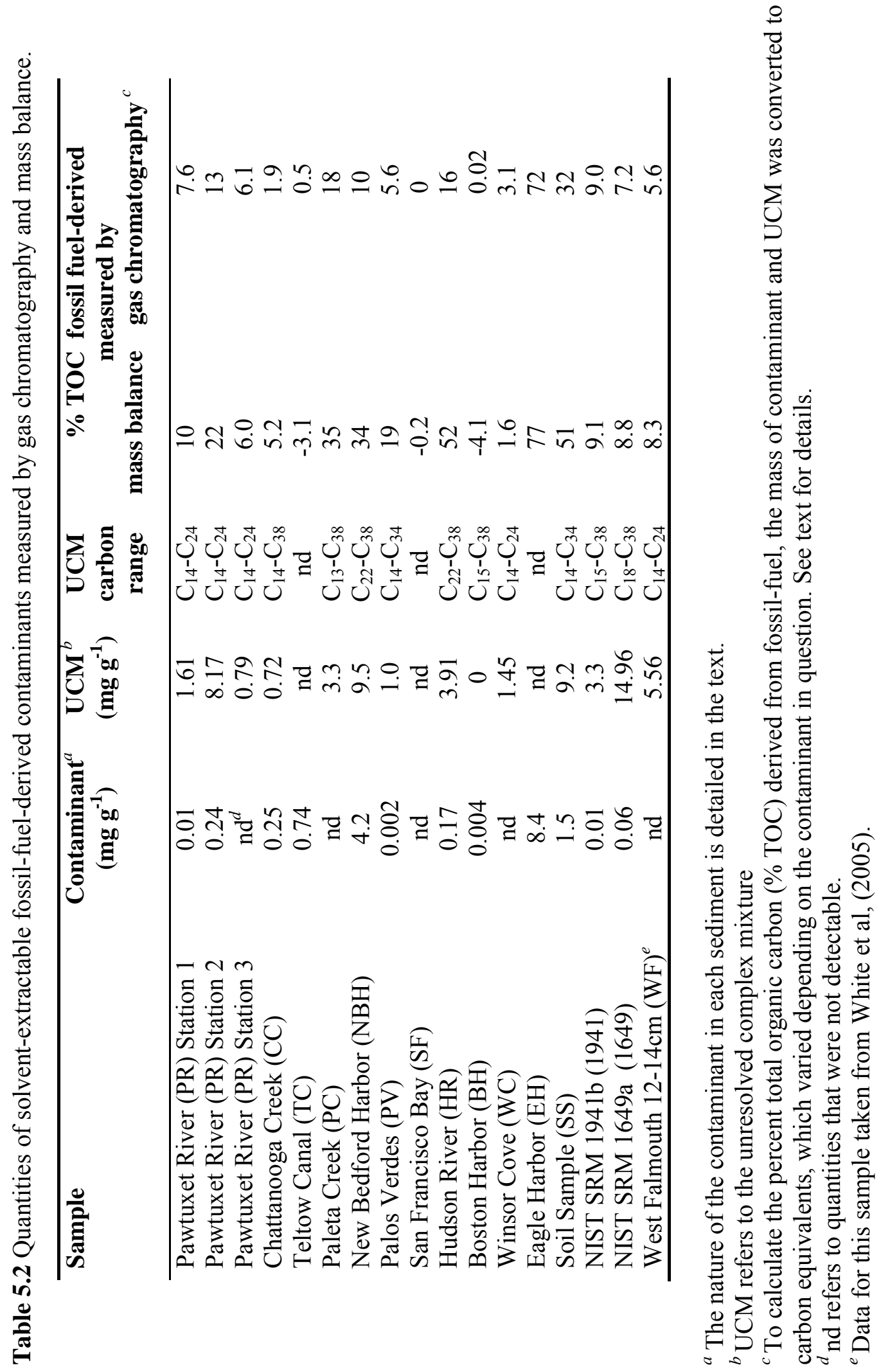


of $740 \mu \mathrm{g} \mathrm{g}^{-1} \mathrm{dw}\left(9.4 \mathrm{mg} \mathrm{g}^{-1} \mathrm{OC}\right)$, whereas PV sediments were much less contaminated $\left(0.002 \mu \mathrm{g} \mathrm{g}^{-1} \mathrm{dw} ; 0.1 \mu \mathrm{g} \mathrm{g}^{-1} \mathrm{OC}\right.$ of DDE). Creosote contaminated extracts from $\mathrm{CC}$ and EH were dominated by PAHs including fluoranthene, pyrene, phenanthrene, benzo $[b]$ fluoranthene, benz $[a]$ anthracene, benzo $[a]$ pyrene, chrysene, fluorene and anthracene with individual PAH concentrations between 10 to $50 \mu \mathrm{g} \mathrm{g}^{-1} \mathrm{dw}(0.23$ to 1.16 $\mathrm{mg} \mathrm{g}^{-1} \mathrm{OC}$ ) in CC, and 100 to $1400 \mu \mathrm{g} \mathrm{g}^{-1} \mathrm{dw}$ (9.1 to $127.3 \mathrm{mg} \mathrm{g}^{-1} \mathrm{OC}$ ) in EH. PAHs also dominated sediment extracts from $\mathrm{BH}$ with fluoranthene, pyrene and benz $[a]$ anthracene at concentrations of 1 to $2 \mu \mathrm{g} \mathrm{g}^{-1} \mathrm{dw}\left(0.06\right.$ to $\left.0.12 \mathrm{mg} \mathrm{g}^{-1} \mathrm{OC}\right)$ as well as SS, which contained phenanthrene, anthracene, pyrene, fluoranthene, chrysene at concentrations of 60 to $570 \mu \mathrm{g} \mathrm{g}^{-1} \mathrm{dw}$ (2.1 to $19.7 \mathrm{mg} \mathrm{g}^{-1} \mathrm{OC}$ ). Details of solvent extractable contaminants and their concentrations from NIST SRM 1941b and NIST SRM 1649a are discussed in the certificates of analysis, but contribute total contaminant concentrations of $\sim 10 \mu \mathrm{g} \mathrm{g}^{-1}$ $\mathrm{dw}\left(0.32 \mathrm{mg} \mathrm{g}^{-1} \mathrm{OC}\right)$ and $\sim 60 \mu \mathrm{g} \mathrm{g}^{-1} \mathrm{dw}\left(0.34 \mathrm{mg} \mathrm{g}^{-1} \mathrm{OC}\right)$ respectively. Varying quantities of UCM with different carbon ranges, and therefore different sources, were also detected in most samples except TC, SF and EH (Table 5.2).

Gas chromatograms of TLE from select sediments including NBH, CC and EH indicate the dominance of HOCs in the GC-resolvable portion of the TLE (Figure 5.3a, c and $\mathrm{d}$ respectively). This is observed for the majority of samples and in general, HOCs comprise more than $90 \%$ of the resolvable TLE (Figure 5.4a). Biogenic hydrocarbons contribute more significantly to sediments such as those from HR (Figure 5.3b), as well as PV and all PR sites where HOCs constitute $50-90 \%$ of the GC-amenable TLE, with the remainder consisting of biogenic hydrocarbons (Figure 5.4b). In some samples, such as $\mathrm{TC}, \mathrm{BH}$ and SF, biogenic hydrocarbons dominate, and HOCs comprise less than 5\% (Figure 5.4c). Contributions from biogenic hydrocarbons to the TLE consist of varying amounts of $n$-alkanoic acids from $n-\mathrm{C}_{14}$ to $n-\mathrm{C}_{30}$ with strong even/odd dominance and $n$ alkanols from $n-\mathrm{C}_{14}$ to $n-\mathrm{C}_{26}$ with strong even/odd dominance. The short chain $\left(n-\mathrm{C}_{12}\right.$ to $n-\mathrm{C}_{22}$ ) compounds are commonly accepted to be predominantly derived from marine algae or bacteria whereas the longer chain compounds $\left(n-C_{24}\right.$ to $\left.n-C_{34}\right)$ have terrestrial origins from higher plant epicuticular waxes. A strong odd/even dominance is observed 

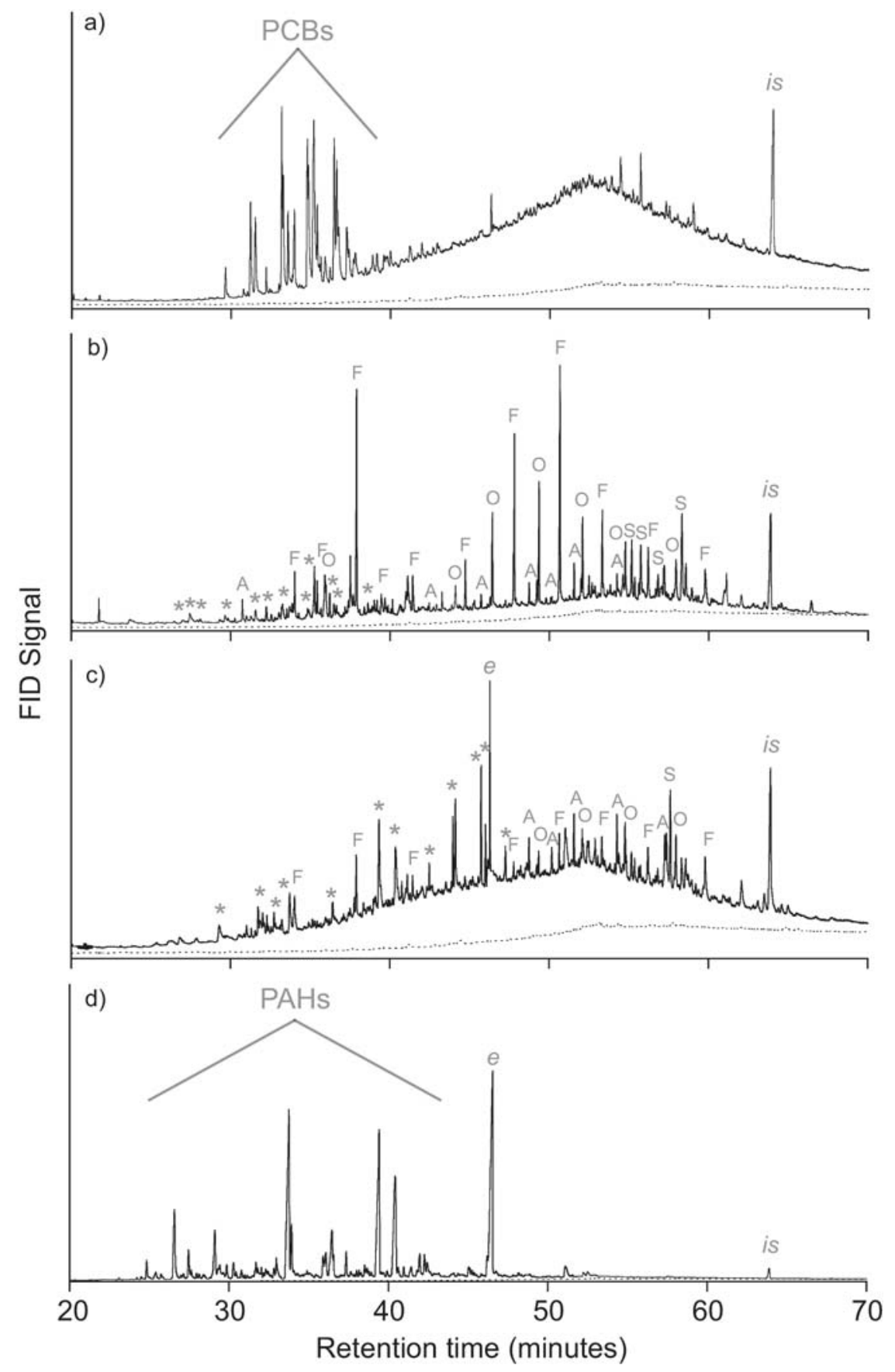

Figure 5.3 Gas chromatograms of total lipid extracts from a) New Bedford Harbor, b) Hudson River, c) Chattanooga Creek and d) Eagle Harbor. The dashed line is the GC baseline. In a) PCBs dominate and in d) PAHs dominate. In b) and c) contaminants are designated with "*" and biogenic hydrocarbons $n$-alkanoic acids, $n$-alkanols, alkanes and sterols are labeled with " $F$ ", "O", " $A$ " and "S" respectively. The internal standard hexatriacontane is designated with "is" and an external contaminant is labeled with "e." 
a)

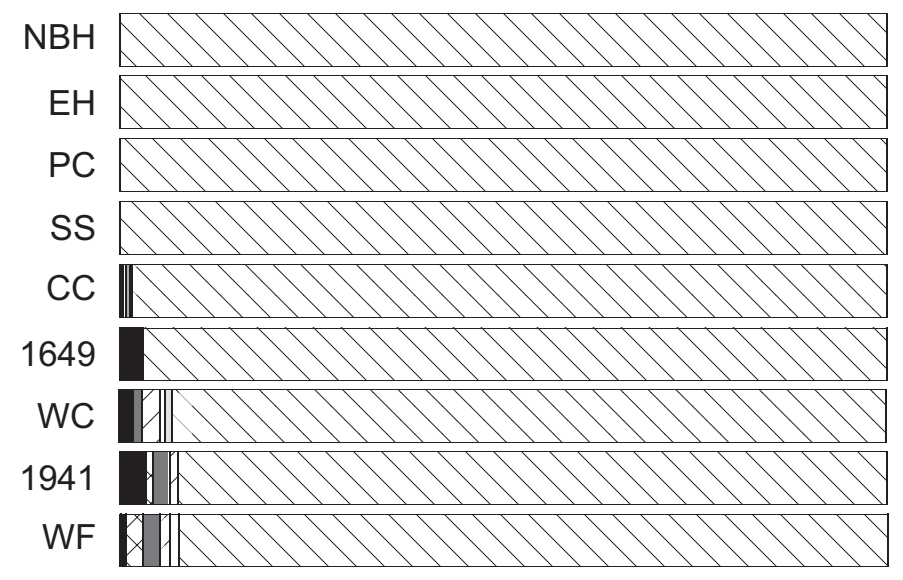

b)

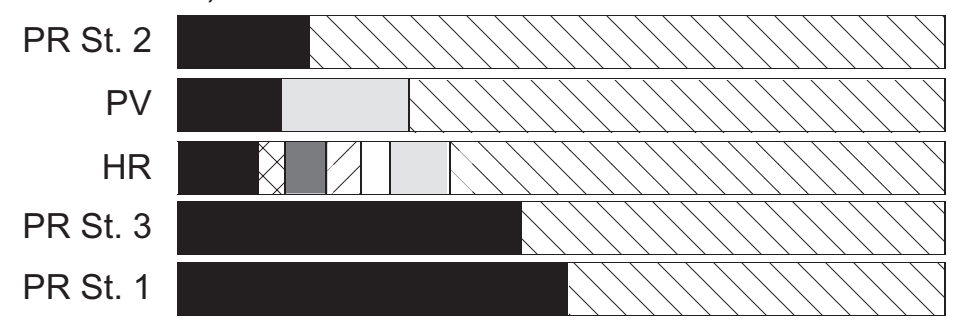

c)

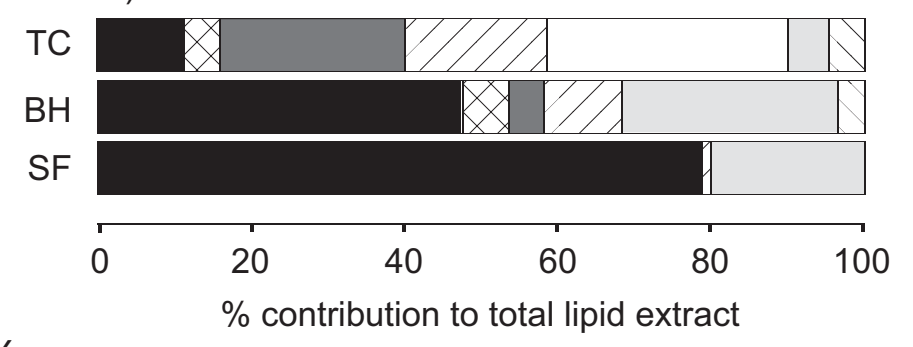

KEY

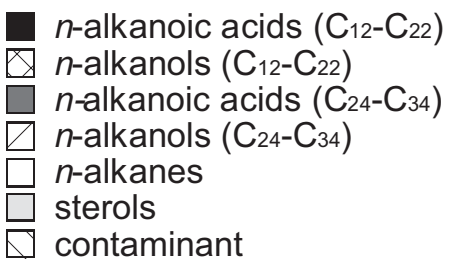

Figure 5.4 Percent contribution of biogenic hydrocarbons and contaminants (specified in the text) to the total lipid extract. 
for $n$-alkanes from $n-C_{23}$ to $n-C_{31}$, which is also typical of higher plants. Sterol contributions were dominated by $\mathrm{C}_{27}$ to $\mathrm{C}_{29}$ compounds including cholesterol, a general biomarker for plants and consumer organisms (Grice et al., 1998), and $\beta$-sitosterol and stigmasterol, which are the major sterols in higher plants (Figures 5.3 and 5.4).

\subsubsection{Nonextractable Contaminants}

Chemical evidence for the incorporation of HOCs into nonextractable residues is observed in PR Station 2, TC, CC9, EH, and SS, and comprises between $0.02-41 \%$ of the total pool of HOCs at each site. At PR Station 2, $1 \mu \mathrm{g} \mathrm{g}^{-1}$ of C1-BZT (Figure 5.5a) is released by alkaline hydrolysis, representing $0.4 \%$ of the total pool of BZTs in the sediment, which is similar to the quantity observed by Reddy et al., 2000a. Known metabolites of DDT, 4,4'-dichlorobenzophenone (4,4'-DBP) and 2,2-bis(4chlorophenyl)-ethanol $\left(4,4^{\prime}-\mathrm{DOH}\right)$ (Figure 5.5b) are present in the SAE from TC at summed concentrations of $300 \mu \mathrm{g} \mathrm{g}^{-1} ; 29 \%$ of the total HOC pool. Creosote-derived compounds, fluoranthene, pyrene and anthracene carbonitrile (Figure 5.5c) were identified in the SAE from $\mathrm{CC}$ at total concentrations of $7 \mu \mathrm{g} \mathrm{g}^{-1} ; 1 \%$ of the total HOC pool. Analysis of the SAE from $\mathrm{EH}$ indicated the presence of $9 \mathrm{H}$-fluoren-9-one, a known metabolite of fluorene (Grifoll et al., 1992) and 9,10-anthracenedione, a known constituent of creosote (Figure 5.5d), at summed concentrations of $2 \mu \mathrm{g} \mathrm{g}^{-1} ; 0.02 \%$ of the total pool of HOCs at the site. In SS, fluoranthene, pyrene, anthracene carbonitrile (Figure 5.5c), acridine, and aminofluoranthene (Figure 5.5e) were identified with summed concentrations of $180 \mu \mathrm{g} \mathrm{g}^{-1} ; 0.02 \%$ of the total pool of HOCs at the site.

Significant quantities of biogenic hydrocarbons are also released as a result of alkaline hydrolysis as evidenced in chromatograms of the acidic (Figure 5.6) and neutral (Figure 5.7) extracts from saponification of NBH, HR, CC and EH. The acidic extracts are dominated by $n$-alkanoic acids from $n-\mathrm{C}_{12}$ to $n-\mathrm{C}_{28}$ with strong even/odd dominance and the neutral extracts are dominated by $n$-alkanols from $n-C_{12}$ to $n-C_{22}$ with strong even/odd dominance and sterols as before. Nonextractable HOC residues are only observed in the neutral extracts (Figure 5.7c and d) and the presence of alkanes in the 
acidic extract from HR (Figure 5.6d) is likely an external contaminant because if alkanes were truly present, they would partition into the neutral fraction. Overall the contribution of biogenic hydrocarbons to the GC-amenable portion of the SAE is between 93 and $100 \%$ and is dominated by short chain $n$-alkanoic acids (Figure 5.8). Where detected, HOCs and/or their metabolites contribute a maximum of $1-7 \%$ of the resolvable SAE (Figure 5.8a), but for the majority of samples, nonextractable residues of HOCs are not observed by GC-FID (Figure 5.8b).

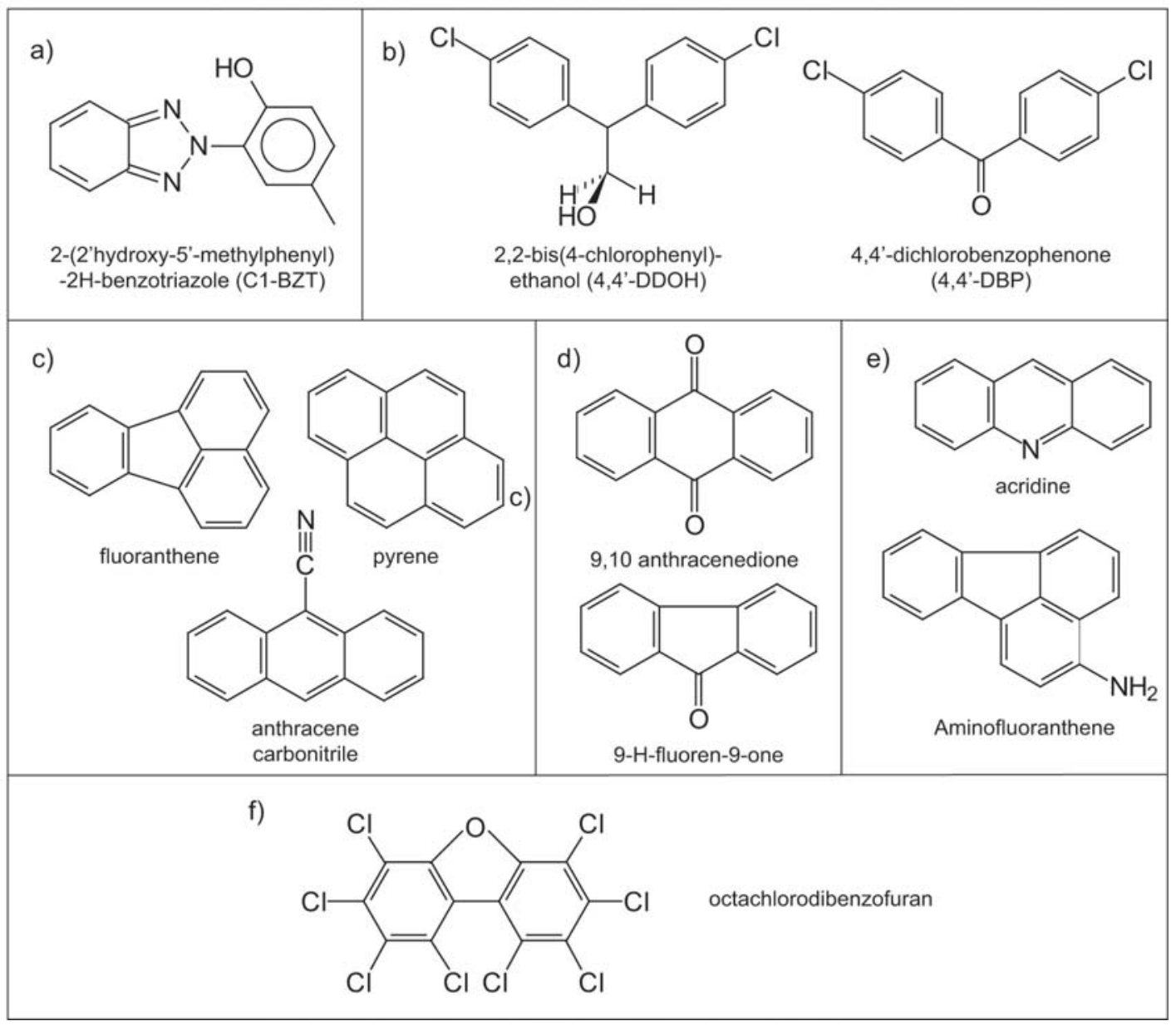

Figure 5.5 Structures of hydrophobic organic contaminants released by alkaline hydrolysis from various samples examined in this study. Compounds in d), e) were tentatively identified by GC/MS. 

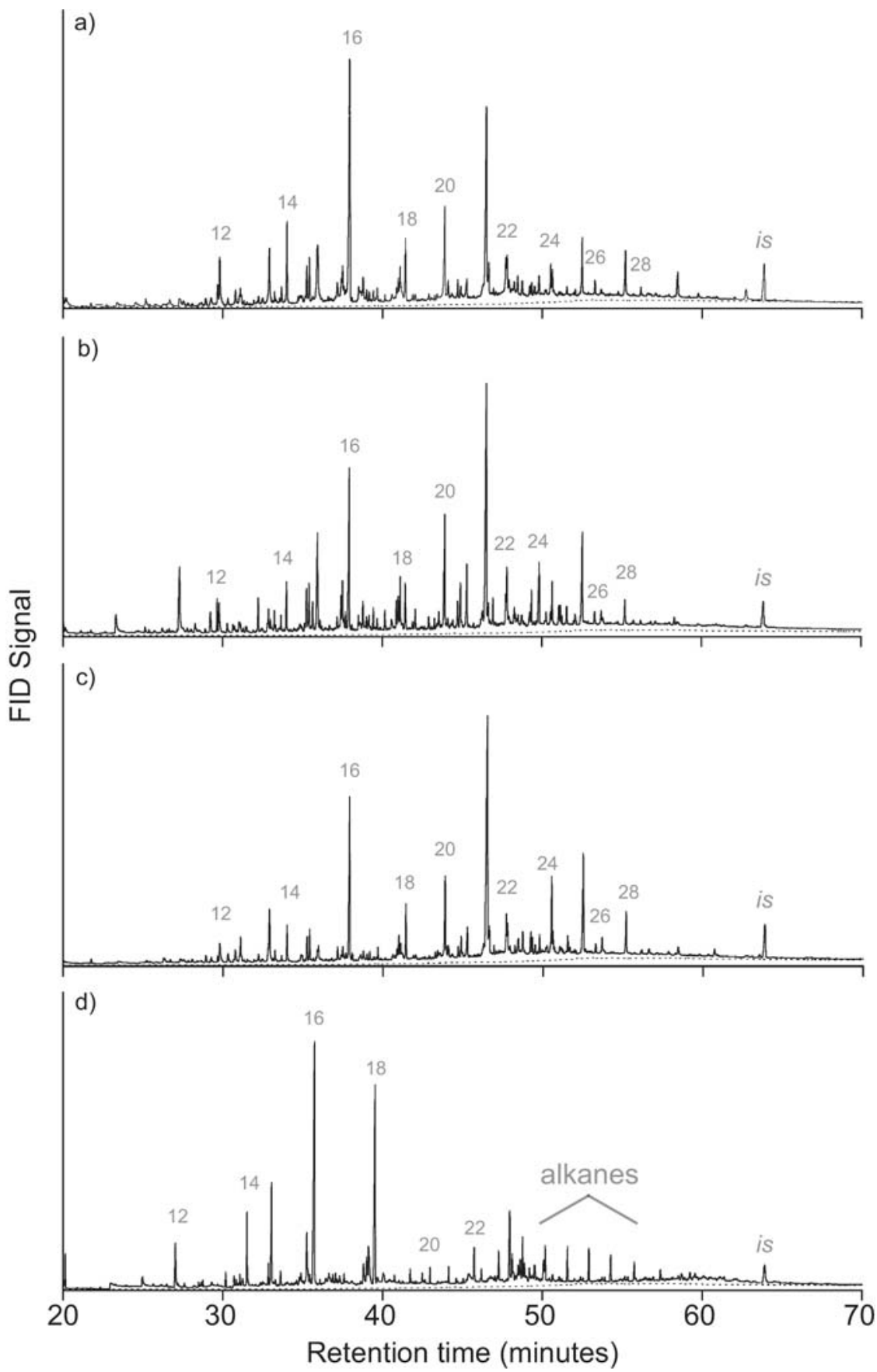

Figure 5.6 Gas chromatograms of saponification acidic extracts from a) New Bedford Harbor, b) Hudson River, c) Chattanooga Creek and d) Eagle Harbor. The dashed line is the GC baseline. In all samples, the $n$-alkanoic acids are numbered. The $n$-alkanoic acids in d) have different retention times as they were methylated in the saponification process. The internal standard hexatriacontane is designated with "is". 

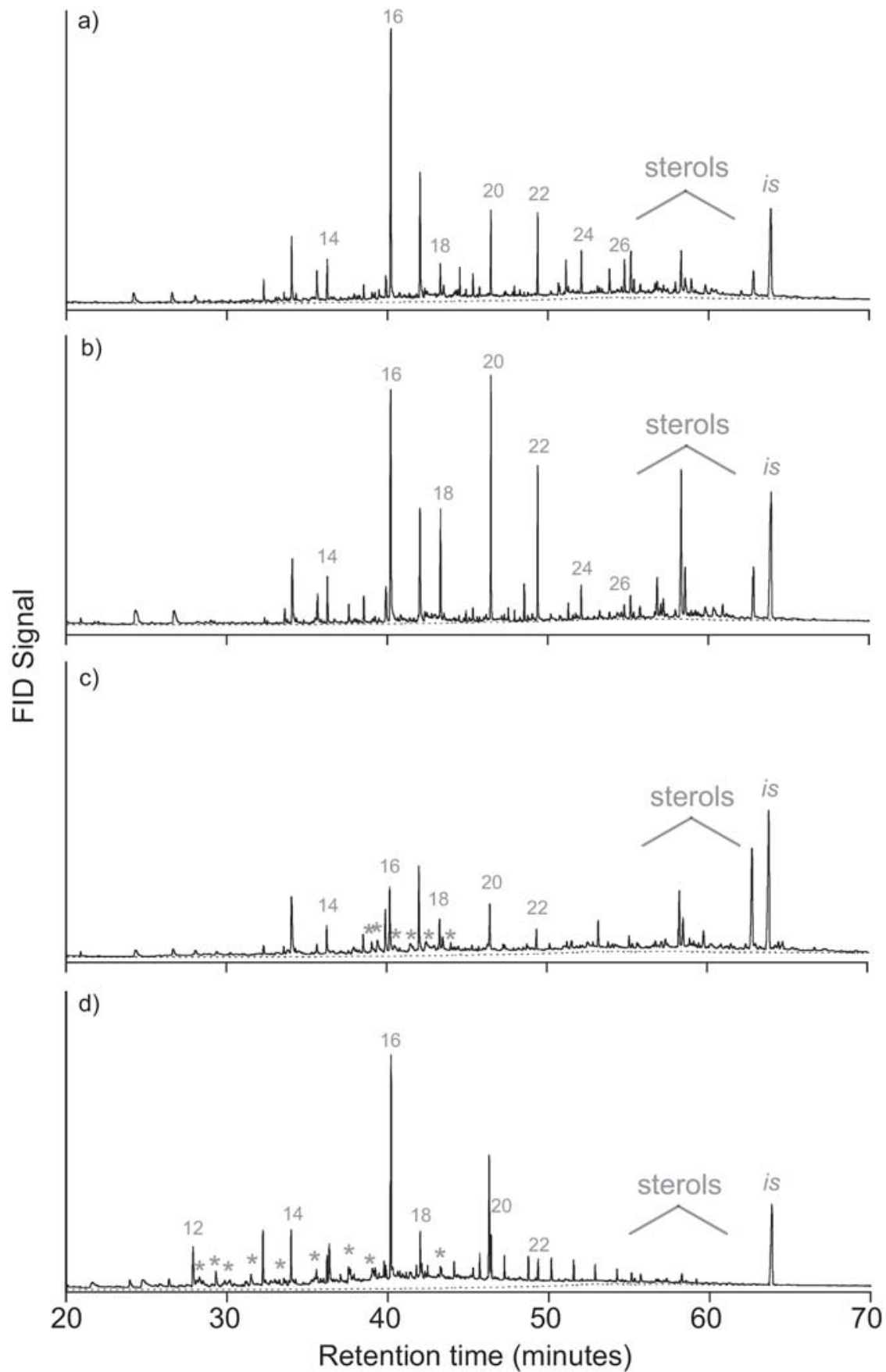

Figure 5.7 Gas chromatograms of saponification neutral extracts from a) New Bedford Harbor, b) Hudson River, c) Chattanooga Creek and d) Eagle Harbor. The dashed line is the GC baseline. In all samples, the $n$-alkanols acids are numbered. Contaminants are designated in c) and d) with "**". The internal standard hexatriacontane is designated with "is". 
a)

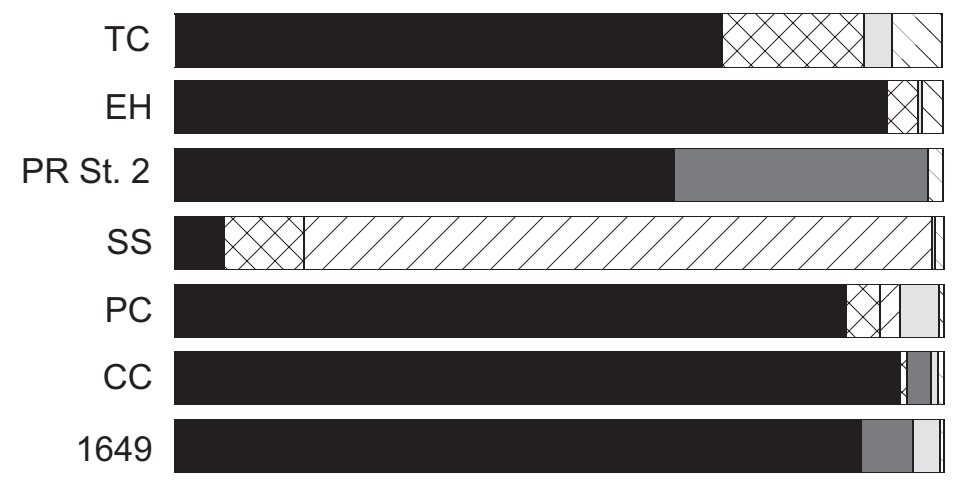

b)

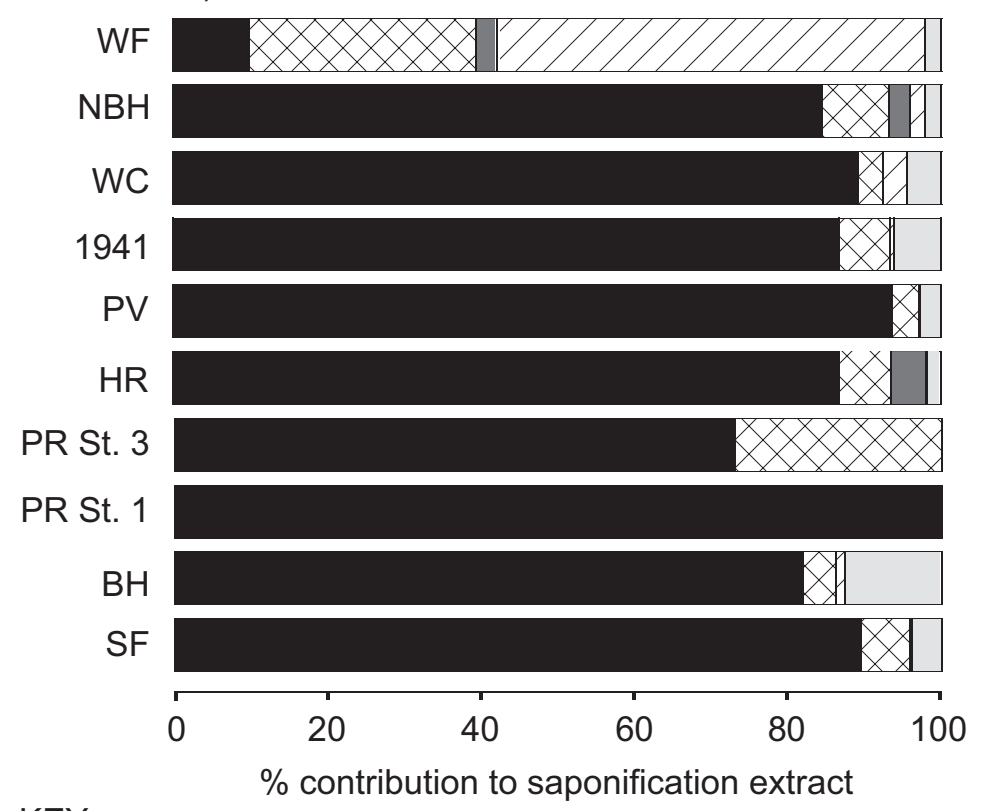

KEY

n-alkanoic acids $\left(\mathrm{C}_{12}-\mathrm{C}_{22}\right)$

$n$-alkanols $\left(\mathrm{C}_{12}-\mathrm{C}_{22}\right)$

$n$-alkanoic acids $\left(\mathrm{C}_{24}-\mathrm{C}_{34}\right)$

$n$-alkanols $\left(\mathrm{C}_{24}-\mathrm{C}_{34}\right)$

$\square n$-alkanes

sterols

contaminant

Figure 5.8 Percent contribution of biogenic hydrocarbons and contaminants (specified in the text) to the saponification extract. 


\subsubsection{Nature of Nonextractable Contaminants}

Possible interactions between HOCs and nonextractable sediment residues can be inferred from the chemical structure of the HOCs present in the SAE (Figure 5.5), as well as the chemical treatment by which they are released. Alkaline hydrolysis is used to target ester linkages liberating products with hydroxyl or carboxyl functional groups, and thus for the HOCs released in this study (Figure 5.5), only C1-BZT and 4,4'DDOH are likely to have been associated via an ester bond. Demineralization of the sediment from PR Station 2, however, liberated the same quantity $\left(1 \mu \mathrm{g} \mathrm{g} \mathrm{g}^{-1} \mathrm{dw}\right)$ of C1-BZT as that released by alkaline hydrolysis, and subsequent alkaline hydrolysis of the demineralized sediment did not release more. This indicates that C1-BZT is unlikely to be bound via an ester bond to OM as previously suggested (Reddy et al., 2000a) and is instead likely to be associated with minerals. The previous suggestion that C1-BZT was bound to OM via an ester linkage was based on the finding that it was the only BZT detected in significant quantities in the bound fraction (as much as $8 \%$ of the total BZT concentration) compared to $\mathrm{C} 8-\mathrm{Cl}-\mathrm{BZT}(0.03 \%$ of the total BZT concentration) and C10-BZT, which was never detected in the bound fraction (Reddy et al., 2000a). This was thought to result from steric hindrance by the presence of alkyl groups at the 3' position for C8-C1-BZT and C10-BZT (see figure 5.1 for structures), which would inhibit binding to OM. If it is to be concluded that $\mathrm{C} 1-\mathrm{BZT}$ is instead associated with minerals, then the preferential association of this compound may arise from the fact that its smaller size allows it to be more easily incorporated into mineral structures. For example, naturally occurring minerals such as anionic clays, also known as layered double hydroxides, may incorporate organic compounds between the layers of the clay, and these layers can impose a restricted geometry on their interlayer guests (Wei et al., 2005). Alternatively, the influence of the 3' alkyl group, present in C8-C1-BZT and C10-BZT may have an affect on the acid dissociation of the adjacent hydroxy group (as suggested by Reddy et al. 2000a), which may then decrease the potential for anionic interactions with minerals.

It is possible that aminofluoranthene may have been bound to OM via a carbonnitrogen $(\mathrm{C}-\mathrm{N})$ bond as oxidative coupling may occur between $\mathrm{OM}$ and compounds with 
amino functional groups (Sjobald and Bollag, 1977). The carbon-nitrogen bond formed between the aminofluoranthene and OM in sediment would be cleaved by base hydrolysis to liberate the amino compound and an aldehyde or ketone group on the OM (March, 1992). It is possible that aminofluoranthene may be physically entrapped within the nonextractable residues in sediment, and in general this appears to be the most likely fate for the other HOCs (Figure 5.5) that do not possess functional groups through which they could be bound. Alkaline hydrolysis releases entrapped HOCs by hydrolysis and sufficient breakdown of the sedimentary macromolecular OM structure (Northcott and Jones, 2000).

\subsubsection{Radiocarbon as an Inverse Tracer of Contaminants}

Assuming that all contaminants are solvent extractable, the relative contribution of solvent-extractable fossil fuel-derived HOCs to the samples examined in this study can be calculated based on an isotope mass balance (see White et al., 2005) where in terms of radiocarbon abundances $(\Delta)$,

$$
f=(\Delta t-\Delta n) /(\Delta x-\Delta n)
$$

where $\mathrm{f}$ is the fraction of the mixture that is fossil fuel-derived, $\Delta t$ is the decay-corrected $\Delta{ }^{14} \mathrm{C}$ value for the untreated sediment, $\Delta n$ is the corrected $\Delta{ }^{14} \mathrm{C}$ value for the extracted sediment residue (Table 5.3) and $\Delta x$ is the $\Delta^{14} \mathrm{C}$ of fossil fuel-derived HOCs and reflects an absence of ${ }^{14} \mathrm{C}$ (i.e., $\Delta{ }^{14} \mathrm{C}=-1000 \%$ ). Solutions of $f$ were obtained for the samples examined in this study, and are expressed as the percentage of TOC that is fossil fuelderived (Table 5.2). These values are compared to those calculated from resolvable contaminant and UCM concentrations (measured by GC-FID; Table 5.2) relative to TOC content (determined by elemental analysis; Table 5.3). The mass of UCM was converted to carbon equivalents considering the mass contribution of hydrogen to the hydrocarbon, which in an alkane typical of the UCM ( $n-C_{10}$ to $n-C_{38}$ as before) is approximately $15 \%$ of the total. Similar conversions of contaminant quantities to carbon equivalents were performed for the other contaminants examined considering non-carbon elements such as oxygen, nitrogen, chlorine and hydrogen. On average, 95\% of PAHs, $70 \%$ of BZTs, $60 \%$ 
of PCBs and $50 \%$ of DDT and its metabolites are derived from carbon. To evaluate the quantity of bulk OC that these compounds represent, the percent of the TOC that is extractable was calculated by weighing a portion of the TLE and converting this weight to carbon equivalents. The percent of the TLE that is GC amenable was also calculated (Table 5.4).

For the majority of sites examined, there is reasonable agreement between the percent TOC that is fossil fuel-derived determined by GC-FID compared to that calculated by isotope mass balance (Table 5.2). To directly compare these approaches, the difference in $\Delta^{14} \mathrm{C}$ between the untreated sediment $\left(\Delta^{14} \mathrm{C}_{\mathrm{TOC}}\right)$ and extracted sediment residue $\left(\Delta^{14} \mathrm{C}_{\text {EX-RES }}\right)$ is plotted against percent TOC that is fossil fuel-derived, as measured by GC-FID (Figure 5.9). The difference between $\Delta \Delta^{14} \mathrm{C}_{\mathrm{TOC}}$ and $\Delta{ }^{14} \mathrm{C}_{\mathrm{EX}-\mathrm{RES}}$ predominantly represents the removal of fossil organic carbon, assuming that the $\Delta^{14} \mathrm{C}$ of biogenic hydrocarbons contributing to the TLE, is the same as the uncontaminated $\Delta{ }^{14} \mathrm{C}_{\mathrm{TOC}}$ from which it was extracted. In general, as the difference between $\Delta{ }^{14} \mathrm{C}_{\mathrm{TOC}}$ and $\Delta{ }^{14} \mathrm{C}_{\text {EX-RES }}$ becomes more negative, reflecting greater removal of fossil fuel-derived carbon, the contribution of fossil fuel-derived carbon measured by GC-FID also increases. This inverse relationship (first, considering EH as an outlier) is indicated by a solid line in Figure 5.9. The quantity of fossil fuel-derived carbon calculated by isotope mass balance and GC-FID for EH is similar (77 and 72\% respectively; Table 5.2) and thus it may be incorrect to consider it as an outlier. If we instead accept the EH data, then significant differences emerge between these two methods for samples from PV, PR Station 2, NBH, PC, HR, SS (Table 5.2; circled in Figure 5.9). Specifically, the quantity of fossil fuel-derived carbon measured by GC-FID at these sites is underestimated relative to that determined by isotope mass balance. Excluding these samples reveals an inverse relationship with a strong correlation $\left(\mathrm{r}^{2}=0.96, \mathrm{p}=9.28 \times 10^{-8}\right)$.

For sites above the regression line such as $\mathrm{TC}$ and $\mathrm{BH}$, the \% $\mathrm{TOC}$ that is fossil fuel-derived as calculated by mass balance is less than that measured by GC-FID. In these sites, the quantity of contaminant is small ( 0.5 and $0.02 \%$, respectively) and the lowest observed in the range of samples examined (Table 5.2). The negative values of 


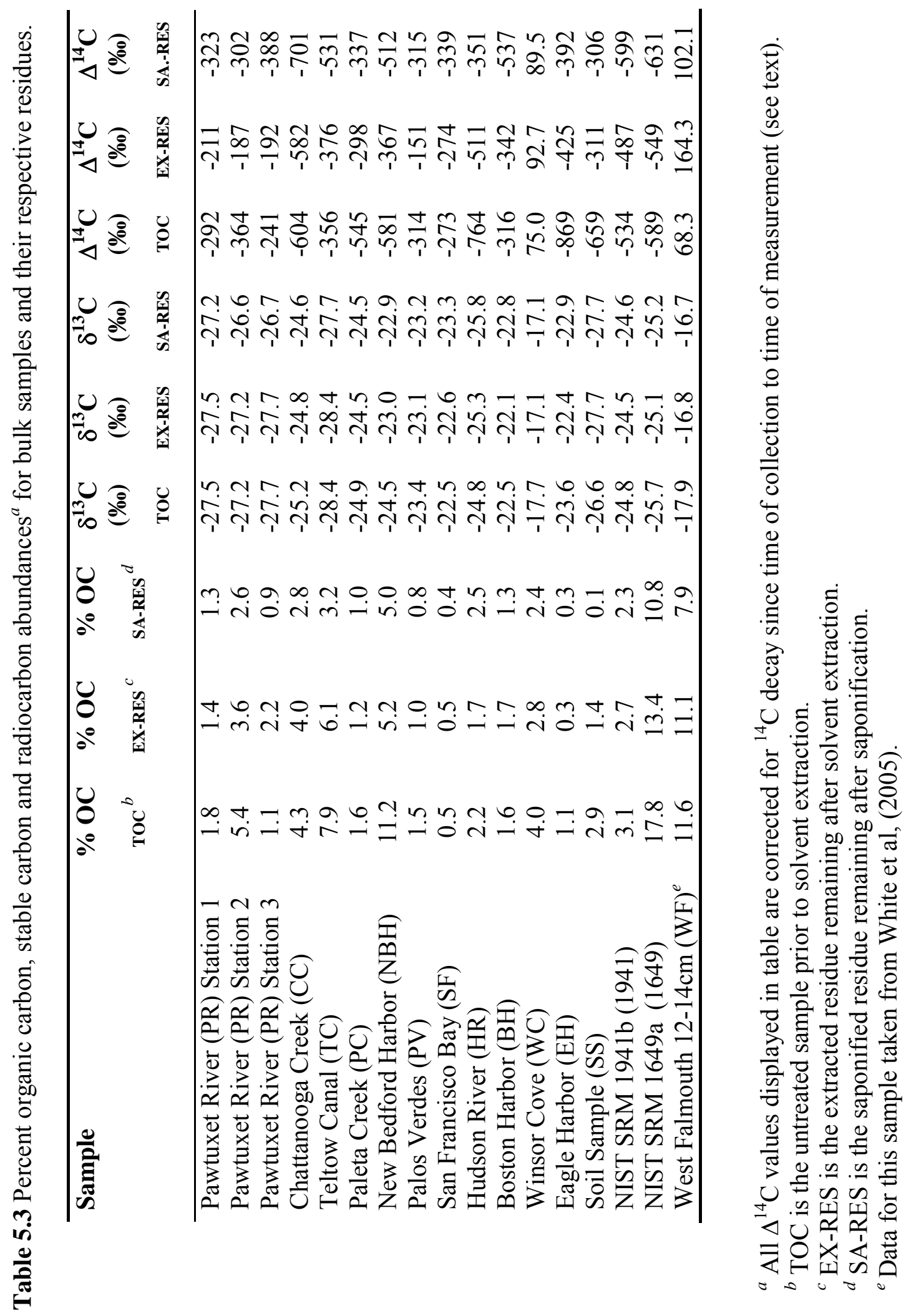


\%TOC that is fossil fuel-derived as calculated by mass balance at these sites and SF,

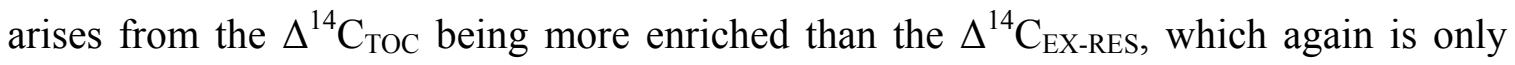
observed at these sites (Table 5.3). This likely occurs as a result of the removal of biogenic, solvent extractable ${ }^{14} \mathrm{C}$ enriched material which leaves behind a relatively depleted EX-RES. This is supported by GC analyses of the TLE for these sites, which are dominated by biogenic hydrocarbons (Figure 5.4c).

Understanding why the quantity of fossil fuel-derived carbon is underestimated by GC-FID, however, is more complex as these samples are contaminated with different HOCs of varying concentrations and include soil as well as marine and freshwater environments. The commonality between them is that they contain significantly more fossil fuel-derived carbon than the sites that fit the trend (19-52\% compared to $0-10 \%$ respectively by mass balance; Table 5.2). Good agreement between the percent contribution of petroleum to the TOC calculated by GC-FID compared to isotope mass balance was observed in the study of West Falmouth sediments (White et al., 2005; a representative contaminated sediment horizon is shown in Figure 5.9), where the contribution of petroleum was always less than $10 \%$. The exception to this, however, is $\mathrm{EH}$, which is the most heavily contaminated sample, but displays good agreement between the percent contribution of fossil fuel-derived contaminants determined by GCFID and mass balance (72 and 77\% respectively; Table 5.2). Compared to other samples, $\mathrm{EH}$ is composed of coarse sandy material and has a low OC content when the creosote is removed $(0.3 \%)$, whereas other sites have OC contents of $0.5-13.4 \%$ (Table 5.3). Organic carbon content may affect the ability to correctly determine the \%TOC that is fossil fuel-derived by GC-FID if sediments are organic carbon rich, and large quantities of extractable biogenic hydrocarbons lessen the impact of ${ }^{14} \mathrm{C}$-dead fossil carbon or mask the contribution of HOCs observable by GC. The outliers in Figure 5.5, however, have varying OC contents $(1.6-11.2 \%$; Table 5.3$)$ and a range in quantities of \%TOC that is extractable ( $3-67 \%$; Table 5.4) and thus this does not appear to be a controlling factor. The quantity of the TLE that is GC amenable, however, plays a more significant role. In the case of EH, 77\% of the TLE is GC-amenable, but for the samples that do not fit the 


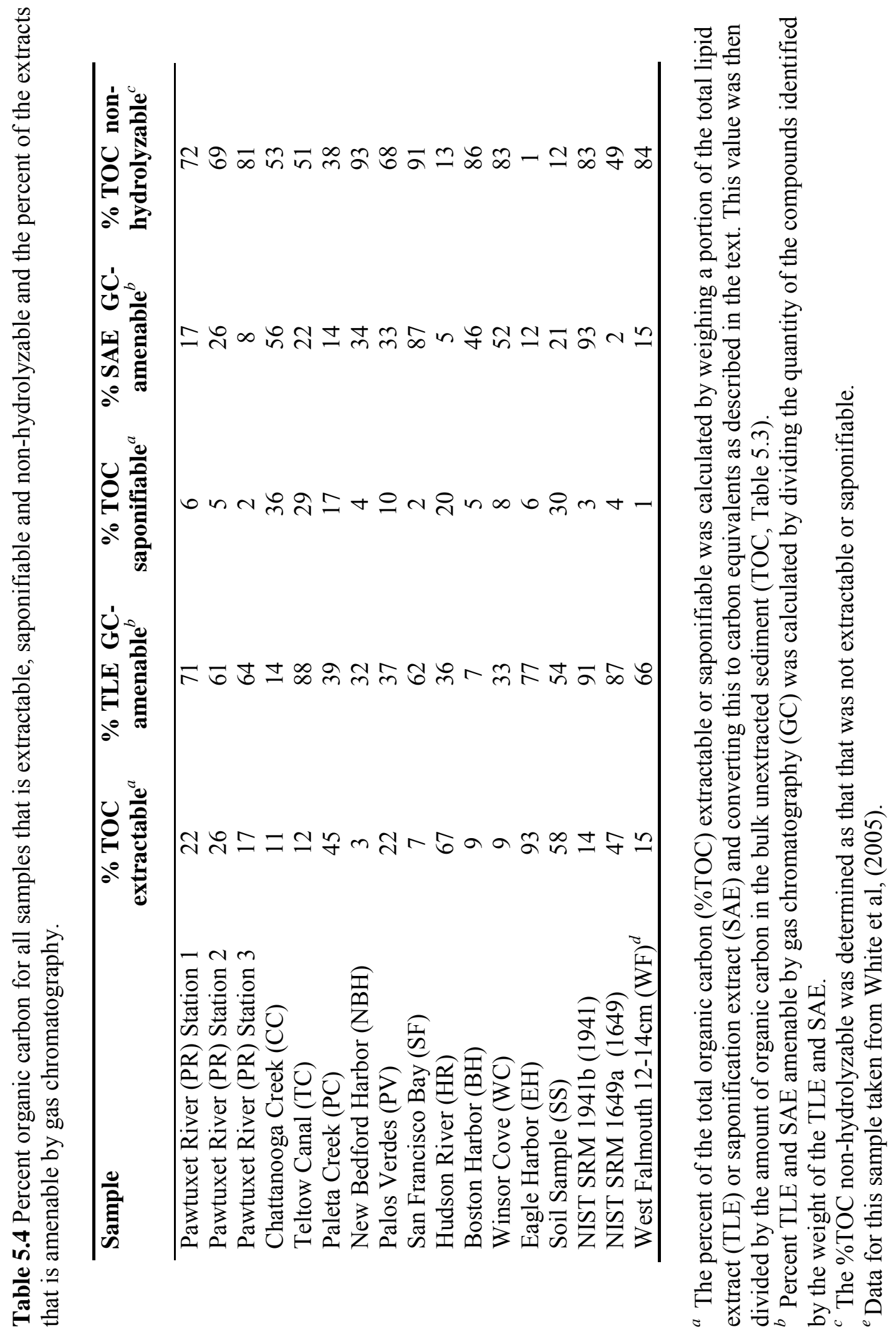




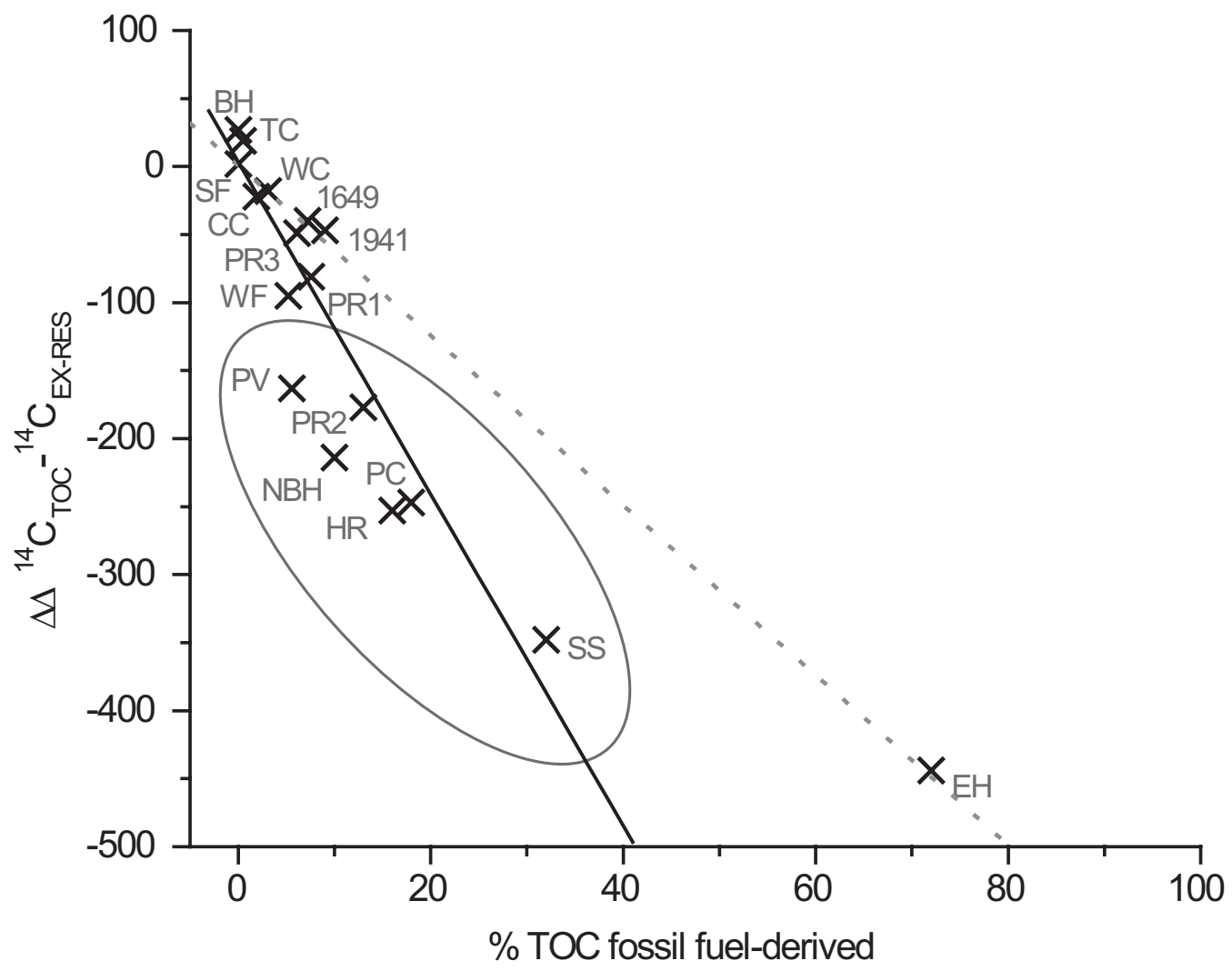

Figure 5.9 Difference between $\Delta^{14} \mathrm{C}$ of unextracted sediment (TOC) and solventextracted sediment residue (EX-RES) as a function of percent TOC that is comprised of solvent-extractable fossil-fuel-derived contaminants measured by gas chromatography.

trend, this value is much less $(32-61 \%$; Table 5.4). To examine this further, the deviation from the linear regression in Figure 5.5 is plotted against \%TLE that is non-GC amenable (Figure 5.10). An inverse relationship with strong correlation $\left(\mathrm{r}^{2}=0.82\right.$, $\mathrm{p}=0.00004$ ) is observed. This regression excludes $\mathrm{BH}, \mathrm{CC}$, and $\mathrm{WC}$ samples that exhibit a high percentage of non-GC-amenable TLE (67 - 93\%), but display reasonable agreement between the \%TOC fossil fuel-derived calculated by the two methods. Fossil fuel-derived HOCs and/or metabolites that are extractable may not be GC-amenable if they are bound within the TLE. This solvent extractable, but chemically bound pool may be quantitatively significant and requires further investigation. 


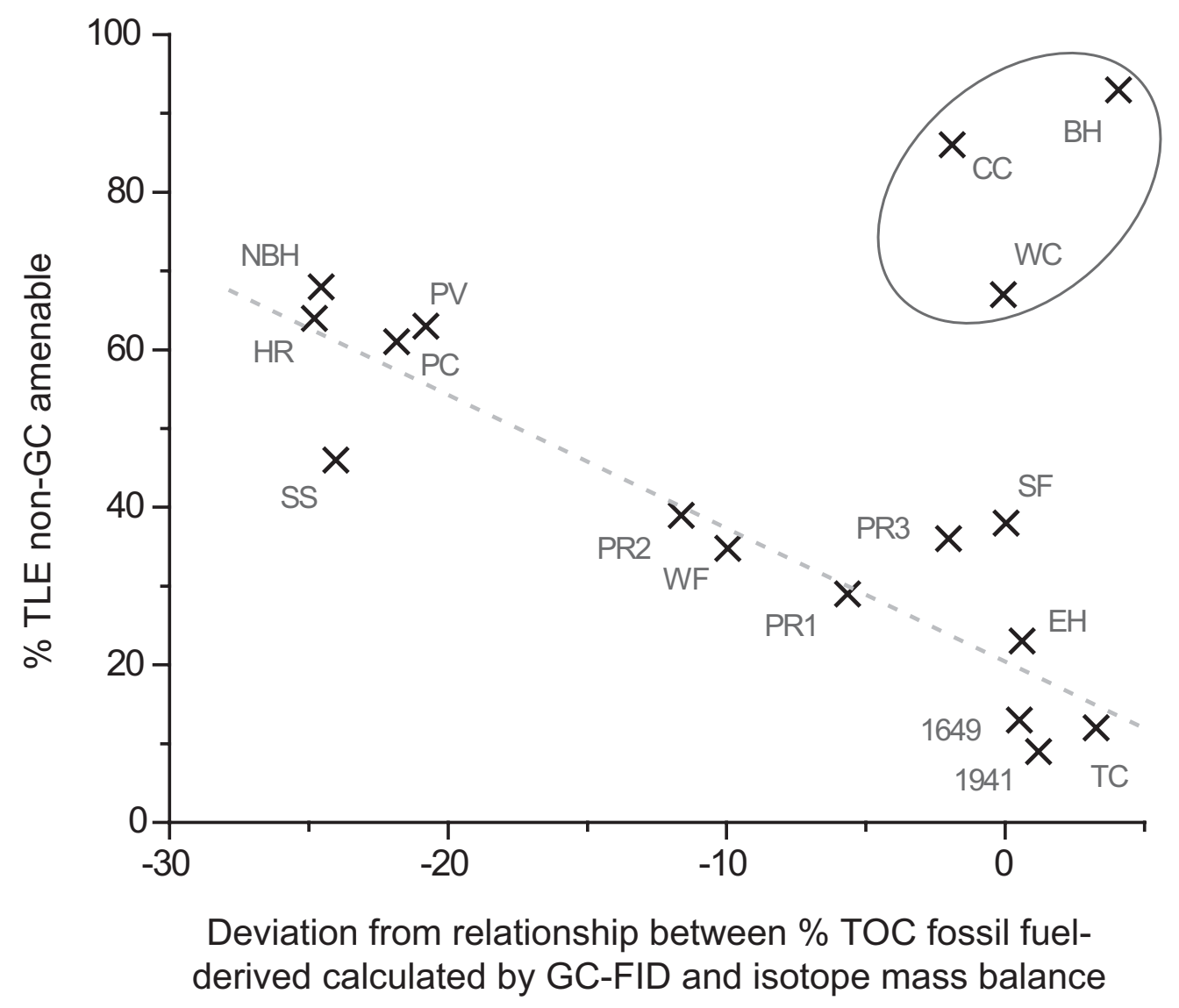

Figure 5.10 Difference between the percent of total lipid extract (TLE) that is non-GC amenable and the deviation from the relationship between the percent total organic carbon (\%TOC) that is fossil-fuel derived calculated by GC-FID and isotope mass balance.

Additional fossil inputs to the sediments that are not contaminant derived, but instead come from "pre-aged" natural organic carbon sources such as remobilization of soil carbon and weathering of sedimentary rocks (Masiello and Druffel, 2001; Blair et al., 2004; Goñi et al., 2005), may also play a role in the underestimation of \%TOC that is fossil fuel-derived as calculated by GC-FID. There is no obvious molecular evidence for contributions of these sources in the SAE, but "pre-aged" carbon may be metabolized by 
microbes and incorporated into biogenic lipids (Petsch et al., 2001) that would not be incorporated into the GC-FID quantification of fossil carbon derived from HOCs. Because of this potential uncontaminated control sites of similar depositional setting provide a useful comparison. This was possible for the PR sites where an upstream site (Station 3) was compared to a contaminated site downstream (Station 2). The $\Delta{ }^{14} \mathrm{C}_{\mathrm{TOC}}$ was different at the two sites owing to the more significant contamination at Station 2 (8.41 $\mathrm{mg} \mathrm{g}^{-1}, \Delta^{14} \mathrm{C}_{\mathrm{TOC}}=-354 \%$ ) than at Station $3\left(0.79 \mathrm{mg} \mathrm{g}^{-1}, \Delta^{14} \mathrm{C}_{\mathrm{TOC}}=-292 \%\right)$, but

once the majority of contaminant was removed the remaining $\Delta{ }^{14} \mathrm{C}_{\mathrm{EX}-\mathrm{RES}}$ of Stations 2 and 3 are very similar (-187\%o and $-192 \%$ respectively) indicating that most of the fossil fuel-derived carbon has been removed by solvent extraction.

\subsubsection{Isotopic Evidence of Nonextractable Contaminants}

To examine the quantity of fossil fuel-derived carbon removed by alkaline hydrolysis, equation (I) as described before is applied, but instead, $\Delta t$ is the corrected $\Delta{ }^{14} \mathrm{C}$ values for EX-RES and $\Delta n$ is the corrected $\Delta{ }^{14} \mathrm{C}$ values for the SA-RES (Table 5.3). Although bound contaminants are observed in PR St. 2, TC and CC9, as previously described, this is not observable by mass balance as they contribute only $0.002 \%, 0.4 \%$, $0.02 \%$, respectively, of OC (calculated by GC-FID) to the EX-RES. This is insufficient to be detected by isotope mass balance (see earlier discussion on sensitivity of approach). Samples from SS and EH, do, however, exhibit isotopic evidence for the presence of nonextractable (i.e. ester-bound) contaminant residues. For SS, isotope mass balance indicates that $1.2 \%$ of $\mathrm{OC}$ in the EX-RES is fossil fuel-derived, which agrees well with that obtained by comparing the amount quantified by GC-FID to the OC content of EXRES (determined by elemental analysis; Table 5.3). At EH, however, isotope mass balance indicates greater formation of nonextractable residues than that measured by GCFID, $5 \%$ compared to $0.1 \%$ respectively. This discrepancy may be due to the reasons discussed previously as only $12 \%$ of the SAE is GC amenable at this site (Table 5.4).

Analysis of the HR saponification extracts by GC-FID did not reveal any detectable contaminants (Figure 5.6b and 5.7b) or potential metabolites, but isotope mass 
balance indicates that $25 \%$ of OC from the EX-RES is fossil fuel-derived. Because this site is contaminated with PCBs, electron capture negative ionization gas chromatography was used to probe for chlorinated compounds. The major chlorinated compound detected in the SAE was octachlorodibenzofuran (OCDF; Figure 5.5), at a concentration of $\sim 1 \mu \mathrm{g}$ $\mathrm{g}^{-1}$, which does not account for all of the fossil carbon detected by mass balance, likely due to the reasons previously discussed for solvent extractable HOCs. Furans are generally unwanted byproducts from the manufacturing of other chemicals such as some disinfectants, wood preservatives and herbicides, as well as being emitted during combustion processes such as the incineration of municipal and industrial waste, wood and gasoline burning. Polychlorinated dibenzo-p-dioxins (PCDD) have previously been observed in geological formations that are free of human impact (Ferrario et al., 2000; Rappe et al., 2000), suggesting that these compounds, that are quite similar in structure to dibenzofuans (PCDF), may be formed in nature. Whilst PCDDs and PCDFs are observed in surface sediments, corresponding pre-industrial coastal sediments (Hashimoto et al., 1990) and lake sediments (Isosaari et al., 2002) detect only PCDDs in pre-industrial horizons and note that OCDF is below detection limits. This suggests therefore that OCDF is most likely to be anthropogenically-derived. The structure of OCDF does not suggest that it was chemically bound to OM, but instead was likely to be physically associated.

At sites where significant quantities of nonextractable HOCs are detected (HR, $\mathrm{EH}$ and SS) the $\Delta^{14} \mathrm{C}_{\mathrm{SA}-\mathrm{RES}}$ is more enriched than $\Delta{ }^{14} \mathrm{C}_{\mathrm{EX}-\mathrm{RES}}$ (Table 5.3), due to the removal of this fossil $\left({ }^{14} \mathrm{C}\right.$-dead) carbon. At all other sites, the $\Delta{ }^{14} \mathrm{C}_{\mathrm{SA}-\mathrm{RES}}$ is more depleted than the $\Delta{ }^{14} \mathrm{C}_{\text {EX-RES }}$ (Table 5.3), indicating the removal of relatively ${ }^{14} \mathrm{C}$ enriched material. These observations are summarized in Figure 5.11 where the difference in $\Delta^{14} \mathrm{C}$ isotopic composition between the two residues $\left(\Delta \Delta^{14} \mathrm{C}_{\text {EX-RES }}-\Delta^{14} \mathrm{C}_{\mathrm{SA}-\mathrm{RES}}\right)$ is plotted against the difference in $\delta^{13} \mathrm{C}$ isotopic composition between the two residues $\left(\Delta \delta^{13} \mathrm{C}_{\mathrm{EX}}\right.$ RES $\left.-\delta^{13} \mathrm{C}_{\mathrm{SA}-\mathrm{RES}}\right)$. The majority of samples examined in this study exhibit $\Delta \Delta^{14} \mathrm{C}_{\text {EX-RES }}$ $\Delta{ }^{14} \mathrm{C}_{\mathrm{SA}-\mathrm{RES}}$ differences $>1$ indicating the removal of modern organic carbon. This has previously been observed (White et al., 2005) and similarly, the saponified extracts are 
mainly comprised of intrinsically labile, but chemically protected biogenic compounds dominated by short chain $n$-alkanoic acids (Figure 5.8). Differences in $\Delta \Delta^{14} \mathrm{C}_{\mathrm{EX}-\mathrm{RES}}$ $\Delta \Delta^{14} \mathrm{C}_{\mathrm{SA}-\mathrm{RES}}<1$ are only observed for SS, EH and HR samples and reflect the removal of varying degrees of fossil fuel-derived HOCs.

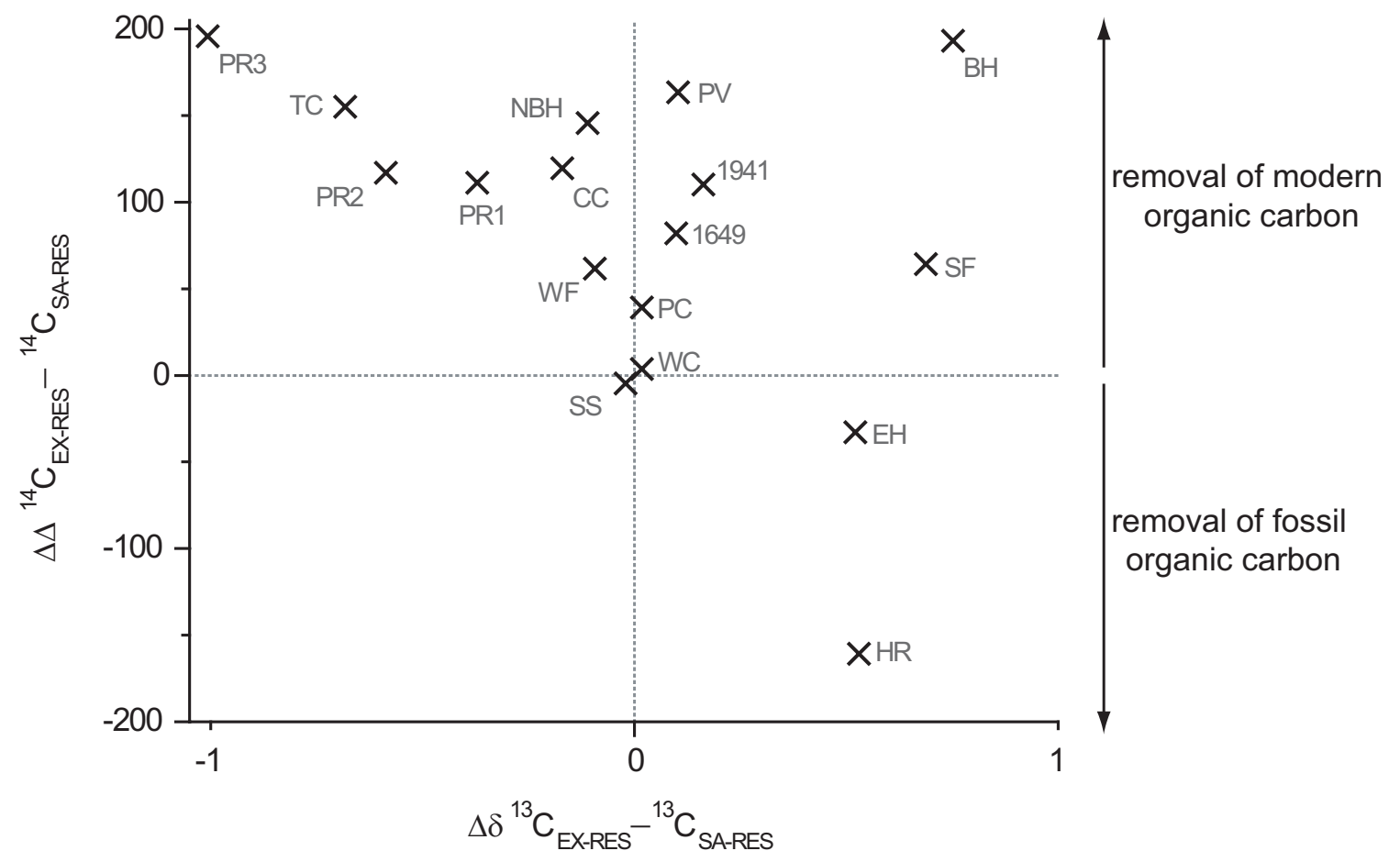

Figure 5.11 Difference between $\Delta^{14} \mathrm{C}$ of solvent-extracted (EX-RES) and saponified (SA-RES) sediment residues plotted against the difference between $\delta^{13} \mathrm{C}$ of solventextracted (EX-RES) and saponified (SA-RES) sediment residues.

By comparison, the $\Delta \delta^{13} \mathrm{C}_{\mathrm{EX} \text {-RES }}-\delta^{13} \mathrm{C}_{\mathrm{SA}-\mathrm{RES}}$ is much less and only a $\pm 1 \%$ difference is observed. In general differences in $\delta^{13} \mathrm{C}$ of the bulk sediments and residues are not observed as a result of the sequential treatments. This is likely due to the fact that there is no significant isotopic difference between the biogenic hydrocarbons and HOCs. The $\delta^{13} \mathrm{C}$ of many of the HOCs examined in this study has been measured, for example, petroleum derived UCM is typically -27\%o (Reddy et al., 2002b), Aroclor mixtures of PCBs range from $-26.6-25.7 \%$ and DDT is $-28.3 \%$ (Drenzek et al., 2002). For samples 
from NBH, PC, BH, CC, EH, WC and 1649 , the $\delta^{13} \mathrm{C}_{\mathrm{TOC}}$ is more depleted than the $\delta^{13} \mathrm{C}_{\mathrm{EX}-\mathrm{RES}}$ reflecting the contribution of these HOCs that are likely more depleted than the uncontaminated TOC represented by the EX-RES. At PV, PR all stations, 1941, TC and $\mathrm{SF}$ the $\delta^{13} \mathrm{C}_{\mathrm{TOC}}$ and $\delta^{13} \mathrm{C}_{\mathrm{EX} \text {-RES }}$ are the same within error (0.1\%) indicating that unlike ${ }^{14} \mathrm{C}$, shifts in $\delta^{13} \mathrm{C}$ are too insensitive to provide evidence for the presence of these HOCs.

\subsection{CONCLUSIONS}

In general the contribution of HOCs to the TOC in sediments as calculated by GC-FID shows good agreement with that calculated by isotope mass balance. Offsets between the two approaches mostly arise from the fact that not all of the fossil fuelderived carbon in the extracts is GC-amenable. Overall, alkaline hydrolysis does not release significant quantities of HOCs, but exceptions exist and up to $40 \%$ of the total pool of DDT and its metabolites are associated with nonextractable residues in TC sediments. This quantity, however, only comprises a small fraction of the TOC and thus the presence of these nonextractable HOCs is not detectable by isotope mass balance. Conversely, in HR sediments, $25 \%$ of the extracted sediment residue is comprised of fossil carbon as calculated by mass balance, but there is little evidence by GC/MS of the HOCs that constitute this pool. It is therefore unclear whether this fossil carbon is derived from HOCs or from natural pre-aged carbon inputs.

The lack of significant chemical binding of HOCs to OM in aquatic sediments may arise from the absence of a suitable chemical environment for this to occur. Sediments are water saturated and thus condensation reactions that form ester linkages are energetically unfavorable and reactive species such as hydroxyl radicals are less present than they are in a soil environment for example. Binding of HOCs to sedimentary $\mathrm{OM}$ is therefore more likely to be dependent on mediation by microorganisms and the lack of binding in these sites reflects an inefficiency of microbial populations to mediate these processes that occur in soil environments. 
It is important to note that the sensitivity of the inverse ${ }^{14} \mathrm{C}$ approach is linked to the TOC content of the sediment. For example, in sediments where TOC and extractable $\mathrm{OM}$ are high, even if absolute concentrations of HOC are also high, they may be diluted by abundant and relatively modern carbon. Conversely in sediments where TOC contents are low, HOCs may be more easily detected. This study, however, has examined a variety of sediments with wide ranging TOC contents and binding of HOCs has not been found to be significant. Future work examining contaminated sediments with low TOC contents, or those where binding has previously been observed could, however, prove this more definitively.

Chemical binding between HOCs and OM enables HOCs to persist in sediments, but in this form, they lose their chemical identity making them less bioavailable and less toxic (Gevao et al., 2000). HOCs are clearly persistent in the sites examined in this study, but this is not due to the presence of covalent bonds between HOCs and OM and therefore the majority of HOCs are freely associated in their original and potentially toxic forms.

\subsection{REFERENCES}

Beller, H.R., Simoneit, B.R.T. 1988. Hexachlorophene distributions in estuarine sediments. Bulletin of Environmental Contamination and Toxicology 41, 645-650.

Blair, N.E., Leithold, E.L., Aller, R.C., 2004. From bedrock to burial: the evolution of particulate organic carbon across coupled watershed-continental margin systems. Marine Chemistry 92, 141-156.

Bothner, M.H., Casso, M.A., Rendigs, R.R. Lamothe, P.J. 2002. The effect of the new Massachusetts Bay sewage outfall on the concentrations of metals and bacterial spores in nearby bottom and suspended sediments. Marine Pollution Bulletin 44, 1063-1070.

Brenner, R.C., Magar, V.S., Ickes, J.A., Abbott, J.E., Stout, S.A., Crecelius, E.A., Bingler, L.S. 2002. Characterization and fate of PAH-contaminated sediments at the Wyckoff/Eagle Harbor Superfund site. Environmental Science and Technology 36, 2605-2613.

Burgess, R.M., McKinney, R.A. 1997 Effects of sediment homogenization on interstitial water PCB geochemistry. Archives of Environmental Contamination and Toxicology $33,125-129$. 
Dec, J., Haider, K., Schäffer, A., Fernandes, E., Bollag, J. -M. 1997. Use of a silylation procedure and ${ }^{13} \mathrm{C}-\mathrm{NMR}$ spectroscopy to characterize bound and sequestered residues of cyprodinil in soil. Environmental Science and Technology 31, 2991-2997.

Dec, J., Bollag, J. -M. 1997. Determination of covalent and noncovalent binding interactions between xenobiotic chemicals and soil. Soil Science 162, 858-874.

Deshmukh, A.P., Chefetz, B., Hatcher, P.G. 2001. Characterization of organic matter in pristine and contaminated coastal marine sediments using solid-state ${ }^{13} \mathrm{C}-\mathrm{NMR}$, pyrolytic and thermochemolytic methods: a case study in the San Diego harbor area. Chemosphere 45, 1007-1022.

Drenzek, N.J., Tarr, C.H., Eglinton, T.I., Heraty, L.J., Sturchio, N.C., Shiner, V.J., Reddy, C.M. 2002.Stable chlorine and carbon isotopic compositions of selected semivolatile organochlorine compounds. Organic Geochemistry 33, 437-444.

Eganhouse, R.P., Pontolillo, J., Leiker, T.J. 2000. Diagenetic fate of organic contaminants on the Palos Verdes Shelf, California. Marine Chemistry 70, 289-315.

Eriksson, J., Frankki, S., Shchukarev, A., Skyllberg, U. 2004. Binding of 2,4,6Trinitrotoluene, Aniline, and Nitrobenzene to Dissolved and Particulate Soil Organic Matter. Environmental Science and Technology 38, 3074-3080.

Ferrario, J.P., Byrne, C.J., Cleverly, D.H. 2000. 2,3,7,8-dibenzo-p-dioxins in mined clay products from the United States. Evidence for possible natural origin. Environmental Science and Technology 34, 4524-4532.

Gevao, B., Semple, K.T., Jones, K.C. 2000. Bound pesticide residues in soils: a review. Environmental Pollution 108, 3-14.

Goñi, M.A., Yunker, M.B., Macdonald, R.W., Eglinton, T.I. 2005. The supply and preservation of ancient and modern components of organic carbon in the Canadian Beaufort Shelf of the Arctic Ocean. Marine Chemistry 93, 53-73.

Greenfield, B.K., Davis, J.A., 2005. A PAH fate model for San Francisco Bay. Chemosphere 60, 515-530.

Grice, K., Klein-Breteler, W.C.M., Schouten, S., Grossi, V., de-Leeuw, J.W., SinningheDamste, J.S. 1998. Effects of zooplankton herbivory on biomarker proxy records. Paleoceanography 13, 686-693.

Grifoll, M., Casellas, M., Bayona, J.M., Solanas, A.M. 1992. Isolation and characterization of a fluorene-degrading bacterium: identification of ring oxidation and ring fission products. Applied and Environmental Microbiology 58, 2910-2917.

Hashimoto, S., Wakimoto, T., Tatsukawa, T. 1990. PCDDs in the sediments accumulated about 8120 years ago from Japanese coastal areas. Chemosphere 21, 825-835.

Heitkamp, M.A., Freeman J.P., Cerniglia C.E. 1987. Naphthalene biodegradation in environmental microcosms: Estimates of degradation rates and characterization of metabolites. Applied and Environmental Microbiology 53, 129-136.

Isosaari, P., Pajunen, H., Vartiainen, T. 2002. PCDD/F and PCB history in dated sediments of a rural lake. Chemosphere 47, 575-583.

Kohl, S.D., Rice, J.A. 1998. The binding of contaminants to humin: a mass balance. Chemosphere 37, 341-361. 
Masiello, C.A., Druffel, E.R.M., 2003. Organic and black carbon C-13 and C-14 through the Santa Monica Basin sediment oxic-anoxic transition. Geophysical Research Letters 30, 1185.

March, J. Advanced Organic Chemistry: Reactions, Mechanisms and Structure. $4^{\text {th }}$ ed. John Wiley \& Sons, Inc., New York 1992.

McNichol, A.P., Osborne, E.A., Gagnon, A.R., Fry, B., Jones, G.A. 1994. TIC, TOC, DIC, DOC, PIC, POC-unique aspects on the preparation of oceanographic samples for ${ }^{14} \mathrm{C}$-AMS. Nuclear Instruments and Methods in Physics Research B92, 162-165.

Northcott, G.L., Jones, K.C. 2000. Experimental approaches and analytical techniques for determining organic compound bound residues in soil and sediment. Environmental Pollution 108, 19-43.

Peacock, E. E., Nelson, R. K., Solow, A. R., Warren, J. D., Baker, J. L., Reddy, C. M. 2005. The West Falmouth oil spill: $100 \mathrm{~kg}$ of oil found to persist decades later. Environmental Forensics 2005, 6, 273-281.

Pearson, A., Eglinton, T.I. 2000. The origin of $n$-alkanes in Santa Monica Basin surface sediment: A model based on compound-specific $\Delta^{14} \mathrm{C}$ and $\delta^{13} \mathrm{C}$ data. Organic Geochemistry 31, 1103-1116.

Petsch, S.T., Eglinton, T.I., Edwards, K.J. 2001. C-14-dead living biomass: Evidence for microbial assimilation of ancient organic carbon during shale weathering. Science 292, 1127-1131.

Rappe, C., Andersson, R., Cooper, K., Bopp, R., Fiedler, H., Howell, F., Bonner, M. 2000. Concentrations of PCDDs in naturally-formed and man-made lake sediment cores from southern Mississippi, USA. Organohalogen Compounds 46, 19-22.

Reddy, C.M., Quinn J.G., King J. 2000a. Free and bound benzotriazoles in marine and freshwater sediments. Environmental Science and Technology 34, 973-979.

Reddy, C.M., Heraty, L.J., Holt, B.D. Sturchio, N.C., Eglinton, T.I., Drenzek, N.J., Xu, L., Lake, J.L., Maruya, K.A. 2000b. Stable chlorine isotopic composition of Aroclors and Aroclor-contaminated sediments. Environmental Science and Technology 34, 2866-2870.

Reddy, C.M., Pearson, A., Xu, L., McNichol, A., Benner Jr, B.A., Wise, S.A., Klouda, G.A., Currie, L.A., Eglinton, T.I. 2002a. Radiocarbon as a tool to apportion the sources of polycyclic aromatic hydrocarbons and black carbon in environmental samples. Environmental Science and Technology 36, 1774-1782.

Reddy, C.M., Xu, L., Quinn, J.G., Hartmann, P.C. 2002b. Investigating the radiocarbon content of the unresolved complex mixture. Abstracts of the American Chemical Society, Division of Environmental Chemistry 224, 32.

Richnow, H.H., Seifert, R., Hefter, J., Kästner, M., Mahro, B., Michaelis, W. 1994. Metabolites of xenobiotica and mineral oil constituents linked to macromolecular organic matter in polluted environments. Organic Geochemistry 22, 671-681.

Richnow, H.H., Seifert, R., Kästner, M., Mahro, B., Horsfield, B., Tiedgen, U., Böhm S., Michaelis, W. 1995. Rapid screening of PAH residues in bioremediated soils. Chemosphere 31, 3991-3999. 
Richnow, H.H., Seifert, R., Hefter, J., Link, M., Francke, W., Schaefer G., Michaelis W. 1997. Organic pollutants associated with macromolecular soil organic matter - a mode of binding. Organic Geochemistry 26, 745-758.

Richnow, H.H., Eschenbach, A., Seifert, R., Wehrung, P., Albrecht P. Michaelis W. 1998. The use of ${ }^{13} \mathrm{C}$-labelled polycyclic aromatic hydrocarbons for the analysis of their transformation in soils. Chemosphere 36, 2211-2224.

Richnow, H.H., Eschenbach, A., Mahro B., Kästner, M., Annweiler, E., Seifert R., Michaelis W. 1999. Formation of nonextractable soil residues: A stable isotope approach. Environmental Science and Technology 33, 3761-3767.

Richnow, H.H., Annweiler, E., Koning, M., Lüth, J.-C., Stegmann, R., Garms, C., Francke W., Michaelis W. 2000. Tracing the transformation of labeled [1-13C] phenanthrene in a soil bioreactor. Environmental Pollution 108, 91-101.

Roberts, T.R. 1984. Nonextractable pesticide residues in soils and plants. IUPAC reports on pesticides. Pure and Applied Chemistry 56, 945-956.

Schwarzbauer, J., Ricking, M., Littke, R. 2003. DDT-Related compounds bound to the nonextractable particulate matter in sediments of the Teltow Canal, Germany. Environmental Science and Technology 37, 488-495.

Sjobald, R.D., Bollag, J.M. 1977. Oxidative coupling of aromatic pesticide intermediates by a fungal phenol oxidase. Applied Environmental Microbiology 33, 906-910.

Slater, G., White, H. K., Eglinton, T. I., Reddy, C.M. 2005. Determination of microbial carbon sources in petroleum contaminated sediments using molecular ${ }^{14} \mathrm{C}$ analysis. Environmental Science and Technology 39, 2552-2558.

Steinberg, S.M., Pignatello, J.J., Sawhney, B.L. 1987. Persistence of 1,2-dibromoethane in soils: Entrapment in intraparticle micropores. Environmental Science and Technology 21, 1201-1208.

Stuiver, M., Polach, H.A., 1977. Discussion: reporting of ${ }^{14} \mathrm{C}$ data. Radiocarbon 19, 355363.

Teal, J.M., Burns, K., Farrington, J. 1978. Analyses of aromatic hydrocarbons in intertidal sediments resulting from two spills of No. 2 fuel oil in Buzzards Bay, Massachusetts. Journal of the Fisheries Research Board of Canada 35, 510-520.

Walker, A. C. 2002. The fate of 13C-phenanthrene in marine harbor sediments under anaerobic conditions. M.Sc., University of Tennessee at Chattanooga, Chattanooga, TN.

Wei, M., Yuan, Q., Evans, D.G., Wang, Z., Duan, X. 2005. Layered solids as "molecular container" for pharmaceutical agents: L-tyrosine-intercalated layered double hydroxides. Journals of Materials Chemistry 15, 1197-1203.

White, H.K., Reddy, C.M., Eglinton, T.I., 2005. Isotopic constraints on the fate of petroleum residues sequestered in salt marsh sediments. Environmental Science and Technology 39, 2545-2551.

Xu, J.M., Gan, J., Papiernik, S.K., Becker, J.O., Yates, S.R. 2003. Incorporation of Fumigants into Soil Organic Matter. Environmental Science and Technology 37, 1288-1291. 
Zhang X., Young, L.Y. 1997. Carboxylation as an initial reaction in the anaerobic metabolism of naphthalene and phenanthrene by sulfidogenic consortia. Applied and Environmental Microbiology 63, 4759-4764. 
5.6 APPENDIX 


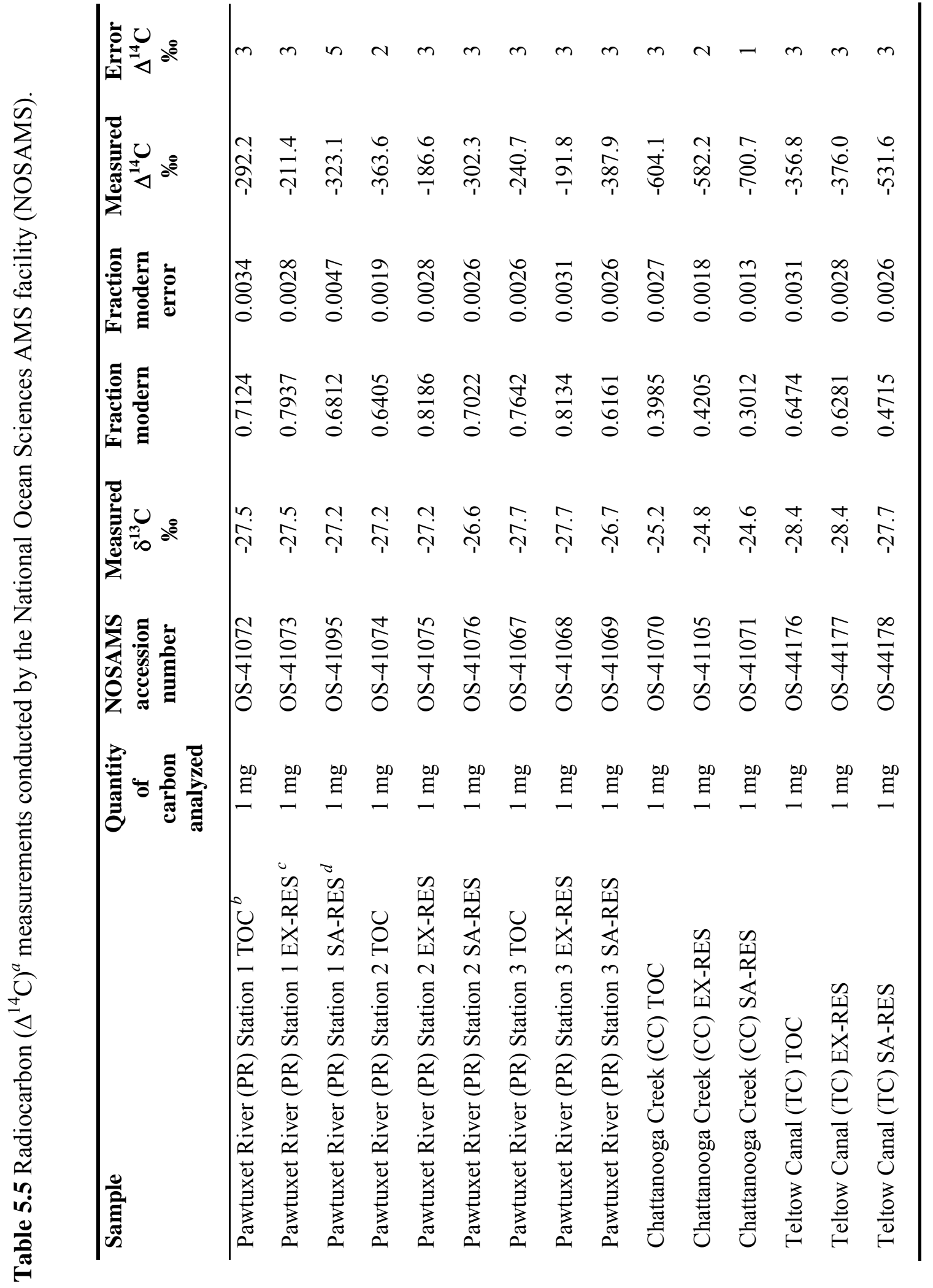




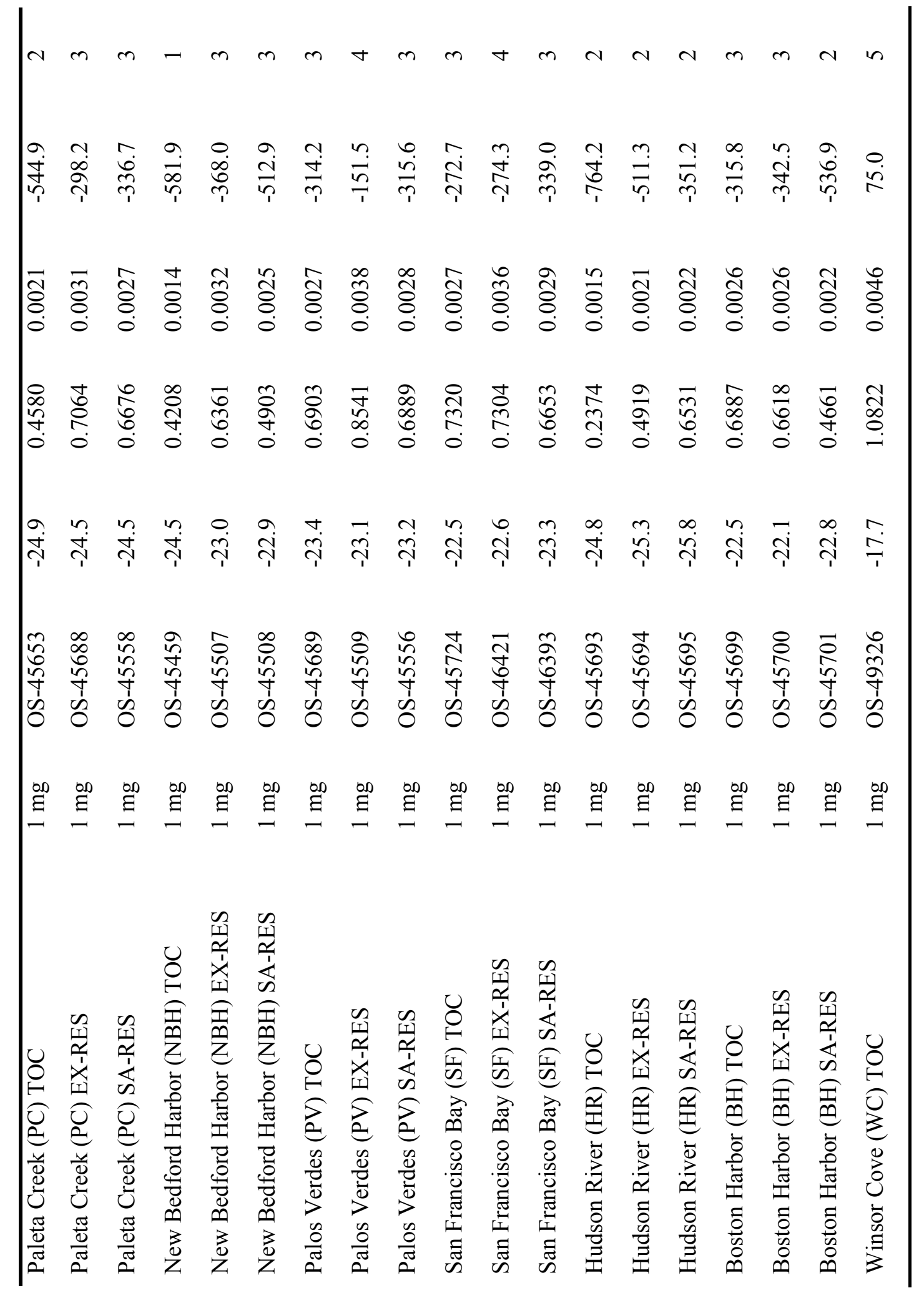




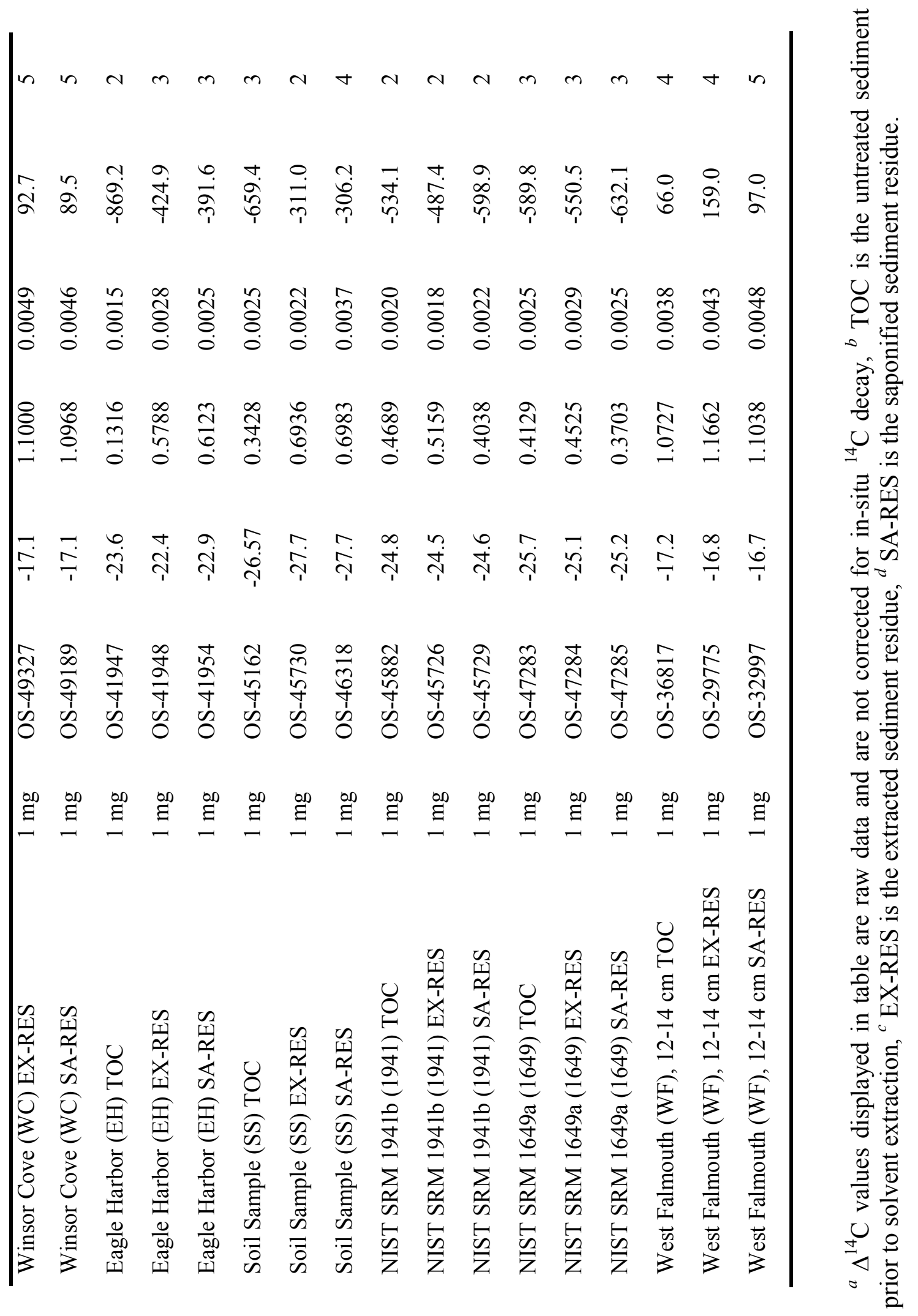




\title{
CHAPTER 6
}

\section{ISOTOPIC CONSTRAINTS ON THE PROVENANCE OF INDIVIDUAL BIOMARKERS IN SALT MARSH SEDIMENTS}

\begin{abstract}
Natural abundance radiocarbon contents $\left(\Delta^{14} \mathrm{C}\right)$ of individual short $\left(n-\mathrm{C}_{14-18}\right)$ and long-chain $\left(n-\mathrm{C}_{24-28}\right)$ fatty acids and long-chain $\left(n-\mathrm{C}_{26}-\mathrm{C}_{32}\right)$ alkanes from salt marsh sediments impacted by an oil spill in 1969 were measured to determine their provenance. The oil spill represents a pulsed introduction of ${ }^{14} \mathrm{C}$-free organic matter, however, the timing of the oil spill coincided with a period of intense above-ground testing of thermonuclear weapons, and thus salt marsh sediments deposited during this period are also influenced by an excess quantity of ${ }^{14} \mathrm{C}$. Compound specific isotope analysis (CSIA) of free and bound short-chain fatty acids displays ${ }^{14} \mathrm{C}$ abundances that reflect marine algal and bacterial inputs to the marsh sediments, while isotopic characteristics $\left({ }^{13} \mathrm{C},{ }^{14} \mathrm{C}\right)$ of long-chain fatty acids are consistent with an origin from the $\mathrm{C}_{4}$ salt marsh cord grass Spartina alterniflora. Molecular distributions and $\Delta^{14} \mathrm{C}$ and $\delta^{13} \mathrm{C}$ values of $n$-alkanes indicate that they are predominantly biogenic with lesser contributions from pyrogenic sources (late $20^{\text {th }}$ century horizons). Even within the oil contaminated sediment horizon, ${ }^{14} \mathrm{C}$ data unequivocally show that petroleum-derived $n$-alkanes are absent, demonstrating that these compounds have been completely removed through processes such as evaporation, dissolution and/or biodegradation. In contrast, the persistence of $n$-alkanes equivalent in carbon number, but instead derived from biogenic and pyrogenic sources, indicates that their resistance to degradation is most likely due to a form of physical protection or association with the sedimentary matrix.
\end{abstract}




\subsection{INTRODUCTION}

To further our understanding of the cycling of organic carbon in salt marsh sediments, and to complement previous studies examining the persistence of petroleum residues in these environments (Reddy et al., 2002; White et al., 2005a; Slater et al., 2005), compound specific isotope analysis (CSIA) of individual solvent-extractable and saponifiable biomarker lipids including long-chain $\left(n-\mathrm{C}_{26-32}\right)$ alkanes and individual short $\left(n-\mathrm{C}_{14-18}\right)$ and long-chain $\left(n-\mathrm{C}_{24-28}\right)$ fatty acids has been performed. These compounds were isolated from different sediment intervals, including a horizon that contains degraded oil residues from a spill of No. 2 fuel oil that occurred and inundated the salt marsh in 1969 (Sanders et al., 1980 and references therein). Persistent oil residues are present in the form of an unresolved complex mixture (UCM) of hydrocarbons in the boiling range of $n-\mathrm{C}_{13}$ to $n-\mathrm{C}_{24}$, consistent with a biodegraded No. 2 fuel oil source (Reddy et al., 2002). Individual biomarkers isolated from uncontaminated sediment horizons at depths above and below the oiled sediments were examined to compare and contrast the sources and fates of both natural and anthropogenically derived carbon inputs to a salt marsh. We aim to not only improve our understanding of both the long-term impact of an oil spill on carbon cycling in a salt marsh environment, but also gain insight into processes controlling the cycling of natural organic matter in these complex heterogeneous systems.

The salt marsh examined in this study is situated in West Falmouth, MA and whilst the concentration of total petroleum hydrocarbons (TPHs) has not markedly changed over the past 30 years (Reddy et al., 2002), analysis by comprehensive twodimensional gas chromatography ( $\mathrm{GCxGC})$ indicates that petroleum-derived $n$-alkanes, which are typically abundant in No. 2 fuel oil, are no longer detectable (Frysinger et al., 2003). Petroleum-derived $n$-alkanes, therefore, are more susceptible to loss processes, such as evaporation, water washing and biodegradation, than the other oil-derived compounds, such as branched alkanes, cycloalkanes and polycyclic aromatic hydrocarbons (PAHs) that comprise the persistent UCM. This preferential loss is in direct 
contrast to the refractory nature of higher plant $n$-alkanes that are known to persist in sediments (Prahl et al., 1997) and manifest themselves in West Falmouth sediments including the oil contaminated horizons.

Long-chain $\left(>n-C_{23}\right)$ alkanes with an odd over even predominance are derived from higher plant epicuticular waxes, and act as protective coatings on leaf surfaces (Eglinton and Hamilton, 1967). They are of particular interest because their abundance and chemical composition varies under different environmental conditions as part of a physiological response by the plant. In addition, their ubiquity and refractory nature relative to other organic compounds renders them well preserved in the sediment record (Prahl et al., 1997). These properties have enabled them to be used to reconstruct palaeoenvironmental changes (Cranwell 1973; Boom et al., 2002). Long-chain ( $n-\mathrm{C}_{24}$ to $\left.n-\mathrm{C}_{34}\right)$ fatty acids with even-over-odd dominance are also derived from plant waxes whereas their short-chain $\left(n-\mathrm{C}_{12}\right.$ to $\left.n-\mathrm{C}_{22}\right)$ counterparts are derived from a broader range of sources including marine algae and bacteria. Microbial biomass may also contribute significantly to fatty acid contents in marine sediments (Hollander and Smith, 2001).

Compound specific isotope analysis is a powerful tool used to determine sources of organic matter in marine sediments (for example, Freeman et al., 1990; Eglinton et al., 1997; Pearson and Eglinton, 2000). Both natural abundance radiocarbon $\left(\Delta{ }^{14} \mathrm{C}\right)$ and stable carbon $\left(\delta^{13} \mathrm{C}\right)$ of individual compounds may be examined, but $\Delta \Delta^{14} \mathrm{C}$ is especially useful as it has a greater dynamic range (-1000 to $\sim+200 \%)$ than $\delta^{13} \mathrm{C}(\sim-32$ to $-12 \%)$ (Raymond and Bauer, 2001). Due to their geologic age, petroleum residues contain no ${ }^{14} \mathrm{C}$, and this characteristic has previously been exploited to determine the fate of petroleum residues in these West Falmouth salt marsh sediments by examining the $\Delta^{14} \mathrm{C}$ values of different bulk sedimentary organic matter pools (White et al., 2005a). The latter study concluded that the majority of petroleum residues are solvent-extractable and have not been incorporated in the insoluble organic matter of the sediment. Natural abundance ${ }^{14} \mathrm{C}$ measurements on individual phospholipids have also been examined at this site and these analyses indicate that the oil is not currently being degraded by the resident microbial population (Slater et al., 2005). These previous studies provide an isotopic 
framework to not only enhance our understanding of the fate of petroleum residues, but also lipid biomarkers from various sources in marine sediments.

\subsection{MATERIALS AND METHODS}

\subsubsection{Study Area and Samples}

A $15 \mathrm{~cm}$ diameter sediment core was collected in August 2000 from the intertidal zone at the M-1 station in Wild Harbor, West Falmouth, MA $\left(41^{\circ} 38.0^{\prime} \mathrm{N}, 70^{\circ} 38.5^{\prime} \mathrm{W}\right)$ as previously described (Reddy et al., 2002). The core was extruded and sectioned at $2 \mathrm{~cm}$ intervals from 0 to $36 \mathrm{~cm}$ and the sections placed in pre-combusted glass jars and frozen $\left(-20^{\circ} \mathrm{C}\right)$ until further analysis. The sediment was later thawed and wet-sieved through a $1.4 \mathrm{~mm}$ sieve to remove the majority of intact roots and other discrete vascular plant debris of the marsh grass Spartina alterniflora that grows at this intertidal site. The sieved sediment was left to air-dry at room temperature before homogenizing with a mortar and pestle.

\subsubsection{Lipid Extraction and Purification}

Approximately $20 \mathrm{~g}$ of air-dried and homogenized sediment from 0-2, 2-4, 12-14, 30-32 and 32-34 cm sediment horizons was extracted with dichloromethane (DCM) and methanol $(\mathrm{MeOH})(9: 1)$ by pressurized-fluid extraction $\left(100^{\circ} \mathrm{C}, 1000 \mathrm{psi}\right)$. The resulting total lipid extracts (TLE) were reduced in volume by rotary evaporation, dried over $\mathrm{Na}_{2} \mathrm{SO}_{4}$ and percolated through a copper column to remove sulfur. The TLEs were then separated into four fractions using silica gel column chromatography (50g, 100-200 mesh, fully activated), eluting with $5 \% \mathrm{DCM}$ in hexane $\left(\mathrm{F}_{1}\right), \mathrm{DCM} / \mathrm{hexane}\left(1: 1 ; \mathrm{F}_{2}\right), 2 \%$

formic acid in $\mathrm{DCM}\left(\mathrm{F}_{3}\right)$ and $2 \%$ formic acid in $\mathrm{MeOH}\left(\mathrm{F}_{4}\right)$. After reduction in volume by rotary evaporation, the hydrocarbon fractions $\left(\mathrm{F}_{1}\right)$ were eluted through silver nitrate $(\sim 10 \% \mathrm{w} / \mathrm{w})$ impregnated silica gel columns with hexane, to provide saturated hydrocarbon fraction $\left(\mathrm{F}_{1-1}\right)$ containing $n$-alkanes. 
Further separation was necessary for the 12-14 cm TLE as it also contained an unresolved complex mixture (UCM) of saturated hydrocarbons in the boiling range of $n$ $\mathrm{C}_{13}$ to $n-\mathrm{C}_{24}$, consistent with a biodegraded No. 2 fuel oil source (Reddy et al., 2002). The $F_{1-1}$ of the UCM consists of $20 \%$ branched alkanes, 50\% 1-ring cycloalkanes and $30 \% 2$ ring and greater cycloalkanes (Frysinger et al., 2003). To separate these compounds from the $n$-alkanes, $F_{1-1}$ was placed into a pre-combusted glass vial containing a zeolite molecular sieve (Geokleen, GHGeochemical Services, 3g, activated at $450{ }^{\circ} \mathrm{C}$ for $4 \mathrm{hr}$ ) and heated at $80{ }^{\circ} \mathrm{C}$ for $8 \mathrm{hr}$ (procedure modified from McDuffee et al., 2004). The mixture was then allowed to cool before passing through a glass pipette plugged with glass wool. The sieve was then washed with hexane $(20 \mathrm{ml})$ to remove the branched and cyclic hydrocarbons that comprised the UCM. The zeolite was allowed to dry overnight and was then transferred to a Teflon ${ }^{\circledR}$ vial that had been pre-cleaned with rinses of $\mathrm{MeOH}, \mathrm{DCM}$ and hexane. Concentrated hydrofluoric acid (48\% HF) was added drop wise to dissolve the zeolite sieve. The sample was then extracted with hexane to yield a clean $n$-alkane fraction, and dried over $\mathrm{Na}_{2} \mathrm{SO}_{4}$.

The $F_{3}$ acidic fraction of the TLE was reduced in volume and back extracted into DCM before separating into two fractions by aminopropyl-bonded silica gel column chromatography $(20 \times 0.5 \mathrm{~cm})$, eluting with DCM/acetone $\left(9: 1 ; \mathrm{F}_{3-1}\right)$ and $2 \%$ formic acid in $\operatorname{DCM}\left(\mathrm{F}_{3-2}\right)$. The acid fraction $\mathrm{F}_{3-2}$ containing "free" fatty acids (FFA) was transesterified using acidic methanol of known carbon isotopic composition $\left(\delta^{13} \mathrm{C}=\right.$ $39.59 \%$; $\Delta \Delta^{14} \mathrm{C}=-989.5 \%$ ) and purified by silica gel column chromatography ( $20 \mathrm{x}$ $0.5 \mathrm{~cm}$ ) to yield a fatty acid methyl ester (FAME) fraction in 5\% ethyl acetate in hexane. This was finally eluted through silica gel columns impregnated with silver nitrate $(\sim 10 \%$ w/w) using DCM:hexane (1:1) to provide only the saturated homologues.

To obtain "bound" fatty acids (BFA), approximately $20 \mathrm{~g}$ of the solvent extracted sediment from 0-2, 2-4, 12-14, 30-32 and 32-34 cm sediment horizons was taken and refluxed at $70{ }^{\circ} \mathrm{C}$ for $2 \mathrm{hr}$ with a solution of $0.5 \mathrm{~N}$ potassium hydroxide $(\mathrm{KOH})$ in $\mathrm{MeOH}$ $(100 \mathrm{~mL})$ and water $\left(\mathrm{H}_{2} \mathrm{O}\right)(20 \mathrm{~mL})$. After cooling, the reaction mixture was separated by centrifugation $(1500 \mathrm{rpm})$ and the remaining sediment rinsed with $\mathrm{MeOH}$, followed by 
DCM, and then hexane. The alkaline solution was back extracted with hexane $(3 \times 50$ $\mathrm{mL}$ ) to obtain a neutral fraction before acidification with $4 \mathrm{~N}$ hydrochloric acid $(\mathrm{HCl})$ to $\mathrm{pH} 2$, and extraction with DCM $(3 \times 50 \mathrm{~mL})$ to obtain an acidic fraction. Both fractions were reduced in volume by rotary evaporation and dried over $\mathrm{Na}_{2} \mathrm{SO}_{4}$. The acidic fraction was taken and transesterified and purified by silica gel column chromatography ( $20 \mathrm{x}$ $0.5 \mathrm{~cm})$ and silver nitrate $(\sim 10 \% \mathrm{w} / \mathrm{w})$ impregnated silica gel columns as previously described.

Purified $n$-alkanes, and bound and free FAMEs for each sediment horizon were quantified by GC/FID.

\subsubsection{Preparative Capillary Gas Chromatography (PCGC)}

Select compounds were isolated from these fractions for radiocarbon $\left({ }^{14} \mathrm{C}\right)$ analysis by preparative capillary gas chromatography (PCGC) using an HP 5890 Series II GC system coupled to a Gerstel preparative fraction collector (see Eglinton et al., 1996 for detailed description) fitted with a DB-XLB $(60 \mathrm{~m} \times 0.53 \mathrm{~mm}$ i.d. $\times 0.5 \mu \mathrm{m}$ film thickness) capillary column. GC temperature programs for all samples were $40^{\circ} \mathrm{C}(1$ $\mathrm{min}$ ), $20^{\circ} \mathrm{C} / \mathrm{min}$ to $160^{\circ} \mathrm{C}$ and $4^{\circ} \mathrm{C} / \mathrm{min}$ to $320^{\circ} \mathrm{C}(30 \mathrm{~min})$. The U-tube traps were kept at room temperature for $n$-alkane samples and all FAMEs greater than $n-C_{20}$. FAMEs smaller than $n-\mathrm{C}_{20}$, were collected with the U-tube traps chilled to $0^{\circ} \mathrm{C}$ to prevent volatile losses. In order to provide sufficient mass ( $>30 \mu \mathrm{g}$ carbon) for AMS ${ }^{14} \mathrm{C}$ analysis $\mathrm{C}_{14}, \mathrm{C}_{16}$ and $\mathrm{C}_{18}$ free FAMEs were combined in the $12-14 \mathrm{~cm}$ and $32-34 \mathrm{~cm}$ sediment horizons. $\mathrm{C}_{14}$ and $\mathrm{C}_{18}$ free FAMEs were combined and $\mathrm{C}_{16}$ was analyzed separately in the $0-2 \mathrm{~cm}$ interval. For bound FAMEs $\mathrm{C}_{14}, \mathrm{C}_{16}$ and $\mathrm{C}_{18}$ homologues were combined in the $0-2 \mathrm{~cm}$ and 32-34 cm horizons and $\mathrm{C}_{14}$ and $\mathrm{C}_{18}$ homologues were combined and $\mathrm{C}_{16}$ analyzed separately in the $12-14 \mathrm{~cm}$ interval. For $n$-alkanes, $\mathrm{C}_{27}, \mathrm{C}_{29}$ and $\mathrm{C}_{31}$ were analyzed separately and the even numbered chains $\mathrm{C}_{26}$ through $\mathrm{C}_{32}$ were combined.

Column bleed was removed from pure $n$-alkanes by eluting the recovered material with hexane through silica gel columns (prepared in Pasteur pipettes) into pre-combusted quartz tubes. For the FAME fractions, the column bleed was removed by eluting the 
recovered material with $10 \%$ ethyl acetate/hexane through silica gel columns into precombusted quartz tubes. The solvent was evaporated from all quartz tubes under ultrahigh-purity nitrogen gas.

\subsubsection{Radiocarbon Analysis}

Pre-combusted copper oxide was added to the quartz tubes containing the samples and the tubes were then attached to a vacuum line, evacuated, flame sealed and combusted to $\mathrm{CO}_{2}\left(850^{\circ} \mathrm{C}\right.$ for $\left.5 \mathrm{hrs}\right)$. The $\mathrm{CO}_{2}$ was then purified on a vacuum line. The stable carbon isotopic ratio $\left(\delta^{13} \mathrm{C}\right)$ of the samples were determined by isotope ratio mass spectrometry (irMS), and radiocarbon $\left({ }^{14} \mathrm{C}\right)$ content measured by accelerator mass spectrometry (AMS) at the National Ocean Sciences Accelerator Mass Spectrometry (NOSAMS) facility at Woods Hole Oceanographic Institution (WHOI), Woods Hole, MA. Radiocarbon analyses were performed after conversion of the $\mathrm{CO}_{2}$ to graphite (McNichol et al., 1994). All ${ }^{14} \mathrm{C}$ measurements are normalized to $\delta{ }^{13} \mathrm{C}$ values of $-25 \%$ and expressed as $\Delta^{14} \mathrm{C}$ values, which is the per mille (\%o) deviation from the international standard for ${ }^{14} \mathrm{C}$ dating, Standard Reference Material 4990B “Oxalic Acid”. Precision for $\delta^{13} \mathrm{C}$ and $\Delta^{14} \mathrm{C}$ measurements are $\sim 0.1$ and $4-21 \%$ o (see Appendix for errors specific to each sample analyzed), respectively. For each sample, the reported $\Delta^{14} \mathrm{C}=\left[f_{\mathrm{m}} e^{(1950-x) \lambda}\right.$ $1] 1000$ (Stuiver and Polach, 1977), where $\lambda=1 / 8267$ (year ${ }^{-1}$ ), $f_{\mathrm{m}}=$ fraction modern ${ }^{14} \mathrm{C}$, corrected for isotopic fractionation using $\delta^{13} \mathrm{C}$, and " $x$ " equals the year of collection. The $\delta^{13} \mathrm{C}$ and $\Delta^{14} \mathrm{C}$ values of "free" and "bound" FA were corrected for the addition of the derivative carbon using a two end-member isotopic mass balance.

\subsection{RESULTS AND DISCUSSION}

\subsubsection{Fatty Acid and Alkane Distributions}

Free fatty acids from $n-\mathrm{C}_{14}$ to $n-\mathrm{C}_{32}$ (Figure 6.1) and bound fatty acids from $n-\mathrm{C}_{12}$ to $n-\mathrm{C}_{26}$ (Figure 6.2) are observed in all horizons and exhibit a strong even-over-odd dominance. Short-chain $\left(n-\mathrm{C}_{14}\right.$ to $\left.n-\mathrm{C}_{18}\right)$ homologues are the dominant FFAs in the 


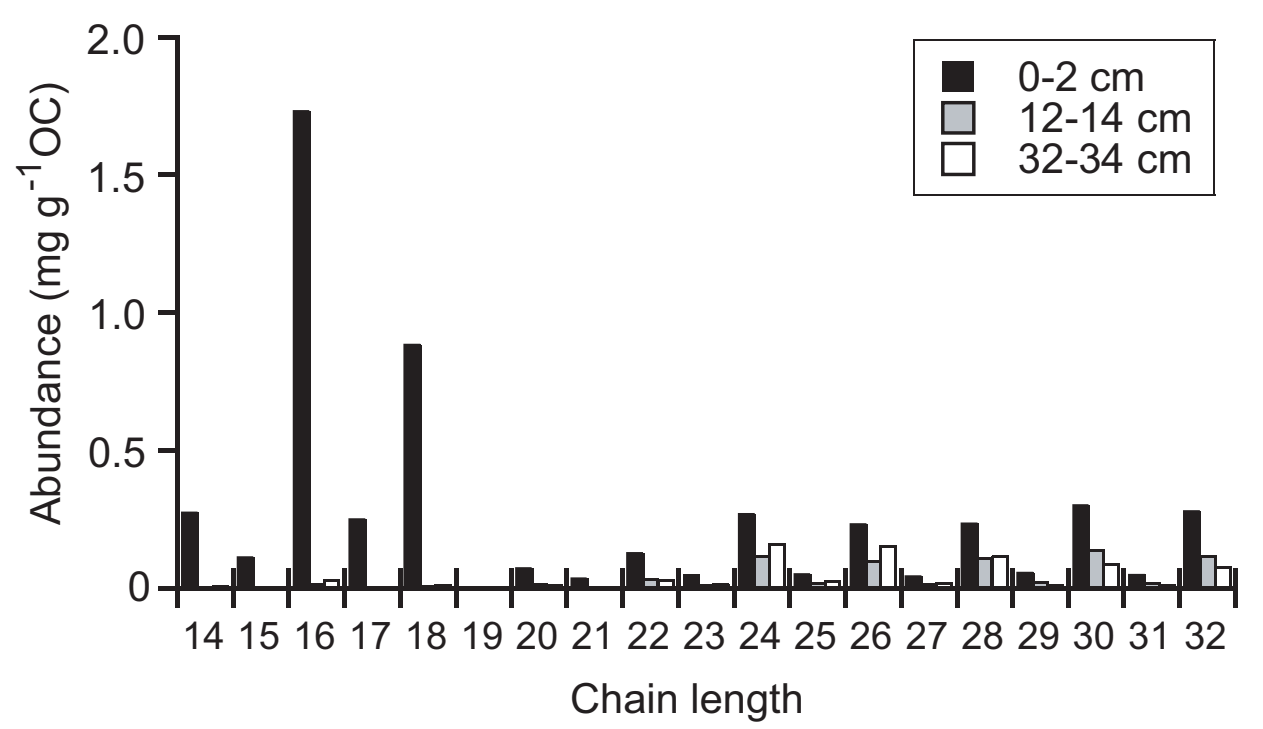

Figure 6.1 Abundance of individual free fatty acids from sediment horizons $0-2,12-14$ and $32-34 \mathrm{~cm}$.

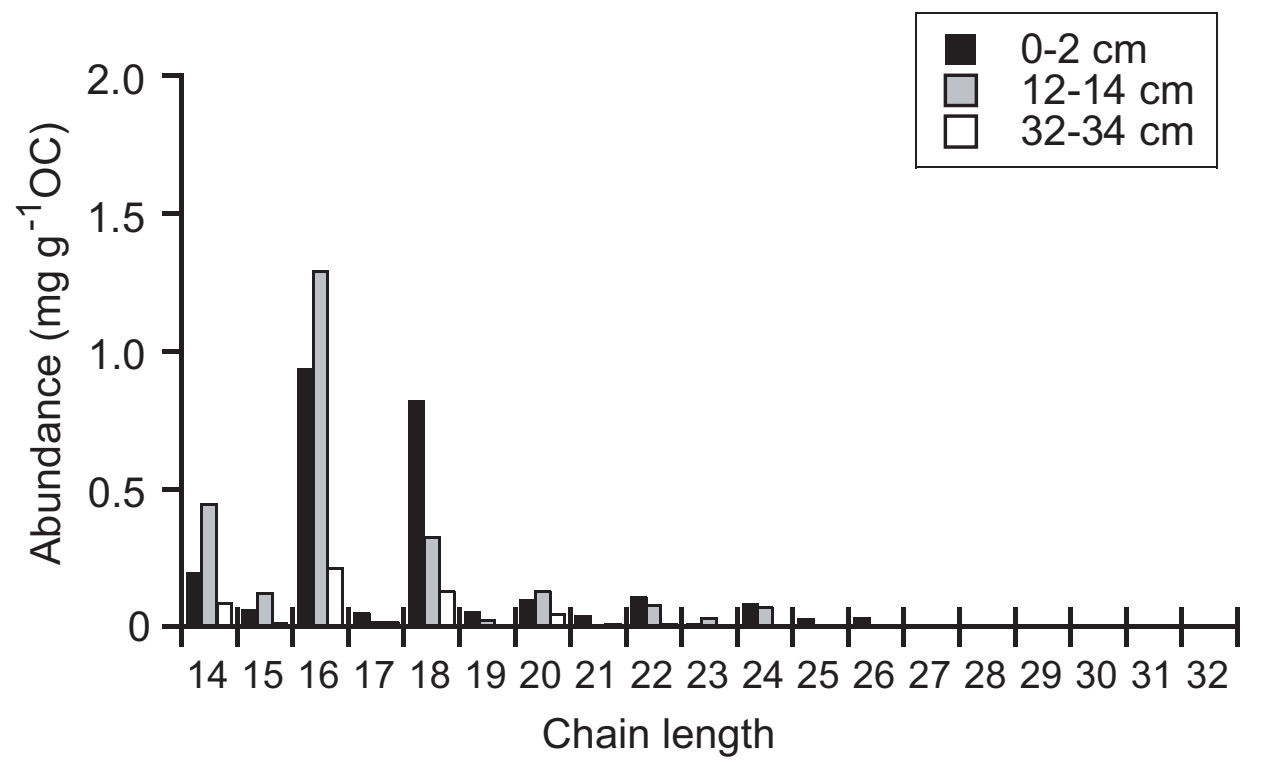

Figure 6.2 Abundance of individual bound fatty acids from sediment horizons 0-2, 12-14 and $32-34 \mathrm{~cm}$. 
surface $(0-2 \mathrm{~cm})$ sediment whereas their long-chain counterparts are more significant at depth. Summed concentrations of FFAs decrease significantly from $5.0 \mathrm{mg} \mathrm{g}^{-1}$ of organic carbon (OC) in the surface sediment to $0.8 \mathrm{mg} \mathrm{g}^{-1} \mathrm{OC}$ at $12-14$ and $32-34 \mathrm{~cm}$. In contrast, BFA contents do not change much between depths of 0-4 and 12-14 cm with summed concentrations of $2.5 \mathrm{mg} \mathrm{g}^{-1} \mathrm{OC}$. At $30-34 \mathrm{~cm}$, however, the content decreases to $0.5 \mathrm{mg}$ $\mathrm{g}^{-1}$ OC. It is not clear whether this change in abundance of BFAs that occurs in the deepest sediment horizon results from diagenetic processes or a change in the source of organic matter.

The abundance of $n$-alkanes in 0-2, 12-14 and 32-34 $\mathrm{cm}$ sediment horizons are shown in Figure 6.2. The most abundant homologue in all horizons is $n-C_{29}$ and concentrations of individual $n$-alkanes decrease slightly with increasing depth within the sediment from $0.22 \mathrm{mg} \mathrm{g}^{-1} \mathrm{OC}(0-2 \mathrm{~cm})$, to $0.19 \mathrm{mg} \mathrm{g}^{-1} \mathrm{OC}(12-14 \mathrm{~cm})$ and $0.16 \mathrm{mg} \mathrm{g}^{-1}$ OC $(32-34 \mathrm{~cm})$. There is a strong odd-over-even carbon number predominance in all sediment horizons which can be numerically represented by carbon preference index

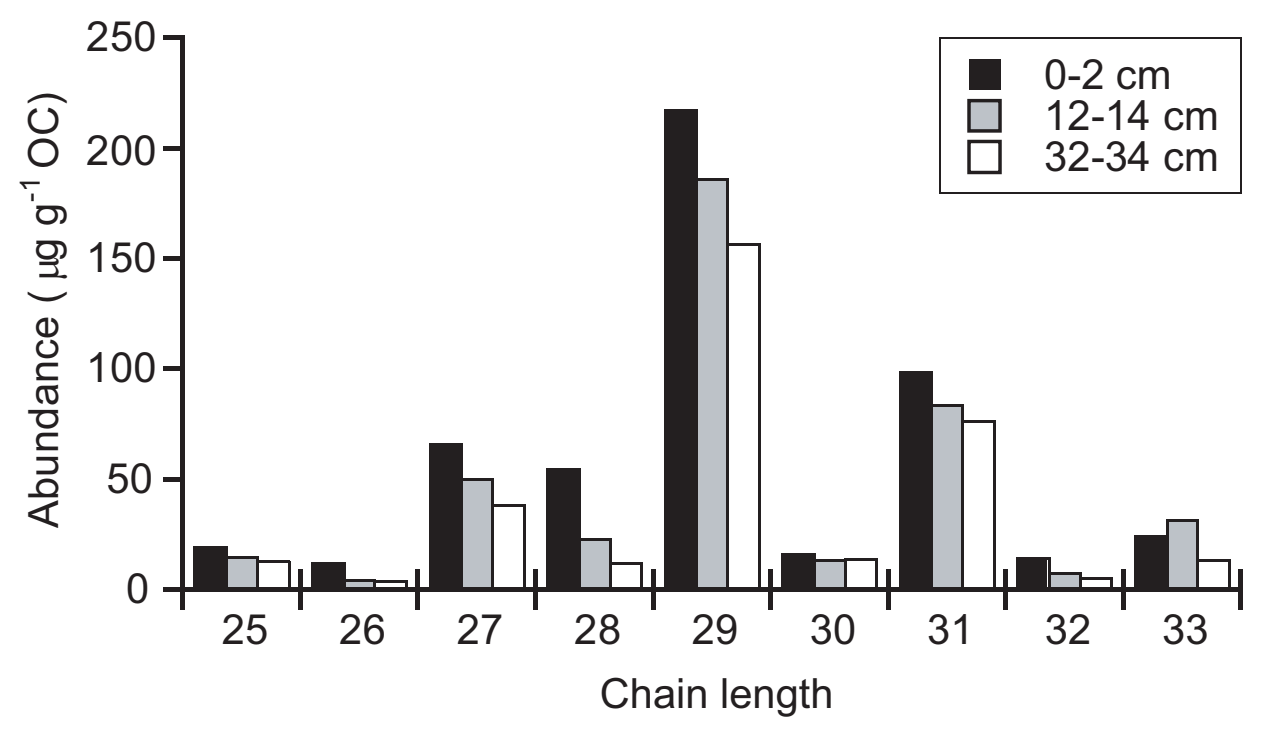

Figure 6.3 Abundance of individual $n$-alkanes $\left(\mathrm{C}_{25}\right.$ through $\left.\mathrm{C}_{33}\right)$ from sediment horizons $0-2,12-14$ and $32-34 \mathrm{~cm}$. 
$\left(\mathrm{CPI},=\Sigma\left[\right.\right.$ odd numbered alkane abundances from $n-\mathrm{C}_{23}$ to $\left.n-\mathrm{C}_{35}\right] / \Sigma$ [even numbered alkane abundances from $n-C_{22}$ to $\left.n-C_{34}\right]$ ). The CPI increases slightly with depth, from 4.4 at $0-2 \mathrm{~cm}$ to 7.6 in $12-14$ and 8.5 at $32-34 \mathrm{~cm}$. These values are within ranges previously exhibited for plant epicuticular waxes (CPI = 4-10; Tulloch, 1976).

Rates of decrease in these biomarkers over the depth examined $(0-34 \mathrm{~cm})$ are $\sim 0.12 \mathrm{mg} \mathrm{g}^{-1} \mathrm{OC} \mathrm{cm}{ }^{-1}$ for free fatty acids and $\sim 0.02 \mathrm{mg} \mathrm{g}^{-1} \mathrm{OC} \mathrm{cm}^{-1}$ for $n$-alkanes, highlighting the preferential degradation of free fatty acids.

\subsubsection{Compound Specific Isotope Analysis of Fatty Acids}

Compound specific $\Delta^{14} \mathrm{C}$ and $\delta^{13} \mathrm{C}$ values for free and bound fatty acids (FFA and BFA respectively) and bulk $\Delta^{14} \mathrm{C}$ and $\delta^{13} \mathrm{C}$ values for the solvent-extracted sediment residue (EX-RES) are shown in Figure 6.3. The isotopic composition of EX-RES represents the bulk OC uncontaminated by petroleum (White et al., 2005a). The $\delta^{13} \mathrm{C}$ values in this study agree well with those for organic carbon in salt marsh sediments where Spartina is the dominant macrophyte. Values of $\delta^{13} \mathrm{C}$ between -24 and $-17 \%$ reflect a mixture of phytoplankton, benthic algae and vascular plant material, including the ${ }^{13} \mathrm{C}$ enriched $\mathrm{C}_{4}$ macrophyte Spartina (Boshker et al., 1999). In this study, the $\delta^{13} \mathrm{C}$ for short-chain ( $\left.n-\mathrm{C}_{14-18}\right)$ FFA (filled triangle and diamond symbols) are relatively similar throughout the core $(-23.6$ to $-22.7 \%$ ), and are consistent with a predominantly algal and/or bacterial source and could also be Spartina derived. The $n-\mathrm{C}_{14-18}$ BFA are somewhat more ${ }^{13} \mathrm{C}$-depleted $(-25.6$ to $-22.9 \%$ ) and likely have a more significant contribution from marine sources. The long-chain $\left(n-\mathrm{C}_{24-28}\right)$ FFA, however, are much more ${ }^{13} \mathrm{C}$-enriched (-20.9 to $-18.7 \%$ ) consistent with an origin from Spartina.

$\Delta^{14} \mathrm{C}$ values of short and long-chain FFA and short-chain BFA from the surface sediment $(0-2 \mathrm{~cm})$ are very close to that of the solvent extracted sediment residue $(\mathrm{EX}-$

RES), a finding similar to that for $\Delta^{14} \mathrm{C}$ of phospholipids fatty acids (PLFAs) previously examined (Slater et al., 2005). The $\delta^{13} \mathrm{C}$ and $\Delta^{14} \mathrm{C}$ values of the EX-RES are driven by the dominant input of Spartina (White et al., 2005a), but also reflect a contribution from 
marine inputs. With depth, PLFAs examined by Slater et al., (2005), and the long-chain FFA, and short-chain BFA (examined in this study) continue to track the $\Delta^{14} \mathrm{C}$ EX-RES, with slight enrichments in ${ }^{14} \mathrm{C}$ for the BFAs and PLFAs. The short-chain FFA, however, become significantly more depleted in ${ }^{14} \mathrm{C}$ with depth, accompanied by a significant decrease in their concentration, as previously noted. The decrease in concentration may result from biodegradation of the fresher and labile material, which is likely the most enriched in ${ }^{14} \mathrm{C}$, and hence the $\Delta{ }^{14} \mathrm{C}$ of the short-chain FFA becomes more depleted with depth. The short-chain FFA that persist are significantly older and may have a different source such as resuspended marine carbon that is washed in by the tide, and would likely be older (Megens et al., 2001), and potentially more resistant to degradation due to association with minerals (Middleburg et al., 1997).

The peak in above-ground testing of thermonuclear weapons reached a maximum at 1963-1964. This corresponds to a depth of approximately $13 \mathrm{~cm}$ in the salt marsh sediment assuming a sedimentation rate of $0.35 \mathrm{~cm} \mathrm{yr}^{-1}$, and is consistent with a maximum of ${ }^{137} \mathrm{Cs}$ at this depth (White et al., 2005b). Whilst long-chain FFA and shortchain BFA are relatively enriched at this depth (142\%o and $187-210 \%$ ), a pronounced bomb-spike is not observed in the $\Delta^{14} \mathrm{C}$ of the long-chain FA as might be expected for vascular plant tissue such as that predominantly derived from Spartina. This would be expected as a result of photosynthetic fixation of atmospheric carbon dioxide $\left(\mathrm{CO}_{2}\right)$ that would have been greatly enriched in ${ }^{14} \mathrm{C}$ at this time. The amount of ${ }^{14} \mathrm{C}$ in the atmosphere nearly doubled in the early $1960 \mathrm{~s}$, and the $\Delta{ }^{14} \mathrm{C}$ of tropospheric $\mathrm{CO}_{2}$ increased to a maximum value of $>900 \%$ (Levin et al., 1985).

The absence of a pronounced bomb-spike in the $\Delta^{14} \mathrm{C}$ of the long-chain FA may arise from a smearing of bomb-produced ${ }^{14} \mathrm{C}$ as a result of sedimentary mixing, which would in turn, dampen the amplitude of the bomb-spike. This would also be evident in the activity profile of ${ }^{137} \mathrm{Cs}$ at the site, which is present throughout depths of 9-15 $\mathrm{cm}$ (White et al., 2005b) corresponding to the years 1951-1974. The first detection of ${ }^{137} \mathrm{Cs}$ in these sediments shows good correlation with the early 1950s increase in total fission yields (Carter and Moghissi, 1977) and the general time span agrees well with the 


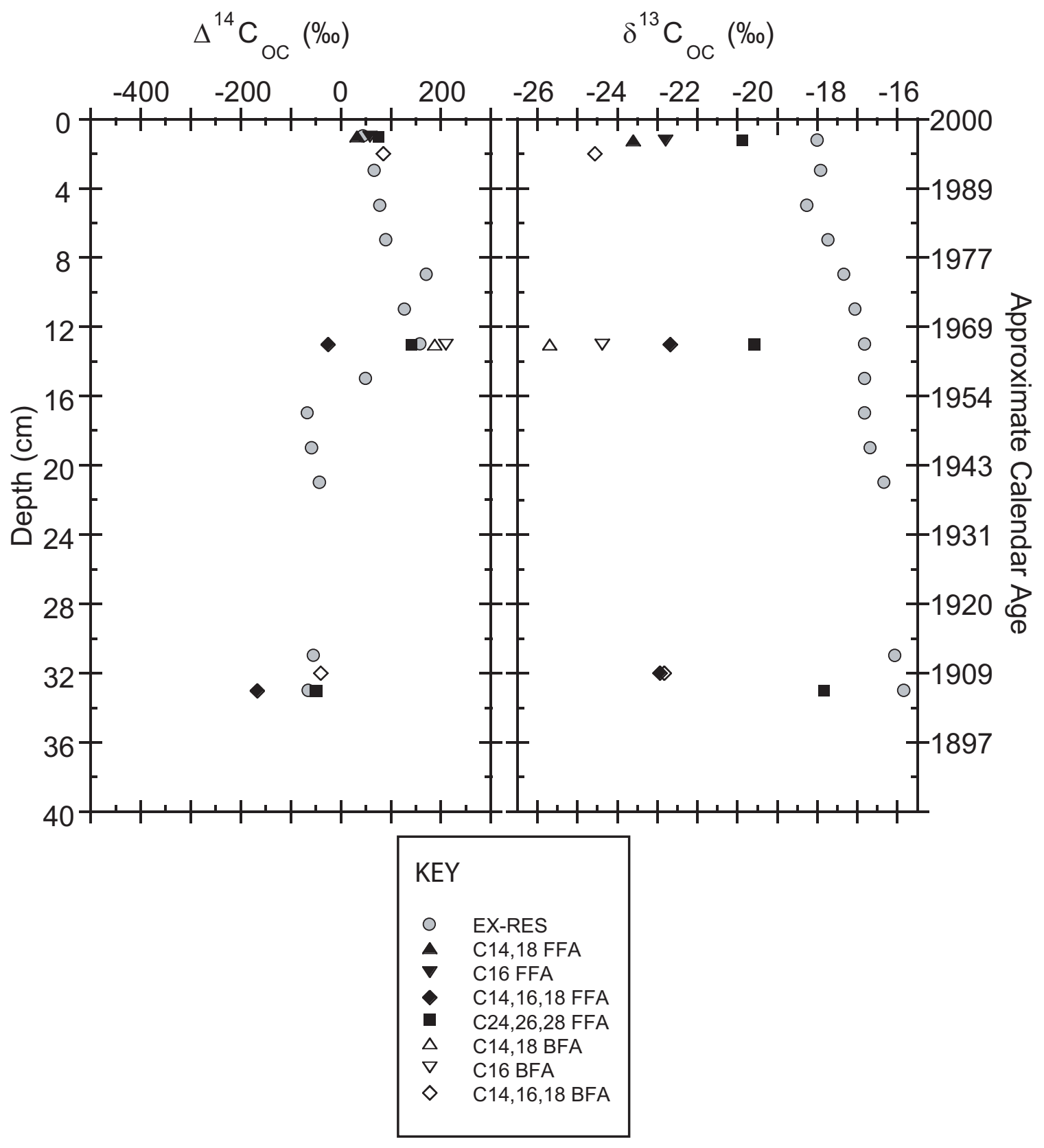

Figure 6.4 $\Delta{ }^{14} \mathrm{C}$ and $\delta^{13} \mathrm{C}$ compositions of individual free (filled symbols) and bound (open symbols) short (triangles and diamonds) and long-chain (squares) fatty acids from $0-2,12-14$ and 32-34 cm compared to the $\Delta^{14} \mathrm{C}$ and $\delta^{13} \mathrm{C}$ composition of the solvent extracted sediment residue (EX-RES) from White et al., 2005a. Errors for $\Delta^{14} \mathrm{C}$ and $\delta^{13} \mathrm{C}$ are smaller than the symbols representing the data and thus are not observed. 
atmospheric history of ${ }^{137} \mathrm{Cs}$ fallout from nuclear weapons testing previously documented from 1952-1970 in Miami, Florida USA (Robbins et al., 2000). It therefore does not appear that the suppression of ${ }^{14} \mathrm{C}$ in these sediments is due to mixing. This is further supported by comparison to the ${ }^{137} \mathrm{Cs}$ activity profile in anoxic and laminated sediments from the Pettaquamscutt River where sediment mixing is absent (Lima et al., 2005). The peak in ${ }^{137} \mathrm{Cs}$ activity corresponding to nuclear weapons testing at this site, spans a similar time frame (1953-1974) and peak width $(8 \mathrm{~cm} ; 14-22 \mathrm{~cm})$ to that observed in West Falmouth sediments. It is worth noting that the ${ }^{137} \mathrm{Cs}$ peak in West Falmouth sediments is not as smoothed as that observed in the laminated sediments of the Pettaquamscutt River and analysis at higher resolution would more definitively determine the significance of sedimentary mixing at the site.

It is unlikely that there is a lag between the incorporation of bomb ${ }^{14} \mathrm{C}$ into the Spartina and its deposition in the sediments as it is a perennial plant and incorporates $\mathrm{CO}_{2}$ year-round. A further alternative, therefore, is that a pronounced bomb-spike is simply not recorded in these sediments. This absence could also occur if the Spartina fixes inorganic carbon from sources other than the atmosphere. Carbon dioxide derived from sediments via the rhizome system and transported by mass flow can be responsible for more than $90 \%$ of the total carbon uptake in emergent plants (Madsen and SanJensen, 1991). Such a mechanism would easily account for the observations in this study if marine porewater dissolved inorganic carbon (DIC) was the source of inorganic carbon. However, in large emergent plants such as Spartina alterniflora, porewater DIC is not thought to be a major contribution because the distance from root to shoot is too long to support high rates of photosynthesis in the leaves (Bowes, 1993). For Spartina alterniflora, only $1-10 \%$ of carbon for photosynthesis has been observed to be sediment derived (Hwang and Morris, 1992) and whilst this may lead to a slightly muted bomb signal in the long-chain FA it would not dilute it to the value observed. The study by Hwang and Morris, however was performed on Spartina grown in the laboratory and therefore without direct ${ }^{14} \mathrm{C}$ measurements of Spartina biomass, and analysis of uptake of DIC in the field, this cause cannot be discounted. 


\subsubsection{Compound Specific Isotope Analysis of Alkanes}

Compound specific $\Delta^{14} \mathrm{C}$ and $\delta^{13} \mathrm{C}$ for $n$-alkanes are shown in Figure 6.4. As for the fatty acids, the $\delta^{13} \mathrm{C}$ of $n$-alkanes becomes more enriched with depth, from -26.1 to $-24.6 \%$ o $(0-2 \mathrm{~cm})$ to -24.0 to $-22.8 \%$ o $(12-14 \mathrm{~cm})$ to -22.4 to $-20.8 \%$ o $(32-34 \mathrm{~cm})$ indicating selective preservation of Spartina-derived carbon. In general $\delta^{13} \mathrm{C}$ values of $n$-alkanes are $\sim 4-6 \%$ more depleted than fatty acids, and this is attributed to additional fractionation against ${ }^{13} \mathrm{C}$ during their biosynthesis comparing well with previous work (Collister et al., 1994).

Consistent with observations made for fatty acids, significant enrichment resulting from the bomb-spike is not observed in the plant wax derived $n$-alkanes $\left(\mathrm{C}_{29}\right.$ and $\left.\mathrm{C}_{31}\right)$ at $12-14 \mathrm{~cm}$ although they are more enriched in ${ }^{14} \mathrm{C}$ than the EX-RES (206-261\% vs. $164 \%$ ) in this interval. Instead, these $n$-alkanes have similar $\Delta{ }^{14} \mathrm{C}$ values to short-chain BFA and long-chain FFA previously discussed. It is evident, therefore that all of these compounds are predominantly derived from Spartina. No evidence is found for a contribution from petroleum hydrocarbons despite the depth corresponding to the peak contamination. Indeed, the odd-chain $n$-alkanes $\left(\mathrm{C}_{29}\right.$ and $\left.\mathrm{C}_{31}\right)$ are more enriched in ${ }^{14} \mathrm{C}$ than the long-chain FAs in the 12-14 cm interval, likely due to the enhanced preservation of these compounds, and a greater legacy of compounds produced during a bomb spike.

In the surface sediment and $12-14 \mathrm{~cm}$ interval, the even-chain $n$-alkanes are significantly more depleted in ${ }^{14} \mathrm{C}$ than their corresponding odd-chain counterparts. For example at $0-2 \mathrm{~cm}$, the even homologues exhibit a $\Delta{ }^{14} \mathrm{C}$ value of $-476 \%$ whereas $n-\mathrm{C}_{27}$ is more enriched (-224\%), and $n-\mathrm{C}_{29}$ is further enriched ( $0 \%$ ). This clearly indicates the input of fossil carbon that has a larger impact on the even-chain $n$-alkanes than it does on the odd homologues. This is due to the lack of carbon number preference in thermally mature fossil sources (Brassell and Eglinton, 1980) relative to the odd-over-even predominance from vascular plant sources. The fossil-fuel carbon inputs therefore have a disproportionate impact on the $\Delta{ }^{14} \mathrm{C}$ value of the even homologues because they are not abundantly produced by terrestrial or marine biomass. The fossil carbon input impacts 


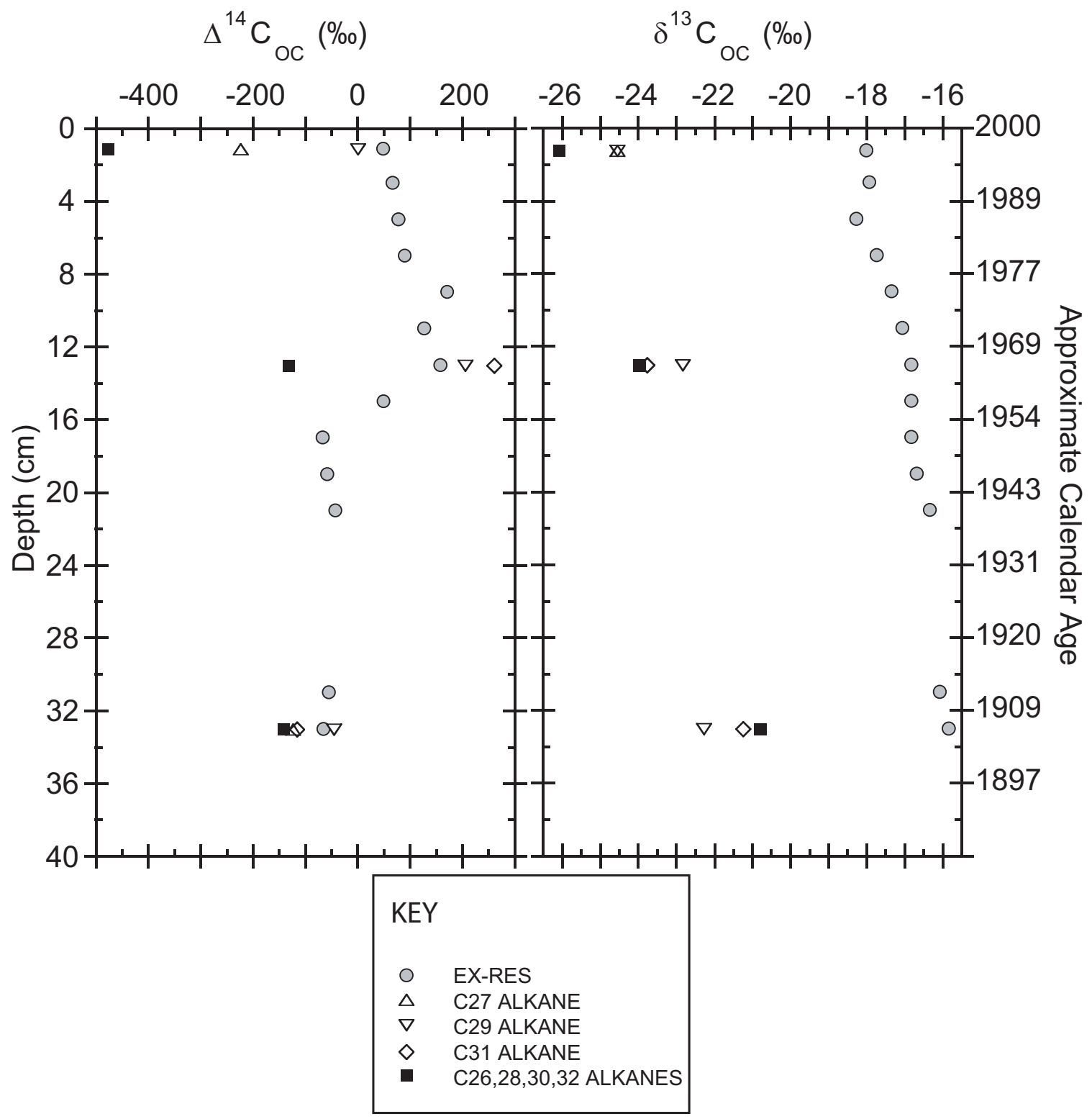

Figure 6.5 $\Delta^{14} \mathrm{C}$ and $\delta^{13} \mathrm{C}$ compositions of individual $n$-alkanes from $0-2,12-14$ and 32 $34 \mathrm{~cm}$ compared to the $\Delta^{14} \mathrm{C}$ and $\delta^{13} \mathrm{C}$ composition of the solvent extracted sediment residue (EX-RES) from White et al., 2005a. Errors for $\Delta^{14} \mathrm{C}$ and $\delta^{13} \mathrm{C}$ are smaller than the symbols representing the data and thus are not observed. 
$n-C_{29}$ less than $n-C_{27}$ as a result of the increased abundance of $n-C_{29}$ in plant waxes. Similar observations are also made at $32-34 \mathrm{~cm}$, although the offset is more subtle. Mixed sources of $n$-alkanes to marine sediments have previously been observed in sediments from the Santa Monica Basin (Pearson and Eglinton 2000). In this study, $\Delta^{14} \mathrm{C}$ and $\delta^{13} \mathrm{C}$ measurements of long-chain alkanes $\left(n-\mathrm{C}_{24-33}\right)$ were measured and a three- component mixing model used to assess the contribution of petroleum (12\%), modern plant wax $(80 \%)$ and shale-derived alkanes $(8 \%)$.

The fraction of $n$-alkanes that are fossil-derived in these sediment horizons can be calculated based on isotope mass balance. Assuming that the total $n$-alkanes in the sediment are a binary mixture $(t)$ comprised of fossil carbon $(x)$ and Spartina plant waxes (n) that can be represented by

$$
\text { (alkane }) t=(\text { alkane }) x+(\text { alkane }) n
$$

and the isotopic composition of the mixture is given by

$$
F t=f F x+(1-f) F n
$$

where the Fs represent isotopic abundances and $f$ is the fraction of the mixture that is fossil-derived. In terms of radiocarbon abundances $(\Delta)$, we can write

$$
f=(\Delta t-\Delta n) /(\Delta x-\Delta n)
$$

The corrected $\Delta{ }^{14} \mathrm{C}$ values for the total $n$-alkanes were used as $\Delta t$ and the corrected $\Delta{ }^{14} \mathrm{C}$ values for the long-chain fatty acids were used to represent $\Delta n$. Assuming $\Delta x$ to reflect an absence of ${ }^{14} \mathrm{C}$ (i.e., $\Delta{ }^{14} \mathrm{C}=-1000 \%$ ), solutions of $f$ were obtained for the $n$-alkanes in the three sediment horizons examined (Table 6.1). The isotope mass balance calculation for sediments from $0-2$ and $12-14 \mathrm{~cm}$ reiterates that a greater fraction of even-chain $n$ alkanes are fossil derived compared to the odd-chain lengths (0.24 to 0.51 vs. -0.10 to 0.27). This offset is not observed in sediments from $32-34 \mathrm{~cm}$ and in general the fraction of fossil carbon is much less for all $n$-alkanes $(0$ to 0.10$)$ in this horizon. Isotope mass balance also indicates that the fraction of fossil carbon is less for $n-C_{29}$ less than $n-C_{27}$ in sediments from $0-2 \mathrm{~cm}$ and $32-34 \mathrm{~cm}$ as previously described. Negative contributions of fossil carbon in sediments from $12-14 \mathrm{~cm}$ arise from the fact that $\Delta^{14} \mathrm{C}$ values for the 
long-chain fatty acids used to represent the Spartina plant waxes are more enriched in ${ }^{14} \mathrm{C}$ than the $n$-alkanes due to the influence of the bomb-spike at this depth.

The source of this fossil carbon to the surface and $12-14 \mathrm{~cm}$ sediment horizon is likely fossil $n$-alkanes entrained on combustion-derived particles derived from local and/or distal sources. The chain length of the $n$-alkanes up to $\mathrm{C}_{32}$ indicates a source from motor boat fuel such as No. 6 fuel oil. These $n$-alkanes may be physically protected from degradation by strong association with combustion particles (McGroddy et al., 1995), or it may be that their long-chain lengths impart a chemical recalcitrance. Plant-wax $n$-alkanes may also be more likely to persist in sediments because of the way in which they are packaged. Leaf waxes occur as microcrystallites in the $\mu \mathrm{m}$ range varying greatly in size, shape and cuticular distribution (Martin and Juniper, 1970) and in this form are less likely to be bioavailable.

Table 6.1 Fraction of fossil-derived $n$-alkanes in West Falmouth sediments

\begin{tabular}{cccc}
\hline $\begin{array}{c}\text { depth } \\
\text { (cm) }\end{array}$ & $\begin{array}{c}\text { approx. } \\
\text { age }\end{array}$ & n-alkane & $\begin{array}{c}\text { fraction } \\
\text { fossil-derived }\end{array}$ \\
\hline $0-2$ & 1997 & $n-\mathrm{C}_{27}$ & 0.27 \\
& & $n-\mathrm{C}_{29}$ & 0.07 \\
& & $n-\mathrm{C}_{26+28+30+32}$ & 0.51 \\
$12-14$ & 1963 & $n-\mathrm{C}_{29}$ & -0.06 \\
& & $n-\mathrm{C}_{31}$ & -0.10 \\
& & $n-\mathrm{C}_{26+28+30+32}$ & 0.24 \\
$32-34$ & 1906 & $n-\mathrm{C}_{27}$ & 0.10 \\
& & $n-\mathrm{C}_{29}$ & 0.08 \\
& & $n-\mathrm{C}_{31}$ & 0.00 \\
& & $n-\mathrm{C}_{26+28+30+32}$ & 0.07 \\
\hline
\end{tabular}




\subsection{CONCLUSIONS}

Natural abundance ${ }^{14} \mathrm{C}$ measurements of specific biomarkers provide a powerful means to determine the source of organic compounds in contemporary environmental matrices. In this study, contributions from petrogenic, pyrogenic and biogenic sources were assessed. Salt marsh derived $n$-hydrocarbons and fatty acids are predominantly derived from the dominant macrophyte Spartina alterniflora, although inputs from marine as well as pyrogenic sources are important. Compound-specific isotope analysis of long-chain fatty acids and alkanes not only provides information about sources of organic matter, but also about post-depositional processes that occur in sediments. For example, petroleum derived $n$-alkanes from the oil spill do not persist in sediments, whereas pyrogenic and biogenic $n$-alkanes do, likely as a result of protective matrix association. It is evident from this study that the mode of association or "packaging" of biomarkers plays a crucial role in determining their long-term fate. Here, we observe that the same compound can undergo very different fates depending on how it is introduced to, and physically disposed, in the sediment.

\subsection{REFERENCES}

Boom, A., Marchant, R., Hooghiemstra, K., Sinninghe Damsté, J.S. 2002. $\mathrm{CO}_{2}$ and temperature-controlled altitudinal shifts of $\mathrm{C}_{4}$ and $\mathrm{C}_{3}$ dominated grasslands allow reconstruction of palaeoatmospheric $\mathrm{pCO}_{2}$. Palaeogeography, Palaeoclimatology, Palaeoecology 177, 151-168.

Brassell, S.C., Eglinton, G., 1980. Environmental Chemistry; an interdisciplinary subject; natural and pollutant organic compounds in contemporary aquatic environments. In: Albaiges, J. (Ed.), Analytical Techniques in Environmental Chemistry, Pergamon series on Environmental Science, vol. 3, pp. 1-22.

Carter M., Moghissi A., 1977. Three decades of nuclear testing. Health Physics 33, 5571.

Collister, J.W., Rieley, G., Stern, B., Eglinton, G., Fry, B., 1994. Compound-specific $\delta^{13} \mathrm{C}$ analyses of leaf lipids from plants with different carbon dioxide metabolisms. Organic Geochemistry 21, 619-627. 
Cranwell, P.A. 1973. Chain-length distribution of n-alkanes from lake sediments in relation to post-glacial environmental change. Freshwater Biology 3, 259-265.

Eglinton, G., Hamilton, R., 1967. Leaf Epicuticular Waxes. Science 156, 1322-1335.

Eglinton T.I., Bauer J.E., Aluwihare L.I., Druffel E.R.M., McNichol A.P. 1996. Gas chromatographic isolation of individual compounds from complex matrices for radiocarbon dating. Analytical Chemistry 68, 904-912.

Eglinton, T. I., Benitez-Nelson, B.C., Pearson, A., McNichol, A.P., Bauer, J.E., Druffel, E.R.M. 1997. Variability in radiocarbon ages of individual organic compounds from marine sediments. Science 277, 796-799.

Freeman, K.H., Hayes, J. M. Trendel, J.-M., Albrecht, P. 1990. Evidence from carbon isotope measurements for diverse origins of sedimentary hydrocarbons. Nature 343, 254-256.

Fry, B., Sherr, E.B. 1984. $\delta^{13}$ C measurements as indicators of carbon flow in marine and freshwater ecosystems. Contributions in Marine Science 27, 13-47.

Frysinger, G.S., Gaines, R.B., Xu, L., Reddy C.M. 2003. Resolving the unresolved complex mixture in petroleum-contaminated sediments. Environmental Science and Technology 37, 1653-1662.

Hollander, D.J., Smith, M.A. 2001. Microbially mediated carbon cycling as a control on the $\delta^{13} \mathrm{C}$ of sedimentary carbon in eutrophic Lake Mendota (USA): New models for interpreting isotopic excursions in the sedimentary record. Geochimica et Cosmochimica Acta 64, 4321-4337.

Knicker, H., Hatcher, P.G. 1997. Survival of protein in an organic-rich sediment:

Possible protection by encapsulation in organic matter. Naturwissenschaften 84,231 234.

Levin, I., Kromer, B., Schoch-Fischer, H., Bruns, M., Münnich, M., Berdau, D., Vogel, J.C., and Münnich, K.O. 1985. 25 yeas of tropospheric ${ }^{14} \mathrm{C}$ observations in Central Europe. Radiocarbon 27, 1-19.

Lima, A.L.C., Eglinton, T.I., Reddy, C.M. 2003. High-resolution record of pyrogenic polycyclic aromatic hydrocarbon deposition during the $20^{\text {th }}$ century. Environmental Science and Technology 37, 53-61.

Lima, A.L., Hubeny, J.B., Reddy, C.M., King, J. W., Hughen, K.A., Eglinton, T.I. 2005. High-resolution historical records from Pettaquamscutt River basin sediments: 1 . ${ }^{210} \mathrm{~Pb}$ and varve chronologies validate record of ${ }^{137} \mathrm{Cs}$ released by the Chernobyl accident. Geochimica et Cosmochimica Achta 69, 1803-1812.

Martin, J.T., Juniper B.E. 1970. The cuticles of plants. St. Martin's Press, New York.

McDuffee, K. E., Eglinton, T. I., Sessions, A. L., Sylva, S., Wagner, T., Hayes, J. M. 2004. Rapid analysis of ${ }^{13} \mathrm{C}$ in plant-wax n-alkanes for reconstruction of terrestrial vegetation signals from aquatic sediments, Geochemistry, Geophysics Geosystems 5, 19 Q10004.

McGroddy, S. E., Farrington, J. W. 1995. Sediment porewater partitioning of polycyclic aromatic hydrocarbons in three cores from Boston Harbor, Massachusetts.

Environmental Science and Technology 29, 1542-1550 
Megens, L., Van der Plicht, J., De Leeuw, J.W. 2001. Temporal variations in ${ }^{13} \mathrm{C}$ and ${ }^{14} \mathrm{C}$ concentrations in particulate organic matter from the southern North Sea. Geochimica et Cosmochimica Acta 65, 2899-2911.

McNichol, A.P., Osborne, E.A., Gagnon, A.R., Fry, B., Jones, G.A. 1994. TIC, TOC, DIC, DOC, PIC, POC-unique aspects on the preparation of oceanographic samples for ${ }^{14} \mathrm{C}$-AMS. Nuclear Instruments and Methods in Physics Research B92, 162-165.

McNichol, A.P., Osborne, E.A., Gagnon, A.R., Fry, B., Jones, G.A. 1994. TIC, TOC, DIC, DOC, PIC, POC-unique aspects on the preparation of oceanographic samples for ${ }^{14} \mathrm{C}$-AMS. Nuclear Instruments and Methods in Physics Research B92, 162-165.

Middleburg, J.J., Nieuwenhuize, J., Lubberts, R.K., van de Plassche, O. 1997. Organic carbon isotope systematics of coastal marshes. Estuarine, Coastal and Shelf Science 45, 681-687.

Pearson, A., Eglinton, T.I., 2000. The origin of $n$-alkanes in Santa Monica Basin surface sediment: a model based on compound-specific $\Delta^{14} \mathrm{C}$ and $\delta{ }^{13} \mathrm{C}$ data. Organic Geochemistry 31, 1103-1116.

Prahl, F.G., De Lange, G.J., Scholten, S., Cowie, G.L. 1997. A case for postdepositional aerobic degradation of terrestrial organic matter in turbidite deposits from the Madeira Abyssal Plain. Organic Geochemistry 27, 141-152.

Raymond, P.A., Bauer, J.E. 2001. Use of ${ }^{14} \mathrm{C}$ and ${ }^{13} \mathrm{C}$ natural abundances for evaluating riverine, estuarine, and coastal DOC and POC sources and cycling: a review and synthesis. Organic Geochemistry 32, 469-485.

Reddy, C.M., Eglinton, T.I., Hounshell, A.H., White, H.K., Xu, L., Gaines, R.B., Frysinger, G.S., 2002. The West Falmouth oil spill after thirty years: The persistence of petroleum hydrocarbons in marsh sediments. Environmental Science and Technology 36, 4754-4760.

Robbins J., Holmes C., Halley R., Bothner M., Shinn E., Graney J., Keeler G., tenBrink M., Orlandini K., Rudnick D., 2000. Time-averaged fluxes of lead and fallout radionuclides to sediments in Florida Bay. Journal of Geophysical Research 105, 28805-28821.

Sanders, H.L., Grassle, J.F., Hampson, G.R., Morse, L.S., Garner-Price, S., Jones, C. 1980. Anatomy of an oil spill: long-term effects from the grounding of the barge Florida off West Falmouth, Massachusetts. Journal of Marine Research, 265-380.

Slater, G., White, H. K., Eglinton, T. I., Reddy, C.M. 2005. Determination of microbial carbon sources in petroleum contaminated sediments using molecular ${ }^{14} \mathrm{C}$ analysis. Environmental Science and Technology 39, 2552-2558.

Stuiver, M., Polach, H.A., 1977. Discussion: reporting of 14C data. Radiocarbon 19, 355363.

Tulloch, A.P. 1976. Chemistry of waxes of higher plants. In: Kolattukudy, P.E. (Ed.), Chemistry and biochemistry of natural waxes. Elsevier, Amsterdam, pp. 236-252.

White, H.K., Reddy, C.M., Eglinton, T.I., 2005a. Isotopic constraints on the fate of petroleum residues sequestered in salt marsh sediments. Environmental Science and Technology 39, 2545-2551. 
White, H.K., Xu, L., Lima, A.L.C., Eglinton, T.I., Reddy, C.M. 2005b. Abundance, composition, and vertical transport of PAHs in marsh sediments. Environmental Science and Technology 39, 8273-8280. 
6.6 APPENDIX 


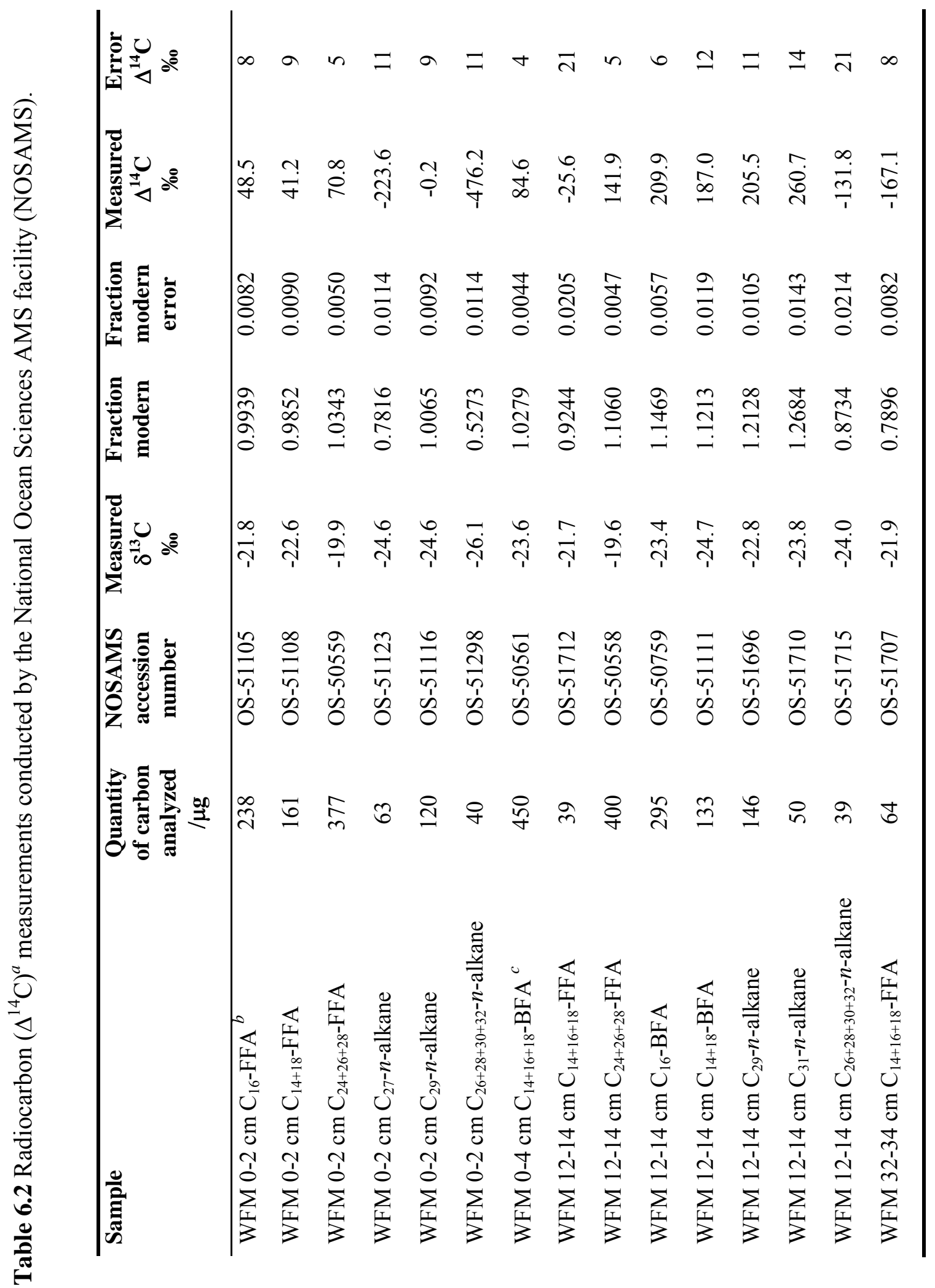




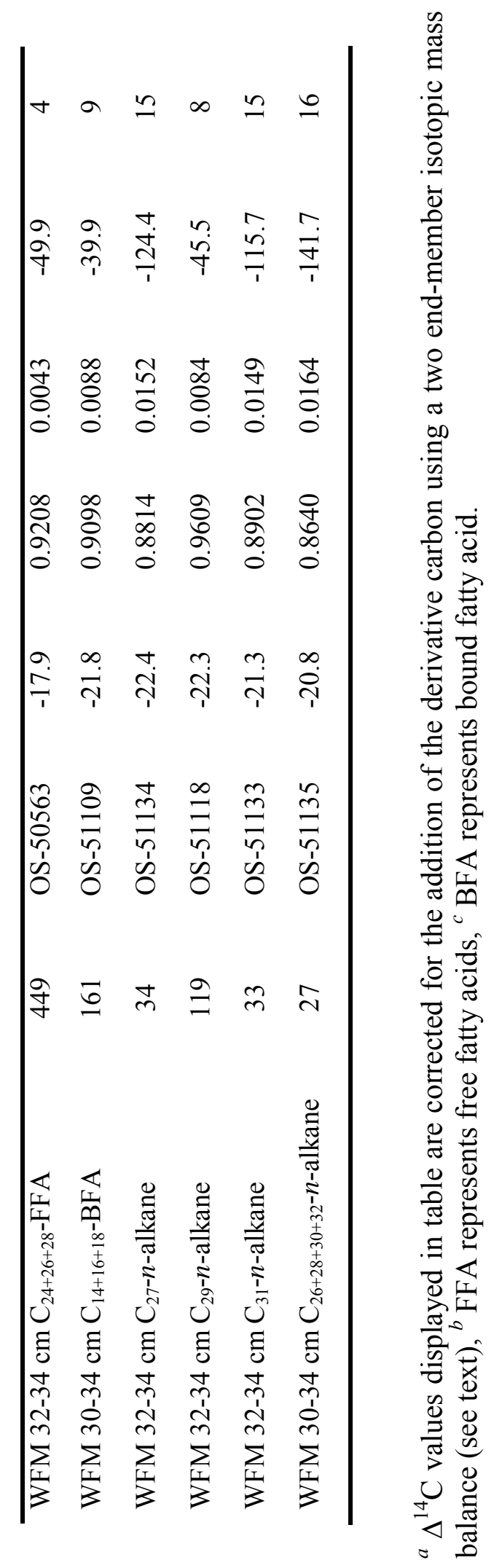




\section{CHAPTER 7}

\section{CONCLUSIONS AND FUTURE WORK}

Natural abundance radiocarbon $\left(\Delta^{14} \mathrm{C}\right)$ measurements provide a powerful means to determine the source of organic compounds in contemporary environmental matrices. Analysis of the ${ }^{14} \mathrm{C}$ content of different fractions of sedimentary organic matter has enhanced our understanding of the associations between specific organic compounds and macromolecular organic matter (MOM), and we can conclude that these associations influence and in some instances, determine the long-term fate of organic compounds.

Surface sediments examined from a variety of different depositional settings display $\Delta^{14} \mathrm{C}$ values from $-737 \%$ to $+44 \%$, encompassing most of the dynamic range of $\Delta{ }^{14} \mathrm{C}$. This highlights the significant inputs of both recently photosynthesized carbon, in the case of the West Falmouth saltmarsh, and pre-aged carbon to marine sediments from a variety of depositional settings including the Eel River Margin, Guaymas Basin, Ross Sea, Mackenzie Shelf and Beaufort Slope.

In terms of associations between natural organic carbon and MOM, we conclude that for the majority of sediments studied, marine algal-derived carbon is preferentially

preserved by association with MOM via ester linkages. Differences in $\Delta^{14} \mathrm{C}$ values and molecular compositions between sediments and their respective residues also highlight the effects of diagenesis (e.g. Benguela Upwelling and Washington Margin sediments) and the presence or absence of oxygenated bottom waters (e.g. Santa Monica Basin sediments).

Hydrophobic organic contaminants (HOCs) persisting in marine sediments, do not have to be "bound" or associated with nonextractable sediment residues, to persist. This is evident in sediments from Wild Harbor, West Falmouth, MA where the majority of No. 2 fuel oil residues are found to be solvent-extractable and not bound to insoluble MOM. Good agreement is observed between isotope mass balance calculations and 
values calculated when total oil concentrations (measured by gas chromatography) are compared to total organic carbon (TOC) content (determined by elemental analysis). This highlights the utility of ${ }^{14} \mathrm{C}$ content as an inverse tracer of fossil fuel-derived HOCs in marine sediments.

Studies of various other HOCs including creosote, coal tar, polychlorinated biphenyls (PCBs), benzotriazoles (BZTs), 2,2-bis(chlorophenyl)-1,1,1-trichloroethane (DDT) provide similar conclusions to those made for West Falmouth sediments and the majority of fossil fuel-derived carbon is solvent-extractable and not bound to MOM. In instances where HOCs and/or their respective metabolites are found to be associated with nonextractable sediment residues, their structures suggest that they are not covalently linked and are instead likely entrapped in mineral or organic matter matrices. Overall, these findings indicate that HOCs may be more available to biota, and more likely to be subjected to transport processes and thus potentially have a greater impact on the environments in which they persist. Where evidence of covalent bonding between HOCs and MOM is observed, it is of interest to determine whether binding occurred prior to entering the aquatic environment. It is possible that binding may have occurred in soils or as a by-product of their synthesis and determination of this will be the focus of future work.

Quantities of fossil fuel-derived carbon released by solvent extraction and/or saponification as determined by gas chromatography (GC) do not always agree with quantities derived from isotope mass balance calculations. Discrepancies between GC and isotope mass balance point to aspects that we do not currently understand. Future work will be aimed at understanding these offsets so that the fate of HOCs in the marine environment can be more conclusively determined.

Sediment from the hydrothermal environment of the Guaymas basin, where petroleum is actively produced in the basin sediments, presents an alternate view of the fate of fossil carbon in sediments. Here, the solvent-extractable fossil carbon pool consists primarily of $n$-alkanoic acids (supported by Pearson et al., 2005), as opposed to those derived directly from petroleum. Petroleum-derived compounds such as polycyclic 
aromatic hydrocarbons (PAHs) are instead associated with non-extractable sediment residues. We therefore conclude that PAHs are protected from degradation or other loss processes by their association with MOM at this site. The PAHs are, however, nonfunctionalized and thus do not appear to be covalently linked to MOM and are instead likely associated with minerals or encapsulated in organic matter domains as observed for the HOCs previously described.

Finally, the importance of the mode of association between organic compounds and MOM is emphasized by molecular-level ${ }^{14} \mathrm{C}$ analysis of individual biomarkers from West Falmouth sediments. Here, compound specific isotope analysis of short chain (n$\left.\mathrm{C}_{14}-\mathrm{C}_{18}\right)$ and long chain $\left(n-\mathrm{C}_{24}-\mathrm{C}_{28}\right)$ fatty acids and long chain alkanes $\left(n-\mathrm{C}_{26}-\mathrm{C}_{32}\right)$ not only provides information regarding the sources of organic matter, but also about sedimentary processes and interactions with the dominant macrophyte at the site, Spartina alterniflora. Petroleum-derived $n$-alkanes from the oil spill do not persist in these sediments, but pyrogenic and biogenic $n$-alkanes do. The persistence of plant-waxderived $n$-alkanes likely results from a form of protective matrix association thus providing evidence that mode of association can play a crucial role in determining the long-term fate of biomarkers.

The absence of a pronounced bomb spike in Spartina-derived biomarkers indicates that either sediment mixing dampens the amplitude of the peak or that there are processes concerning the uptake of $\mathrm{CO}_{2}$ by Spartina that are not fully understood and are more complex than the fixation of atmospheric $\mathrm{CO}_{2}$ alone. Future work will be aimed at performing ${ }^{137} \mathrm{Cs}$ analysis at a higher resolution to constrain sediment mixing in the salt marsh. Radiocarbon analysis of individual Spartina biomarkers at a higher resolution in the sediment as well as ${ }^{14} \mathrm{C}$ analysis of the Spartina itself (including roots and leaves) and sedimentary dissolved inorganic carbon should also be performed. These results will allow us to more fully constrain the inputs of carbon to the saltmarsh so that we can improve our understanding of organic carbon cycling in this environment. Coastal environments and shelf and slope sediments play an important role in the global organic carbon cycle at the interface between land and ocean (Hedges et al., 2000). Developing a 
more complete understanding of the processes that control these systems and the sources and sinks of organic carbon has implications for understanding the global organic carbon cycle as a whole.

\section{REFERENCES}

Hedges, J. I., Eglinton, G., Hatcher, P.G., Kirchman, D.L., Arnosti, C., Derenne, S., Evershed, R.P., Kögel-Knaber, I., de Leeuw, J.W., Littke, R., Michaelis, W., Rullkötter, J. 2000. The molecularly-uncharacterized component of nonliving organic matter in natural environments. Organic Geochemistry 31, 945-958.

Pearson, A., Seewald, J.S., Eglinton, T.I., 2005. Bacterial incorporation of relict carbon in the hydrothermal environment of Guaymas Basin. Geochimica et Cosmochimica Acta 69, 5477-5486. 